

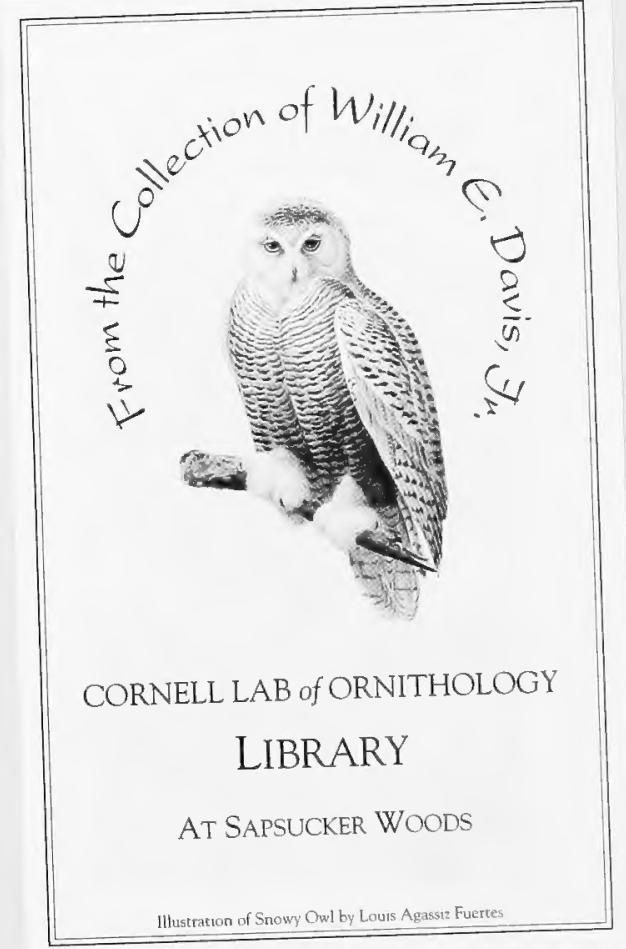


DATE DUE

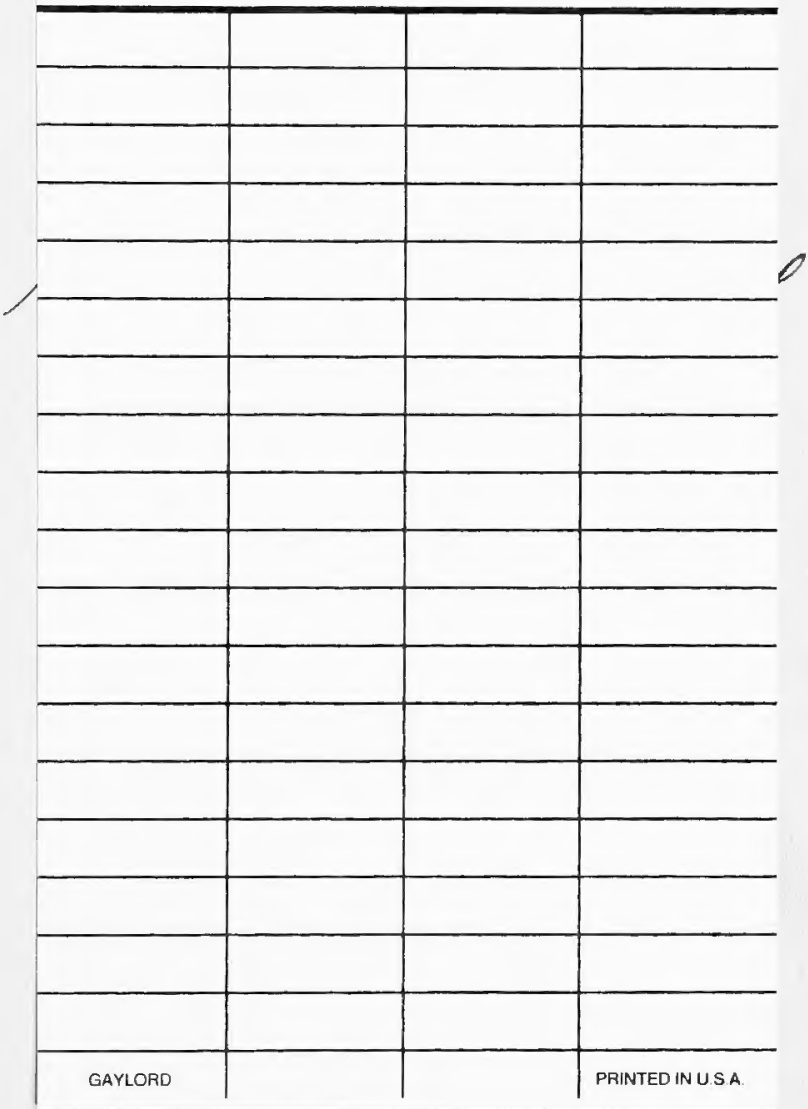



THE AMERICAN SPORTSMAN'S LIBRARY EDITED $B Y$

CASPAR WHITNEY

\section{PHOTOGRAPHY}

FOR THE

SPORTSMAN NATURALIST 



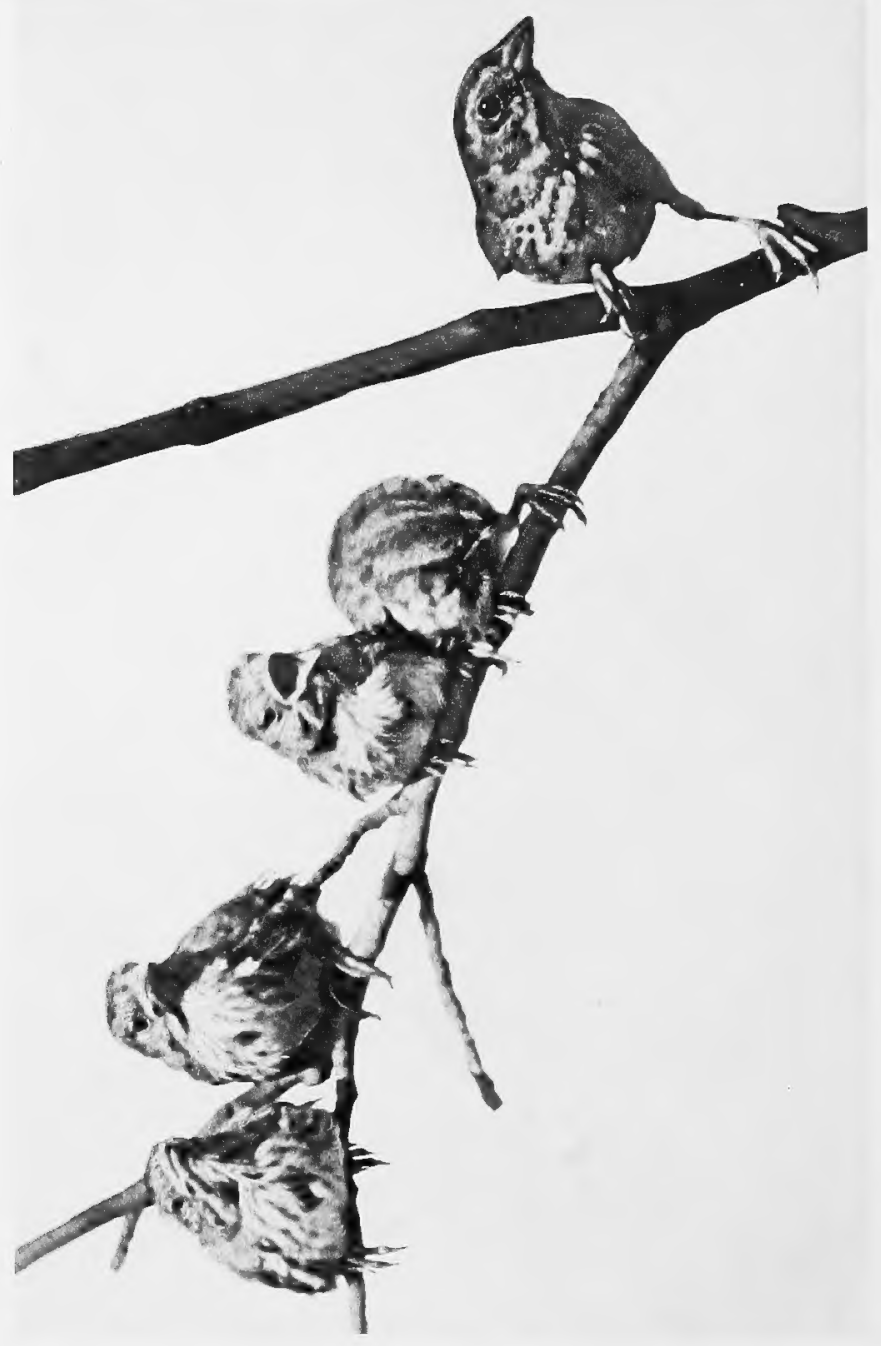




\section{PHOTOGRAPHY}

FOR THE

\section{SPORTSMAN NATURALIST}

BV

L. W. BROWNELL

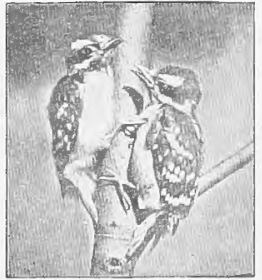

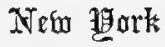

THE MACMILLAN COMPANY

LONDON: MACMILLAN \& CO., LTD.

I 904

All rights reserved 


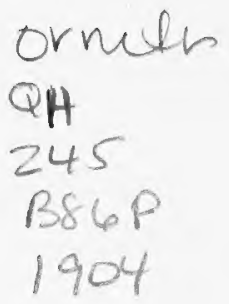

Copyright, IgO4,

By THE MACMILLAN COMPANY.

Set up and electrotyped. Published November, rgo4.

Norwood Press

F. S. Cusbing $\sigma^{\circ}$ Co. - Berwick \& Smitb Co. Norwood, Mass., U.S.A. 
TO

\section{fftin fflotfint}

WHO, BY HER APPRECIATION OF AND INTEREST

IN MY WORK,

HAS BEEN MY GREATEST AID

I AFFECTIONATELY DEDICATE THIS VOLUME 


\section{CONTENTS}

CHAPTER

PAGE

I. Nature Photography: Its Scope and UsefulNESS • • • • • • • • . I I

II. Photography and the Sportsman . • • I9

III. Cameras, Lenses, and Shutters . . . 29

IV. The Dark Room: Developing and Printing . 49

V. The Telephotographic Lens and its Uses - 70

Vi. Apparatus for a Field Worker . . . 8I

VII. Photographing the Larger Animals . . Ioz

VIII. Photographing the Smaller Mammals . . I23

IX. Photographing Birds' Nests . . . . I38

X. Photographing Birds and their Young . . I60

XI. Photographing Insects . • . . . Igo

XII. Photographing Fish and Other Forms of

Aquatic LIFE • • • • . . . 208

XiII. Photographing Reptiles, etc. • . • . 227

XiV. Photographing Wild Flowers, Cut and Grow-

ING . . . . . . . . . 244

XV. Photographing Trees, Fungi, EtC. • . 268

XVI. Photographing in the Zoos . . . . $28 \mathrm{I}$

XVII. Photography In Camp and Woods . . . 292

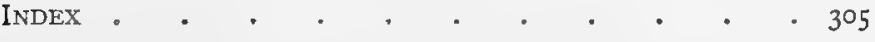





\section{ILLUSTRATIONS}

Song Sparrow Family . . . . . . Frontispiece

Taken, from a distance of about 75 yards, with an eight-inch lens . . . . . . . . 76

Taken, from same distance as photograph on page 76 , with same lens and telephoto attachment . . . . 79 American Elk, Horns in Velvet . . . . . 104 Half-grown White-tailed Buck . . . . . . III White-tailed Deer. Doe . . . . . . . II6

Prairie Dog at Entrance to Burrow . . . . . 124

Cotton Mouse . • • c . . • • . 125 Fox Squirrel . . . . . . . . . 127

Half-grown Woodchuck . . . . . . . . r 30

Porcupine feeding on Root . . . . . . . I33

Muskrat . . . . . • . • . . I34

Little Brown Bat asleep . • . . . . . • I35

Nest and Eggs of Ruffed Grouse . . . . . . I40

Nest and Eggs of Green Heron . . . . . . I42

Nest and Eggs of Spotted Sandpiper . . . . . I43

Nest and Eggs of Chestnut-sided Warbler in Low Bush . . I46

Nest and Eggs of Kingbird . . . . . . . 149

Nest and Eggs of American Crow . . . . . . 152

Bluebird's Nest and Eggs . . . . • • • I55

Entrance Holes to Bank Swallows' Nests . • • . I57

Nest of Bank Swallow . . . . . . . . I58

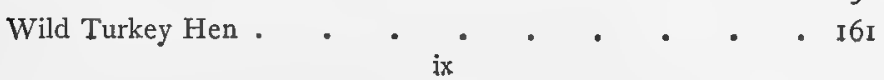


Red-eyed Vireo at Nest feeding Young . . . . . ${ }^{163}$

Field Sparrow on Nest . . . . . . . . 165

Chipping Sparrow feeding Young . . . . . . I68

Young Flickers . . . . . . . . . . $\quad$ I69

Screech Owl asleep by Nest Hole . . . . . . I70

Bluebird at Nest Hole . . . . . . . . 172

Young Shrikes at Nest . . . . . . . . 174

Chickadee feeding Young . . . . . . . 177

Young Blackbirds . . . . . . . . . 178

Young Downy Woodpeckers . . . . . . . 179

Young Wood Thrush . . . . . . . . $18 \mathrm{I}$

American Crow . . . . . . . . . 185

Young Green Herons • • • . . . . . 187

Spider repairing Web . . . . . . . . 192

Lana Moth hanging from Cocoon . . . . . . 193

Mourning-cloak Butterfly . . . . . . . 194

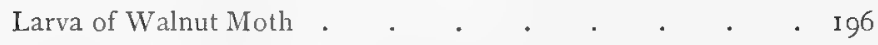

Newly Emerged Cecropia Moth . . . . . . . I98

Cabbage Butterfly . . . . . . . . . 200

Black Swallow-tails . . . . . . . . 201

Moths asleep in Daytime . . . . . . . 203

Moth on Tree Trunk . . . . . . . . 204

Dragon Flies . . . . . . . . . . 206

Common Crab . . . . . . . . . 212

Jellyfish . • . . . • • . . . . 222

Sea Anemones . . . . . . . . . . . 225

Milk Snake . . . . . . . . . . . 228

Garter Snake. . . . . . . . . 230

Common Frog . . . . . . . . . 238

Snapping Turtle . . . . . . . . 239

Tree Toad "singing" . . . . . . . . $24 \mathrm{I}$

Common Toad . . . . . . . . . 242 
Shinleaf in Tangle of Herbage

Blue Flag

Jack-in-pulpit

- 248

Tansy

- 250

Spring Orchis

253

White Violets

Young Skunk Cabbage .

Trailing Arbutus

Common Purple Violets

Bank of Christmas Ferns

Indian Pipes .

White Birch in Winter .

Trunk of Red Cedar

Locust Blossoms . . . . . . . . . 272

Spruce Cones

- 274

Blossoms of American Chestnut . . . . . . 276

Mushrooms

- 278

Head of Lion .

- 283

Snowy Herons

286

Head of White-tailed Deer

White Pelican

. 288

Trophies

Hitting the Trail

- 290

A Temporary Shack

Whipping a Mountain Stream

- 292

In Quiet Waters

. 293

Bringing in the Quarry . . . . . . . 300

A Fair Shot . . . . . . . . . 30r

Finis

303 



\section{INTRODUCTION}

NEARLy a century has passed since the first experiments, that amounted to anything, were made in trying to reproduce the image of any object, mechanically, by means of light rays.

Niepce was, probably, the first to start these experiments, but almost simultaneously with him Daguerre commenced work along slightly different lines and he gave the result of his researches to the world, while Niepce hesitated to publish even the smallest details concerning his, so that we have come to consider Daguerre as the real father of photography.

For many years the advancement in the photographic art was extremely slow, but for the past twenty years it has advanced with enormous strides, until now we have but one thing more to look forward to, - the taking of photographs in natural colors. To attain this object scientists have been working for some years, but no material results have as yet been accomplished.

The first photographic process which was of any commercial value was invented by Daguerre, and named after him, "daguerreotype." This process was finally perfected, after tedious years of experimenting, in I 839 , and held sway in both England and America for about twelve years. The two most serious objections to it were the cost of the plate, which was excessive, and the impracticability of multiplying the reproduction, owing to the opacity of the plate. 
This was practically the commencement of photography, and its invention entitles Daguerre to rank with the foremost inventors of the nineteenth century.

At the same time that Daguerre was pursuing his researches in France an Englishman, named Fox Talbot, was working along somewhat similar lines in England, and in $184 \mathrm{I}$ he patented what he called the calotype process.

It is unnecessary to go into a description here of these two processes. Suffice it to say that the image was made in the former on copper, plated with silver, while in the latter it was made upon paper. This latter was really a negative, for on it the qualities of the image were reversed as we now have them on our dry plates. The correct picture, in black and white, was obtained by oiling the original, which caused it to become transparent, and then printing through it on to another piece of sensitized paper, exactly as we do at the present time.

The collodion process of glass plates was the next great step in advancement. It was invented by an Englishman named Scott Archer, and was first given to the world in $185 \mathrm{I}$. In a few years it had so far displaced both the calotype and the daguerreotype that it reigned supreme from 1855 to 1880 .

Up to about 1853 a photograph was considered nothing short of a curiosity, but with the introduction and perfection of the collodion process photography became an almost popular pursuit. In the collodion process, as introduced by Archer, it was absolutely necessary that the glass plates, coated with collodion containing iodide and nitrate of silver, should be ex- 
posed while wet and developed immediately after the exposure, before the surface had time to dry.

While a collodion dry plate was invented shortly after Archer's process was given to the public, still it did not supersede the wet plate, and it was not until the late seventies that the gelatine negative plate was introduced.

The years from 1877 to 1880 could be called, photographically, the years of the struggle between the wet and the dry plate processes; but the dry plate won, as was bound to be the case from its greater practicability, and in a few years it completely took the place of the antiquated wet plate.

Now commenced the rapid advancement in photography that has not yet ceased. New and better appliances were constantly being perfected. Every year saw a faster lens and shutter on the market. Men of the arts and sciences took greater and greater interest in photography, until, finally, when the apparatus had reached that stage of perfection that permitted it, nature workers took up the camera.

Nowadays the equipment of a worker in any of the branches of the natural sciences is incomplete unless it includes a photographic outfit, and it should be so with the sportsman.

It is in the hopes of inducing many who have heretofore never used a camera to take it up, and of helping those who wish to photograph the wild denizens of our woods, fields, and streams, that this book is written.

It is distinctly a book for the beginner, and to the expert in nature photography it will probably prove of little or no use. The suggestions and advice which I 
have given are based mostly on my own, partly on others', experience, and should they clash with the ideas of any of my fellow-workers, I trust they will not be too harsh in their criticism, but will remember that two workers in the same field hardly ever follow along identical lines.

Even to the beginner it is written with the intention of merely starting him properly, so that he may lose as little time as possible in learning things by sad experience. However, this is bound to happen, to a greater or less extent; and, after all, Experience is the best teacher, for what we learn at her hands we are apt never to forget. As he advances along his chosen line of work he will find less and less use for this book, until, finally, he will discard it entirely, and then, undoubtedly, will shortly be able to teach me new tricks and methods. If, however, in the meantime, it has helped him to a better knowledge of the task before him, it will have served its purpose, and I shall be content.

I have endeavored to make it as complete a text-book of nature photography as possible, and as such I have devoted two chapters to the camera, lens, shutter, etc., and to the manipulation of the plates in developing and printing. This may, to many, seem an unnecessary waste of space, but to any one who is taking up the camera for the first time a thorough knowledge of all this is absolutely essential.

In other chapters I have treated each branch of nature photography separately, giving in each case, as fully and explicitly as possible, the directions, as I know them, for obtaining the best results. I have, in fact, 
made each chapter practically a separate book, even to the extent of often repeating myself, in order that any one looking for a certain piece of information need not be forced to look through the entire volume before he can find it. Now, if he wishes to take up a single branch of nature work, - the photography of birds, for instance, - he has but to read the three chapters on the camera, the dark room, and bird photography in order to get all the information which this book can vouchsafe him.

Work in nature is, at its best, one of the most difficult branches of all photographic art, and knowing as I do how many and various are the difficulties and how enormous they seem to a beginner, it has been my endeavor to set forth, as clearly as possible, all the devices by which these difficulties can best be surmounted.

I can look back now and see how much valuable time I lost, when I first entered this field, by having to learn everything for myself, - time that could have been used to so much better advantage had I but had a better knowledge of my subject before I started. So I am endeavoring to give that knowledge, which I have gained in the number of years during which I have been, more or less constantly, working with my camera among the wild life, to him who is about to enter the same paths, and I am trusting that, to those who really need aid, this volume will be welcome and prove of some material use.

The camera, particularly in the last half-dozen years, has done much toward making wild animal life real to those who have never had the opportunity of seeing it 
in its natural state, and has aided tremendously in the nature movement now assuming so much force and importance in our schools and elsewhere. We need more serious workers, however, - more who will take it up, not as a mere pastime, but with the object in view of increasing the world's stock of knowledge, and I wish that I might induce many to do so.

The illustrations throughout the volume are, of course, from life, and were made, with a few exceptions, amid the natural surroundings. Those which were made from captive animals were taken in the Bronx Zoölogical Park, New York City. The nests were taken, in every instance, in situ and often at great trouble.

These photographs were principally selected from a collection of about three thousand negatives taken by myself, but I wish to acknowledge my indebtedness to Mr. F. M. Hale and Mr. S. D. Dixon for the use of those which are attributed to them. 


\section{PHOTOGRAPHY \\ FOR THE}

\section{SPORTSMAN NATURALIST}





\title{
Photography for the Sportsman Naturalist
}

\author{
CHAPTER I \\ NATURE PHOTOGRAPHY: ITS SCOPE AND \\ USEFULNESS
}

IT is of comparatively late years (about seven or eight) that the camera has been used for picturing our wild life to any extent; but so very rapid has been the advancement in this branch of the camerist's art that photographs that were once deemed impossible - pictures of animals in their native haunts, of birds flying and attending to their home duties, of fish in their natural element, of insects during the various stages of their metamorphoses - are now obtained, not always exactly easily, but with at least not too great a tax upon the ingenuity and resources of the operator.

This has been made possible, to a large extent, by the immense improvement in apparatus that has been accomplished in the past few years, and especially by the extremely rapid lenses that have been placed upon the market, making an exposure of a thousandth of a second practicable. 


\section{Pbotograpby for the Sportsman Naturalist}

It is difficult to say just who was the pioneer in this line of photography, if indeed there was any single person who could be called by that name. Many tried it tentatively and, obtaining but indifferent results, grew discouraged and gave it up. Others attempted it, but did not seem to grasp the subject with a thorough understanding or else were not well enough versed in the use of their apparatus or in the habits of their subjects, for the results they turned out were anything but good.

Finally, however, some eight years or so ago, a number of serious workers entered the field almost simultaneously, each one determined to do his best to show what could be accomplished with a camera among the wild life of the woods and fields. As soon as these workers had cleared a way, so to speak, had shown the others how to surmount the many difficulties that had been confronting them and which had proved too much for them to tackle single-handed, there were plenty ready to follow, as is always the case in almost any enterprise.

Many of these soon lost their interest, however. The results seemed too few for the energy expended, and so they one by one dropped out of the ranks, until to-day there are but comparatively few serious workers still left in the field. These, however, are the ones who naturally would rise to the top, - those who entered into the work for the 


\section{Nature Pbotograpby}

love of it and the love of the wild things with which it brought them into close contact, and who had tenacity and determination enough to stick at it, no matter how many were the difficulties that confronted them.

One of the first to do the best work in this country was a close friend of mine; a man who all his life had been an ardent sportsman, but who laid down his rifle and shot-gun to take up the camera in their stead. He has never had cause to regret the exchange, for he has found just as much excitement in the hunt with a camera as with a gun and much more pleasure in the results. Many of his pictures stand to-day as the best in their line and will undoubtedly so stand for all time, as it would seem to be impossible to improve upon them.

Nature work with a camera forms an epoch, not only in the photographic world, but in the art of illustrating as well. Heretofore, in our nature works and sportsman's books we have had to be content with drawings, always inaccurate, often ludicrous, and sometimes even grotesque in their untruthfulness to nature. This was not always the fault of the artist, for there is nothing more difficult truthfully to portray with pen or brush than the wild life. These unnatural illustrations are now a thing of the past, for photographs have superseded them. 


\section{Pbotograpby for the Sportsman Naturalist}

While the camera can be made to lie, despite the fact that it has been said that it cannot, yet it never does except when made to do so, or by accident, and the pictures obtained by means of it are pretty sure to be absolutely true to life, accurate in drawing and detail, and showing the subject exactly as it was when the shutter was snapped. The camera can do more in the fraction of a second than the most skilful artist can accomplish through hours of hard labor.

The scope of nature photography is almost limitless, its only real limitation being the impracticability of photographing in color. To be sure, photographs can and have been made by what is known as the three-color process, but this is at its best unsatisfactory, often giving false color values, and so I always advocate the use of monotones in their reproduction.

The field to be covered, however, is endless, as one soon discovers when he enters it, and a single lifetime is too short a while in which to do all that one would along these lines. If each one can contribute a little of the best of his work, however, to increase the stock of the world's knowledge, for all he knows that little may be of great value and importance.

As a means, also, of studying nature there is nothing so helpful as a camera, for not only does it aid us in seeing things that might otherwise be 
passed by unnoticed, but it enables us to make accurate records of the things which we do see, and it causes us to be constantly on the outlook for those things. It helps to teach us the value of animal life, and the senseless and absolutely wanton killing of that life which is constantly going on would cease if there was only a greater knowledge of its value.

The sweeping manner in which the farmer and sportsman condemn all birds of prey because of the offences of the few aptly exemplifies the old adage that "A little knowledge is a dangerous thing." The farmer misses a pullet, finding in its place a few scattered feathers, or he may see a hawk swoop down and carry off one of his pet broilers, spreading dire confusion among the rest. The sportsman, while beating the woods for his game, finds the remains of a quail, and at once concludes that it has been the victim of some depredating ow]. Without further investigation and with absolutely no knowledge of the subject, they both sweepingly and generally condemn the whole family of Raptores, letting no opportunity pass to destroy one of its members.

If the man who kills a hawk, or even a snake, would first learn something of its habits, he would in all probability find that he was about to kill one of his best friends.

Did the farmer but know it, he is, in killing the 


\section{Pbotograpby for the Sportsman Naturalist}

hawk, but aiding in the extermination of one of his very good allies, who, by catching and eating numerous of the small rodents and insects which injure his crops, helps him materially in gaining his livelihood. The sportsman might well ask himself who has the better right to the quail,- - he who shoots it for the pleasure it affords him, or the owl who takes it in order that he may live? In point of fact, however, the owls, and but few of the entire family Raptores, catch game or other birds to any extent, and we are doing them a grave injustice when we unreservedly accuse them all.

It is these and other useful facts that the camera helps us to learn, and so, as the interest in natural history is constantly on the increase, it is well that we who may should turn our attention and devote our energies toward photographing, in detail, almost any common object in nature, especially as nowadays nearly every one, young or old, possesses some kind of a camera.

The scientific value of nature photography lies largely in the fact that, as I have already stated, the results are accurate and true to life, and by no other means can the wild life be so truthfully portrayed. No mere wordy description, no drawing, no matter how good, can adequately answer the purpose. Where is the artist who can reproduce the intricate construction of a bird's nest so perfectly as can the camera? Or where is the 
writer, clever though he may be with his pen, who can give us as clear a conception of the manifold duties of a bird's daily life as can a series of photographs? In accuracy of detail as well as artistic conception the late W. Hamilton Gibson far surpassed all other artists in his delineation of animal and insect life, and yet he left much to be desired. He was not infallible. The camera, when properly used, is.

Then, too, a photograph of any animal life that is now common may at some future time be of extreme value to naturalists, for we can never tell how soon any of the mammals or birds may become extinct.

Some species of herons are rapidly becoming fewer and fewer in number, and may soon be a thing of the past; and photographic records of the few remaining large rookeries which exist in this country, where once there were many, will preserve for all time to come impressions of conditions which will soon be no more.

What would the scientists of to-day not give if only our ancestors of the past ages had been versed in camera art and had left, among their other relics, photographic plates of the monsters that at that time inhabited the world. That, of course, is stretching the limits of the possible; but to come down to more modern times, what an invaluable addition to our knowledge of the life 


\section{Photograpby for the Sportsman Naturalist}

and habits of the great auk or the pied duck, both of which have within recent years become extinct, would be a scries of photographs of them taken when they were fairly numerous, as they once were.

The younger generation of to-day can hardly believe the stories of the immense flights of the passenger pigeon which so frequently occurred only a few years ago. These birds suddenly became almost extinct, and the country which once knew tham literally by the thousands upon thousands now rarely sees one. What became of them forms one of the mysteries of nature, and it is entirely probable that future generations will think the stories told of their numbers nothing but pieces of pure fiction, while, if there were but some photographs to back up these facts, they could not help but believe.

This is also true of the buffalo which once inhabited our Western plains in such immense herds, but of which there is now only one known wild herd in existence, and this composed only of a few individuals. Of what surpassing interest would be photographs of these immense herds that were once such common sights.

Unfortunately the birth of nature photography is of too recent a date for us to have these records, which would have been invaluable; but we all have it in our power to leave for future generations photographs which may be to them just as 
absorbingly interesting as these would have been to us. Then why not, rather than devoting our cameras and our time to the producing of irredeemably bad bits of scenery and snap shots of our friends, turn our energies into the making of nature pictures and do something that will be worth while? There is room for all who wish to enter this field, and there are plenty of directions along which one may work and never tire or find that he has reached the end of his road. Unless you intend to take it up seriously, however, you had much better remain where you are and continue in your course of "snapping," for there are already too many of the mere dabblers.

As I have already said, there are but few really serious workers in the field, but there are many who work at it in the most amateurish of ways and who seem to have no care to improve their methods or better their results. These results are, for the most part, poor, or, at the best, indifferently passable, and they are not only no credit to their makers, but often prove a serious detriment to those few who are doing something.

Their authors do not hesitate to use any means that will obtain for them some kind of results with the least possible expenditure of energy or patience. They even go so far as to use stuffed subjects and be willing to swear that they were alive, when the veriest novice could detect the falsehood. This 


\section{Io Pbotograpby for the Sportsman Naturalist}

tends to cast a doubt, in the minds of those who cannot detect the real from the false, over all the products of the nature workers, and so I say that the men who do these things are a hinderance to the advancement of nature photography.

I remember once seeing a lady looking at a photograph of mine that happened to be in an exhibition. It was a picture of an old bird feeding her young, and the exposure had been made at just the happy moment when she was in the very act of giving the food to one of the fledglings. It is one of my favorite photographs of all those which I have taken, and it cost me some four hours of patient waiting to obtain. Naturally it rather disgusted me to hear the lady exclaim to a companion, "Oh! I know how that was done; the birds were stuffed and wired to the branch." Perhaps I should have immediately corrected her and pointed out to her the reasons why it could not have been a stuffed bird, but would she have thanked me for doing so? I think not. So I sat down instead and moralized to myself on the futility of striving for the best results when those results received no more praise or commendation than almost worthless ones.

But it is worth while to do your best work and always to attempt to make your photographs from living wild subjects. They are the only ones that have any real value, and not everybody in the 


\section{Nature Photography}

world is like the lady quoted above. She undoubtedly had known of some one who made photographs in the way she mentioned and so jumped to the conclusion that all others must, necessarily, do the same.

Not many months ago I saw, in one of our leading monthly magazines, an article on nesting birds illustrated with photographs which the author took care to explain had taken him many hours of hard work to obtain. No doubt he had spent some time in shooting, stuffing, and arranging his specimens, for, to a practised eyc, it was entirely obvious that, without an exception, they were stuffed birds. No doubt many who read that article were entirely credulous and thought the results wonderful; but there were many others, like myself, who were disgusted with it, and who thought it no credit, not only to the author, but to the editor of the magazine who had allowed such productions to pass muster. In another magazine I also remember seeing the photograph of a deer which was such a poor specimen of the taxidermist's art that no one who had ever seen a deer alive could be fooled by it, and yet the author of the monstrosity had the temerity to describe at length just how he had obtained it and what hours of patience and hard work it had cost him.

I cite these instances to show the beginner 


\section{Pbotograpby for the Sportsman Naturalist}

what pitfalls are awaiting him, and as a warning not to fall into them.

This is but one step, and a very poor one, in advance of the old-time methods of illustrating works on nature. Indeed, I am not certain that it is not a retrograde movement. There is much to be said in favor of the old style over this, for, surely, the artists never claimed more for their drawings than appeared on the face of them, while the authors of these photographs do all they can to mislead people into the belief that they are the truthful representation of living things, while they are almost always entirely false in drawing, pose, and surroundings.

I can readily understand why it is that some who call themselves photographer naturalists can allow themselves to be led into these falsehoods, especially if their consciences are not in active operation. The photographing of any of our wild cousins is, at the best, difficult, and, to one who is not working conscientiously for the best possible results, anything, no matter what, that tends to lessen the obstacles, is welcome. To take advantage of any means that will make the difficulties fewer is perfectly legitimate so long as the means employed does not tend to detract from the realism of the finished picture, but photographs of stuffed animals never were known to make realistic pictures. 


\section{Nature Pbotography}

Unfortunately, also, there are many who, while they decry the use of mounted specimens, work on a different method, which gives just as poor results.

They, apparently, do not consider it at all necessary that the ensemble of the picture be natural so long as the image of the beast, bird, or whatever the main object may be is large and well defined. To gain these ends they employ methods, in many instances, which, by removing the subject from its natural surroundings, show it in a false position and make the picture untrue to nature.

In a branch of photography the results of which must, obviously, be true to nature if they would have any real value, one cannot afford to miss any of the small details that go to make up a truthful whole in depicting incidents in the everyday life of birds or beasts. In order that we should miss none of these details, it is equally obvious that these wild things should be photographed in their native haunts, and I cannot think that removing them to a studio especially prepared, as some photographers do, and keeping them there until they are reduced from their original wild condition to a state of semi-tameness before photographing them is true nature photography, no matter what backgrounds and surroundings may be arranged to make them feel and look at ease. 


\section{I4 Photograpby for the Sportsman Naturalist}

Of course, if one wants simply pictures of the animals themselves, this method is all right; but then we should not attempt to give the impression that they were photographed in the open by using home-made surroundings and accessories of grass, leaves, tree-trunks, rocks, etc., but should photograph them free from all surroundings and leave the products to speak for themselves as mere anatomical studies of the animals. The use of these accessories is misleading in its results, for while these results may be perfect pictures of the animals themselves the idea conveyed by them to the average mind of how these same animals live their everyday life is almost certain to be erroneous, for there is almost invariably a false note struck somewhere.

I have in mind a certain picture of a woodcock, taken by a well-known advocate of this method of work, in which, while the photograph of the bird itself is admirable, the setting is so obviously manufactured as to give one the impression that it is nothing more or less than a reproduction of a rather poorly mounted specimen.

It may be that I am hypercritical; that, having worked for years among the inhabitants of the fields and woods in my chosen branch of study, natural history, I have come to know our wild neighbors of the ground and air too well, and that in consequence I can too easily detect any false 
note struck by the photographer. That these false notes do exist, and that photographs containing them are constantly being turned out, I think no one who has kept in touch with recent literature upon the subject and who is well acquainted with his wild brethren can deny.

It is a pity that this should be so, that a branch of photography that holds such limitless possibilities in the material aid which it can give to the advancement of the natural sciences should be injured, as it is being injured, by unconscientious workers. It is a field where each worker should unhesitatingly give what aid he can to each new worker entering it, where all should pull together as much as is possible, where no petty jealousies or rivalries should exist, and, above all, where no one should resort to tricks or chicanery to obtain results.

Therefore I would that none might enter it except those who do so with the intention of doing the best possible work along their chosen lines. These I would gladly welcome to the ranks of the nature photographers, and to these do I wish to speak in this book, and most especially to those sportsmen who wish either to exchange their gun for a camera or to combine the pleasures of hunting with a camera with those of hunting with a gun.

It is these men who are best fitted for this work 


\section{Pbotograpby for the Sportsman Naturalist}

and who have the best opportunities for obtaining valuable photographs, for they have the first essential, - knowledge of the wild life which they would photograph. Also they have the time to devote to the work which a great many of us cannot give, and the pursuit of their quarry takes them, naturally, to such places as are most favorable for photographing wild life and where it is most prolific.

Let no one enter this field, however, without a due appreciation of the difficulties which are before him, for if he begins with the idea that it is easy sailing, the undeceiving process is likely to prove painful. There is no pursuit that I know of that contains more disappointments, and there is none that requires a larger amount of patience. Job would have made a good nature photographer, if all the accounts which we hear of his stock of patience are true, for with a sufficient amount of this commodity judiciously mixed with a modicum of ingenuity and common sense, every obstacle that presents itself can be overcome.

It is no unusual thing for one to work a whole day, and work hard too, only to be forced to quit at nightfall with no results to show. I have done this frequently. The most disheartening part, though, is to take home a batch of exposed plates which we have every reason to believe should 


\section{Nature Pbotograpby}

turn out to be good negatives, only to find, when we get into the dark room with them, that they are all irredeemably bad.

This will happen to all, as it often has to me, and it is almost enough to make one forswear the use of the camera altogether. Perseverance will always win in the end, however, and when we do get something that is really good the pleasure is so much the greater for the many disappointments which we have undergone.

One great thing to remember, as all woodsmen know, is that a wild animal is much more easily frightened by noise than he is by movement; in fact, many animals are curious enough to approach a moving object to discover what it is, when a sudden, quick movement or a noise would immediately frighten them away. This can be, and often is, taken advantage of by those who photograph the larger animals especially.

But the key-note of success with all wild things is gentleness and quietness of movement. Do nothing hurriedly or with quick, sudden movements, and above all, make just as little noise as possible.

Do not be discouraged if at first you do not get more than one or two good negatives out of every ten or a dozen plates exposed. This will be a fair average for a beginner. As you become more and more proficient the average will in- 


\section{IS Photograpby for the Sportsman Naturalist}

crease, but at no time must you expect to obtain a good negative with every exposure. It is therefore a good plan, when it is possible, to make more than one exposure on the same subject; it lessens the chance of failure.

This is not a "press the button" kind of photography, but it requires all the ingenuity and taxes all the resources which one has at his command, and the results are a lasting pleasure, fully repaying us for all the expenditure of time, energy, and patience. 


\section{CHAPTER II}

\section{PHOTOGRAPHY AND THE SPORTSMAN}

As I have before said, I wish to interest the sportsman in this book more than any other one class of individuals, for I think it is to him, largely, that we must look in the future for a large percentage of the pictures which we will get of animal life, especially of the larger mammals: the deer, moose, caribou, elk, bear, wildcat, etc.

By sportsmen I mean, not those men who shoot from the pure love of killing something, and whose sole ambition is to kill as much as possible in a given length of time. They are the ones who helped to exterminate our buffalo, and who are now doing all they can to lessen the diminishing numbers of the elk and caribou still in this country; who find pleasure in standing on the deck of a Florida river boat and shooting the alligators and any other wild life they may see on the shore as the boat passes; and who would as soon shoot a grouse or a woodcock on its nest as flying. They have none of the true sportsman's blood in them and are, consequently, 


\section{Pbotograpby for the Sportsman Naturalist}

undeserving of the name; and they could find but little to interest them in work with a camera unless they could find it useful in helping them to prove how many ducks or grouse they had killed in a day, or how many trout they had taken from a single brook.

But I am writing to those true sportsmen who go to the wilds for the love of it and of the free, untrammelled life they can lead there; who know their wild brethren and appreciate their right to live sufficiently to give them, at least, a fighting chance; who carry their gun or rod, and use it for the pleasure it affords them to pit their strength, endurance, and ingenuity against the cunning and ofttimes greater strength of their quarry; and who, when they have won, and the beast, bird, or fish, as the case may be, falls to their prowess, feel elated, not at the fact that they have taken a life, but that, by their perseverance and superior skill, they have been able to gain the victory over their opponent.

For these men, I say, I am in particular preparing this book, for they are the men who find a greater pleasure in winning a three or four hours' hard-fought battle with a tarpon than if the same fight had been won with greater ease in less time, and who think a week or two not wasted if it only brings to them one splendid pair of moose antlers. I think that these same men 
could find a similar pleasure in working equally hard for like results with a camera, and I am sure if they could once be induced to try it that they would agree with me when I say that so far as excitement is concerned the sports are about equal, or, if anything, the advantage lies with the camera.

Nowadays, in our hunting with a camera, the continued life of the animal we are after is an absolute necessity to the successful outcome of our quest, and he who would be in the fore ranks of the sportsman photographers must be ready to follow and photograph the moose and panther at bay and even the rattlesnake coiled for a strike. Does it not require a greater amount of courage to face an angry mountain lion with a camera than with a Winchester.30-.40? I think it does. And he who is equal to the nerve and endurance testing stalk of a deer in order to photograph it can, in my mind, lay claim to being a truer hunter and sportsman than he who would shoot that same deer from a distance three or four times as great. So I will unhesitatingly say, that to any one who follows the chase for the mere excitement that it affords, the camera can offer far greater advantages for attaining his object than can the rifle.

Let me quote from one of these men who was at all times an ardent lover of nature and a sports- 


\section{Pbotograpby for the Sportsman Naturalist}

man: "As a one-time sportsman who yielded to none in his enjoyment of the chase I can affirm "that there is a fascination about the hunting of wild animals with a camera as far ahead of the pleasure to be derived from their pursuit with shot-gun or rifle as the sport found in shooting quail is beyond that of breaking clay pigeons. Continuing the comparison, from a sportsmans' standpoint, hunting with the camera is the highest development of man's inherent love of the chase.

" The killing of a bird with a gun seems little short of murder after one has attempted to capture its image with a lens. The demands on the skill and patience of the bird photographer are endless, and his pleasure is intensified in proportion to the nature of the difficulties to be overcome, and in the event of success it is perpetuated by the infinitely more satisfactory results obtained. He does not rejoice over a bag of mutilated flesh and feathers, but in the possession of a trophy an eloquent token of his prowess as a hunter, a talisman which holds the power of revivifying the circumstances attending its acquisition.

"What mental vision of falling birds can be as potent as the actual picture of living birds in their homes? And how immeasurably one's memories are brightened by the fact that this is not a picture of what has been, but of what is! 
"The camera thus opens the door to a field of sport previously closed to those who love the birds too much to find pleasure in killing them; to whom Bob White's ringing whistle does not give rise to murderous speculation as to the number of his family, but to an echo of the season's joy which his note voices. They therefore have a new incentive to take them out of doors; for however much we love nature for nature's sake there are few of us whose pleasure in an outing is not intensified by securing some definite, lasting result."

All this from a man who once would shoot with the best, but who has now forsworn the use of the gun except when occasion demands it, and who finds his pleasure and recreation in hunting with a camera solely. That there are many others who think and feel the same way is evidenced by the number of ardent sportsmen who are taking up the camera in preference to the gun.

One man, whom I have previously mentioned as being one of the first to see the possibilities in nature photography, had been up to that time through all his previous life a most active advocate of sports afield with shot-gun, rifle, and rod. There was seldom a season passed that he did not take month's long hunting trips, but now that hunting is done entirely with a camera, for he has almost forsworn the use of any other weapon. 


\section{Pbotograpby for the Sportsman Naturalist}

Even so great a lover of the sport of hunting as Theodore Roosevelt said, in his introduction to A. G. Wallihan's "Camera Shots at Big Game," that: "The shot is, after all, only a small part of the free life of the wilderness. The chief attractions lie in the physical hardihood for which the life calls, the sense of limitless freedom which it brings, and the remoteness and wild charm and beauty of primitive nature. All of this we get exactly as much in hunting with the camera as in hunting with the rifle; and of the two the former is the kind of sport which calls for the highest degree of skill, patience, resolution, and knowledge of the life history of the animal sought."

But it is not necessary for the sportsman to entirely give up hunting with a gun in order to do so with a camera.

I am not an advocate of a continual close season, nor do I wish to preach against the sports of the chase except to those who are mean-spirited enough not to see wherein the true sport lies and will shoot, indiscriminately, everything in sight.

I am, preëminently, a naturalist, but I have enough of the sportsman's instinct in me to keenly enjoy a day with the quails behind a pair of good dogs. I find much more real and lasting pleasure, however, in the use of my camera than of my gun. 
But why not combine the use of the two judiciously? It is an easy thing to do, and the two sports need not conflict with each other. Many sportsmen now carry small kodaks with them on their trips to the woods. These, while answering some purposes, do not give as satisfactory results as would a different camera better suited to the work; and it is my intention, in this volume, to give to the sportsman who wishes either to actually give up his gun for a camera or to combine the use of the two, full and explicit directions, not only as to how he should use his outfit, but the best outfit for the different uses.

$\mathrm{He}$ who does thus combine photographing with his other sports afield will find the pleasures of his outing doubled. He can bring home with him not only trophies in the way of antlers and skins, but also pictures of the game he was seeking, taken in their native haunts. He can make photographs of his companion, for few travel alone, capturing the prize fish of the trip, for it is entirely possible to photograph jumping fish, provided one has the proper outfit and is quick enough. He can have innumerable mementos that will prove a lasting pleasure, and which, during the months that he must spend in the city or town, will serve to take him back in memory, away from the haunts of men, to the woods; and he can, while looking over them, live again 
26 Pbotography for the Sportsman Naturalist

the moment when, after patient waiting, he at last secured the picture that he sought.

And what of the skill required for camera hunting? Does that count for nothing? We must realize that in order to make successful pictures of the game we are stalking we must approach it much nearer than would be necessary if using a gun and one must, obviously, be a much more skilful hunter to be entirely successful in this new style of hunting. Every device and precaution known to the hunter is called into requisition. It will often be found not only advisable, but necessary, to seek the most advantageous position, and, after it is found, to wait, sometimes even for hours, until the subject presents itself in a suitable attitude.

One could have the opportunity for a dozen or more shots with a gun at the game he is stalking before he is able to make one with his camera, and so it must be unquestioned that, so far as the chance for one to display his skill as a woodsman and hunter is concerned, hunting with a camera is far ahead of hunting with a gun.

And to able-bodied, active men does this not afford greater opportunities for pleasure? Who is there that finds the greatest amount of enjoyment in the thing which is obtained through little or no real endeavor? But when we obtain an object by the surmounting of many real obstacles, 
when we have to bring into play all the skill and ingenuity we possess in order to gain our end, that end is worth the gaining, that object worth the having, and we would not exchange it for dozens of those reached through little effort.

There are thousands of people who own cameras and who imagine they are finding pleasure in photographing such steadfast and patiently immovable objects as houses, statues, bits of scenery, etc. What is the enjoyment of such comparatively prosaic employment when the whole field of nature photography is open to any one who wishes to enter it, and when such successes as one may have are not only of real value in themselves, but are undeniable tributes to one's skill both as a photographer and a hunter?

Furthermore, the sportsman who hunts with a camera has the advantage over the man who does not in the fact that everything is "game" that comes his way. There is no bird or animal that is too small to be of interest photographically. He will find that even the flowers, the trees, the insects, and the thousand and one things which may be photographed in the woods are worth considering and not without their full quota of interest, and he will gradually learn how much more numerous are nature's offspring than he has ever before considered them.

Moreover, another thing that must be taken 
28 Photograpby for the Sportsman Naturalist

into consideration is the fact that there is no closed season for the camerist. Every month in the year is prolific with the wild life, and there is no time when one cannot obtain pictures of it. So we need not choose our time to go on a hunting trip according to the game laws, but can start whenever the spirit moves us or the opportunity presents itself.

Should the photographing of American game pall on one or become too tame a pastime, there is an immense field for work in other countries for any one who has the time, money, and ambition to enter it. It would seem to me that if one is looking for true excitement, he could have his heart's desire by taking his camera into the jungles of India or Africa. There would, of course, be more or less danger attending such an undertaking, but danger is one of the underlying essentials of excitement; and think of the results one could obtain!

This has been done to a small extent by one or two English sportsmen, but the photographs coming from that portion of the world are few and far between, and science needs more of them.

However, there is an immense field to be covered in America, for the good photographs of our native big game are still all too uncommon, and it is to the sportsmen that I look in the future to increase their numbers. 


\section{CHAPTER III}

\section{CAMERAS, LENSES, AND SHUTTERS}

In a letter written to his brother, in I 8 I 6, Niepce describes how he secured what was probably the first picture ever made with a camera. He says: "My object glass being broken, and being no longer able to use my camera, I made an artificial eye with Isidore's ring box, a little thing from sixteen to eighteen lines square... I I placed this little apparatus in my workroom, facing the open window, looking on to the pigeon house. I made the experiment in the way you are acquainted with, and I saw on the white paper the whole of the pigeon house seen from the window."

This tells, in a few words, the basic principles of a camera; for it is, in fact, nothing but a lighttight box so arranged that, only when the image is to be projected, a few rays may be admitted through one end, and they form the image of whatever object or objects we may be photographing, on the ground glass at the other end. The very name "camera" means only a chamber or compartment. 


\section{Photograpby for the Sportsman Naturalist}

The principles of the projecting of images of objects by means of light rays were known, however, a long time before the camera was invented. About the middle of the sixteenth century an Italian by the name of Baptista Porta invented the "camera obscura," which, as its name implies, was nothing more or less than a darkened room to which light was admitted only through a single small hole in the window shutter. We can any one of us easily repeat his experiments by tightly closing the windows of a room with dark shades and through one shade cutting a small hole. On the wall opposite this window hang a sheet, and, when the sun is shining, we can see a faint, inverted image on the sheet of whatever the window may look out upon. It is inverted because the rays of light emanating from the bottom of the object looked upon pass upward at an angle, and, entering through the hole in the shade, strike the sheet at its upper edge, and vice versa. This is true also of the modern camera. Porta somewhat improved upon the primitive contrivance just described by placing a double convex glass lens in the aperture of the shutter, outside of which a mirror was placed to receive the rays of light and reflect them through the lens. The image upon the screen was thus made much brighter and more distinct, and was, moreover, shown in its natural, upright position. Crowds flocked to 
his house every day to see these light-painted pictures, which were at first thought to be nothing short of marvellous. In a short time, however, the camera obscura was made an adjunct of many country houses, taking the shape of a small, round house with a conical roof, in the centre of which the lens was placed. Slanting mirrors were so arranged as to reflect the light from surrounding objects on to a table in the centre of the room so that a reduced facsimile of the entire view to be seen from the roof top was reproduced on the table top. Its only disadvantage was the fact that the picture could never be changed except with the natural change of the seasons. Up to within a very few years such places were still in existence, and I am not sure that some of them cannot be found to this very day, if anywhere, in some of the old country seats in Europe.

The photographic camera of to-day is, in fact, nothing but a miniature camera obscura, for it is simply a box with a lens at one end and a ground glass screen, upon which the image is projected, at the other. A modern camera, that is made by any one of the numerous manufacturers in this and other countries who turn out first-class goods, is a veritable work of art. It is supplied with all the appliances for simplifying the labor of the operator and for producing absolutely the best results, and is correspondingly expensive. 


\section{Pbotograpby for the Sportsman Naturalist}

Cameras, broadly speaking, are of two classes: the camera which is held in the hands during the exposure, with which only instantaneous exposures or "snap shots" can be made, and which is termed a "hand camera," and the one that must be set upon a tripod in order to be used.

Of the ordinary form of hand camera, the "press the button" type, I shall not speak, for they are of almost no use to the nature worker.

There are two types of cameras in this class, however, that are the outcome of the almost continuous experiments of the manufacturers in late years, and which have done more to revolutionize nature photography than any other appliance or appliances, and these, I think, are worthy of a few words.

They are the "twin lens" and the "reflex" cameras. The twin lens was the first to be placed on the market, and it consisted of a "double-decker" box that was practically two cameras in one. There were two lenses, one above the other, of exactly the same focal length and attached to the same front board so that both could be racked out or in at the same time. The lower lens made the picture, and the upper lens acted as a view finder. At the back of this upper lens was a mirror, placed at such an angle that it reflected the image, thrown upon it by the lens, on to a ground glass which was set in the top 
of the camera. This was protected by a hood and was the exact size of the plate used in the camera, so that the operator, in looking at it, saw the image not only the exact size that it would be reproduced on the plate he was using, but also right side up; and, moreover, he could watch it up to the very instant of exposure. The focussing was accomplished by means of a thumb-screw on one side, while a button upon the other side, when pressed, released the shutter, if it was a focal plane, or, if the ordinary shutter was used, it could be released in the usual way by means of a bulb.

The advantage of this camera over all the styles of tripod cameras lay in the fact that the plateholder might be inserted, the slide drawn, and the shutter set, all in readiness for an exposure, before the focussing was done. One can readily see that, in photographing animate objects that are only too likely to move, and especially those that are already in motion, this was a great advantage, for there was none of the useless delay between the time of focussing and releasing the shutter that is necessary when using the ordinary tripod box; instead, the shutter could be released the instant that a sharp focus was obtained and one could be reasonably certain of having the image of the object he was attempting to photograph on the plate.

The only drawbacks to this camera were the 


\section{Pbotograpby for the Sportsman Naturalist}

facts that the use of two lenses made it unnecessarily expensive, while the increased size made it cumbersome and heavy. So the manufacturers set themselves to remedy these defects, and the result was the reflex camera, an instrument that no nature worker can afford to be without. Its principles are the same as were those of the twin lens, which it has practically superseded, with the exception that there is only one lens used by which both the focussing is done and the exposure made. This is accomplished by means of a mirror, placed between the lens and the plate, so arranged that, by pressing a button, a spring is released that throws it up and out of the way a fraction of a second previous to the release of the shutter. As it is obvious that the shutter must be back, and not in front, of this mirror, naturally the focal plane is the only one that can be used on this camera.

It can easily be seen that this instrument has all of the advantages of the twin lens, together with some added virtues. With it pictures can be obtained with comparative ease that were, heretofore, thought to be entirely out of the question; and so much do I depend upon it in my work, that I should almost feel inclined to advise a man who could only afford one camera to get the reflex.

When buying a camera, no matter of what type, 
if we have never used one before, we had better let some one select our instrument that has some knowledge of them, and not depend upon the advice of the dealer. Afterward, we should become thoroughly acquainted with all its various movements and how they affect the image before we attempt to make any exposures with it, for by so doing we will find that we can work quicker and to better advantage when we do begin, and will make fewer failures in consequence.

Tripod cameras are of two types: the long and the short focus, that is, those having a long extension of bellows and those whose bellows are much shorter. For nature workers the former is the type that should always be used, as with it we are enabled to obtain a much larger image, in other words, work closer to our subject, than with the short focus camera. The ones that have an extension of bellows both at front and rear are the most convenient, as they allow of being focussed either from the back or front as we please, besides being much more rigid than are those whose bellows extend only in the front.

The swing-back is an essential feature of the modern camera. It is a device by which the back, holding the plate-holder, is allowed to swing, either vertically or horizontally, to a considerable angle. Let me explain the advantages of this contrivance. The nearer the camera is to an 


\section{Pbotography for the Sportsman Naturalist}

object, the greater must be the distance between the lens and the plate in order to have the image in sharp focus; and when the distance between the lens and the object is very short, say less than two feet, a small deviation in the distance between the lens and the plate suffices to entirely throw the image out of focus. Now, when the camera is pointing downward at any upright object, such as a growing flower or a bird's nest in a low bush, as the camera must necessarily be tilted at a considerable angle, it is obvious that the plate cannot be parallel with the object if the back of the camera is rigid; and therefore if the top of the object is in focus, the bottom, being much farther away from the plate, will be out of focus, and vice versa. This defect can be corrected, to a large extent, by the proper use of the swing-back. It also prevents distortion of lines, which is bound to occur when the plate and the object being photographed are not parallel. This can best be illustrated by focussing the camera upon a tall building, where it is necessary to tilt the instrument $\mathrm{u}_{1}$ in order to include the top of the building. When this is done, it will be seen that the lines of the building in the image converge at the top, giving it the appearance of falling over. This is caused by the plate being tilted back, and the lines can be straightened by the use of the swing-back. If we ever try to use a camera that 
is not fitted with one, after having become accustomed to the use of it, we will discover what a really invaluable adjunct it is.

Another very useful appliance is the rising and falling front, which, by changing the position of the lens, without changing the position of the camera, allows one to get more or less foreground, as he may desire, in his picture.

When focussing upon an object that is near by, especially when we are trying to make it approximately life-size, it is always best to do so with the back extension, leaving the front extension entirely alone. By doing so we do not change the distance between the lens and the object, and this is very important in such close work, for it is extremely difficult to obtain a perfect focus when in the very act of doing so we are constantly changing the point of focus.

In order to take a picture it is not necessary to have a lens, that is if we are always photographing stationary objects and the length of time that we have in which to make the exposure is not an important factor; but it is necessary to have one when we wish to do instantaneous work. A picture can be taken, however, by using a piece of black cardboard, or any other opaque substance, in the centre of which a pinhole has been made, and which is inserted in the place that is meant to be occupied by the lens. 


\section{Photograpby for the Sportsman Naturalist}

A lens does not form the image; the rays of light do that, and a pinhole will allow the rays of light to pass as well as will a lens. The lens, however, gathers together these rays and sifts them, discarding those that are not needed and allowing only those to pass which are necessary to the formation of the picture.

If we wish to understand thoroughly the principles of a lens, and how it does its work, we must obtain some book, of which there are many published, upon this subject and read it, for here I shall only touch upon the more important points. In fact, I should advise the beginner to study some elementary work on optics as applied to photography, and also the elements of photographic chemistry. He will find that the knowledge he will thus gain will cause him to work to much better advantage, and the time spent in studying these things will not by any means be lost.

The modern double lens is made in two combinations, that is, there are two sets of glass used in its construction, and, therefore, it is what is termed "convertible," i.e. each combination can be used separately, or the two can be used together, thus making, in reality, three lenses in one.

The "focal length" of a lens is, roughly speaking, the distance between it and the ground glass when an object at a distance is in focus, or, in 
other words, when the lens is at what is ordinarily called "universal focus."

Different lenses have different focal lengths, and, also, the different combinations of a double lens have different focal lengths (the single combination being, usually, twice the focal length of the double). The longer the focal length of a lens the larger will be the image of an object at a fixed distance. That is to say, if we make a photograph of an object at a certain distance with a lens of eight-inch focus, and then make another of the same object from the same distance with one of sixteen-inch focus, we will see that the image taken with the latter is double the size and covers four times the area of that taken with the former. This is due to a law of optics which there is no room here to explain; but it can be readily seen that, for nature workers, the lenses of the longer focal lengths are by far the best to use, if size of image is the only consideration. Unfortunately, there are other things to be considered, and one of these is the fact that, on the other hand, the longer the focus of the lens the less speed it has, for, while a lens of sixteen-inch focus admits just as much light as does one of eightinch focus, in the former instance the light must cover four times the area of the latter, and therefore the speed of the latter is, approximately, four times as great. 


\section{Pbolograpby for the Sportsman Naturalist}

The depth of focus of a lens is the distance that the ground glass can be moved to and fro without the image of the object upon which the lens is focussed becoming visibly unsharp. This permissible racking increases correspondingly as the lens is stopped down. This term is often confused with depth of field, which is the distance between two objects lying in a straight line with the camera and which are at both extremes of the field of sharp focus. This also increases materially with each smaller stop used.

The "stops" or "diaphragms" of a lens are used to increase sharpness of detail, depth of field, and depth of focus. These stops are simply a series of apertures of varying sizes, which are either made in a rotating plate, when they are known as "rotating stops"; or in separate plates which are slipped into the lens mount and are called "Waterhouse diaphragms" after the inventor; or, and this is the most usual form, the apertures are formed by a set of thin plates which open and close like the iris of the eye, and which, consequently, are called "iris diaphragms."

The most practical function of the diaphragm is that, by decreasing the aperture, various planes are brought equally into focus at the same time. This, necessarily, by lessening the illumination of the plate, increases the requisite length of exposure correspondingly with the diminishing 
of the size of the aperture. The stops of a lens are all numbered, and, speaking very roughly, the time of exposure must be doubled with each smaller stop used. That is to say, if one second is the proper exposure on a subject when the lens is wide open, then, when using the next smaller stop, two seconds must be given, and when the next smaller is used, four seconds, and so on.

We can see by this that the larger the aperture of a lens the more speed it has, and by this means the speed of a lens is determined; but, also, with the larger apertures there is a corresponding diminishing of the depth of field. A lens working at F.6 (which means that its largest aperture is F.6) is twice as fast as one working at F.8, but its depth of field is diminished accordingly. However, by stopping it down to F.8 we have the same depth of field and the same speed as we would have with the one working at F.8 used wide open.

The different systems of marking lenses are too intricate and would take up too much room for me to go into a detailed explanation of them here, nor do I think it at all necessary. Suffice it to say that the $\mathrm{F}$. system is the one most generally used, and it represents the different aperture ratios and is intended to give the operator an idea of the relative speed of his lens when used at the 


\section{Pbotograpby for the Sportsman Naturalist}

different apertures. If he would learn more about it, and know exactly how each system is worked out, he can find it in one of the books on lenses of which I have already spoken.

The angle of view of a lens is the diameter of the field that is sharply covered by that lens. There are narrow, medium, and wide angle lenses. The greater the focal length of a lens compared with the size of the plate the narrower the angle, but as any lens which will cover a large plate will cover a smaller one - the greater includes the less - and as many lenses when stopped down will cover a much larger plate than when at full opening, there is only one way in which we can call lenses wide or narrow angle. There are lenses which will only cover a plate at a certain narrow angle, and stopping down does not extend their fields. They are rightly called narrow angle lenses. There are other lenses which will work at a very wide angle, covering a plate sharply from corner to corner at an angle of ninety degrees and even more. All lenses will not do this, and therefore those that will are correctly called wide angle. To a nature worker a wide angle lens is seldom necessary, although sometimes extremely useful.

In choosing a lens for nature work we must be governed principally by two considerations: speed and focal length. Lenses vary in price 
from those that cost less than a dollar and are put in the very cheapest of cameras, to those that cost up in the hundreds. If we can afford it, it is well to have more than one lens, even though we are doing all our work on the same size plate with the same camera. We should have one lens that will work very rapidly, for use where we are willing to sacrifice depth of field and focal length to speed. We should have another for use where depth of field and focal length are necessary; and we should, without question, have a telephoto, of which I shall speak at length in another chapter.

It is always a good plan, when buying a lens, to get one that is made to cover a plate one size larger than the one we intend to use, as by so doing we acquire greater focal length and greater illumination of the plate, which necessarily gives greater speed than will the same style of lens one size smaller.

An anastigmatic lens is always preferable to the cheaper rapid rectilinear. The advantages of the former over the latter are: rapidity, extremely fine definition over a very large flat field at a large aperture, portability, and freedom from astigmatism. The great covering power of the anastigmat is an immense advantage alone. The front of the camera may be raised to any extent that the camera will allow, without fear of leaving 
44 Pbotograpby for the Sportsman Naturalist

the bottom of the plate uncovered or out of focus; and the lens can be used to include a very wide angle on a larger plate than the one it is really intended to cover.

In nature work the entire success of a picture depends upon the sharpness of focus that is obtained. There must be no diffusion of detail in any part of the main object, and as much of the surroundings as possible should be in sharp focus also. It is therefore obvious that we should pay particular attention to how we focus our lens. As has been before stated, objects at different distances from the camera may be brought into equally sharp focus by stopping down if there is not too great a distance between them. One of the first things a beginner will observe, when he is trying to photograph an object that is very near to the camera, is that the whole object cannot usually be rendered sharply with the lens at the fuil aperture. In these cases he must focus sharply upon the point nearest the camera, and then stop down until all is brought into the field of sharp focus and make his exposure accordingly.

In the care of lenses one cannot be too particular. They are expensive articles, for they are made by the very highest class of skilled labor. They are easily damaged and should be treated accordingly. They should be kept as free from dust, 
dirt of any kind, and grease as possible; and in handling them the fingers should never be allowed to come into contact with the surfaces of the glass. When cleaning them, which should be frequently done, never use anything that is at all rough, for the glass of which a lens is made is comparatively soft and, consequently, easily scratched. Chamois is not a good thing to use. An old piece of silk or very soft old linen or muslin is good, but better still is the soft paper that is manufactured expressly for this purpose, and which can be obtained from any dealer in optical goods. The paper from which Chinese napkins is made is also good.

In cleaning a lens do not scrub it as you would a window pane, but rub it very gently with a circular movement around the lens. If there is a dirt spot that cannot be removed by simply rubbing, then either breathe gently upon it, or use a drop of alcohol, which must immediately be dried off. On no account ever apply water, ammonia, or any chemicals.

Lenses deteriorate with age, especially when left exposed to the light or air, and so they should be protected as much as possible. Chamois bags or round cardboard boxes are good receptacles for them, and, when they are out of the camera, they should always be capped at both ends.

In fitting a flange to the front board, one should 


\section{Pbotograpby for the Sportsman Naturalist}

be very careful that it fits perfectly tight, with no possible chance for the admission of light. Also, in screwing the lens into the flange, there is a right and a wrong way, as one writer puts it. He says: "The right way is first to turn the tube backward - i.e. the wrong way of the thread until the two click at the point where the threads meet. Then reverse the movement, and the lens will enter its flange quite easily."

If a lens sticks in its tube or flange, it is my advice not to attempt to force it out by the use of a vice or any other means, but take it to the maker, who has the proper appliances and knows how to do it, and who will not injure it as you would be very likely to do.

Finally, before buying a lens, first test it. The dealers will generally allow this, and if you do not understand how to do it yourself, you had best ask some one to do it for you who is well acquainted with the different lenses.

Of shutters there is really little to be said, as they are not complex and should be easily understood by the average amateur. They can be roughly divided into two classes: the diaphragm shutter and the focal plane. The former is usually fitted between the two combinations of the doublet or in front of a single lens and is made to give, automatically, exposures ranging from $\frac{1}{150}$ of a second, in the best ones, to three min- 
utes, and is also capable of being left open in order to give an exposure of any length of time that is required. As I have said elsewhere, the time marks on a shutter should never be absolutely relied upon, as they are put there more to aid us in judging the differences rather than the absolute measurements of time.

The focal plane shutter is one that, as its name implies, works on a plane. It is composed of a black curtain that crosses in front of the plate. This curtain is divided in the centre by a slit that can be made wider or narrower at the will of the operator, and as this slit is the entire width of the plate and exposes in its passage only one section of the plate at a time, we are enabled by the use of this shutter to get the greatest amount of illumination in the shortest space of time. This shutter is capable of being worked automatically and with almost absolute exactness, giving exposures ranging from about $\frac{1}{10}$ to $\frac{1}{100 \overline{0}}$ of a second. Obviously, for very rapid work it is the only one that can be used.

No matter what style of shutter we are using, we should learn to know it and its capabilities thoroughly, and be able to judge quickly and accurately how to set it for any given exposure, so that as little time may be lost in manipulation of the shutter as possible, for in nature work time is very valuable, and the quicker we 
48 Photograpby for the Sportsman Naturalist

can do things the greater the chances of our obtaining the picture we are after.

Shutters, as well as lenses, should be well cared for, as dust or dirt of any kind or the least rust will cause them to work slower or sometimes to refuse to work altogether. In fact, we cannot well afford to ill-treat any of our photographic outfit, for the better it is cared for the longer it will last and the better the work it will do for us. 


\section{CHAPTER IV}

THE DARK ROOM: DEVELOPING AND PRINTING

Plate-holders may be loaded and the plates developed in almost any place, from a small, dark closet to a sleeping bag, but that is no reason why we should not, when we can, have a comfortable place for a dark room. This need not be large. All the space that is absolutely necessary is enough for a chair and a table, but in order that we may work in entire comfort it should be at least five feet square.

In making this room the one thing to be most particular about is the temperature. Coolness is a great consideration, both as regards our own personal comfort and the welfare of the plates. Therefore, if we happen to have a dry cellar beneath our house, that is the best possible place for the dark room, as it is likely to be fairly cool in the summer and also fairly warm in winter.

Any carpenter can build this room at a very small cost, or if we have the time, we can do so ourselves even cheaper. It should be made of half or three quarter inch pine boards, and 


\section{Pbotograpby for the Sportsman Naturalist}

these should be dovetailed so as to leave no cracks through which any daylight may creep. If our house is wired for electricity, it is easy to run a wire to this room, and it makes by far the best light, as it is steady and gives less heat than any other. Otherwise we can get our light by cutting a square hole in one side of the room and placing a lamp upon a bracket outside of the hole. This hole should be covered with several thicknesses of ruby cloth and orange paper, for the least white ray in the light that strikes the plate will inevitably fog it. The light, by this arrangement, will be sufficiently strong for all practical purposes, and by keeping the lamp outside it will not heat the room as it would were it inside.

If we can have running water in the room we will find it a great convenience, but it is not necessary. A plentiful supply of water, however, is requisite in order that we may have entire cleanliness in our work.

The shelves inside the room should be so arranged that we may have everything within easy reach without moving from our seat, for it is often necessary to work quickly when developing a plate. It is well, therefore, to have one shelf for the trays and another for the chemicals on the lefthand side; one, which should always be kept perfectly dry and free from dirt of any kind, on the 


\section{The Dark Room: Developing and Printing 5 I}

right-hand side for changing the plates; and the long shelf or table beneath the window on which to do the developing. If a second shelf is placed below this last one, on which to put the hypo tray, it will materially lessen the chances of any of the hypo spattering into the developer. Over the window there should be a curtain of very dark red cloth which may be raised to get all the light necessary when using the ordinary plate, but which can be lowered to give less light when the orthochromatic plate is being developed, for this plate, being sensitive to the red rays, must be exposed to the light as little as possible.

Many people who will read this book are undoubtedly already adepts at developing and printing, and so this chapter will be of little or no use to them; but to the beginner, who has never done any work in photography, a few words of advice in the manipulation of his plates, both in development and printing, may not come amiss.

In the first place, cleanliness is absolutely essential to good work in photography, and on this point one cannot be too particular. The plateholders and camera should be kept free from dust, and the plates should be dusted with a soft camel's-hair brush both before placing them in the holders and after taking them out, before development. If this is not done, "pinholes" in the negative are apt to be the result. These are 


\section{Pbotography for the Sportsman Naturalist}

minute transparent spots caused by dust on the plates either when the exposure was made or during the development.

Another thing that we must be careful to avoid is air bubbles on the plate during development, for these will also cause transparent spots. The developer should be flowed over the plate quickly and evenly, and the tray must be constantly rocked until the development is completed. It is even a good plan to pass a wad of absorbent cotton over the face of the negative, after it has been immersed, to break any bubbles that may have formed upon it, for these sometimes will not break simply by the action of rocking the tray.

After development the plate should be rinsed in clear water before being placed in the hypo. This is not absolutely necessary, but will sometimes prevent staining. It should be allowed to remain in the hypo bath until it is thoroughly fixed, for a plate insufficiently fixed will invariably show stains sooner or later, and these stains cannot be removed. Therefore it is always best to leave the plate in the hypo for several minutes after it has the appearance of being completely fixed. The double-coated or non-halation plates take much longer to fix out than do the ordinary ones, and therefore extra care should be taken with them in this respect. An old hypo bath that has turned yellow should never be used, as its 
The Durk Rocin: Developing and Printing 53

action is slow and it is liable to stain the plates. In the winter a plain hypo bath of one part hypo to four or five parts water may be used, but this should be made fresh every day. In the summer the acid bath should be used. This is made by adding two hundred grains of acetone sulphite to every quart of a twenty per cent solution of hypo. There are many other formulas for acid fixing baths, but I have found this one to be the simplest and best. It not only hardens the film of the plate sufficiently to prevent it from "frilling" or "blistering" (which is the object of the acid bath, for plates will invariably do this in the warm weather if they are not hardened), but it clears the plate perfectly and will keep in good condition for an almost indefinite period.

Another good hardener is formaline (use one part to about thirty parts of water), but its only bad feature is the fact that if we are not very careful it is likely to harden the film so much that it will be impossible to either reduce or intensify it afterward should we so desire. The plate should be placed in this solution immediately after being taken from the hypo (of course when using this the acid bath is unnecessary) and allowed to remain in it from one-half a minute tr three minutes according to the strength of the solution. This solution will keep well and may be used repeatedly until it becomes too weak. 
54 Photography for the Sportsman Naturalist

Should it become discolored, it will not injure the negative.

A negative should always be well washed in running water for at least an hour, for it is important that all traces of hypo be eliminated from it. If we have not running water, then the time of washing should be at least doubled and the water changed at least seven or eight times. After washing it should be placed to dry in some place where there is a free passage of air and as little dust as possible, and the more quickly it dries the better.

As to the best developer to use, this is entirely a matter of opinion. There are many different ones on the market, and all are equally good if they are properly used. The pyro developer is the oldest and probably the most universally used at present. Its only defect is the fact that it will stain the fingers very badly and often the negative as well, although this stain can be removed from the fingers; and, if it is equally distributed over the negative, it does not destroy its printing qualities. When one is well acquainted with this developer, he will find that he will be enabled to obtain any quality of negative with it that he desires. It is really an excellently good developer for all around work. It is somewhat slow in its action, but this is in its favor rather than against it, as it gives one ample time for the manipulation of his plate 


\section{The Dark Room: Developing and Printing 55}

and allows him to develop it more exactly in accordance with the exposure.

A good formula, that produces vigorous negatives, is made up in two solutions, as follows: No. I. Dissolve $2 \frac{1}{2}$ ounces sulphite of soda, crystals, and $1 \frac{1}{4}$ ounces carbonate of soda, crystals, in I 5 ounces of water. No. 2. Dissolve 8 grains oxalic acid in 12 ounces of water and add $\frac{1}{2}$ ounce of pyro. To develop, take I ounce of No. I, $\frac{1}{2}$ an ounce of No. 2, and add 3 ounces of water. Another good formula is: No. I. Water I6 ounces; sulphite of soda, crystals, 4 ounces; carbonate of potash, dry, $\frac{1}{2}$ ounce. No. 2. Dissolve 8 grains oxalic acid in 12 ounces of water and add $\frac{1}{2}$ ounce of pyro. For use take $\frac{1}{2}$ ounce of No. I, 2 drams of No. 2, and add $I \frac{1}{2}$ to 3 ounces of water according to whether the negative be over or under exposed. If the latter, the most water should be used; if the former, the least. With a normal exposure about 2 to $2 \frac{1}{2}$ ounces of water should be used.

Of all the new developers that have been placed on the market in late years, metol has probably found the greatest favor. It is a very rapid developer, causing the image to appear, on a normally exposed plate, in from three to six seconds, and the entire development should be accomplished in from one and a half to two minutes. For soft effects it is excellent, giving plenty of 
56 Pbotograpby for the Sportsman Naturalist

detail without any hardness, provided the plate has been properly exposed.

It should be made up in two solutions, as then it will keep longer than when made in one. A good formula is as follows: No. I. Water, 16 ounces; metol, $\frac{1}{4}$ ounce; when thoroughly dissolved, add $2 \frac{1}{2}$ ounces sulphite of soda, crystals. No. 2. Water, I6 ounces; carbonate of potassium, I $\frac{1}{4}$ ounces; bromide of potassium, Io grains. For a normal exposure take $I$ ounce of No. I, $\frac{1}{2}$ ounce of No. 2, and add $I \frac{1}{2}$ ounces of water. In dealing with over exposure the amount of No. 2 should be decreased and a slightly larger amount of No. I used with a few drops of a ten per cent solution of bromide potassium added. For under exposure use $\frac{1}{4}$ ounce of No. I, $\frac{1}{2}$ ounce of No. 2, and $1 \frac{1}{4}$ ounces of water.

The characteristics of a metol-developed negative are softness and "thinness"; in other words, it is hard to get density. The development should always be carried much farther than what looks, by transmitted light, to be correct, for the density loses considerably in fixing. With pyro it loses but little, and therefore the development, when using pyro, should be carried but little beyond what seems to be the proper density for the finished negative.

This question of how far to carry a negative in development is one that everybody must learn for 


\section{The Dark Room: Developing and Printing 57}

themselves by experience, for it is one where our own judgment alone can aid us. With different levelopers the negative requires to be carried to different degrees of density before being placed in the hypo bath. The only advice that can be offered upon the subject is, no matter what developer you are using, always to make the image somewhat denser than would appear to be necessary by looking at it in the dark room.

For myself, I prefer, for most work, metol used in conjunction with hydrokinone, for, as metol is a soft working developer, and hydrokinone gives hard results, the combination of the two strikes a happy medium that produces a brilliant, snappy negative that is full of half-tones and detail. The following is an excellent formula, simple and efficient: Water, 16 ounces; metol, 45 grains; hydrokinone, 90 grains; sulphite of soda, crystals, 2 ounces; carbonate of soda, 2 ounces. Dissolve in the order given and use, for normal exposures, I ounce of the solution to 4 of water. If the exposure is uncertain, use ro ounces of water, and when the detail appears in the plate throw off this developer and finish with the normal mixture. This developer may be used repeatedly until its action becomes too slow, when it must be discarded, or it will be liable to stain the negative. It gives clear negatives with no trace of fog, if used properly, and is, in my 


\section{Pbotography for the Sportsman Naturalist}

opinion, by far the best developer for general work.

There are many other developers on the market, all good, but it is unnecessary to enumerate them here.

We should always have a bottle of a ten per cent solution of bromide of potassium in the dark room for use in cases of over exposure, for a few drops added to any developer acts as a retarder.

In development we should always watch the negative carefully. It is well to have two strengths of developer mixed ready for use, one normal and the other much weaker. Commence development with the weak solution, and if the image appears too quickly and has a tendency toward "flatness," then the plate has been overexposed and must be treated accordingly by using the normal developer with some of the bromide solution added to it. If the image, on the other hand, comes up very slowly and has the appearance of being spotty and "hard," then it has been underexposed and the developer must be weakened still more and no bromide added. This will bring out what detail there may be in the plate, but, of course, if it has been very badly underexposed, nothing can be done with it.

If we know that a plate is very badly overexposed, before we commence development, it can often be saved by first soaking it in water to which 


\section{The Dark Room: Developing and Printing 59}

has been added about a dram of the bromide solution and then developing it in a developer strong with bromide. The development of an overexposed plate must be carried much farther than when the exposure is normal, otherwise the result will be flat with no contrasts.

For normal or under exposures tank development is an excellent method. This consists in placing the plates in a covered tank of developer and allowing them to remain there until completely developed. The hard rubber tanks are the best, but much more expensive than are those made of composition. I should recommend that metal tanks never be used. The developer should be diluted with about twenty times the amount of water used for normal development, and this should develop a correctly exposed plate in about an hour. The tank should be thoroughly washed before being used, and sufficient developer placed in it to completely cover the plates. The plates should not be placed so close together that they cannot be removed with perfect ease, and they should be handled very little or none at all during the process of development.

If a negative is too dense, from over exposure or over development, it can be reduced after being fixed by placing it in a weak hypo bath to which has been added enough red prussiate of potash to turn it to a lemon-yellow. The tray should be 
6o Pbotography for the Sportsman Naturalist

rocked constantly during this process, else the reduction will be uneven, and the negative examined frequently until the desired density is reached, otherwise it may be carried too far and made too thin.

Negatives can be thus reduced after having been dried, but should then first be soaked in water until the film is perfectly softened. This reducer should only be used when the density is equal over the entire plate. When this is not so, that is, when some portions of the negative are much denser than others, causing that portion to print out white, with a loss of detail, then it can be reduced to an equal density by placing it in a three per cent solution of persulphate of ammonia. The negative must be closely watched, for this reducer acts very quickly after it once starts; and when it has been sufficiently reduced it must be placed immediately in a ten per cent solution of sulphite of soda and allowed to remain in it for five or ten minutes. This stops the action of the reducer, which would otherwise continue even after the negative had been placed in water. After reducing a negative in either solution, it should be thoroughly washed in running water. The last solution should never be used except after all traces of hypo have been eliminated from the negative, for, if there is any hypo in the film, stains will occur. Neither of the 
The Dark Room: Developing and Printing 6I

solutions will act upon a very much hardened film.

When the negative is too thin from under development or under exposure it may be intensified, but not until after it has been thoroughly washed. The Agfa intensifier, which comes already prepared, is the most convenient and gives as good results as any. Intensification can be carried as far as desired and a negative may be reintensified several times, but it must be entirely free from hypo, or else again we will have resulting stains. Where there is a loss of detail from under exposure, if it cannot be brought out by developing in a weak developer, then intensification will do no good but only serve to make it harder. We can bring out what is in a negative and force it up to a good printing quality, but we cannot put into it what is not already there.

Of the local manipulation of plates in development, reduction, and intensification, I shall say nothing, as the nature photographer will have but little recourse to this, and when he does the knowledge of how to do it will best come to him through experience. In fact, in all the processes of photography a little of this kind of knowledge is worth much advice.

Great care should be exercised in the development of the orthochromatic plates, especially the fast ones, to expose them to even the ruby light 
62 Photography for the Sportsman Naturalist

as little as possible. I usually develop them in a covered tray if I am not using the tank. All plates should be handled during development very little and should be taken from the tray and held up to the light only when we think that development is nearing completion.

In printing we come to the final process of photography, and much may be done in the way of improving a bad picture by manipulation of the various printing processes. The knowledge of how this can best be done is, however, only gained after much practice.

I should advise the beginner to try the use of but one or two papers at the start and thoroughly acquaint himself with the working of these before he ventures to try his hand at the others. The two papers that are almost indispensable to all workers are the silver printing-out paper and velox. Of the printing-out papers (so named from the fact that the image shows while printing) there are many varieties, but the process of working them is the same in every case. They are the best for use with strong negatives, while the velox papers give better results when the negative is at all weak or thin.

Directions for the use of the latter paper are enclosed in all packages, so it is a useless waste of space to repeat them here.

With any of the silver papers the print must 
The Dark Room: Developing and Printing 63

be made several shades darker than we wish the finished picture, for it will fade in the toning bath. For toning we can use any of the double or single toning solutions sold by dealers, but the best of them are more or less unreliable. We had much better buy the chloride of gold and make our own bath. The one that I have used for years and found eminently satisfactory is as follows: Bicarbonate of soda, 4 grains; gold, $\frac{1}{2}$ grain; water, 16 ounces.

The prints should first be washed in five or six changes of water or in running water for fifteen or twenty minutes, to remove all the free silver. They should then be transferred directly to the toning bath, and while in this they should be constantly moved until the required tone is reached, when they should be placed in a weak hypo and alum bath. In this they should be allowed to remain for ten or fifteen minutes and then washed in running water for at least half an hour.

For reproduction purposes glossy prints are required by most publishers, and for this the silver paper is by far the best. The gloss may be obtained either by burnishing them, on a machine made expressly for that purpose, after they have been mounted, or by "squeegeeing" them to a ferrotype board. The boards must be kept perfectly clean and free from scratches, otherwise the prints will stick to them. 


\section{Photography for the Sportsman Naturalist}

Direct enlargements from the negatives upon bromide paper are easy to make if we have the proper appliances. We must have a dark room for this purpose fitted with a specially arranged camera, and the source of light must be either daylight or electric light (gas or lamplight is not strong enough). I cannot now go into a detailed account of this process, as it would necessitate a small volume to properly describe it and the necessary apparatus. For those who wish to use it, however, I should advise the perusal of "PhotoMiniature," No. 16, published by Tennant and Ward, 289 Fourth Avenue, New York City, for it gives full and explicit directions much better than could I.

For making enlarged negatives an enlarging camera is necessary, and we must first make a positive on glass or celluloid and the enlarged negative from that.

There are many occasions that arise where the background of a picture is bad and we wish to eliminate it while preserving the image of the main object. There are two ways of accomplishing this. The simplest is to make a dead-white background by "stopping out" all but the image we wish to preserve. This is done by painting out the entire background with a preparation which is known as "opaque." Onc's hand must needs be very steady to do this successfully 
The Dark Room: Developing and Printing 65

and preserve the perfect outline of the main object.

If we wish a background other than the one that is in the original negative, we can obtain it by what is known as double printing. To do this we must have two negatives, the one we have already stopped out for the main object and another one for the background, and the two must be in exact proportion to each other. A print must first be made of the figure on the opaqued negative and this print carefully cut out (the outline must be followed exactly). This cut-out is then placed against the background negative, in the exact position in which we wish the figure to appear, and a print, of the depth which we wish it to be for toning, made from that negative. This will, naturally, show a white space of the exact size and form of the figure, or whatever the main object that we are using may be. Against this the figure in the opaqued negative must be fitted carefully, so that no sign of the joining will show, and allowed to print into the depth of the background. This is really not so difficult or tedious a process as it might seem and gives some very excellent results when used judiciously; but it should only be resorted to when absolutely necessary, for it is one of the methods of "faking" which all nature photographers should avoid when possible. 
66 Pbotography for the Sportsman Naturalist

Retouching and "spotting out," both on negative and print, are ofttimes necessary, for pinholes will come despite all our precautions, and often details can be worked up and better pictures thus obtained. Especially is this so where prints are being made for reproduction, for here they must be as clear and full of detail as possible; and where the negative has not got these qualities in it, it is obvious, if we would use it, that we must put them there in some way.

In retouching the negative it must first be covered with a preparation of balsam known as a "retouching fluid," which can be bought already prepared at any supply store. Without this the pencil will not make sufficiently heavy marks on the film to be of any material use. When the work is delicate, such as touching up the feathers of a bird or the fur of an animal, a very hard pencil (about six $H$ ) should be used, and this should be sharpened to a very fine point and never allowed to become in the least dull. For coarser work, such as filling in shadows, etc., a softer pencil can be used. All this retouching should be done with the utmost care in order that it may not show for what it is in the print. If it is done hurriedly or carelessly, it will inevitably show and spoil the photographic qualities of the print. If there is a heavy background or very deep shadows that should be held back or light- 
ened, this can be done by a wash of paint (either blue or yellow) on the back of the negative.

Spotting out simply consists of filling in the transparent spots caused by specks of dust or bubbles in the developer. This may be done with opaque, water colors, or India ink.

In working upon the print itself, if it is on a matt surface paper (such as platinum, velox, etc.), we should use either the soft, dull pencils, known to artists as the "negro pencil," or else India ink applied with a fine brush. For work on the glossy prints, water colors mixed with a little gum arabic will give good results.

At times it will be found advisable to locally print some portion of the picture more than the rest. This can be accomplished by carefully shading the remainder of the negative with a piece of cardboard. It should not be held too close to the negative and should be slightly moved about during the time it is held there in order that no sharp line of demarcation may appear on the print.

The keeping of a large collection of negatives is often a problem. To repack them in the boxes in which the plates originally came only necessitates a useless expenditure of time in looking over them when any particular negative is wanted. I enclose each negative in an envelope, on the outside of which I mark the number and name of the 
68 Photograpby for the Sportsman Naturalist

negative. These I pack upright, in numerical order, in long, lidless boxes which are just the width of the envelopes. These I put away on shelves just deep enough and high enough to receive them, and in this manner I can store a large number of negatives in a comparatively small place and yet have easy access to any one that I may need. On the front of each box I have a label which tells me what subjects and what numbers that box contains, and, by the aid of my catalogue (and it is necessary for any one to keep a catalogue if he has a large number of negatives from which he is constantly working), I can get, without loss of time, any negative from which I wish to print.

This also insures greater safety to the negatives, for it necessitates less handling of them. In all my photographic career I have broken, unintentionally, just three negatives, and I attribute this largely to my method of keeping them.

Necessarily, in the confined space of one chapter it is impossible to give, in full detail, all the various processes of developing, printing, etc. I have, however, attempted to give the more essential details which a beginner should know, and the rest he must learn for himself.

One last word of precaution. If you would succeed and turn out good work, you can never afford to be careless. Never work in a hurry, but 
The Dark Room: Developing and Printing 69

always give yourself ample time for what you have to do. Mix your solutions with care and exactness, and unless your water supply is fairly pure, it should be distilled. After mixing a solution always filter before using it, for there is much dirt that remains in it that might injure the negative; and, above all things, be cleanly in all your operations. 


\section{CHAPTER V}

THE TELEPHOTOGRAPHIC LENS AND ITS USES

THE telephoto lens is of such inestimable value to the nature worker, and so few people really give it credit for what it can do, that I think a chapter none too little to devote to it and its uses.

To define it very untechnically, it is a lens having the properties of a telescope in a diminished degree. Its main characteristics are two: it will give photographs of objects on a larger scale than will an ordinary lens with the same extension of bellows and from the same point of view; it is not of any fixed focal length and can be focussed to give a sharp image at any camera extension (measured from the negative lens to the ground glass), provicled only that the extension is as great as, or greater than, the focal length of the front, or positive, lens.

The front lens is generally an ordinary photographic lens, and any make can be used for that purpose. The faster lenses are, however, preferable, as the addition of the rear, or negative, 


\section{The Telepbotograpbic Lens and its Uses 7I}

element very greatly reduces the speed. The negative lens is useless by itself and can, therefore, be used only in conjunction with the ordinary, or positive, element.

The telephoto lens is focussed by altering the distance between the front, or positive, lens and the back, or negative, lens. This is done by means of a thumb-screw on the barrel of the lens. The shorter the camera extension the greater must be the separation of the positive and negative elements, and vice versa. In focussing one must use extreme care, for the plane of sharpness is limited, and therefore the focus must be exact or the resulting picture will be blurred.

In order to secure as great a range of focal lengths (and consequent magnifications of the size of the image) as possible, the camera used should be capable of a considerable amount of extension, at least twenty to twenty-five inches in a five by seven and correspondingly more in the larger sizes. A telephoto lens will then give enlargements over the ordinary lens of anywhere from three to twelve or fifteen diameters. Of course, the longer the extension of the bellows the greater the resulting enlargement, but there is a consequent diminishing of speed; therefore we are often forced to sacrifice size of the image where speed is absolutely necessary.

The best telephoto lenses are capable of work- 


\section{Pbotography for the Sportsman Naturalist}

ing, under ordinary conditions, at from one second to $\frac{1}{10}$ of a second at full opening, according to the length of the bellows' extension; and, under very favorable conditions, where the light is very strong, exposures can be made in from $\frac{1}{25}$ to $\frac{1}{50}$ of a second. When such rapid exposures are made, however, the negative is liable to be underexposed and must be developed, accordingly, with the greatest care, in order to bring out a satisfactory image. In fact it is always well, in work with the telephoto, to presuppose that your negative is underexposed. If it is not, no damage is done; but if it is, as is most apt to be the case, and the ordinary strength developer is used upon it, then a chemical fog will result, and it will be impossible for you to bring out all the detail there is in the negative, or to carry it to anywhere near the desired density.

Absolute rigidity of the camera and stand is necessary, for, on account of the enlargement of the image, the least vibration will cause blurring and an unsatisfactory result. The telephoto lens is, naturally, much heavier than the ordinary lens, and, therefore, where long extension of the bellows is desired, it is well to use braces to hold the front board perfectly rigid; for often the mere releasing of the shutter will jar it sufficiently to cause a blurred image. For this reason it is difficult to use this lens in any kind of a hand camera, but, 


\section{The Telephotograpbic Lens and its Uses}

by the exercise of great care, it can be done and some very excellent results obtained. It has even been used on flying birds; but the negatives, in such an instance, are bound to be so badly underexposed on account of the necessarily rapid exposure that must be made that, even by the exercise of the greatest care in the development, they are seldom all that could be desired.

The stops on a telephoto lens act in directly the opposite manner than do those on an ordinary one, for while, in an ordinary lens, the smaller the stop used the greater the covering power obtained, with a telephoto the reverse is true, and the more it is stopped down the smaller will be the covering power, until, if the smallest stop is used, only a circle in the centre of the plate will be exposed unless the lens is made to cover a much larger plate than the one it is being worked with. So it is always best to use it wide open, or at its largest aperture, and obtain sharpness of definition by accurate focussing. This not only gives better covering power, but also, naturally, greater speed.

In selecting a shutter for use with this lens one which works as smoothly and with as little jar as possible is desirable, for when an exposure of one or two seconds is required, the jar made by the opening of the shutter will sometimes cause a sufficient vibration to blur the image.

The usefulness of a telephoto lens lies entirely 


\section{Pbotograpby for the Sportsman Naturalist}

in the fact that distant objects can be photographed with comparatively little trouble, and fairly large images of them be obtained, when it would be impracticable to get a picture that would show anything with the ordinary lens.

In nature work it is often impossible to approach near enough to one's subject to use the ordinary lens satisfactorily, but with the telephoto one can, practically, cause his subject to approach him close enough to give a good-sized image. Its only drawbacks are those which I have mentioned: lack of speed and the care which must be used both in focussing and making the exposure. In short, the photographer using a telephoto lens needs more time both before and during the exposure than the wild things are always willing to give; and yet it is an indispensable adjunct to a nature worker's outfit, for there are many occasions, constantly arising, when the use of any other lens would be impossible.

A deer or any other animal will often lie or stand perfectly still long enough to allow us to set up our camera and make, not only one, but several exposures if the work is done from a distance of seventy-five or a hundred yards; but should we attempt to approach that same animal close enough to use an ordinary lens, he would leave long before we got within anything like the necessary range. A bird will often sit quietly on her nest and allow 


\section{The Telepbstograpbic Lens and its Uses 75}

one to photograph her with a telephoto from a distance of twenty-five or thirty feet, but few of them will sit quietly when one tries to come much closer to them than this.

Then, too, there are times when one cannot, even if the subject will allow it, approach close enough to use the ordinary lens. For photographing birds' nests on inaccessible cliffs or at the end of branches too small to hold even the weight of the camera, the telephoto lens is invaluable; and when one becomes thoroughly conversant with the workings of one and its various uses, he will find that he will often employ it in preference to any other of his lenses and will never cease to wonder at the ease with which he can obtain pictures that had always before seemed to him impossible. Many of the nature photographs at which the uninitiated are apt to exclaim in wonder do not seem such miracles of the photographic art when looked at through the medium of a telephoto lens; and one has but to gain a thorough knowledge of the possibilities which are opened up by the use of one of these instruments to cause him to forever afterwards swear by them. When he once does gain this knowledge, he will never again be without one.

As I have already said, any lens which one happens to have can be used as the positive, or front, element, and the cost of the telephoto, the rear or 
76 Pbotography for the Sportsman Naturalist

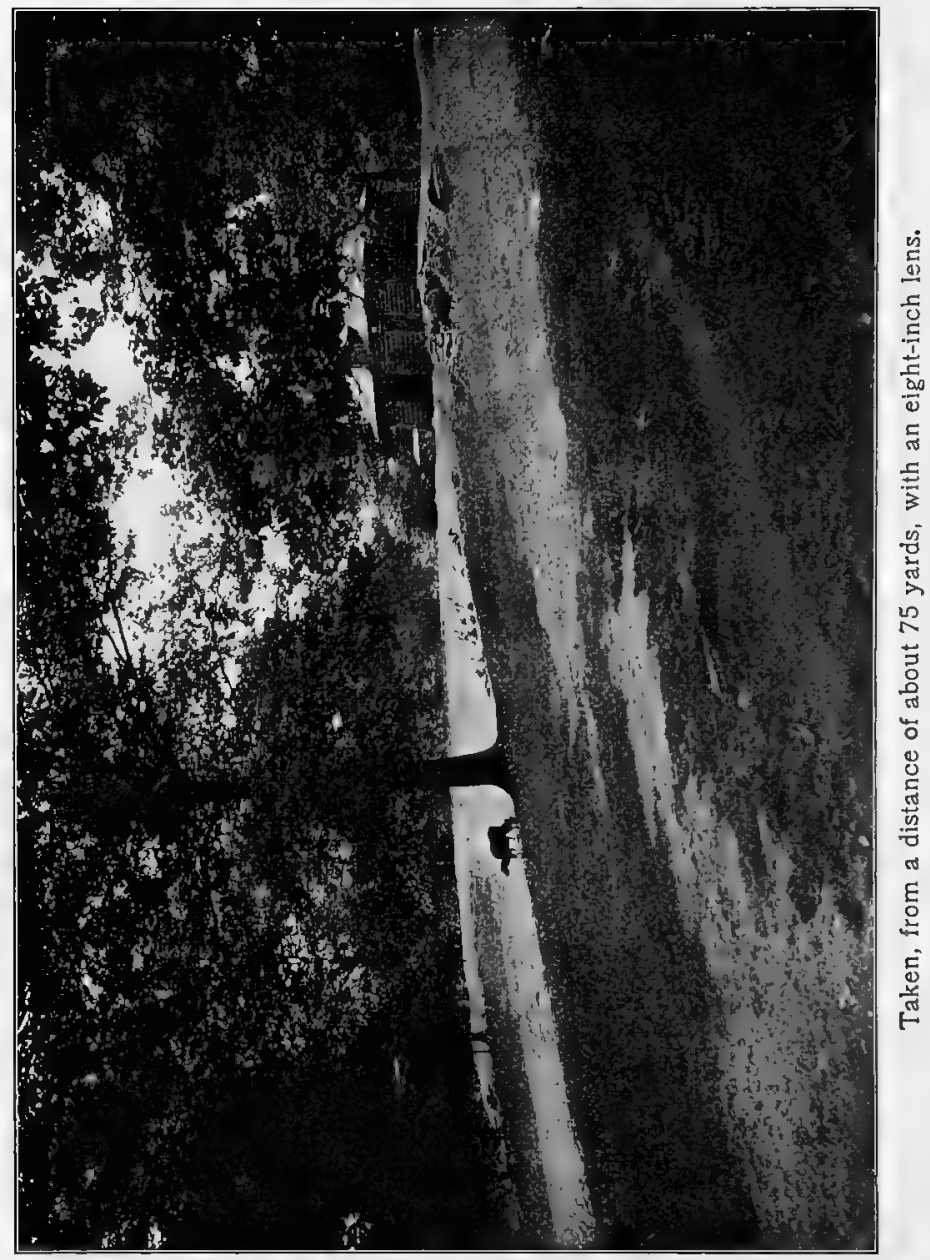




\section{The Telephotograpbic Lens and its Uses 77}

negative element, is but a slight additional expense. In consideration of its usefulness it is the cheapest part of a nature worker's outfit and is easily within the reach of anybody's pocketbook.

To the beginner it may seem absurd, and, indeed, to those who know nothing of the possibilities of this lens it seems nothing short of miraculous, that photographs can be taken of an animal the size of a deer at distances varying from one hundred to two hundred yards and good-sized images be obtained. Yet this is not only possible, but easy of accomplishment, when the camera is used at its greatest extension and, in the bright sunlight, the exposure necessary to obtain a perfect negative does not exceed one to two seconds. In fact, when one first uses this instrument he is apt to over rather than under expose his negatives. I know this was the case with me, for I found it hard to realize that negatives could be made with it with no greater exposure than I soon found was necessary. I remember that when developing the first negative I ever took with one I was completely mystified that it should come up positively black, with almost no detail showing. This I could not understand until I learned that instead of the five-second exposure I had given I should have used less than a quarter of a second.

It is difficult to give any definite instructions in regard to the exposure, as it increases in accord- 


\section{Photograpby for the Sportsman Naturalist}

ance with the extension of bellows used and varies according to the speed of the positive lens. One must learn for himself, which he can do by a little experimenting, just how much longer exposure it is necessary to give when using the telephoto attachment, and in just what proportion to increase it as he increases the length of bellows.

Roughly speaking, about four times the length of exposure is needed when the magnification does not exceed two and a half to three diameters as would be required with the ordinary lens, and this increases proportionately to the number of magnifications.

Another great advantage of the telephoto lens over one of the ordinary type is that it shows much better perspective. With its use we get none of that grotesque foreshortening which it is almost impossible to avoid when using the short focus lenses on near-by objects, and which often does much to mar the beauty and usefulness of an otherwise successful picture, if, indeed, it does not ruin it entirely.

The telephoto may be used successfully in the reflex, but only in bright sunlight and by the exercise of the greatest care, for it would be impossible to hold the camera absolutely immovable during an exposure exceeding a fifth of a second. It can be used, however, with entire success on birds and animals in cases where they would not 
The Telephotograpbic Lens and its Uses 79

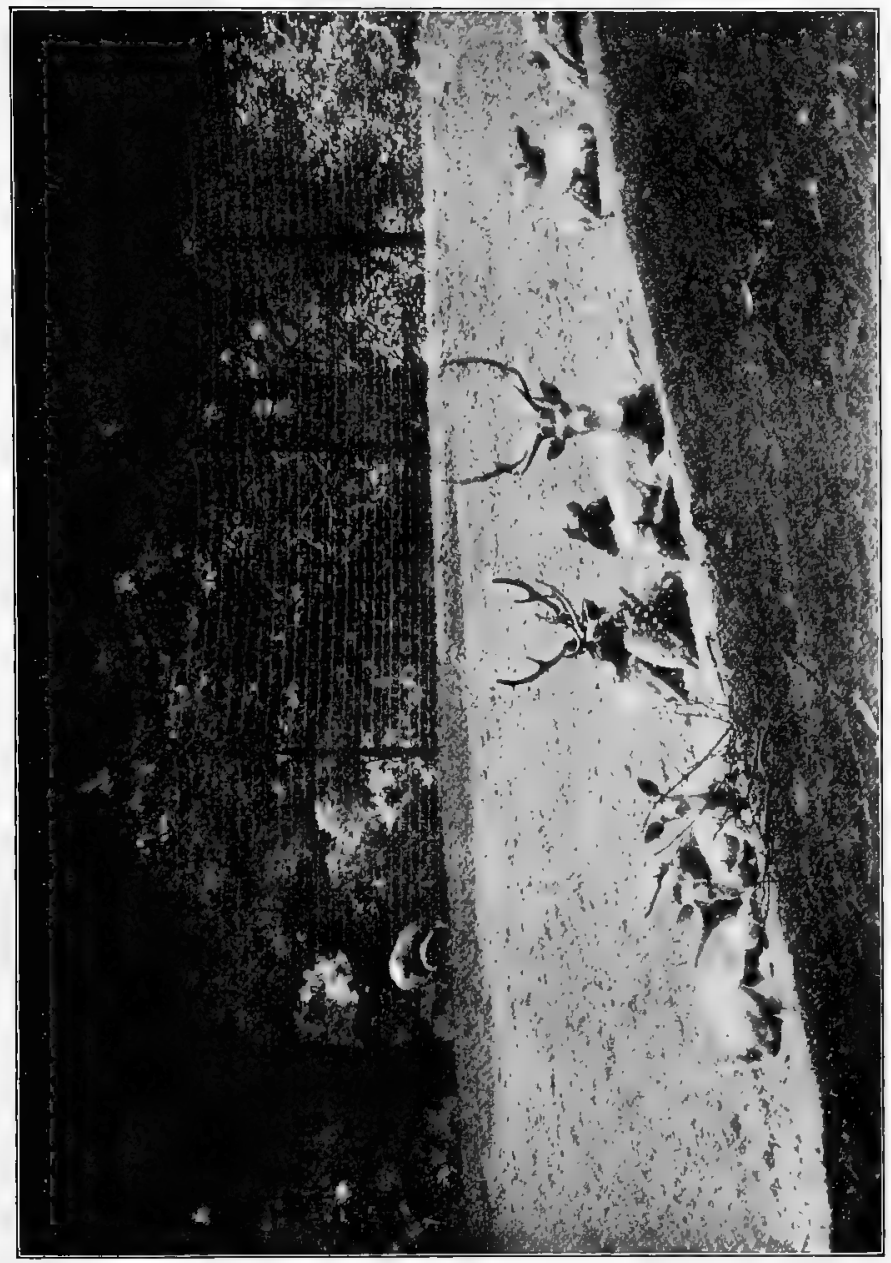

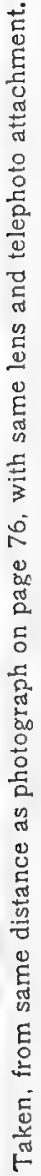


8o Pbotography for the Sportsman Naturalist

allow us the time to set up and focus with a tripod instrument.

The accompanying photographs, which I have used to illustrate this chapter, have been made expressly for this volume, with the idea of clearly showing the comparative advantage of a telephoto lens over an ordinary one. That this advantage is great I think no one can deny, and no one who has ever used a telephoto in nature work will dispute me, I feel sure, when I say that, next to the reflex type of camera, it is the one appliance that has done more than anything else toward making possible much that has been accomplished in nature photography. Therefore, no nature worker's outfit is entirely complete without one. 


\section{CHAPTER VI}

\section{APPARATUS FOR A FIELD WORKER}

THE absolutely necessary apparatus which one must have in order to work along the lines of nature photography is not very extensive or very expensive. It is always well, however, when one wishes to do the best work possible, to be supplied with the best tools possible. So it is always advisable to start out with the proper outfit, even though it does cost a little more than one anticipated, than to spend less money and find that one's apparatus is inadequate to the demands made upon it and be forced to discard it eventually in favor of that which should have been originally bought.

This will inevitably happen if one starts out with a poor outfit, although I should advise the beginner to start with but one camera until he has become somewhat familiar with the work and found out whether or not he wishes to continue at it. By that time, too, he will have become better acquainted with the different makes of cameras and lenses and will, consequently, be 
82 Pbotograpby for the Sportsman Naturalist

better able to choose for himself than I am to choose for him.

It is said that a good workman can work with any tools, but it is not so in photography; for no one can take a picture requiring an exposure of $\frac{1}{5} \pi$ of a second with a lens whose limit of capacity in speed does not exceed $\frac{1}{50}$ of a second, and no one can make a shutter whose highest tension allows it to work no faster than $\frac{1}{100}$ of a second answer the purpose of one that is manufactured especially to make exposures ranging from $\frac{1}{10}$ to $\frac{1}{100 \overline{0}}$ of a second.

In work on the living wild things speed is preeminently necessary. We cannot tell our subjects to "sit still and look pleasant," but we must be ready to catch their images whenever and wherever we may; and in order to do this an exposure of $\frac{1}{1000}$ of a second is no unusual thing. This may seem to be an absurdly small length of time, and, indeed, it is almost smaller than we can appreciate. It is faster than the human eye can work, and yet it is none too fast to stop the action in the wings of a flying bird and it is entirely inadequate when applied to the rapidly fluttering wings of a butterfly. Photographs are taken in less time than this, remarkable as it may seem to some, but not, however, with the orthodox camera and lens; and it is unnecessary for me to enter into a description of anything but those appli- 
ances which are a necessity to the nature photographer.

To try to tell a man just what make of camera, lens, and shutter he must use would, in my opinion, be almost if not quite as absurd as to try to influence him in his choice of a rifle or shotgun, especially when he already knows something about them. With cameras, as with guns, there are many makes upon the market, all equally good; but naturally each photographer has his favorite make, as each sportsman has his favorite gun, and each is apt to think that the particular make which he uses is the best.

So, to the experienced man, who already has his ideas inviolately fixed and with whose ideas some of mine may conflict, I make my apologies and beg him to remember that, as I have already stated, this volume is written as an aid to the mere tyro, he who knows nothing of the work he is about to attempt, and not to the man who is already experienced in that work.

It is almost always discouraging to the beginner to look over the long list of photographic apparatus and to try to pick out the camera, lens, and other appliances which he thinks he will need, realizing, as he must inevitably do, that he really knows nothing about it. I know this was the case with me, even a number of years ago, when the name of the different makes was not so nearly 


\section{Pbotograpby for the Sportsman Naturalist}

legion as it is now. One is very apt in his perplexity to turn to the dealer for aid, and he, rarely being a practical photographer and almost never one who has any knowledge of the nature end of it, will induce him to buy a number of absolutely useless things and omit many that are necessary. Moreover he will, naturally, try to sell him those things upon which he makes the largest profits, regardless of whether they are necessary to the outfit or not, unless, as is infrequently the case, that particular dealer happens to be a thoroughly conscientious man.

I find, with all due regard to the dealers in photographic goods and supplies, that most of them are entirely without conscience and would much rather sell a man who knows nothing about it a camera of the vintage of '9o than one that is up to date; and cameras are not like wine, they do not improve with age.

A great difficulty in trying to give anything like a complete list of the apparatus needed for successful work is the fact of the constant change and improvement in that apparatus. The thing that may be the best for to-day's work may be superseded by something infinitely better tomorrow, and that may again be supplanted on the following day; for there is actually scarcely a day passes that does not find some new appliance placed on the market, or, at least, some improve- 
ment on the old, to simplify the various processes of photography.

However, I shall give from my experience, combined with what I know of the experience of others, hints concerning the apparatus which I have found most useful, and shall hope that those hints will be taken for what they are worth; for my opinions, while based upon a fair amount of knowledge, I do not for a moment consider infallible, nor do I wish any of my readers to consider them as such.

In the first place, I would advise all beginners to use as little apparatus as possible and to make that apparatus as light as is compatible with strength and rigidity. When one starts out for a ten or fifteen mile tramp in the quest of subjects it is well that the burden he has to carry should be as small as possible, for every extra pound will begin to tell after the second or third mile, and before he has returned he will think that the weight has increased tenfold.

I almost invariably use, on my long jaunts, a four by five camera. This size is, I think, the most practical for all-round nature work. It is light and can be carried long distances without inconvenience, takes up little room, and at least two dozen plates can easily be carried with it in plate-holders or magazine.

The plates, after development, can be much 
86 Pbotography for the Sportsman Naturalist

more easily packed away and cared for than can those of a larger size, and they are of the most convenient size and shape both for making enlargements from and for reducing for lantern slides. Moreover, and this is of no little consequence, they are much cheaper than are the larger ones.

The camera should be a long-focus one, with extension of bellows at both front and back, and should be of the best and most substantial make; for it will receive many a hard knock before you are done with it, knocks that a lightly built camera will not stand. It should have both the reversible and swing back and the rising front, all of which have been described in a previous chapter. With this style of camera I have done much of my best work, and for all general photography there is none better.

As the worker advances and becomes more and more adept in his art, he will find other cameras of different sizes, while not absolutely necessary to the successful issue of his work, at least very useful, and he can add them to his outfit as occasion demands; but at first one camera will be sufficient for all his needs.

As to plate-holders, one can be none too careful in his selection of them, for upon them a great deal of his future success depends. There is nothing more discouraging or maddening than 
to find that an exposure from which one expected much has been irredeemably ruined by a defective plate-holder. It is strange that, while such immense improvements have been made in cameras, the one part that is of almost the most importance, the plate-holder, should still be inadequate to the demands made upon it. There are almost no plate-holders made in this country that are absolutely light-tight, for the best of them will not stand the test of a half-hour's exposure to the direct rays of the sun without fogging the plate, and many cannot be left with safety in the sunlight for more than a few seconds. They are the one part of the apparatus that we should never select on account of their lightness, for the lighter they are the more flimsily are they made; and although the cheaper, lighter ones may answer when used with the greatest care and exposed to a strong light as little as possible, still, they will not stand the wear and tear that is bound to fall to their lot and will soon be in such a condition that they will be entirely useless. I am partial to a plate-holder with a hard rubber slide, for, although it is apt to become brittle in cold weather and correspondingly soft in warm, it is the most opaque of any and cannot be injured by dampness. The ones made with a dull finish are the best.

So, in selecting your plate-holders, get those 
that are as strongly made as possible, regardless of the weight, and above all do not buy any pattern that does not allow of the plate being inserted and removed with the greatest ease. It will often be found necessary to change plates in the dark, in any closet or other place that is lighttight, and sometimes even in the open, after dark, or inside a closed tent or even a sleeping bag. This is frequently a test of one's patience under the best conditions, and if the plates insist on sticking in the plate-holders it increases the difficulties. At least one dozen plate-holders should be purchased, for one should carry not less than two dozen plates on a day's photographing trip.

Magazine plate-holders are useful, inasmuch as they allow one to carry more plates in less space, and the manipulation of them is easier and quicker than when plate-holders are used. I do not unreservedly recommend them, however, as I think they are still far from being perfected. They are too easily gotten out of order and the plates stick at just the critical moment; or else a small hole or break appears, usually in the leather top, of which we know nothing and which will admit enough light to ruin a dozen plates before we discover the damage that is being done. Therefore I always stick to the old-fashioned plate-holders, which, while being somewhat cum- 
bersome, I consider more satisfactory in the long run.

In this connection a changing bag is often a useful thing, although it is difficult to find one that is satisfactory and that will not wear out and become useless in a short time.

When one is going on a camera hunting trip, however, where he will have no access to anything resembling a dark room, it is well enough to take one along, as by its use one can remove his plates from and reload his plate-holders even in broad daylight. Mr. Dugmore describes one which he has found useful as follows: "A simple form that answers for a changing bag is a square, box-shaped bag, well reënforced and bound at the edges. At each corner there is a loop to which cords are attached that will hold the bag in position; two sleevelike openings (with rubber bands to hold them closely about one's arms) on one side admit the arms and should be made large enough to let the plate-holders enter." He further says that one made of pantasote is the best, as any material in which rubber is used will soon harden and crack. In this I fully agree with him, and I think that the one he describes is probably the simplest and best form of a changing bag that one could use. When in use it is swung from any convenient branch or branches, and while one cannot well see what he is doing, when he once knows 


\section{Pbotography for the Sportsman Naturalist}

his plate-holders and the manner in which the plates are packed in boxes, this is not necessary, for feeling is all that is then requisite.

In regard to the tripod: one that combines lightness with thorough rigidity is desirable. These two qualities are in no way incompatible if the tripod is made of the proper kind of wood. English ash is good, but heavier than mahogany or willow, and both the latter make good, strong tripods. The head should be broad, so that when the camera is attached it will have a solid base upon which to rest. The legs should telescope or fold at least three times or, better still, four, so that it can be packed in as small a space as possible, but the screw nuts at the joints should be strong enough to hold absolutely firmly. The tripod is not necessarily indispensable, but it is an extremely important adjunct to the outfit, and as it will receive much hard usage it should be so built as to withstand it. The telescope tripods made of aluminum are very pretty to look at, but their only recommendation lies in their lightness. So far as rigidity is concerned they are useless, for the merest breath of air will cause them to sway, and therefore they should never be used. The screw bolt which attaches the camera to the tripod head should be undetachable, otherwise it can easily be lost and so destroy the usefulness of the tripod. 
A tilting table is sometimes useful in cases where the camera is to be pointed downward, but it is a heavy contrivance, increasing one's load, and is never absolutely necessary.

For certain work indoors it will be found necessary to have a form of camera stand that will permit the placing of the subject on a piece of plate-glass maintained in a horizontal position, while the camera is secured vertically above and pointing directly downward at it. There are a number of such devices, and any of the larger photographic houses can fulfil your wants in this direction.

A ball and socket clamp, which is made in different sizes and which can be carried in one's pocket, is almost indispensable when photographing from trees, for it not only fastens the camera securely to any branch, but allows of its being tilted or swung in any direction, even in a vertical position, and held there securely.

Now as to the lens, and in this respect one must rely largely on his own judgment and the capacity of his pocket-book. There are many lenses on the market, and those of the highest grades are all equally good. The cheaper anastigmatic lenses which are usually sold with an outfit will answer many purposes, but when it comes to very rapid work, they fall short of the requirements. For a beginner this style of lens 


\section{Pbotography for the Sportsman Naturalist}

will probably do, but as he advances he will find that it is inadequate for the various uses to which he may wish to put it. In most branches of work speed is necessary, as is also depth of field and definition. All these qualities are combined in the highest possible degree in the best lenses. The longer the focus of your lens the better, and it is always well to get a lens that will cover a plate one size larger than the plate you intend to use. By doing so you acquire greater length of focus and greater covering power, which is useful where the rising front of the camera is used.

A short-focus lens distorts objects that are close to the camera, often to such an extent that the results are grotesque and ludicrous in the extreme. Unfortunately those lenses of the very highest speed have the least depth of field, and I would advise that for all-round use one working at about F.6 be used. This gives sufficient speed for all work, under ordinary conditions, combining with it a fairly considerable depth of field. The best lens is one whose two systems of combinations have different foci and can be used separately. In such an instrument we have practically three lenses in one, the front combination being of one length of focus, the rear of another, and the entire lens, or couplet, of a third. Of course the single combination is much slower than the double, and this must be taken into consideration when using it. 
Of the telephoto lens I have already written, and it needs only to be said here that it forms an invaluable adjunct to the outfit.

Among the shutters there is almost as great a choice as among the lenses, but in buying one we should be careful that, in making the exposure, it works as smoothly and makes as little noise as possible, for the click of a shutter is often sufficient to scare a wary bird or animal. We must also remember that, while each shutter has its time-scale, these scales are seldom absolutely correct, and that they are intended more to represent degrees of difference than exact measurements of time. Thus, while most of the later patterns of shutters are scaled to work automatically at from about three seconds to the $\frac{1}{1.50}$ of a second, they rarely exceed in speed $\frac{1}{100}$ of a second, and frequently the best they can do is less than that. For extremely rapid work the choice is not so great, however, but is limited to one type: the focal plane shutter, which is capable of making an exposure in $\frac{1}{1000}$ of a second, but which has been described elsewhere and so needs no further mention here.

For rapid work, also, such as birds flying, fish leaping, animals running, etc., the only camera that can be used successfully is one of the reflecting type, which I have also fully described elsewhere, or else a twin lens, which is more cumbersome, 


\section{Photography for the Sportsman Naturalist}

more expensive, and not so good. The photographer, as soon as he has mastered the intricacies of the tripod camera, will do well to add one of these indispensable, although rather expensive, boxes to his outfit. He will never have cause to regret the necessary expenditure, for with it he can obtain pictures that it would be absolute folly to attempt with an ordinary camera.

So much for the actual camera; but the accessories are of great importance and must not be overlooked or slighted, for upon them often depends the success of the picture.

The focussing cloth is of some importance. It should be of some stout material that will wear well and let as little light through as possible. The ordinary focussing cloth sold by the dealers is not good, for, while at first its quality is excellent, it soon wears at the creases where it is folded and becomes useless. I use a rubber cloth, made by a few rubber goods houses, in which the rubber is woven into the texture of the goods and not merely coated upon the surface. This wears well and is practically opaque. The cloth should be large enough to admit of its being wrapped completely about the camera when the latter is set up and opened, leaving nothing but the lens uncovered. This is often necessary in order that the plate may be thoroughly protected when the camera is left standing in the sunlight, as 
is frequently the case, in photographing birds especially.

About one hundred feet of small rubber tubing and a large rubber bulb or small hand bicycle pump should always be carried, - this for use when it is found necessary, or at least advisable, to release the shutter from a distance. The best form of bulb that I have found is the large rubber syringe used for sprinkling plants. The nozzle can be cut off and a plug fitted to attach to the end of the tubing. This bulb, by a slight squeeze, will give a sufficient air pressure, which the ordinary exposure bulb, sold by photographic dealers, will not.

For those who make extended trips after subjects it is always well to carry with them a small quantity of concentrated developer and fixer. Water for washing can, most usually, be found, as any stream or pond will answer the purpose. While it is not wise to attempt to develop all the negatives you make before returning to your proper dark room and apparatus, it is well to develop a few now and then in order that you may be sure that there is nothing wrong with the working of your camera or with the exposures you are giving. I am acquainted with a man who once went on a long photographic trip, during which he made some three or four hundred exposures. He was foolish enough not to test 


\section{Photograpby for the Sportsman Naturalist}

any of them, however, for which he paid dearly, for when he came to do his developing upon his return home, he found that every plate had been light-struck by a small hole in the bellows of his camera which had escaped his notice. This is apt to happen to any one, and it is not always safe to trust to luck, especially when the results are important.

In order to do any developing afield a portable developing tent is needed. Unfortunately there are none at present on the market that are really good, but I am living in the hopes that some day one of the numerous photographic supply houses will correct this deficiency.

There are, however, two patterns, from which one may choose, that serve to answer the purpose. In one of these the arms only are put inside. There are two pieces of yellow glass on opposite sides, one of which to look through in order to follow development, the other to illuminate the plate. This has the disadvantage of not allowing one to see the plate with distinctness, but at least allows him to keep cool while he is working.

The other style admits one's head, shoulders, and arms, and is then fastened about the waist. It has but one glass window and in cold weather is well enough; but in hot weather it is equal to a Turkish bath, as well as nearly 
suffocating one, and is dangerous, also, to the welfare of the plates.

There are many sundries which one can use to advantage and which are not usually included in a regulation photographic outfit. Among these may be mentioned a pair of good climbers for ascending trees. These should be made with longer spurs than are on those ordinarily used by the telegraphic linemen, so that they may easily penetrate through the bark of the tree and into the solid wood beneath. I should not recommend any one to make his first attempt at their use on a very high tree. A plentiful supply of stout cord is also useful in many cases. It should be strong enough to admit of hauling up and lowering the camera from tree-tops. Many photographers screen their cameras with leaf-covered boughs, etc. I use merely a large piece of green cloth. It often will be found necessary to thus screen the camera, for the two things about it that seem to frighten the subjects most are the lens and the legs of the tripod. The former it is impossible to entirely cover up, but the latter can be made invisible, and for this purpose, as I have said, I use a piece of green cloth, which blends sufficiently well with the surrounding foliage to allay, in most cases, the fears of my subject.

A mirror is frequently of extreme assistance. It should be of heavy plate-glass, so as not to 
98 Pbotograpby for the Sportsman Naturalist

break easily, and at least eight or ten inches square. Its usefulness consists of reflecting light upon dark subjects, such as birds' nests in holes, etc., which could not be successfully photographed without the aid of such reflected light. A smaller mirror, which can be held in front of the camera and which will enable the operator to set his shutter at any desired speed from the back of the camera by reading the reflection in the mirror, will also be found useful, for many occasions arise, especially in work from tree-tops, where it is impossible to get to the front of the camera.

Last in my list, but by no means the least in importance, is the choice of plates to be used. This question of which is the best plate to use is one upon which different photographers differ greatly, for while one will swear by a certain brand of plate, another will say that that particular brand is worthless, or nearly so, when compared with some other. The fact of the matter is that there are many good plates on the market, and I have arrived at the conclusion that the plate with which any worker can obtain the best results is the best plate for him to use and to stick to, for the constant changing of makes of plates is foolish.

As I have not said anything elsewhere on the subject of plates, it may be well to put in a few words here.

There are three styles of plates on the market 
that are useful to the nature photographer. These are: the ordinary fast plate, of which Secd's 27 or Cramer's Crown are probably the best examples; the Iso- or Orthochromatic plate; and the Non-halation plate. The first is a plate of fast emulsion, with no particular quality, useful in all ordinary cases, and up to within the past few years the best plate on the market. The isochromatic or orthochromatic plate is one that is coated with an emulsion made especially sensitive to the reds, greens, and yellows, and therefore gives more accurate color values. The non-halation plate is one which prevents, by a double coating of the emulsion, blurring around strongly lighted places such as the window of a room looked at from the inside. There is also a plate, which has lately been placed upon the market, which combines these two qualities and which is called the nonhalation orthochromatic plate. This is, to my mind, the finest plate that has ever been manufactured, and is most excellent for every style of work.

For general use I should recommend the orthochromatic plate as giving the best results under all circumstances. It is made in three grades: fast, medium, and slow. The slow gives the best color values, but cannot be used for instantaneous work. Ordinary plates will do well enough for snap-shot work and are easier to manipulate in the 
Ioo Pbotograpby for the Sportsman Naturalist

dark room, as they are capable of standing much more light without fogging; but in flower work, especially, orthochromatic plates are a necessity.

A ray filter or color screen is a helpful adjunct in use with these plates, as it accentuates the color values. The best consists of simply a piece of glass stained yellow. Any one can make one for himself by thoroughly fixing an unexposed plate in fresh hypo and then, after a short washing, soak it in a ten per cent solution of bichromate of potash until the required density of color is reached. After it has dried, cover the film side with a piece of clean glass, bind the edges, and you will have a perfect color screen. It should be fastened either to the front or back of the lens, and should be so fixed that no rays of light can pass through the lens that do not also pass through the screen; otherwise it would not answer its purpose of entirely "filtering" the light. It must be remembered, however, that, when using one of these screens, the exposure which would be given without it must be increased from four to ten times, according to the density of the screen.

On long trips, where weight and space are a consideration, the cut film is really an excellent substitute for the glass plate and has the added virtue of being absolutely unbreakable. It is made of heavier celluloid than are the roll films, and is carried in a film-holder made for the purpose and 
inserted in the ordinary plate-holder in the same manner as a plate.

In my work I use the orthochromatic plates, to the almost exclusion of all others, both with and without the color screen, as I find that they invariably give me the best results. The beginner, however, must experiment for himself until he finds the plate which he considers best adapted to his uses. 


\section{CHAPTER VII}

\section{PHOTOGRAPHING THE LARGER ANIMALS}

THere are few people, of those who use a camera or of those who do not, who realize the immense possibilities there are for pleasure and excitement in the photographing of the wild animals, the "big game." It is a field in which but little has as yet been accomplished, but in which much can be done, and it is undoubtedly the sportsmen who can do this better than any one else. This is because they know the animals, their habits and haunts, better than do most of us, and because they know also the best and surest means of approaching them.

This is not a field, however, that any one can enter, for it means work that necessitates the taking of long trips into the denser wooded parts of the country, and not every one can afford the time to do this.

Here we cannot go out for a day's work, as we can when photographing the birds or even the smaller mammals, but we must prepare for it weeks in advance; for it means the collecting of 
apparatus and camping outfit and, unless we are well acquainted with the part of the country we would visit, the looking up of travelling routes and the hiring of guides. In fact it is nothing more or less than a hunting trip on which the camera takes the place of the rifle, or, at least, is used in conjunction with it.

Moreover, it should not be taken except by those men who are physically capable of withstanding much in the way of exposure, fatigue, and hard, nerve-racking exertion. Photographs of the larger wild things, the deer, moose, cougar, etc., are only obtained by strenuous and often dangerous work, and the ability to follow, at no matter what cost, wherever your subject may lead, until you have had your opportunity to catch his image on your sensitive plate. It requires a strength and endurance with which not many of us are blessed, and those who are not possessed of these necessary qualities or have not the nerve to face at close quarters an angry elk at bay, or a cougar treed and ready to spring, had better not attempt it, but confine their labors to some branch of photography that requires, perhaps, just as much real brain-work and ingenuity, but less of actual physical power.

Recent literature has given us really astonishing and wonderful proof of the courage, hardihood, and skill of those naturalist sportsmen who 
I04 Photograpby for the Sportsman Naturalist

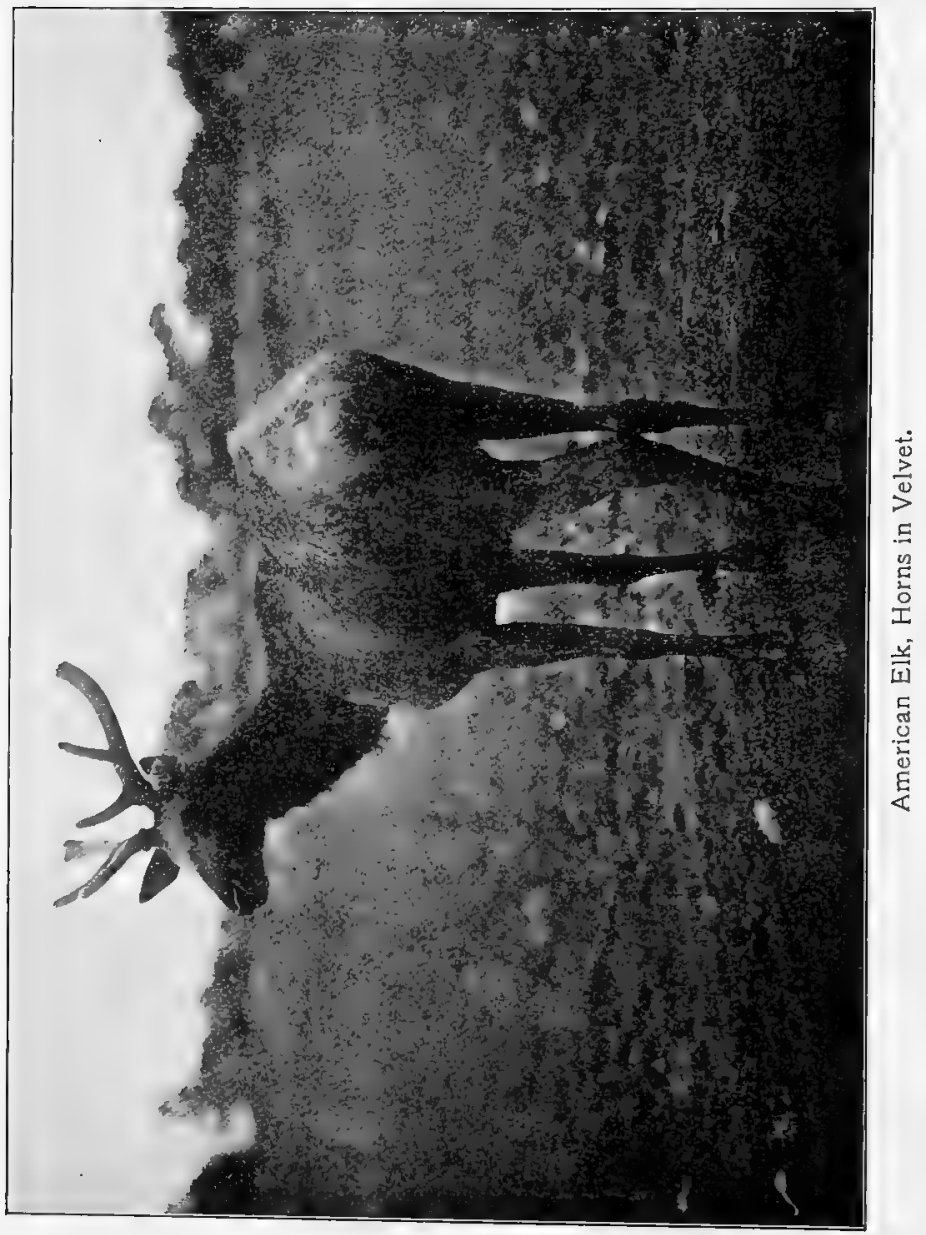


will follow in the track of any animal, sometimes even for days or weeks, regardless of danger, toil, or exposure, until the desired picture is obtained. Of these Mr. A. G. Wallihan of Colorado is, perhaps, the most indefatigable, and he has to his credit some truly marvellous results of his hunting.

With an eight by ten camera on his back and a pack of hounds he considers it nothing to follow in the tracks of a cougar for miles over the roughest country and through deep snow, hanging on with a grim tenacity, until his quarry is treed, then approaching with his camera, while his dogs hold the creature at bay, sometimes even climbing the same tree in which the cougar has sought refuge, regardless of the danger of so close an approach to the enraged beast, until he is near enough to obtain such a picture as he wishes.

His results, however, must be a sufficient recompense to him for all his hard work and exposure to imminent danger, for his photographs are, undoubtedly, the most remarkable products of the camera in the line of nature work that have ever been made and will so stand for some time. The most remarkable one of them all that I have seen is, to my mind, one in which he photographed the cougar as he sprang at him from a tree-top and which actually shows the animal in mid-air. 


\section{Io6 Photography for the Sportsman Naturalist}

If this kind of work is not exciting enough for the most exacting, calling, as it does, for a display of the greatest coolness and nerve under trying circumstances, then I am at a loss to know just what could satisfy him.

Mr. W. E. Carlin, who was at one time a most enthusiastic sportsman, but who has of late years used a camera almost exclusively, in preference to a gun, on his hunting trips, has done much excellent work, principally in the Bitter Root Mountains in Montana and Idaho. I am inclined to believe that with the black and the white tailed deer, particularly, no one has done any better work than has he, for many of his photographs of these animals are as near perfection as possible.

He has used entirely a telephoto lens on these subjects, photographing from a blind at a distance of from seventy-five to one hundred yards from the deer. His photographs of lynxes are also most excellent. These he obtained by trapping the animals and tying to one of their hind legs a clog heavy enough to keep them from running, but not so heavy as to entirely impede their motion. Then, by following them about until they assumed natural and characteristic attitudes, he was enabled to obtain just what he wanted. This may seem simple and easy enough to the uninitiated, but to face an enraged lynx, even 
though he is clogged, at a distance of three or four feet, and calmly focus your camera and make an exposure, for he was not using a reflex, takes an amount of courage and an exhibition of nerve of which not every one is possessed. That the results are not always all that can be wished is evidenced by the fact that Mr. Carlin once made a snow-shoe trip of three days' duration in the quest of photographs of these animals, sleeping out on the snow at night, and carrying, besides his provisions and a blanket, his heavy six and a half by eight and a half camera outfit. While he made many exposures, when he came to develop them he discovered that, through one cause or another, only two or three of the lot were good. This certainly is disheartening, but tends to make those good pictures which we do obtain the more valuable and worth having.

Success in work on the larger animals is due not only to the capability of endurance, but also to absolute vigilance and the strictest attention to every detail.

Once stalk a deer with a camera instead of with a rifle and you will soon learn the difference between the two methods of hunting; and you will, in all probability, agree with me when I say that for the display of all the skill and ingenuity, coolness and patience, that one may possess there is no comparison between the use of a gun and a 


\section{Io8 Pbotograply for the Sportsman Naturalist}

camera, as the advantage lies too heavily with the latter.

Learn all there is to know about still hunting and then double every precaution known to the hunter's art and you may succeed in your hunting with a camera, but fail in a single particular or let your caution abate for one second of time and the chances are that you will get no picture, but, instead, will be forced to stand and watch your quarry go crashing off through the woods.

Above all, the excitement of the chase must not cause you to forget your object, or to cease to be cognizant of everything that you are doing. You may not think this is liable to happen, but it is. I have known of a man, and he was no novice at the game either, who let an excellent opportunity to get a picture of an elk escape him simply because, as he himself said, in the excitement of seeing the animal so close to him he entirely forgot that he had a camera in his hands.

Mr. A. R. Dugmore tells of an experience of a similar nature that he had while photographing moose in northern Maine. He says: "Once when I was on a hunting trip trying to secure some moose pictures, I came across a fine large bull. The situation was perfect from a pictorial point of view. He was in a large pond where the lily pads were abundant; in the background was a bank of trees, mostly birch; beyond stood 


\section{Pbotograpbing the Larger Animals}

Mount Katahdin in the misty distance; the moose was feeding in shallow water, the light was bright, and as the wind was in the right direction, everything pointed to a successful picture. We were in a canoe; slowly and noiselessly we came through the smooth water; scarcely a ripple did the canoe make. Nearer and nearer, and still the bull had not seen us. When within about seventy feet (I was using a telephoto lens) I stood up slowly and quietly, while the animal was feeding. No sooner was I in position than he looked up. A finer picture could not be imagined. His enormous antlers, still in velvet, seemed almost out of proportion to his size. And he stood absolutely still while I, trembling with excitement, focussed the camera and pressed the button. Instantly the huge beast made a dash for shore and in a second was lost to view, and I sat down congratulating myself upon having secured such a fine picture. Imagine my disgust when, on going to change the plate-holder, I discovered that in my excitement I had neglected to draw the slide. My chance was gone, and never again did such an opportunity present itself."

I quote this little tale simply to show how easily chances may escape us and excellent pictures be lost if we do not always keep our presence of mind. Double exposures, that is two exposures made on the same plate, is one of the commonest 


\section{10 Photograpby for the Sportsman Naturalist}

faults of the beginner. Every little detail must be thought of, and a good way to avoid these unpleasant experiences is to have a regular routine of procedure, both before and after exposure, and never vary from it. If you do this regularly, it will soon become so much of a habit that you will do it unconsciously, and the chances of failure through having overlooked an important detail of procedure will be reduced to a minimum.

In this work the ordinary tripod camera is of but little use, unless you are photographing from ambush, as, under the usual circumstances, by the time you have opened and set up your tripod, attached your camera, focussed, set the shutter, and inserted the plate-holder, the animal you had wished to photograph would be a mile or two away and "still running." The only manner in which a tripod camera can be used successfully is by focussing from a well-screened ambush or "blind" upon some objective point (such as a salt lick) to which you may be reasonably certain the animal will come, and then waiting until he gets there.

This can often be done successfully from a distance of twenty or thirty yards, or even farther, and, by the use of the telephoto lens, large images obtained.

Sometimes, but not often, a deer, moose, or elk will be discovered standing knee-deep in some pond or grazing in some grassy opening, which, if 
we approach with great caution to within fifty or seventy-five yards, will continue to be unconscious of our presence until we have had time to set up our camera and make several exposures. These are the chances that we must always be on the lookout for and of which we must always be

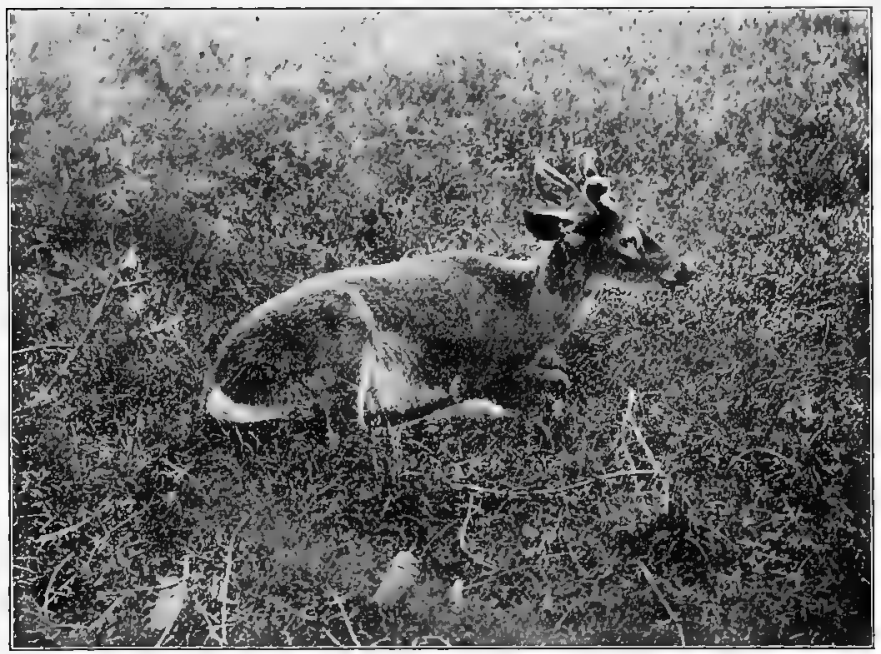

Half-grown White-tailed Buck.

ready to take advantage when they present themselves.

I remember once, when hunting in the Adirondacks, that two deer waded into a pond not more than fifty yards from the spot where one of the party sat watching for them. They stood perfectly motionless while he emptied the magazine 
I 2 Photography for the Sportsman Naturalist

of his rifle at them without hitting either one (it was afterwards discovered that the rear sight of the rifle had been inadvertently raised and every shot must have gone at least two feet over them). They did not seem to be in the least frightened by the noise of the shots and even remained where they were when he called to the next one of the party, who was some three or four hundred yards distant. They slowly waded from the pond, however, before he could reload his magazine, disappearing into the woods, and, for all I know, they are wandering around up there yet.

Had he had a camera with him he would have had ample opportunity to make several exposures and would have obtained some invaluable photographs, for the conditions were just right for good work, and it is very seldom that one has the chance to get the photographs of two deer on the same plate.

This only shows that it is impossible to give any explicit directions as to the manner in which wild animals should be approached, for it all depends upon the individuality of the animal. Especially is this true of the deer tribe, for while some individuals will take fright before you have even sighted them, others will allow of a close approach, even though you may be in plain sight and with the wind blowing directly from you to them, and seem to be entirely indifferent to your 


\section{Pbotograpbing the Larger Animals}

presence and dead to all sense of fear. It is best, however, never to risk a close approach until you have secured at least one negative, no matter at what distance, when the deer is first sighted; otherwise the opportunity of securing one of that particular animal may escape you altogether, and any picture of a deer or other wild animal, no matter how small the image may be, is of value, for it can always be enlarged.

Ordinarily the reflex camera is the one to use and the one which will give the most and the best results. This should be fitted not only with an ordinary fast, long-focus lens, but with a telephoto lens as well. This latter should be one that is made especially for hand camera work, for, while it has a magnification of only three and a half diameters, still it works fast enough to allow of an exposure of at least $\frac{1}{50}$ of a second in the strong sunlight, and even on a cloudy day exposures of from $\frac{1}{5}$ to $\frac{1}{10}$ of a second can be made with it and produce good results.

Never use a short-focus lens in work upon animals, for it not only renders your subjects too small to be of much use, but, when close enough to make a fair-sized image, it is very difficult to prevent the distortion due to the exaggerated foreshortening that is a characteristic of this style of lens. Therefore, I should say, never use a lens of a shorter focal length than nine inches, and, of 


\section{4 Photograpby for the Sportsman Naturalist}

course, as much longer than this as you desire. The longer the better.

In selecting your camera and apparatus for this work, strength should be the first consideration, for, in the trips over exceedingly rough country, which you will be obliged to take, it will receive some hard knocks. Especial care should be taken in the selection of plate-holders, and all those that are at all flimsy in their construction should be discarded. But all this I have spoken of in the chapter on apparatus, and it is only necessary to add here that in this particular branch the outfit will be liable to be subjected to the severest tests and therefore greater care should be exercised in its selection for this work than for any other, or otherwise many exposures will be lost.

When out looking for subjects in the woods and, especially, when following up watercourses in a boat or canoe, always have your reflex in your hands with the plate-holder inserted, the shutter set, and everything in readiness for instant use, for you can never tell when you may get a chance for an exposure.

Once, in Florida, when going up the Miami River in a canoe, on rounding a sharp bend I suddenly came upon a deer drinking at the edge of the water. He was not over twenty-five yards from me, and as he heard the swish of my paddle 


\section{Photographing the Larger Animals}

he raised his head and stood absolutely motionless for as much as two or three minutes while I let the canoe drift. His surprise and curiosity were evidently greater than his fear, and he made a beautiful picture as he stood against the background of green foliage, his whole body reflected in the clear water, in which he stood knee-deep; but, as the canoe continued to drift closer to him, he suddenly turned and bounded off into the woods and out of sight, leaving in my mind an impression of as pretty a little scene in wild life as it had ever been my good fortune to look upon.

At another time, as I was passing through a piece of "hammock" at Cape Sable (the southernmost point of Florida), a lynx, which seemed to me the biggest one I had ever seen, jumped from the low herbage at my very feet and, springing upon a fallen tree not over ten feet distant, stood there growling, his back partly toward me and his head turned over his shoulder. It made a splendid study of natural wild life, and one which I stopped to admire. I would have given much to have been able to obtain a negative of him as he stood there in all the magnificence of his assumed anger, but, unfortunately for me, I did not have a camera with me on either one of these occasions, and so two unique opportunities were lost. 


\section{in6 Pbotograpby for the Sportsman Naturalist}

One never knows when such opportunities will present themselves, and, if you would obtain pictures that you might look in vain to have repeated, you must always be in readiness for whatever may happen.

Some remarkably effective pictures can be

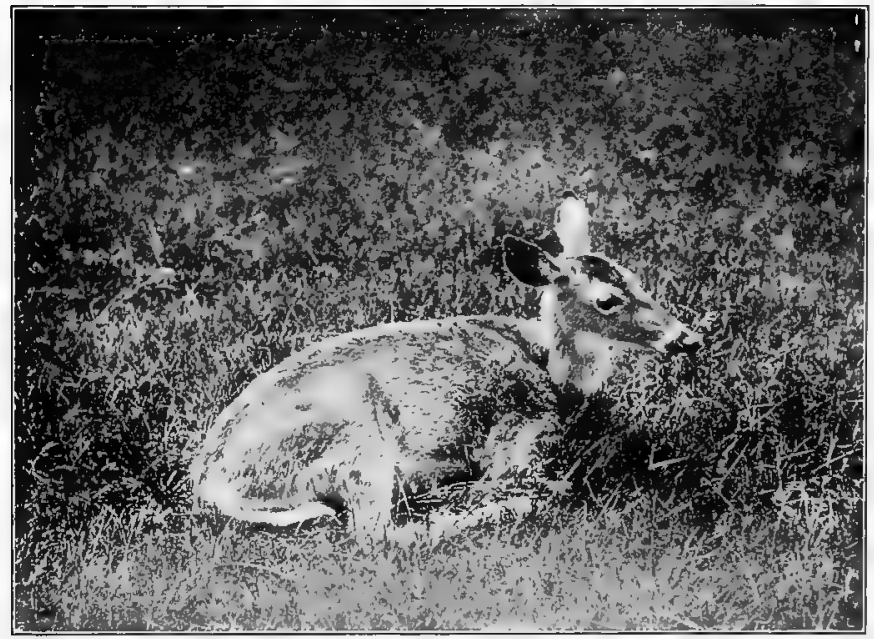

White-tailed Deer. Doe.

made of deer at night by means of the "firelighting" methods, with which all sportsmen are familiar. This consists in rowing quietly around the edges of some pond frequented by deer and flashing a light, reflected from a mirror or other highly polished surface into the dark places. When this light is flashed into the eyes of a deer, 
it dazzles him to such an extent that he can see nothing else, and, in consequence, he will stand absolutely still, staring at it.

It is generally considered a somewhat unsportsmanlike way of hunting these creatures, as it gives them but little chance for their lives; and, in most places, it is prohibited by the game laws. It is, however, an excellent method of taking their photographs. Of course a "flash-light" must be used, and it needs two people to work successfully, one to manipulate the search- and flash-light and the other to do the photographing. The camera must be one of the "fixed focus "variety or else set for the focus of a certain distance and the exposure made when, in the judgment of the operator, he is at that distance from his subject, for it is impossible to see to focus in the dark even when a strong light is reflected upon the object.

Another way of photographing by means of the flash-light is to set up the camera focussed on a deer's runway and insert the plate-holder, with the slide drawn, after dark, leaving the shutter open. Set up the flash gun by the side of the camera so that the deer may discharge it himself by means of a string stretched across the runway at the point upon which you have focussed. The flash powder in the gun should be protected from the damp by covering it with a piece of oiled 


\section{I1 8 Pbotograpby for the Sportsman Naturalist}

paper. This will not prevent it from exploding when the trigger is pulled, but will protect it from the dew, which would otherwise dampen it to such an extent that it would not ignite. The slide of the plate-holder must always be replaced before daylight, otherwise the plate would be overexposed, besides giving a conglomerate picture of foliage showing through the deer's image.

If one is ingenious enough, an arrangement of strings can be made that will release the shutter at the same time that it fires the flash gun, thus obviating the necessity of leaving the plate exposed.

This method of flash-light photography is somewhat uncertain, but often gives good results. Mr. Shiras of Pittsburg has done some really remarkable work by both of these methods, and where it has once been done it certainly can be repeated.

A considerable amount of flash powder must be used, especially in the former method, for the distance and space to be illuminated are considerable, and it is remarkable how much more light is absorbed in the open than in a confined space, such as a room. The proper amount will be ascertained after one or two experiments.

These methods of forcing the animal to photograph itself are often productive of astonishing results. Once a friend of mine had fixed his apparatus at nightfall, and upon examining it in the 
morning and finding that the flash had been exploded he naturally concluded that he had a negative of a deer. Much to his surprise, however, when he came to develop it, it turned out to be an excellent picture of a porcupine. To avoid having the smaller animals spring the "gun," when you do not wish their photographs, the string should be placed at such a height that they may pass beneath it.

Photographs of swimming caribou are easily obtainable, - especially in Newfoundland, where these animals are still plentiful and are liable to remain so for some time to come, owing to the restrictions of a sensible game law that will not allow indiscriminate and continuous shooting, even in the open season. These animals, as well as almost any other for that matter, are practically incapable of defending themselves while in the water, although they are strong swimmers. They can, therefore, be followed up at one's will in a canoe, and any number of "shots" be made at them with the reflex camera.

If you know of the whereabouts of a "yard" of any of the deer family in the winter time, you can have an opportunity such as is not often vouchsafed to one for obtaining a long series of pictures of them, and such an opportunity should never be missed by any one who can take advantage of it.

In the summer time a salt lick is a place pro- 


\section{I20 Photograpby for the Sportsman Naturalist}

ductive of good results and should be watched almost constantly. As any old hunter knows, such a place can be made by salting an old stump, in a deer-frequented place, with rock salt, repeatedly. They will soon get to know of it and will come there regularly to find it.

In the early spring deer come into the open to feed more frequently than at any other season, as at this time the sprouts have not yet begun to appear in the woods, while things are fairly green in the open places, and consequently they can find more to their liking in these places than in the deeper woods. They then offer many good opportunities for pictures to any one who is ready for them. This is the time when a tripod camera, used from an ambush, can best be employed.

But sportsmen undoubtedly know these and many other habits of the Deer family much better than I can teach them, and so it is simply wasting time and space for me to enumerate the different places where one should hunt.

Mr. Wallihan, as I have before mentioned, hunts his cougar with a pack of hounds, running them until they are treed. This has the disadvantage of nearly always forcing your cat into a tree, for it is very seldom that they will take a stand on the ground. It is the only way of getting close to them, however, unless you do as Mr. Carlin did with his lynxes and first trap them. 


\section{Photographing the Larger Animals}

While with the latter method better pictures can probably be obtained with less danger to the operator, the former has more of the element of excitement in it and adds the pleasures of a stern chase to those of photographing, and this, to any one of true sportsman proclivities, counts as not the least of the reasons for hunting.

Photographs of the Rocky Mountain sheep are very scarce, but such as have been taken are exceedingly interesting. Owing to the extreme shyness of the animals and the almost inaccessible places which they frequent, they are difficult to approach to within even the distance of a rifleshot, but by the use of the high-power telephoto lens good pictures of them may be obtained by patience and perseverance.

Bears, in their absolute wild state, are probably the most difficult of any of the wild animals to photograph; but in the Yellowstone Park they can be closely approached without danger, for, owing to the fact that all the animals in this place are most carefully protected and shooting not allowed, they have no fear of man, and, fortunately, while guns of any sort are prohibited in the park, cameras are not, and one may hunt with them to his heart's desire.

In work on the large animals, necessitating, as it does, long trips afield, I should not advise the use of the orthochromatic plates, for, although 


\section{I22 Photograpby for the Sportsman Naturalist}

they undoubtedly give much better results than do any other kind, they have not the keeping qualities of the ordinary plate, and, especially when they cannot be kept free from the least dampness, as it would be almost impossible to do on a camping trip, they deteriorate very rapidly. Moreover, they are not quite so rapid as are the fastest ordinary plates, and speed is one of the first essentials for animal work.

In "packing" into camp and at all times while there, the camera and outfit should be the one thing to be most carefully protected against accident; for even the best and strongest are easily damaged, and this damage may be such as cannot be remedied and the results of a whole trip thereby forfeited. I have known of several instances where this has happened through sheer carelessness, and one cannot afford to treat his outfit with anything but the greatest consideration.

The one great thing to remember in photographing all wild animals is to get them in as natural and unconstrained an attitude as is possible. This can best be done when they are caught unawares, for they are apt to be more or less frightened when they realize that something is being done with them and this fright will inevitably show in the picture, either in an unnatural pose or in some other unmistakable manner. 


\section{CHAPTER VIII}

PHOTOGRAPHING THE SMALLER MAMMALS

Here is a field in which, while the possibilities for excitement are not so great as they are in work with the larger animals, the chances for pictures are greater. It is a field, however, in which a knowledge of the habits of the subjects is, in most cases, much more necessary than in any other.

Should one attempt to hunt for the smaller creatures without a fairly accurate knowledge of their daily lives, he might tramp the woods or fields for weeks and find nothing but the squirrels and chipmunks while, unawares, he has passed time and again within a few feet of some tiny fur-bearer watching him with inquisitive black eyes in fear and trembling.

One never realizes the immense army of small mammals, especially of the Rodent family (the mice, rats, squirrels, etc.), that inhabits our woods and fields, until he starts to look for them. They are innumerable, but, as they are abroad principally at night, one who is not well versed in their 


\section{I24 Pbotograpby for the Sportsman Naturalist}

ways may never have the good fortune to see one.

The red and gray squirrels and the chipmunks we all know, for they are the inquisitive busybodies of the woods, and nothing delights them more than to scold at an intruder upon what

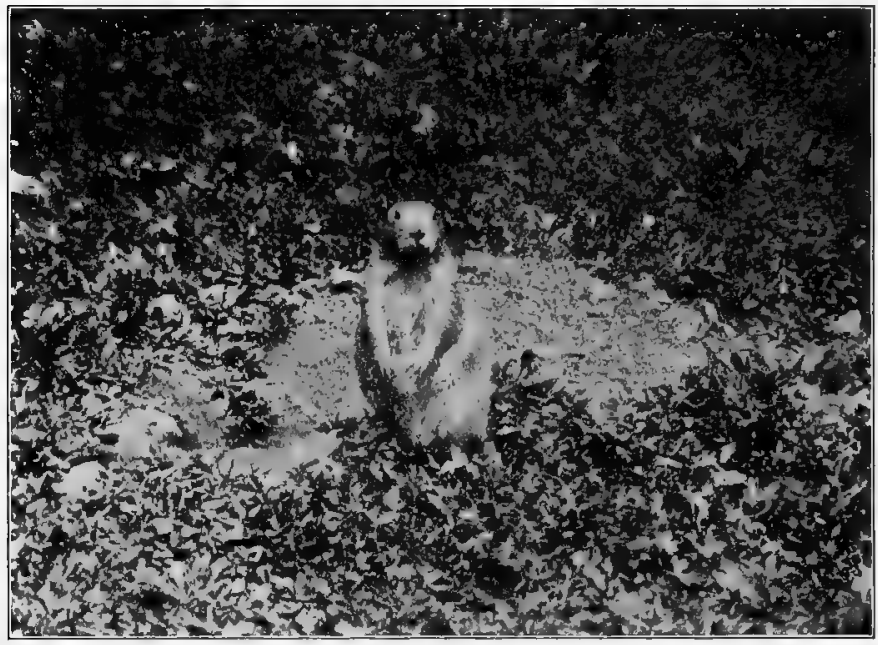

Prairie Dog at Entrance to Burrow.

they are pleased to consider their especial reserve. But these form the smallest part of this army. The mice, of which there are many species besides the common one whose acquaintance we have made through its habit of using our dwelling-places as its home, are numerous everywhere. There is probably hardly a meadow that does not 


\section{Pbotograpbing the Smaller Mammals I25}

harbor at least several hundred of these little fellows, and yet, except for an occasional squeak and rustle in the grass, we may never know of their presence.

Let us look beneath the tangled grass and we will find their narrow but well-defined "runways" stretching in every direction, intersecting and crossing each other, until we discover that the field is a veritable network of these miniature roadways, and that there is a population and a busy life be-

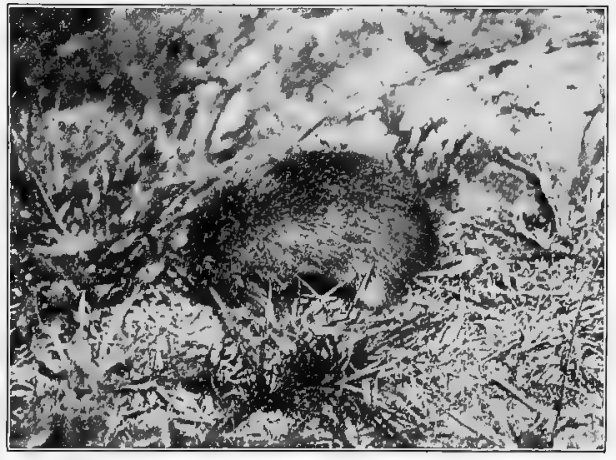

Cotton Mouse.

neath our feet of which we have heretofore known nothing. Follow one of these "run-ways." It may lead nowhere and it may lead to the maker's home: a small, round bunch of dead grass, well woven together, half sunken in the ground and thoroughly concealed by the tangle of grass and herbage above. If we approach carefully, we may be fortunate enough to catch the owner at home, coiled up in the soft, warm interior, taking his midday sleep, but we must be quick or he will 
I26 Photograpby for the Sportsman Naturalist

slip out and away before we can even catch a glimpse of him.

Should we be lucky enough to capture him, however, we can take both him and his nest home with us and photograph them at our leisure.

As it is an exceedingly difficult thing to restrict the range of any of the smaller mammals so as to get satisfactory photographs of them, it is sometimes best to photograph them in captivity. This can be done successfully by the use of a glass cage. The front, sides, and top should be of glass and the bottom and back of wood, covered inside with tin so that the occupant cannot gnaw his way through. Inside of this cage we may arrange what accessories we wish and place our captive. At first he will be very wild, and we shall be able to do nothing with him; but after a while, as he becomes somewhat better acquainted with his surroundings, he will quiet down and will assume the attitudes we wish.

In order to escape reflection on the glass the cage should be so placed that the sun's rays strike it full, and even then it is best not to use a black background.

If there is the least possibility of our being able to do so, it is always desirable to at least attempt the photographing of even these small mammals wild and in their native haunts, as both 
the animals and their surroundings are bound to look much more natural under these conditions.

It can be accomplished, and successfully, if one is willing to use his time and exercise his patience, with either the reflex or the tripod camera. The latter can usually be used to better advantage, however, and the methods followed are much the same as when photographing birds at their nests.

Nearly all of the smaller mammals are in the habit of using one particular stump or rock as a place of observation from which to survey the land before venturing forth. By

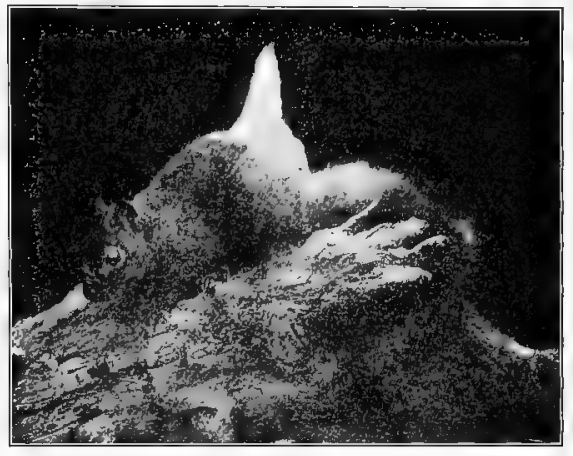

Fox Squirrel.

carefully watching for several days, this vantage point may generally be discovered. If not then, we may get them into the habit of coming to such a spot by baiting it for several days with something to their liking. This will work most successfully if we select a spot in close proximity to their nest. After they have become accustomed to coming to look for the bait, then we can set up our camera, focus it upon the 


\section{I28 Photography for the Sportsman Naturalist}

spot we have baited, screen it well so that it will be invisible to the sharp, inquisitive eyes of our sitter, and, with ourselves hidden at the end of seventy-five or one hundred feet of the rubber tubing, wait for our subject to put in his appearance. Whether we obtain a picture or not depends entirely upon our ability to wait patiently and quietly for an indefinite period. The one absolutely necessary precaution is quietness. The smaller mammals are easily frightened by any unexpected movement or noise, and slight carelessness on the part of the operator will often cause them to leave and not return for a number of hours, if, indeed, they will do so again that same day.

Mr. Carlin, using this method, did some remarkable work on the small mammals of the Bitter Root Mountains. Among these he secured several fine pictures of the Rocky Mountain pika, or, as it is locally called, the little chief hare. These are the only photographs, of which I know, that have ever been secured of this interesting little animal. Of him Mr. Carlin says: "He lives in certain parts of the Rocky Mountain system among the great masses of broken slide rock, and in many ways is one of the most interesting little animals on our continent. In the lower altitudes, say about four thousand feet, he is out and about a good deal of the winter, but in the high altitudes, 
from six thousand to nine thousand feet, his home is buried under from ten to fifty feet of snow and he does not make his appearance until June or July. When he first comes out, he is rather lazy and likes to sit and sun himself. Later on he is seldom quiet for any length of time excepting in the early morning. He has many household duties and begins early in August to gather in his supply of winter hay, for the snow and frosts come early up where he lives. If you are watching by a pile of rocks, you will see him pop suddenly out of some crevasse, look hurriedly around to see that the coast is clear of any prowling weasel or hawk, and, after uttering his peculiar little cry, he will scamper over the broken masses of rock with incredible swiftness to his favorite 'hayfield,' where he gathers a large mouthful and hurries back to arrange a little haycock where his grass will dry protected from the winds. He works incessantly and, should a storm threaten, he will work all night, if necessary, to gather in his haycocks to one of the common storehouses under the rocks. In photographing him the camera was focussed on his favorite sunning place, partially hidden by leaves and weeds, while I sat fifty feet away and waited his appearance. I worked on and off for over a month before I got his picture."

This evidences an amount of patience and perseverance that was deserving of the reward that 
I30 Photograpby for the Sportsman Naturalist

he obtained, the only photographs of the pika in existence; and there is probably no one who now knows the habits of this little mammal better than does Mr. Carlin.

He also obtained, while on this same trip, a photograph of a weasel as he was about to leave his home among the rocks, and that weasel shows

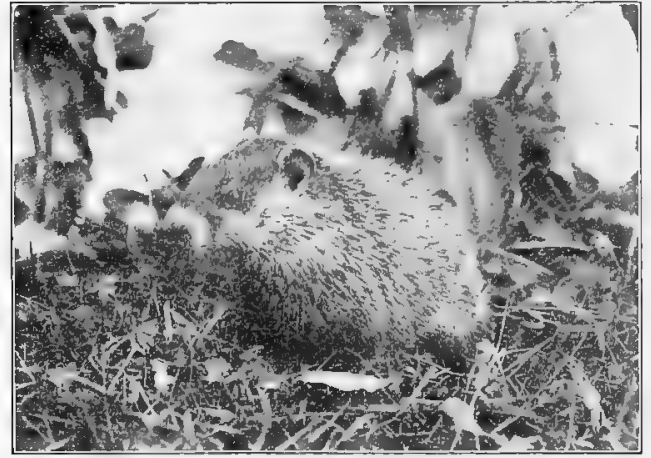

Half-grown Woodchuck. all too plainly in his picture that he was not caught asleep.

Many of the animals that live in holes in the ground, such as woodchucks, gophers, etc., can be successfully photographed by focussing upon the entrance to their burrows and waiting for them to come out. This sometimes necessitates a long wait, but makes most interesting pictures as showing both the animal and the place in which he lives.

The 'possum is, probably, the easiest of all the small mammals to photograph, as his slowness of movement makes it possible to catch him and he can be handled without danger of his attempting 


\section{Pbotographing the Smaller Mammals I3 I}

to bite. His first act, when he is approached, is not to try to escape, but to feign death or "play 'possum." During this stage of the proceedings he is most tantalizing, for no amount of poking will cause him to show any sign of life. He may be picked up, and to do so by his tail is the only natural way, and placed in the crotch or on the branch of a tree or in any other elevated position; but he will not attempt to hold himself there, rolling immediately off and falling to the ground with a resounding thud, apparently lifeless. No falls of this kind, no matter from what height, appear to injure him in the least, for he is the toughest of all our animals and will receive any amount of hard knocks or blows with seeming indifference. Pay no attention to him, however, and he will soon slowly open his eyes, and, if he thinks he is not observed, will begin cautiously to move away and try, by stealth, to get out of sight before he is detected. When he learns that his "playing 'possum" is not benefiting him he will wake up, and then one can have no better subject. By the aid of the reflex or even with the ordinary outfit one can then easily photograph him in any position he may desire.

The porcupine makes another easy subject, although he cannot be handled with impunity if one would not have his hand made into the appearance of a pincushion by his sharp, barbed 


\section{32 Pbotograpby for the Sportsman Naturalist}

quills. Moreover, if we try to influence his movements to any extent, by urging him either with our foot or a stick, the endeavor is invariably attended by a loss of many of his quills, and without these he presents a sorry appearance and is not worthy of being photographed. These quills form his only means of defence, for, although he will chatter vindictively with his teeth, he will seldom bite. The bridge of his nose is his one vulnerable spot, and when that is struck a sharp blow it will generally kill him. Knowing this, as he must, he will, when approached, invariably turn his head downward, and, with his nose well buried in the fur of his chest and every quill standing erect, he will lash about with his tail, and wherever this formidable weapon strikes it leaves a number of tiny javelins which are as sharp as needles and so barbed that they are not easily extracted.

In this manner he has been known to kill even such large animals as wildcats by driving his tail quills into their eyes and thus penetrating to their brain. From this fact most wild animals know enough to leave him alone and will always give him the road except when driven to extremities by hunger. He is stubborn, and when in the position of defence no amount of prodding will elicit anything but a continued lashing of the tail. The only thing to do is to wait patiently 


\section{Photograpbing the Smaller Mammals I33}

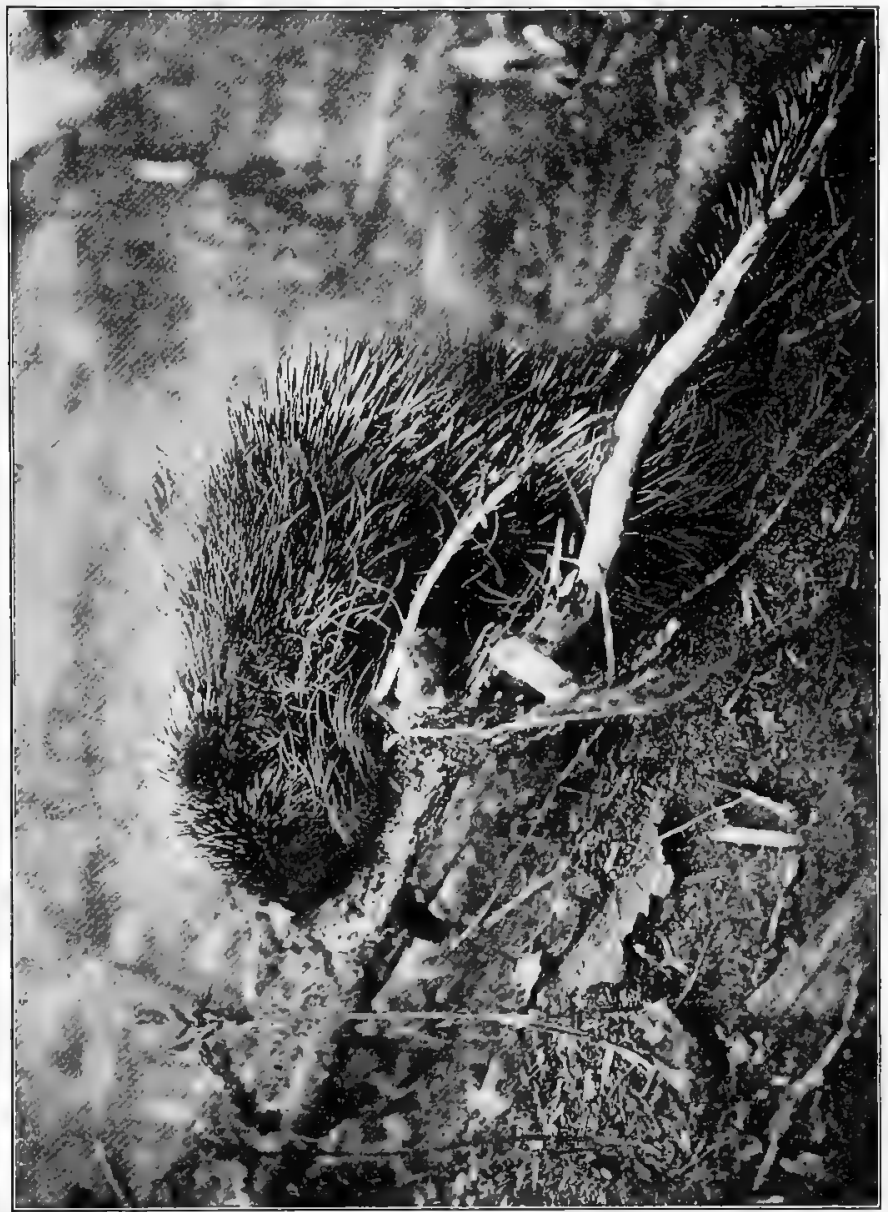

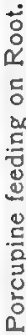




\section{I34 Photograpby for the Sportsman Naturalist}

until he decides to move and then follow him with the camera until he assumes such attitudes as may satisfy us from a photographic standpoint.

The raccoon is an interesting and usually wellbehaved subject, but is not so easy to capture. When handling him we must look out for his

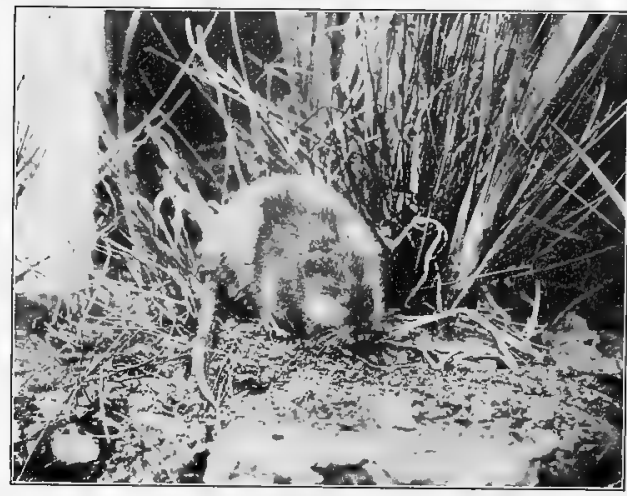

Muskrat. teeth, for he knows well how to use them and can inflict very painful wounds.

In any park or private grounds where there are gray squirrels they are usually more or less tame and easily approached. In Central Park, New York City, there are thousands, and they are so tame through never having been molested that they will not only fearlessly come close to a person, but will even go so far as to explore his pockets for nuts. These are excellent subjects for the beginner to try his hand on, for he can always get his squirrel to come to the spot he has focussed upon by placing a peanut there.

In all this work the ordinary long-focus outfit is 
the best to use. Of course the reflex will frequently be needed and the telephoto lens often be found indispensable, but the ordinary camera is the one that is most frequently called into service.

In this, as well as the other branches, the two indispensable requisites are perseverance and patience, as was proved by Mr. Carlin's experience which I have related. Of the latter luxury one needs, perhaps, more in this branch than in any other, unless he is photographing his animals in captivity, and he must be supplied with considerable more than the usual amount with which man is blessed, for it will sometimes be necessary for him to sit motionless for

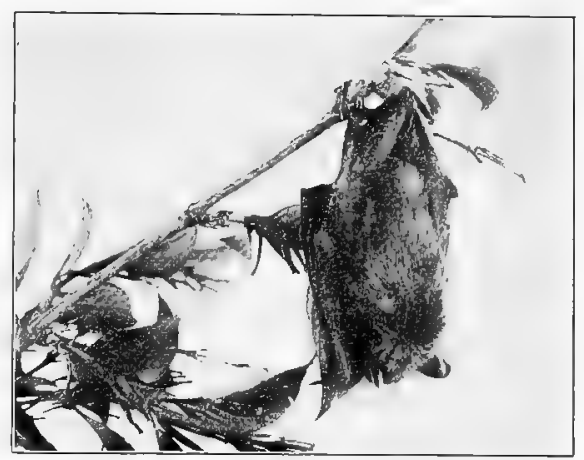

Little Brown Bat Asleep.

hours ere he will succeed in obtaining the picture for which he is striving.

Animals, especially the smaller ones, are naturally extremely timid and shy, and the mere presence of man will often cause them to remain in concealment for an interminable length of time.

From the fact of the extreme difficulty with 


\section{36 Pbotography for the Sportsman Naturalist}

which good photographs of any of these smaller animals, especially the rodents, are obtained in the open, I am more in favor of the use of a cage in this branch than in any other. If one is careful in the placing of the accessories, very natural surroundings can be arranged and the resulting picture be excellent, but always make these accessories conform with the nature of the habitat of the subject and, above all, never make the exposure when the animal shows the least sign of fear either in pose or expression. It is best, therefore, to keep him in the cage for two or three days, until he becomes thoroughly accustomed to his new home, before trying to photograph him. Often, with mice, if we put some grass and other like material in the cage, they will construct a nest, and this always adds a note of naturalness to the picture.

Shrews, moles, etc., are easier subjects than are the mice. The only trouble that I have experienced in photographing moles is the fact that in the photograph they always appear to be dead. This is because they have no eyes, and eyes are the things that do more than anything else to show life in a picture.

The white-footed mouse often makes its home in a deserted woodpecker's hole, and if we can find one of these nests and capture the inmate, we can remove the branch and take the home as well as 


\section{Pbotograpbing the Smaller Mammals I37}

its owner away with us to the cage and we shall need no other accessories.

Beaver are not difficult to photograph if we can find one of their villages, but they are rapidly diminishing in numbers and bid fair soon to become extinct.

The first and the final word of advice which I have to give is: know your subjects. Otherwise the difficulties will be increased tenfold and many opportunities will be entirely lost. 


\section{CHAPTER IX}

\section{PHOTOGRAPHING BIRDS' NESTS}

UnDOUBTEDLY the easiest branch of nature photography, and yet one in which there are many difficulties to be overcome, is the photographing of birds' nests. It offers more possibilities for really artistic results than does any other branch, with the exception of flower photography; and, if we study our subject well before making an exposure, to discover from what point of view the best lighting and general effect is obtainable, the resulting picture will often be a thing of beauty that may well call for the admiration of all who see it.

Therefore we should be in no hurry when photographing a bird's nest, for it will not run or fly away and we can take our time. Look at it and study it from every direction, through the camera, for one is better able to judge how a thing will look in the picture by seeing it upon the ground glass than by looking at it as it appears naturally. When we have decided from which direction it makes the best appearance, then is the 


\section{Photographing Birds' Nests}

time to make the exposure, but not before. In other words, give what artistic ability we may possess full sway in this field, for with most nature work art must take a back seat, while in this branch it can be successfully employed, by any one who is capable of doing so, to the ofttimes great improvement of the picture.

All this, of course, applies only to such nests as are built in low bushes or upon the ground. Those that are placed in trees, on the ledges of cliffs, and in like inaccessible places, can usually be photographed from but one direction if, indeed, we can get at them at all, and we may consider ourselves lucky to obtain the picture without troubling much about the artistic quality of it.

It must be remembered, primarily, that a picture of a bird's nest, to be of any value, scientifically or otherwise, must show as much as is possible of its surroundings and also the detail of its construction and the manner in which it is fastened to its support. In order to do this, so as to obtain the best and most natural results, the nest should always be photographed in situ, and this, as can readily be seen, often presents great difficulties, the overcoming of which affords one of the chief pleasures of the work to any one who is seriously interested in it.

The nests that are built on or near the ground present an easy mark, but those that are high up 


\section{I40 Photograpby for the Sportsman Naturalist}

among the branches of the trees and particularly, as frequently happens, when they are at the extremity of some branch, these are the ones that tax the ingenuity of the operator to the utmost limit.

Another particular in which we must exercise the greatest care is the arrangement of the sur-

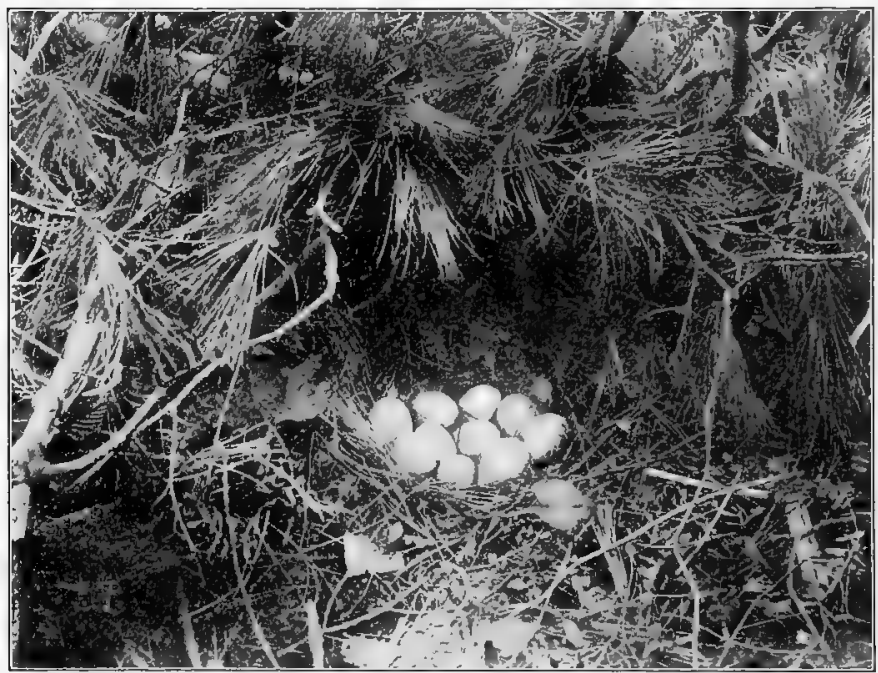

Nest and Eggs of Ruffed Grouse.

roundings. It will be often found necessary to remove some of the branches, leaves, or grass from in front of the nest, so as to obtain a clear, unobstructed view of it and its contents. In doing this we should be most particular not to remove too much, for if this is done it will give the effect of bareness in the photograph, besides leaving the 
nest unprotected when we are done with it and causing the bird to desert. It is best, therefore, when possible, to bend back the branches or other herbage instead of cutting them off, so that they may be returned to their former position when we are through. Where it is necessary to cut a twig the end should be hidden by a leaf, or in some other manner, so that it will not show in the picture. Touch the nest and eggs as seldom as possible, for the natural set and arrangement of it is one of the important features and this is easily disturbed; besides, a bird will frequently refuse to return to a nest that has been handled. We should always try to avoid doing anything that will drive the birds from their nests. Remember that they have a greater right to them than have we, and then, too, we may wish to use them again later when the eggs have hatched and the old birds are feeding their young.

The nest photographer's outfit consists of a four by five long-focus camera; any ordinary lens (those of the longer focal lengths are best); the long and the short legged tripods; the balland-socket clamp; the large mirror and a pair of climbing irons. A pair of pruning shears will be found a useful adjunct also, for with them twigs can be clipped with less jar to the nest than with a knife.

This may seem to be a formidable outfit, but one 


\section{Pbotograpby for the Sportsman Naturalist}

can hardly work satisfactorily with less, and sometimes even other accessories will be found necessary, such as a screening cloth, a small keyhole saw, etc.

Now let us make our first photograph of a nest, and it will be best for our first endeavor to be upon some low-built nest. The sandpiper's nest

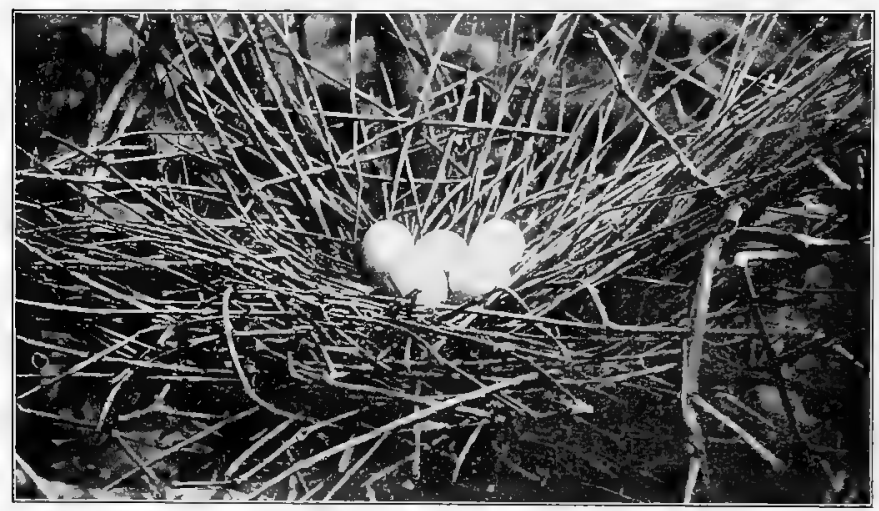

Nest and Eggs of Green Heron.

Photographed twenty-five feet from ground.

(a photograph of which is shown on page 143 ) is a good type of the ground nest and is an easy one to begin our work upon.

One of the things we must always avoid, if possible, is having the camera pointed directly downward at a nest. It not only shows the nest in an entirely false position, but also gives little idea of its form or construction.

Having found our nest and selected the point 
of view from which it can be photographed to the best advantage, we first press back or cut away all the intervening foliage that obstructs the view of it. Then the camera is set up on the short tripod at a distance of about three feet from and

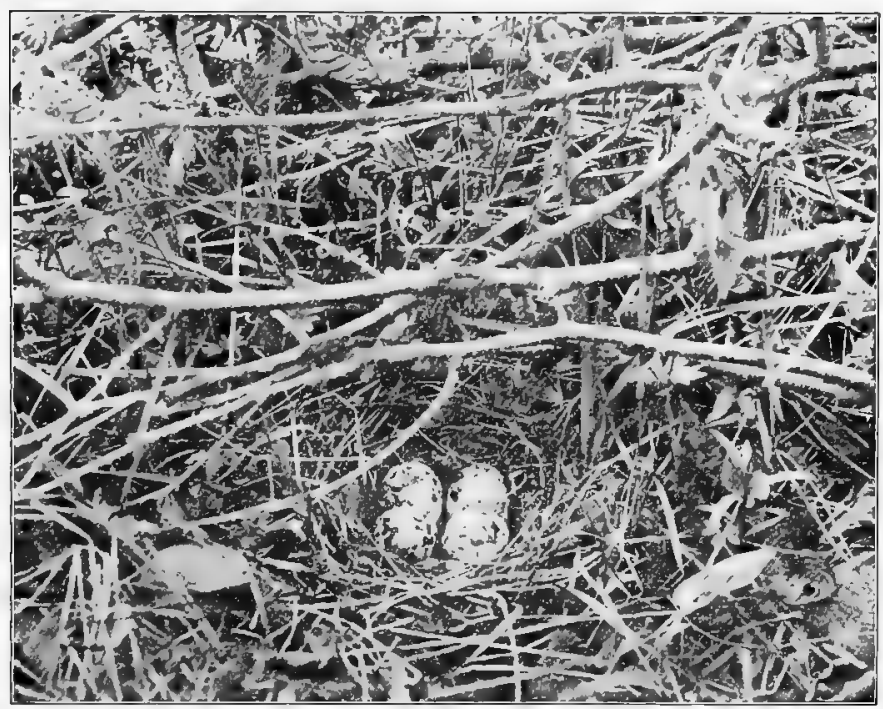

Nest and Eggs of Spotted Sandpiper.

pointing slightly downward at the nest. This will allow a view of a part of its inner as well as most of its outer construction, and the picture will carry to the mind of the person who sees it a correct idea of the manner in which it is built, which would not be the case if the camera was pointed directly downward at it. It is not necessary to show all 
I44 Pbotograpby for the Sportsman Naturalist

the eggs, although some people seem to think so, but if two or three of them show above the rim of the nest it is sufficient. When the nest is so deep that the eggs are entirely hidden, a small tuft of cotton may be carefully inserted beneath them. This will raise them into view and will not, as may seem probable, give a false idea of their position in the nest. Care must be taken, however, that none of the cotton shows.

When the camera is set up at the required distance, and all the intervening foliage fixed to our satisfaction, we must focus upon the rim of the nest nearest to the camera, regardless of all the surroundings. Then by the use of the swingback it will be found that much of the foreground and background will be sharpened up, but it will still be necessary to stop down the lens, sometimes to its fullest extent, before all the surroundings are brought into as sharp focus as is desirable. This, naturally, means a long exposure, which is a drawback when the wind is blowing, so that it is best, when we can, to work on a calm day.

Try not to underexpose, as the results have a distinctly disagreeable hardness, showing the eggs as blotches of white against a black background. Much better to err on the side of over exposure, as this fault can be corrected in development.

Never make an exposure in the direct sunlight, 
for that also gives too contrasty a negative with no delicate half-tones and poor detail. If the nest is not already in the shade, where no patches of sunlight fall upon it, then it must be shaded by holding the focussing cloth, a coat, or some other screen between it and the sun. Be careful, though, that the screen does not show in the picture.

As can be seen from the foregoing, the ideal day for nest photography is one that is calm and with the sky slightly overcast; but this we cannot always have, nor would we entirely desire it, so we must meet the emergencies as we find them. I have done some excellent work in the pouring rain, but this is hard on the camera unless it is thoroughly protected, and the raindrops collected on the foliage will show, and, even though shaken off just before the exposure, are bound to collect again before it is over.

If the nest itself should be in a dark place while its immediate surroundings are comparatively well lighted, as will sometimes be found to be the case, we can overcome the difficulty by the use of the mirror. For instance, should we conclude that about a minute would be the correct exposure for the surroundings with the lens stopped well down, then, with the mirror, throw a shaft of light upon the nest for say from six to ten seconds about the middle of the exposure, but be careful 


\section{I46 Photograpby for the Sportsman Naturalist}

to keep the mirror moving so that no part of the nest will be, better illuminated than another.

So much for the ground builders. The nests placed from one to five feet from the ground are the most satisfactory to work upon. They are easy to get at, generally require but little pre-

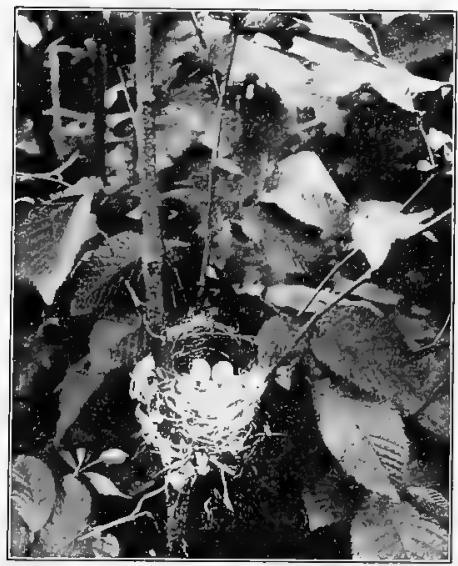

Nest and Eggs of Chestnut-sided Warbler in Low Bush.

liminary preparation or arrangement, and they offer, from the nature of their surroundings, far better possibilities for fine results than do the ones that are placed either high up in the trees or on the ground.

The tripod should be made sufficiently long to elcvate the camera from six inches to a foot above the level of the nest and so tilted as to point the lens diagonally downward at it. Should the nest be placed so high up in a bush, too small to bear a person's weight, as to make it impossible to reach it by the aid of the ordinary tripod, sticks must be cut and bound tightly to the legs of the tripod, thus lengthening them to the desired extent. Upon several occasions I have made my tri- 


\section{Pbotographing Birds' Nests}

pod legs at least ten feet long in this manner and have done my focussing while standing upon the shoulders of an assistant. This may seem hard on the assistant, but it is better than carrying a stepladder to the site of the nest, although. I should advise the use of an assistant with a good pair of shoulders, especially should you be of some weight yourself; otherwise you may take a hasty tumble to earth in the midst of the focussing and will be more or less likely to bring the camera down with you in your fall, which would benefit neither you nor your camera.

All the advice given for the lighting and arrangement of the ground nests should be followed here, although when working in the manner I have just described it will be found impossible to shade the nest; but in such cases, when the nest is not in the shade of some other tree or bush, wait, if you can, until some passing cloud obscures the sun long enough for you to make the desired exposure.

Mr. Dugmore advocates the use, in some instances, of a white screen placed beneath the nest, so as to reflect light on the under side of it. This, he says, "may easily be done by taking a yard or two of white muslin and fastening a stick at each end. The sticks should be pointed at one end so that they may be put into the ground, and the cloth, tightly stretched, will be held at such an angle that the light will reflect from it upon 


\section{I48 Photography for the Sportsman Naturalist}

the nest." This may be advantageous at times. I have never used it, as I have never found it necessary; moreover I am inclined to believe that it would give false lighting, as the under part of a nest is naturally more shaded than the upper and should so appear in a picture.

It will be found difficult and often impossible to give as long an exposure with these bush nests as with those built on the ground and, consequently, the lens cannot, generally, be stopped down so far. Therefore greater care must be exercised in the focussing and the use of the swing-back to get all the surroundings in as sharp focus as possible. The slightest breath of air will often sway the supports of the nest sufficiently to spoil all the sharpness of outline, and when there is much of a wind blowing they are seldom entirely still for more than two or three consecutive seconds. It is very annoying, to say the least, to see the nest move just in the middle of an exposure and to realize that the picture is spoiled and we must try it over again. This can sometimes be obviated by means of guy ropes of stout twine fastened in several directions to stationary objects.

In cases of nests swung at the ends of branches, such as vireos', orioles', etc., if they are not more than ten or twelve feet above the ground, the branch can usually be bent down and fastened in the desired position with twine; but in doing this 
be sure to prop up the end of the branch so that the nest will be in its original horizontal position. Above all things never remove the nest from its site, except when absolutely necessary, either by taking it from the crotch or other situation in which it was placed by the birds and placing it in another more convenient, or by removing it and its support bodily to where it can be more easily photographed. To do this is, I know, a great temptation to all photographers, but the results are never as satisfactory. The value of a

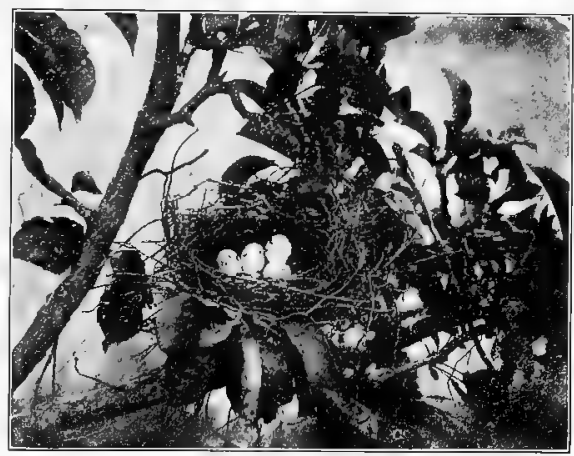

Nest and Eggs of Kingbird.

Photographed in topmost branches of apple tree.

nest picture, from a scientific point of view, lies largely in the fact that it is an exact representation of the nest in precisely the position that the bird built it with all its natural surroundings intact; and, no matter how careful we may be to arrange it after its removal, it is not the same, and the man who knows the nests and the manner of their construction can almost always detect the difference. Morecover it despoils the birds of their home, for 
very few birds will return to a nest that has once been removed from the spot in which they built it, although it may be replaced, with the greatest care, in the original site.

In arranging the eggs, too, when such arrangement is necessary, care should be taken to put them in the same position as they were left by the bird. The position in which an egg lies often counts for much, as, for instance, in pointed eggs the small ends are always together, never pointing outward.

It is permissible, and sometimes even desirable, to introduce some accessories to the picture by placing objects near the nests that were not originally there. These objects should never be incongruous, however, with the other surroundings, and should only be placed there to illustrate some point. Thus, I have often placed some flower near a nest to show that that flower was in bloom at the time the nest was built, but it must always be some flower that is found blooming in the immediate proximity of the nesting site. This also serves to give an idea of the locality in which a nest is found, as the wild raspberry bloom near the nest of a hooded warbler or indigo bunting, for both of these birds are partial to this plant as a nesting site; or the false hellebore, placed near the nest of a Wilson's thrush, as both flower and nest are found in low, swampy places. An old 


\section{Pbotograpbing Birds' Nests.}

chestnut bur near an ovenbird's nest will show that it is built in the woods, and a clover head by the side of a bobolink's home will tell any one that the lush clover fields are the places in which this bird delights to breed. Thus the judicious introduction of new objects in the immediate surroundings of the nest is, as I have said, entirely permissible, and they not only serve the purposes I have stated, but also greatly enhance the beauty of the picture.

As for the size that the image of the nest should be, that is a matter for the judgment of the operator. I, myself, do not favor the nest occupying too much of the plate, for I think that the more of the surroundings that are shown the better, so long as the nest shows large enough to bring out clearly the details of its construction and the markings on the eggs. To show distinctly the shape and markings of the eggs is important, for they must be capable of showing for themselves that they belong in the nest and are not merely any eggs photographed in any nest.

When it comes to photographing the nests of the tree builders, especially those that build in the very tallest trees, the hawks, crows, eagles, etc., the problem immediately becomes much more difficult and, in many instances, unsolvable. Many times it is necessary, however, to work in the tree-tops, and much good work has already 
I52 Photography for the Sportsman Naturalist

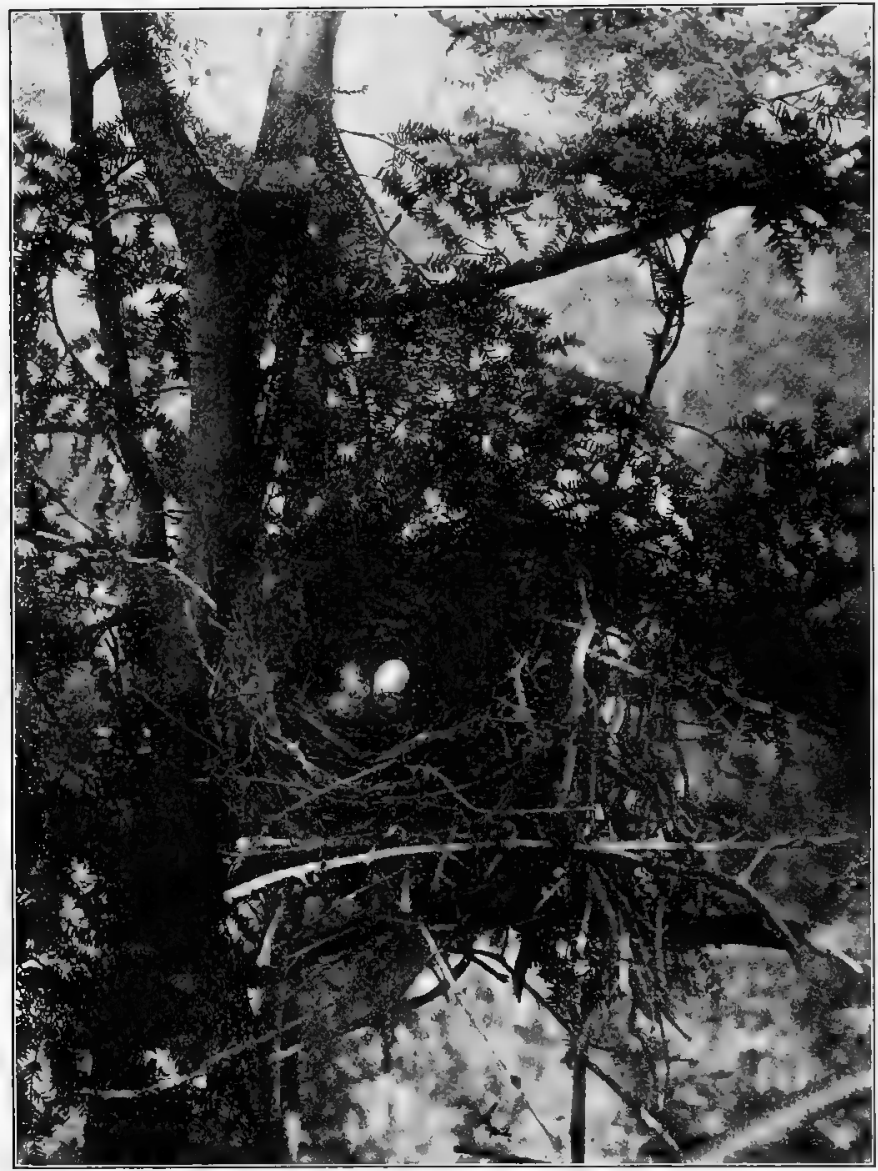

Nest and Eggs of American Crow.

Photographed fifty feet above ground. 


\section{Pbotographing Birds' Nests}

been done there; but I would not advise any but those who are perfectly level-headed and surefooted, in other words good climbers, to try it, for the situations are often dangerous, necessitating, as they do, the use of both hands for the manipulation of the camera, and thus leaving to the legs and feet alone the duty of holding one in the tree.

Two methods can be used for securing the camera in the tree. The tripod can be lashed securely to several of the limbs or branches, or the camera can be fastened directly to one of them by means of the ball-and-socket clamp. The latter method is by far the easiest and most satisfactory, although upon some occasions it will be found necessary to employ the former.

The same general directions hold good here concerning the surroundings of the nest, except that a greater number of leaves in the foreground will have to be removed in most cases. This is owing to the fact that the slightest breeze will often sway not only the branch upon which the nest is built, but also the one upon which the camera is fastened, and this is ruination to all sharpness of outline in the picture. Guy ropes are here of no avail, and so a short exposure is almost always absolutely necessary.

This necessitates a larger stop and, consequently, less depth of field. Leaves in the background must, obviously, be out of focus, but it is 


\section{I54 Pbotograpby for the Sportsman Naturalist}

important that there should be nothing between the nest and the lens that is not sharply defined. In fact, the less of anything there is in front of the nest the better will be the picture.

Nests at the extreme ends of or in the very topmost branches, or in trees that cannot be climbed, may often be successfully photographed from some adjacent tree by means of the telephoto lens. In these instances the camera should be placed as near the trunk of the tree as practicable, so as to obviate as much as is possible any vibration.

It is never well, when climbing to a nest, to attempt to carry your camera with you. Leave it on the ground attached to the end of a ball of twine which you can carry in your pocket and pay out as you climb. When you have reached the desired spot in the tree, the apparatus can be easily hauled up to you. If you attempt to carry it up, you not only run the risk of dropping it, but of its causing you to fall, yourself, by getting in your way.

As a last resort, when all other attempts at photographing the nest fail and if it is one that you particularly desire, which cannot easily be found again, then you must remove it; but only do this when it is impossible to obtain the photograph by any other means. When it is found to be absolutely necessary, then remove the branch and all, just as it is, cutting it off carefully so as 
to disturb the nest as little as is possible. Carry it to some spot where its original surroundings can be reproduced with, at least, an approach to faithfulness and try to make yourself think that the negative you have thus obtained is a sufficient recompense for robbing the birds of their home; for, no matter how you may tie the branch back in its original place or return the nest to its natural site, or near it, they will never, except in very rare instances, return to it.

The nests of woodpeckers, wrens, and all the other birds that breed in excavations in the limbs or trunks of trees must be treated in a much different manner from those of

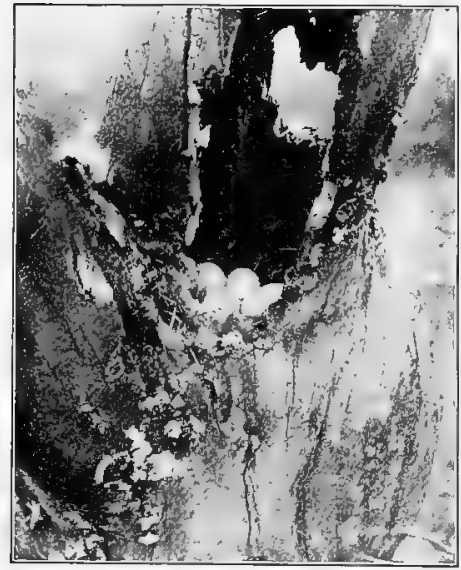

Bluebird's Nest and Eggs. any other bird. Here, in many instances, it will be found necessary to remove the $\operatorname{limb}$, as no amount of ingenuity will devise a scheme for photographing them in situ when, as frequently is the case, they are on the under side of a limb that is forty or fifty feet from the ground and projecting from a dead tree at an angle of fortyfive degrees, with no other limb below it. More- 
I56 Pbotograpby for the Sportsman Naturalist

over, to remove the limb, in these cases, does not in any way impair the naturalness of the nest's surroundings, as the only surroundings it has are the limb in which it is built. The birds will desert, of course, but they would anyway, as the hole must be cut open to show the contents and there are only one or two species of birds that will return to their nests after this has been done. It is unfortunate for the birds, but there is no other method of obtaining pictures of their nests.

In cutting open the nests to show the inner construction and the eggs, the wall of bark and rotten wood may either be cut away from the entrance hole to the eggs or else, after ascertaining by the aid of a small twig the exact depth of the hole, a small, square piece may be cut out, making an entrance at the bottom of the hole and leaving the rest of the wall intact. This can best be done with a small keyhole saw. By this latter method one can show both the entrance hole and the eggs and nest complete, and it is by far the better method of the two. It is well, however, to remove the eggs first by tipping up the limb and allowing them to roll down to the entrance hole; otherwise they will be very liable to be broken by the saw.

I began by explaining the ways of working on the nests of those birds that build on the ground. Now I will go back to those that make their 
homes underneath the ground, - the kingfishers, bank swallows, burrowing owls, etc. Here, of course, to show the nest and eggrs, the hole must be excavated, but first a photograph of the entrance hole should be made.

The excavating must be done with great care, that the loosened earth and stones may not choke

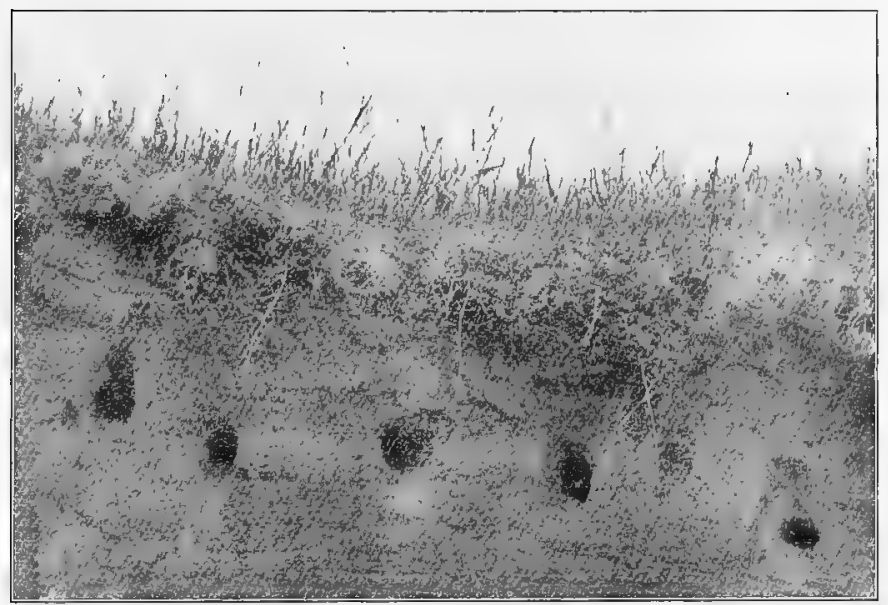

Entrance Holes to Bank Swallows' Nests.

the hole or roll down and break the eggs. The excavation must not be carried beyond that point which will show the nest and eggs to the best advantage.

In photographing the nests of any of the "cavedwellers" that make their abodes either in holes in trees or in the ground, the mirror will come 
I $5^{8}$ Pbotograpby for the Sportsman Naturalist

into play to reflect light into the hole and give perfect illumination to the contents. Care must be observed not to make the illumination too intense, or otherwise the effect of a cavity will be lost.

To those who are ambitious enough to wish to use their cameras on the cliff breeders I am very

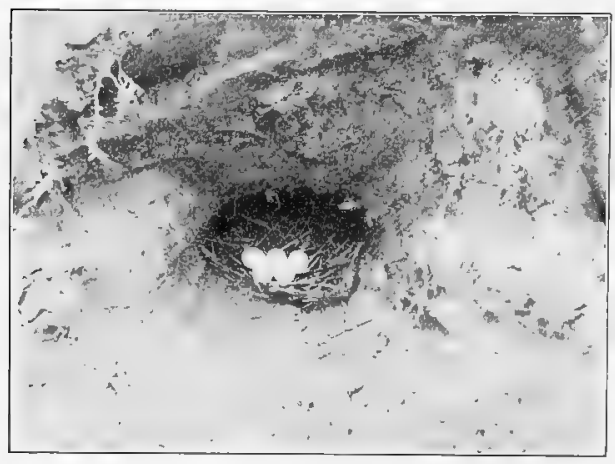

Nest of Bank Swallow.

Bank cut away to show eggs. much afraid I can give no directions, as I will freely confess to never having done any of it; and my desire to dangle at the end of a rope over a hundred feet or more of empty space is, I fear, not great enough ever to lead me to attempt it. The Kearton brothers of England have, however, done much of it and, through their utter fearlessness, have accomplished some wonderful results. Their methods are all fully described in their admirable book, "Wild Life at Home," and should any one desire to emulate them, I should advise him to obtain this book. 
I sincerely trust that every one who enters this field of work will do so with a thorough regard for, and an appreciation of, the rights of the birds. Let the collecting of the photographs take the place of the collecting of the eggs which is done so indiscriminately nowadays, and in collecting these photographs let everybody give the owners of the nests as little cause for complaint as he can. The more nests you find, photograph, and leave intact, the more broods of young you will have to work upon a little later and, consequently, the greater number of photographs you will be enabled to obtain. So your care to disturb the nest as little as possible will work not only for the bird's good, but to your own advantage. 


\section{CHAPTER $\mathrm{X}$}

PHOTOGRAPHING BIRDS AND THEIR YOUNG

THIs is, to me, the most interesting branch of nature work, and yet it is the one that is attended with, perhaps, the greatest amount of diffculty. Yet these very difficulties that must be overcome should, to an able-bodied man, add to the interest and enhance the value of the photographs, for it is human nature to care more for those things which are obtained through hard work and persistent effort than for the ones that come to us easily.

Possibly it is because I have taken a great interest in the feathered inhabitants of the woods and fields, since I was old enough to follow and study them, that I find the photographing of them so intensely enjoyable. Certain it is that it was my love of the birds and the wish to become more intimately acquainted with them and their home life that caused me to take up the camera; and, although I have often been discouraged at the results, still I have never been sorry that I turned my attention and energy to the photographing of the wild things. 
Pbotograpbing Birds and their Young $\mathrm{I61}$

To one who has any love of nature and her children one of the greatest pleasures to be derived from the use of a camera is this very insight

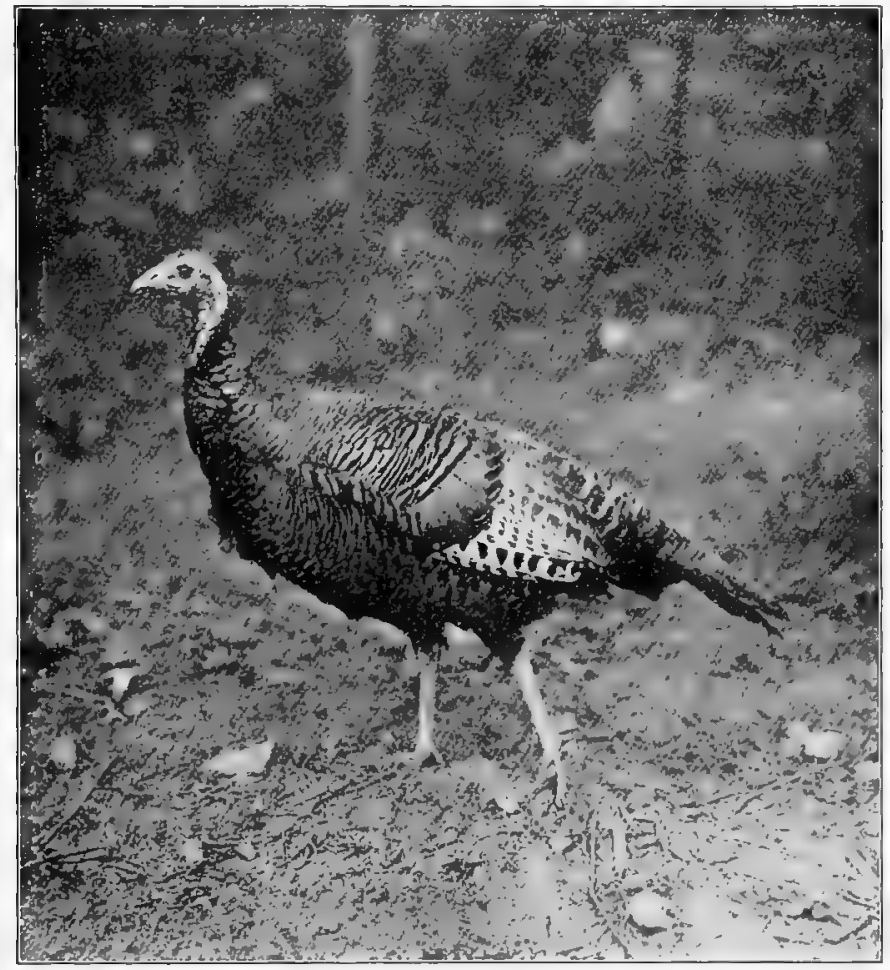

Wild Turkey Hen.

and intimate knowledge that it enables us to obtain of the home life of the wild creatures. Through this new sport as by no other means can we become thoroughly acquainted with the 
I62 Pbotograpby for the Sportsman Naturalist

inhabitants of our woods and fields and really know them at their best; and, in thus learning to know them, our affection for them and love of nature in general is bound to increase.

As a recorder of facts concerning the home life of the birds there is nothing that can equal the camera, for it rarely lies; whereas the brush or pencil almost invariably does in some detail and often in larger and more important points. Then, too, photographs of any of the birds are invaluable from a scientific standpoint. They show accurately and beyond dispute points which, heretofore, the artist has been forced to guess at, - such as the manner in which they feed their young; the various attitudes which they assume when perching; and even, with some birds, the manner of their flight.

In photographing birds the breeding season is by far the best time, for, at this season of the year, the birds are in their best and fullest plumage and many of them have donned, for this especial season, extra finery that they do not wear at any other time of the year, - as, for instance, many of the herons; and, therefore, pictures can be obtained of them at this time that cannot be duplicated, at least for another twelve months. Moreover each pair of birds are restricted to a comparatively limited range surrounding their nest, and one is always certain of 
Pbotograpbing Birds and their Young i63

finding one or both of them at home when he calls. The pictures obtained at this time are of the utmost value and interest, and should, where possible, be taken in series, from the building of the nest up to the time when the young leave it to shift for themselves; showing the nest and eggs, the old birds incubating, the young when first hatched, the manner in which they are fed, the old birds brooding them, and, finally, as they appear after having left the nest and just prior to flight. If

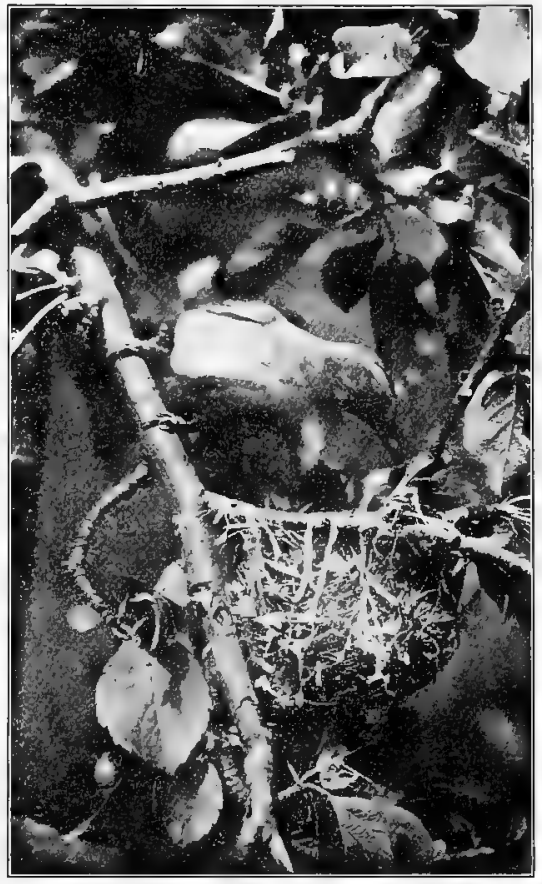

Red-eyed Vireo at Nest feeding Young. we make intimate friends of such a family, we will find them by far more interesting than any mere human being could possibly be, and, by closely studying their ways, we can learn from them many a lesson. At this time of the year, too, birds are more 
${ }^{6} 64$ Photograpby for the Sportsman Naturalist

tractable than at any other season. This is probably due to the fact that the fear for their own safety is overshadowed by their desire to protect their home and young to the best of their ability. Certain it is that we can do with them at this period what would be entirely out of the question at any other time.

The fear of mankind is inherent in all birds, and, in fact, all wild animals, but by careful management and gentle treatment this fear can, temporarily and often to a large extent, be allayed; although, owing to the fact that it has been inborn through so many generations, we can never hope to entirely eradicate it. In the breeding time, however, as at no other, can we come the nearest to doing this, even, in some cases, to such a degree as might, to the inexperienced, seen almost incredible. This is entircly dependent upon the individuality of the bird, for birds, as well as human beings, have individuality and many individuals of the same species vary remarkably in their temperament.

Many times I have found it impossible to convince a pair of these feathered friends of ours that I meant neither them nor their home any harm, although I have striven, not only for hours, but actually for days, to prove this to them. On the other hand I have so far won the confidence of another pair, possibly of the same species, that 


\section{Pbotographing Birds and their Young ${ }_{165}$}

they have not only come to their nest and young while I was in close proximity, but have actually perched upon my hand in order to feed their offspring. This I have done repeatedly and with different species, some of which have the reputation of being among the shyest of all the members of our avifauna.

There is no describing the delightful sensation which comes

over one when one of these diminutive creatures places such confidence in our friendship as to actually alight upon the hand that

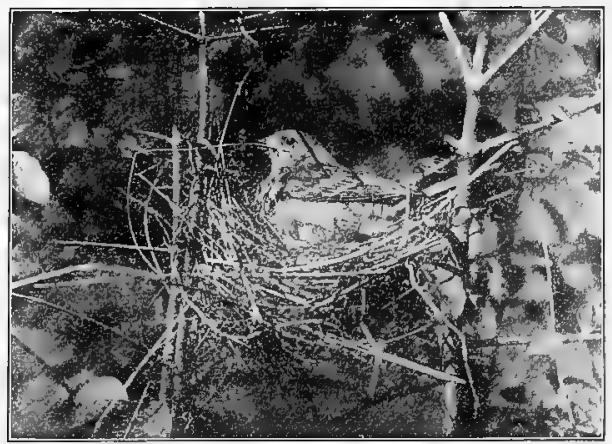

Field Sparrow on Nest.

could crush it into a shapeless mass in an instant. I do not think there is a person living so low and mean that he could violate such a trust.

I have found birds, at times, so fearless that they were almost a nuisance. I remember once that I wished to obtain a photograph of a nest full of young field sparrows. While I was focussing, the mother bird flew up and quietly settled upon the nest, seemingly without so much as 
i66 Photograpby for the Sportsman Naturalist

noticing me or the camera. Of course I did not let such an opportunity pass to obtain pictures of the old bird, but I also wanted some of the young. Do what I would, however, she would not remain off the nest long enough for me to focus properly and make an exposure, until I finally was forced to take her in my hand and hold her while I was doing this. Even then she returned to her young the instant that I released her. At another time I found it necessary to forcibly remove a female bluebird from her nest before I could obtain the picture which I wanted of the eggs that it contained.

It is not always the case that the female is the most fearless, although I am bound to admit that this is more often so. I have had instances, however, as in the case of a male chestnut-sided warbler, which I once photographed at its nest, where he went repeatedly, and within a short time of the setting up of the camera, with food for the young, while the female refused to approach within several feet of it. She would bring food and hop among the bushes, in close proximity to the nest, uttering distressed cries, but, while the male did his duty, she could not overcome her fear of the camera sufficiently to allow her to come within three or four feet of it and her young ones.

Some species of birds I have found invariably 
Photograpbing Birds and their Young 167

unaffected by all my blandishments and I have never been able to obtain any pictures of them. Among these are the yellow-breasted chat and the blackbird, both of which I have tried to photograph time and again, and have spent long, discouraging hours in the vain hope of obtaining the pictures which I desired of them. Once a chat came to her nest of young upon which my camera was focussed, but only to touch it and immediately leave; and, although I pressed the bulb, I was not quick enough, and the resulting picture showed no sign of the old bird.

However, these are the disappointments to which we will find that we must continually submit, and we must have the patience to bear them without becoming discouraged. Often have I spent an entire day in the endeavor to photograph some particularly intractable bird, with absolutely no success, and have been forced to return home in the evening with no results to show, but determined to photograph that same bird at some future time if such a thing were possible. Of course young birds, before they are able to fly, are much more easily photographed than are the old ones, for they cannot escape the evil eye of the lens by flight. So these are the ones upon which the would-be bird photographer should first experiment. He will find that he has his work cut out for him, however, for, although 


\section{I68 Photography for the Sportsman Naturalist}

they cannot easily escape him, they compensate for this, to the best of their ability, and show their disapproval of the proceedings of the photographer, by being as unresponsive and tantalizing as it is possible for any animate thing to be. Often the patience of a Job is required to pose them, and I have sometimes spent hours in work-

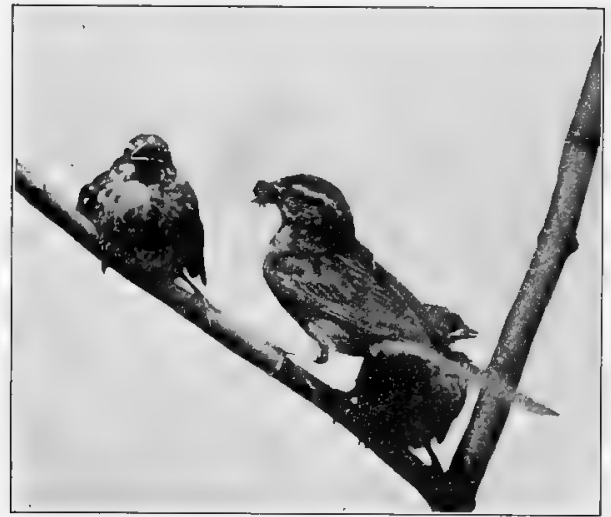

Chipping Sparrow feeding Young. ing over the young alone before an exposure was made. At such times I have arrived at the conclusion that their chief end and aim in life was to defeat my object.

That which they most delight in doing is to fall off the twig or branch upon which one is trying to pose them as fast as he can place them there. This seems to be through no inability to stand there, for if they do not actually fall off, and in doing so drag a companion or two with them, they will deliberately hop off, and their favorite place to perch is the camera itself if they have the strength necessary to flutter to it. Any 
Pbotographing Birds and their Young 169

place seems to offer greater attractions to them than that identical twig upon which you wish to place them. They will jump from it repeatedly, as fast as you can place them there, and then look at you in a self-satisfied manner, as much as to say, "I won't stay there and what are you going to do about it?" And the only thing to be done is to keep your patience as well as you may until you obtain their final consent to stay where you put them, which will only be after they have grown tired of objecting. Even then the excitement occasioned by the ap-

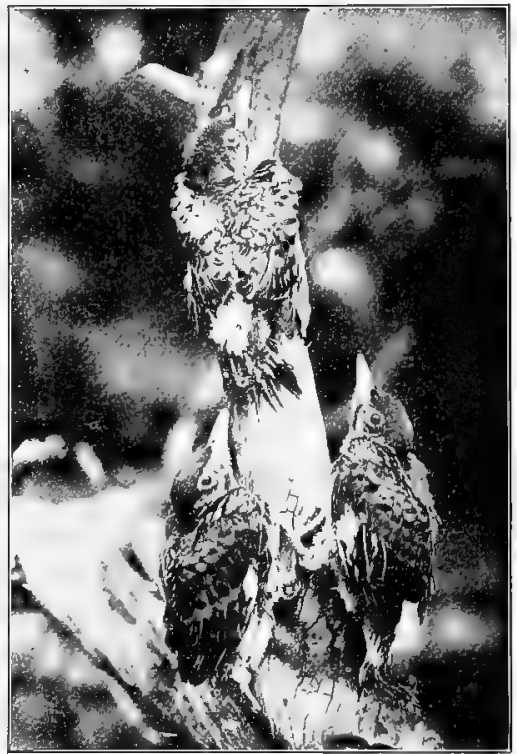

Young Flickers. proach of the parent bird with food is usually enough to cause one or two to fall to earth.

A young bird, however, is interesting from the time he leaves the shell, and is a featherless mite all neck and head, until he is fully fledged and ready to launch himself forth upon the world. 
I70 Photograpby for the Sportsman Naturalist

When the young are still in the nest they are easily photographed, and a series showing the different stages of their growth is very interesting. In doing this it is sometimes necessary to admit the sunlight to the nest, but the foliage should be pressed and tied back in such a manner that it. can be readily returned to its former position,

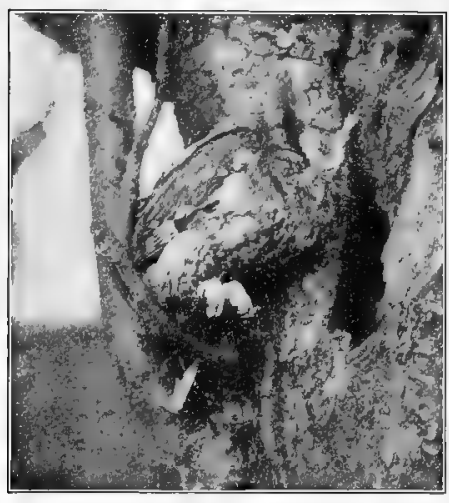

Screech Owl Asleep by Nest Hole. and the direct rays of the sun allowed to remain on the nest as short a time as possible; for, with very young birds especially, a short exposure to the sun is sufficient to kill them.

Now is the time, too, to obtain pictures of the old bird feeding and brooding her young and attending to the other duties at the nest. It is best not to attempt to do this until the young are at least half grown and have strength to enable them to bear a considerable exposure to the sun's rays, for it is necessary to have as strong a light upon them as possible, as on account of the extreme shortness of the exposure that we must give it is impossible to obtain a picture in the shade. 


\section{Pbotograpbing Birds and their Young I I I}

In this work, when possible, I like to get the birds so accustomed to my presence, by constant association with them, that they will attend to their duties while I am close to the nest, for, when near by, one can study them to better advantage and can also tell when they are in a position best suited to a picture.

Of course this is often out of the question, although the Kearton brothers of England have devised a blind in the shape of an artificial tree trunk, which is large enough to conceal both the camera and the operator. This is made of a framework of bamboo, or other light material, upon which is stretched cloth painted to resemble a tree trunk and covered over with lichens, pieces of moss, bark, etc, to make it look more natural. This can be set up near the nest, with the camera in position inside, and the operator take up his stand in it also. A hole is made in the side toward the nest through which to thrust the lens, and another one to allow the operator to watch his bird. Pictures of many of the more timid birds, that it would be impossible to obtain otherwise, may be made by means of this contrivance.

I should not advise its use, however, except when absolutely necessary, for it is exceedingly cumbersome to carry and its most disagreeable feature is the fact that it forms a miniature Turk- 


\section{Pbotograpby for the Sportsman Naturalist}

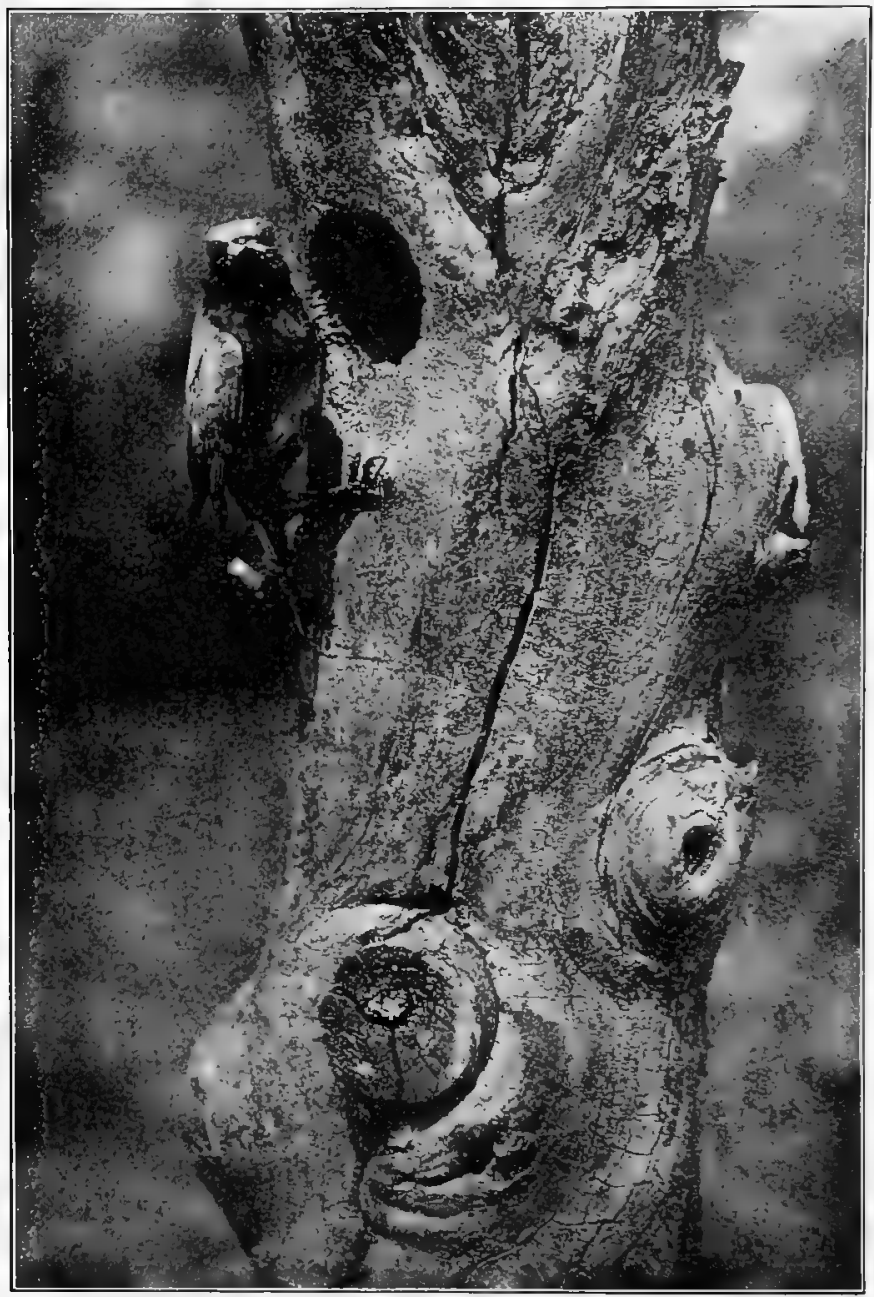

Bluebird at Nest Hole. 
ish bath for the person concealed inside, and this becomes distinctly uninteresting in cases where a wait of an hour or two is necessary.

I find that, with many of the birds, the camera needs no hiding so long as the operator is at a distance, and so I simply use the long rubber tubing and large bulb that will allow me to work the shutter from a distance of seventy-five to one hundred feet. With some birds, however, it is necessary to somewhat conceal the camera, and this can be easily accomplished by the use of leafy boughs, or a long piece of green cloth that will completely drape the camera and tripod, or, better still, by a conjunction of the two.

My course of procedure, after having found a nest of half-grown fledglings, is to set up and focus my camera upon the nest, leaving enough space on either side of the nest in the image to admit of the old bird. Then cut away or tie back (preferably the latter) all the intervening foliage that interferes, in the least, with an unobstructed view; insert the plate-holder, attach the long tubing, set the shutter, and cover the whole with the green cloth (leaving the lens protruding), which serves not only to conceal the camera, but as a further protection to the plate from the sun's rays. This protection is important, as the plate, during the long wait that is often necessary, would be liable to fog if left with no other pro- 


\section{I74 Photograpby for the Sportsman Naturalist}

tection than that which the camera itself affords. The outside of this cloth can, as I have said, be made to conform more closely with its surroundings by pinning or tying to it twigs, leaves, and small branches. Care should be taken that nothing interferes with the free working of the shutter. After these arrangements are completed

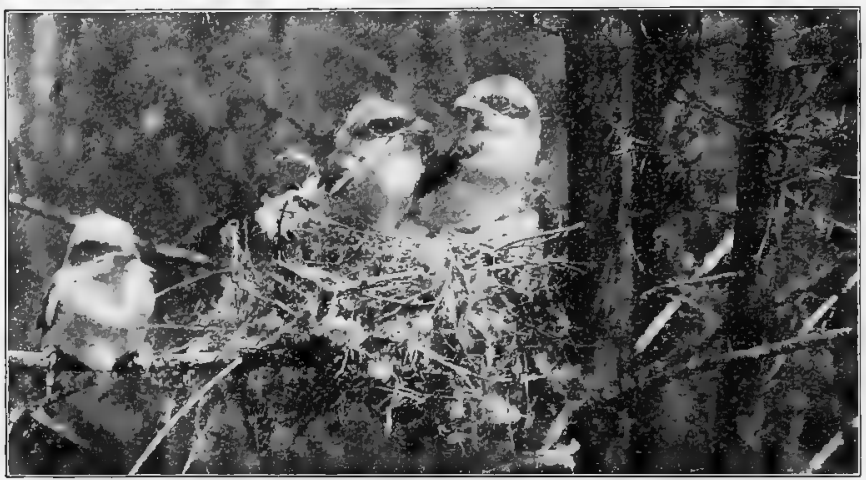

Young Shrikes at Nest.

Photographed at a height of twenty feet.

nothing remains to be done but to retire to the end of the tubing and wait in the shade, yourself concealed as much as possible, until the old birds see fit to return to their nest and young. This may be in a very short time, or it may not be for several hours; but there are few birds whose parental love will not overcome their natural fear and take them to their young before those young have had the chance to die from neglect, which 


\section{Photographing Birds and their Young $\mathrm{I} 75$}

would happen if the old birds should stay away too long.

I do not believe in, nor can I advocate, the changing of the nesting site under any but the most extraordinary conditions, for it not only shows the nest and contents among false surroundings, but it greatly endangers the life of the young. To cut off the limb of a tree containing a nest and remove it to some more convenient place is, I know, often an easier matter than to photograph it in situ, especially when that nest happens to be some distance from the ground; and so this is the method employed by many bird photographers to save themselves time and trouble.

In fact, one man openly advocates doing this in a book which he has written and in which he terms it "control of the nesting site." When a nest is so situated that it is difficult to photograph it in its original position, he removes it, branch and all, to a suitable spot and sets it up again outside of a tent placed there for the purpose of concealing himself and camera. "This sudden displacement of the nesting bough," the author remarks, "is of no special importance to either young or old, provided certain precautions are taken;" and he goes on to say that "with some species it is possible to make the necessary change without evil consequences when there are 


\section{I76 Pbotograpby for the Sportsman Naturalist}

eggs in the nest." With all due respect to the author, I must differ with him, for an experience of some twenty-five years with the birds has taught me that but one or two species will return to their nests containing eggs when those nests have been removed from their original site, and many will desert if they have been in the slightest way disturbed. Moreover, even after the young are in the nest, it is not always that the old birds will return to them after they have been removed to a distance, and it must be some one well acquainted with the habits of the bird who can successfully avail himself of this method; and, even then, it must needs be attended with numerous casualties.

That the results justify the means I cannot admit, for no matter how carefully the nest is set up again the change in the character of its surroundings is bound to show and produce a more or less artificial effect. This is the one thing above all others that should be avoided in nature photography.

I cannot help thinking the book of which I speak a menace to our songsters; for it will serve to teach the uninitiated a method by which they will imagine they may easily photograph the birds, and it will take many nests full of dead young to prove to them their error. In the hands of an expert field ornithologist this method 
has some advantages as giving one ample opportunity to study the nest lives of the birds at close range, but it should emphatically be undertaken only by those who are thoroughly competent to take advantage of the opportunity and who will have due respect for the welfare of the nest's in-

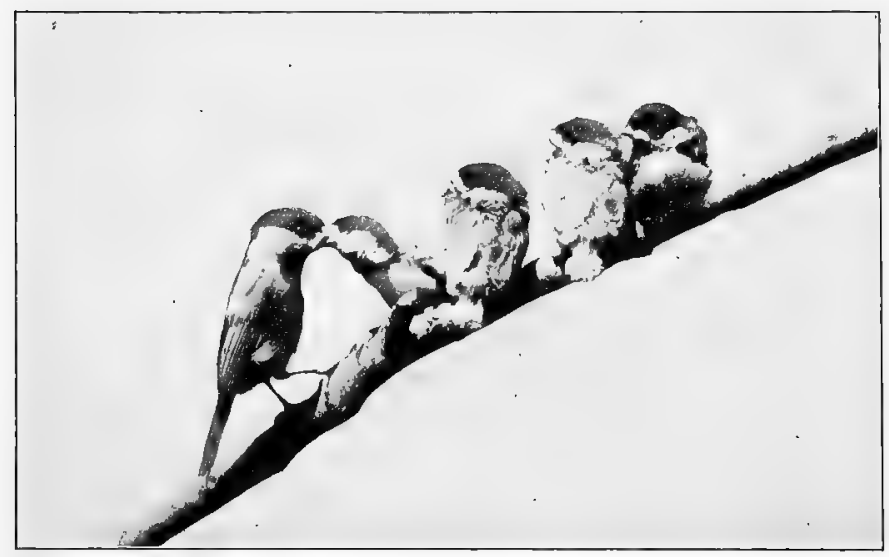

Chickadee feeding Young.

Negative with background stopped out.

mates. Even then it should only be used when all other means fail.

When the young birds are ready to leave the nest they, with the old birds, can be photographed with the aid of the long tubing in the manner described, either perching on or about the nest or posed upon a twig. In focussing upon them we must always be careful to leave a sufficient space 


\section{I78 Pbotograpby for the Sportsman Naturalist}

for the old bird, that its image may be entirely upon the plate when the exposure is made. It will not do to leave this space at one side only, for as surely as

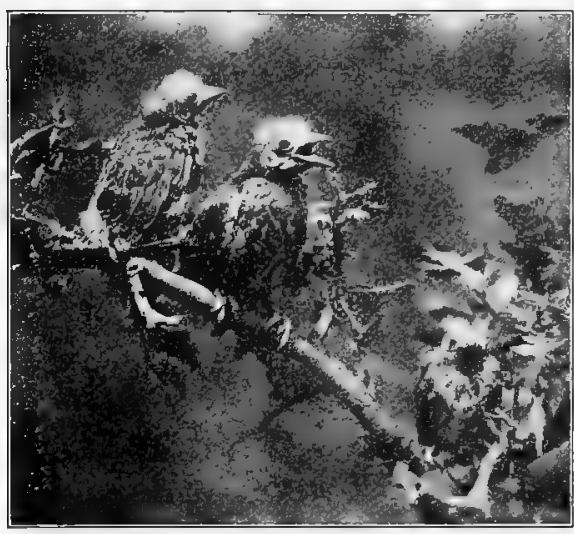

Young Blackbirds. we do this the bird will conclude to alight upon the opposite side, no matter if it should be the most inconvenient. A bird seems to be naturally obstinate and will invariably try to do just the things that we do not wish of it. In order to surely secure these young birds as they leave the nest we must have some knowledge of their habits and must watch them carefully, for the period of time that the young remain in the nest varies greatly in different species. The quails, sandpipers, etc., leave almost as soon as they are hatched, and every egg in a grouse's nest may hatch out and the young leave in the course of two or three hours. Swallows always remain in their nests until they are able to fly, and none of the birds that breed high leave their nests until 


\section{Pbotograpbing Birds and their Young I 79}

they are nearly to this condition and can perch with safety in the surrounding branches. The ground breeders and those that build in the low bushes desert their nests, on the other hand, as soon as they can struggle out, and when they are once gone it is difficult to find them among the long grass and low herbage.

Now is the time, as I have already said, when your patience will be tried to the utmost, but by perseverance you will nearly always win. An experience which I had with a young and old vireo adequately illustrates the troubles which you will have. I had but one of the young ones, all the rest had escaped me, and it took me nearly an hour to make that one stand where I wished him. Finally I had him posed to my satisfaction and, after waiting for nearly two hours, had the pleasure of seeing

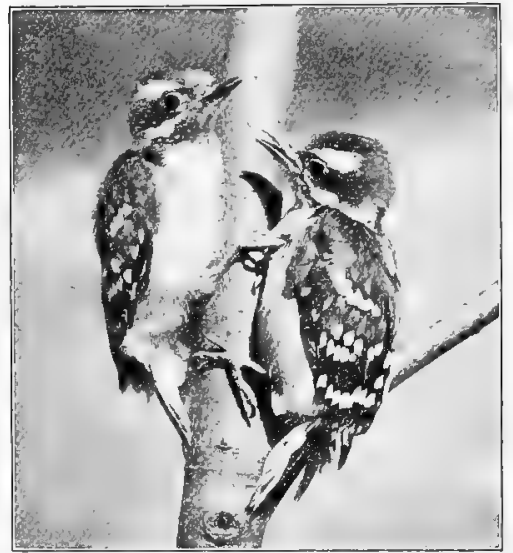

Young Downy Woodpeckers. the old bird approach with some food in her mouth. My pleasure was short lived, however, for she paused on a twig some little distance 


\section{I80 Pbotography for the Sportsman Naturalist}

from her offspring and commenced a series of calls as though telling him to come to her. This, I think, is what she really was doing, for, much to my disgust, he immediately jumped from the perch and fluttered to meet her. I returned him to the branch, and after two repetitions of this act the old bird concluded to come to him; and I finally succeeded in obtaining some very good photographs, but it occupied over five hours of my time to get them.

If an old bird is very obdurate and does not come to her young inside of a couple of hours, it is well to remove the camera for a short time and allow her to feed them. This prevents them from becoming too hungry and consequently restless, and the old bird will often return more quickly after the camera has been replaced.

Always, in handling young birds, use the greatest care, for they are easily injured by being held too tightly.

The full-fledged young by themselves make interesting pictures, and should we capture them when they have just left the nest they can be taken home and reared easily. Then we can photograph them at will, up to the time when they are full grown, after which we can let them go back to their native wilds if we have no further use for them.

Some photographers use a small cage made of mosquito netting and tapering to a funnel, the neck 


\section{Pbotograpbing Birds and their Young i $8 \mathrm{I}$}

of which is fastened about the barrel of the lens. This device admits of being moved into any position and lighting required, and may be useful in some cases. I have never tried it, and therefore cannot speak knowingly about it. It would seem to me, however, that it would be of but little use with anything but young birds that had just learned to fly. For photographing the old birds in captivity I would much rather follow the plan of one photographer who has a studio devoted entirely to this purpose, in which he has different perches in the

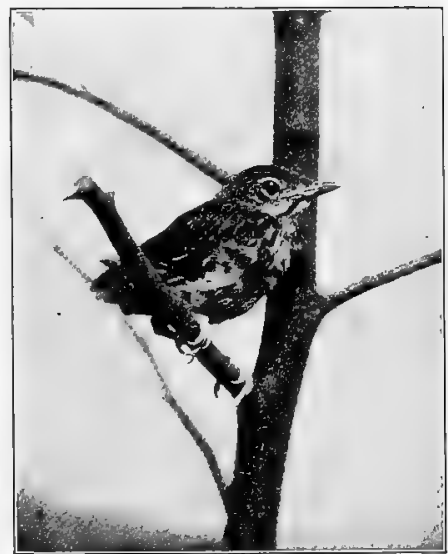

Young Wood Thrush. shape of various tree trunks, branches, etc., and where he can arrange any accessories he may think necessary. In this place he liberates his birds, allowing them the run of the whole room, and does not attempt to do any work with them until they are sufficiently tamed to allow of his close approach. By this method he has done some fine work from a merely anatomical standpoint, but, as far as pictures are concerned, I cannot think them a success. 


\section{I82 Pbotograpby for the Sportsman Naturalist}

I have mentioned these two methods of photographing the birds simply because they are methods that are used by some of the bird photographers, not because I advocate their use. I have never taken a picture of a bird in captivity, except of some of the larger water-birds in the Zoos, and I cannot think that as good results are thus obtained as by photographing them in their native haunts.

Of course, to photograph an old wild bird presents great difficulties, but I have shown how it can be done with their young, and there are many ways in which single pictures of them can be obtained. In going to and from her young when feeding them, a bird usually has some resting point upon which she perches more often than elsewhere. By watching her while she is making three or four trips we can learn where this point is, and by focussing upon it we are often enabled to obtain characteristic and satisfactory pictures of the old bird alone.

Mr. F. M. Chapman, who has done some very clever bird photography, says he has had some excellent opportunities to photograph by decoying the birds by means of a mounted screech owl. As I have never tried this I cannot speak from experience and will quote what he says: "My plan is to select some spot where birds are numerous, preferably near the home of a catbird, place 


\section{Pbotograpbing Birds and their Young $\mathrm{I}_{3}$}

the owl in a conspicuous position, and erect near it a 'scolding perch,' from which the protesting bird may conveniently vituperate the poor, unoffending bunch of feathers with its staring eyes. The camera is then focussed on the scolding perch and the photographer retires into the underbrush, and, bulb in hand, waits for some bird to take the desired stand. A catbird's domain is chosen for the reason that this species is the alarmist of whatever neighborhood it may inhabit, and once its attention has been attracted to the owl by 'squeaking' or uttering the alarm notes of other birds, the photographer may subside and allow the catbird to do the rest.

"The bird's rage is remarkable, its fear painful. Should the owl be near to the catbird's nest it will utter notes in a tone of voice I have never heard it use on other occasions. It loses all fear of the camera, and from the scolding perch screams at the owl with a vehemence which threatens to crack its throat. One is glad to remove the offending cause.

"Other birds in the vicinity are of course attracted, and hasten to learn the meaning of the uproar. Often a bit of undergrowth of which the catbird was apparently the only feathered tenant will be found to possess a large bird population. It is interesting to observe the difference in the actions of various birds as they learn the 


\section{I84 Pbotograpby for the Sportsman Naturalist}

reason of the disturbance. On the whole, each species displays its characteristic disposition in a somewhat accentuated manner. The blue-winged warblers flit to and fro for a moment and then are gone; the chestnut-sided warbler is quite anxious; the Maryland yellowthroat somewhat annoyed; the ovenbird decidedly concerned; the towhee bustles about, but seems to pay no especial attention to the owl; the wood thrush utters its sharp 'pit-pit,' but is content to let well enough alone if its own nest is not threatened; and the yellow-throated, red-eyed and whiteeyed vireos, particularly the latter, add their conplaining notes to the chorus of protests. Not one, however, approaches the catbird in the force of its remarks, nor does the bird cease its outcry so long as the owl is visible."

With the water-birds, the blinds, decoys, sneakboxes, and batteries of the sportsman can be used to advantage, and, needless to say, here it is necessary to use the reflex with as long focus a lens as possible. In fact, a long focus lens is always preferable. When photographing over water, where the light is intensified by reflection, the telephoto can be used for instantaneous exposures ranging from $\frac{1}{5}$ to $\frac{1}{50}$ of a second and very excellent results thus obtained.

In the winter time birds may readily be brought within range of the camera by baiting them, for 
Photographing Birds and their Young 185

they are then sometimes short of food and continually on the lookout for it. A good plan is to bait a spot repeatedly for several days before attempting to do any photographing. Then set up your camera, focussed upon some of the bait, and, retiring to a distance, wait until the birds

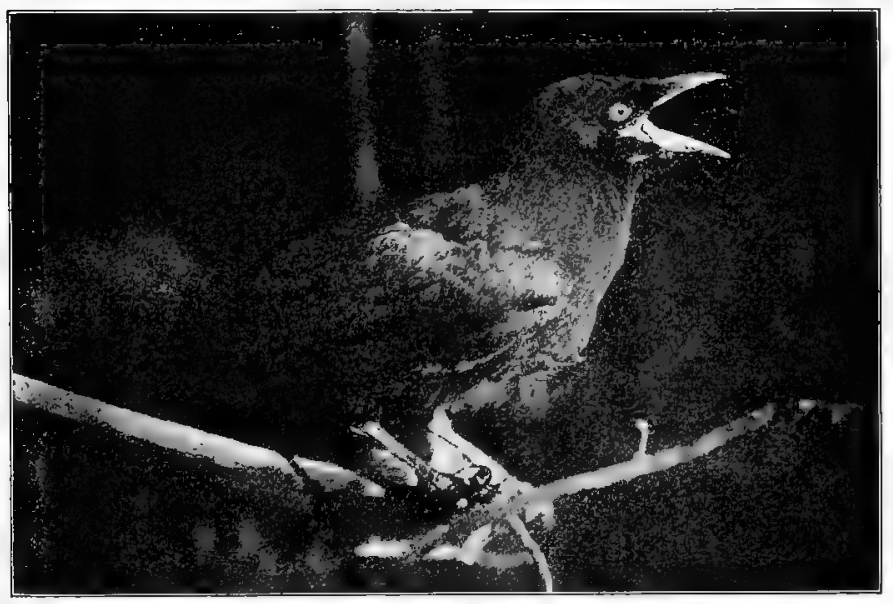

American Crow.

come to that particular spot, making the exposure by means of the long tubing. If this is done near a building, you can do your waiting indoors in greater comfort. At this season of the year, also, some birds, as the chickadee, can be enticed to one's very hand by the use of bait. In fact, the winter is a very good time for photographing such birds as remain with us during that season, 
I86 Pbotography for the Sportsman Naturalist

for they then seem to be more fearless and many of them congregate in flocks. A flock of cedarwaxwings, sitting upon some bare tree in the peculiar attitude which they assume, could be easily photographed with the telephoto lens.

At any time in releasing your shutter from a distance a piece of twine can be substituted for the tubing, but it is not so good, for on several occasions I have had birds alight on the tubing, and once, when photographing a catbird at her nest, the old bird actually fought with it, catching it in her bill and claws and giving it vicious tugs. Had I been using the twine, this would have released the shutter, and a number of plates would have been needlessly wasted.

Old birds sitting upon their eggs or brooding their young can be photographed successfully, even in the shade, by means of the telephoto lens at a distance of twenty-five or fifty feet or even more, for they sit perfectly motionless, allowing of sufficient time for any length of exposure. With this, as well as with all work upon birds, absolute quietness and slowness of motion are requisite. A bird will often remain calmly upon her nest and allow one to approach to within a few feet of her if the approach is made slowly and gently, but any sudden movement or sharp noise, such as the snapping of a twig, will cause her to leave instantly. 
There has been done some little work in photographing adult birds by means of a flash-light. This has been accomplished by going to the place where they are known to roost and using a fixed focus camera. I have never tried it myself, nor do I think it a satisfactory method.

The photography of flying or soaring birds is extremely difficult, necessitating, as it does, not only a very rapid exposure, but extreme quickness of eye and hand. Need-

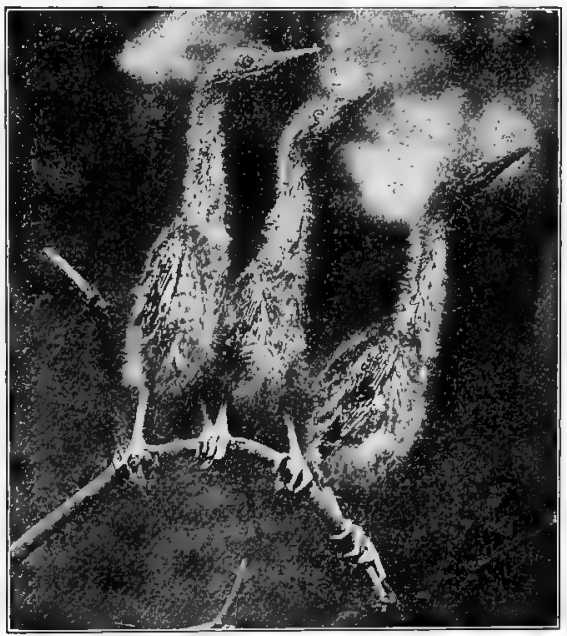

Young Green Herons.

less to say, the only camera that can be used to advantage in this work is the reflex. It was not until this type of camera was placed on the market that we had any pictures of birds in flight, but already much excellent work has been done in that direction. The best places for making these photographs are in localities where the birds colonize. A gull or heron rookery offers many opportunities, but we 
I88 Photograpby for the Sportsman Naturalist

must be quick to catch their image as they rise or soar over our heads, and the exposure must be made the instant that image is caught.

But quickness is the keynote of success in all work with birds. We must be ready to take advantage of every opportunity that is offered and never let a chance to get a photograph escape us.

The great water-bird rookeries of Florida are the ideal places for bird work. Unfortunately many of these have been nearly wiped out by the feather hunters, but there are still some left, although they are difficult to get at. Since the law causing the traffic in these feathers to be a penal offence has gone into effect, these birds have been steadily on the increase, and I look for those rookeries to be, in time, as numerous and as large as they once were.

In I895 I visited one comprised of at least five thousand pairs of breeding birds. This is probably the largest rookery now in Florida and has been undisturbed, owing to the extreme difficulty with which it is approached. Unfortunately for me, at the time I did not have a camera with me, but I could not help seeing the photographic possibilities of the place. Some day I hope to return to it with all the proper outfit, and when I do I shall not be satisfied until I have photographed. it thoroughly; and I therefore intend to keep its 


\section{Photograpbing Birds and their Young $\mathrm{I} 89$}

whereabouts a secret, for it is known to but few people.

The great Cuthbert rookery, which I have also visited, and which is situated in the almost unapproachable depths of the cypress swamp that surrounds the Everglades, is, probably, the largest of the better known rookeries; but it does not approach, either in the number of the individuals or of the species of birds which it contains, the one of which I speak. 


\section{CHAPTER XI}

\section{PHOTOGRAPHING INSECTS}

THE first thought that is apt to come into one's mind when the photography of insects is mentioned is the smallness of the subjects as a general rule. To be sure, there are a number of moths and butterflies that are as large as goodsized birds, but the great majority of the insect life is small, even minute.

This is, of course, one of the main obstacles in the path of the insect photographer, as it necessitates close work; and yet this branch, when compared to the photographing of birds or animals, is easy. It needs but a little patience and at least a working knowledge of your subjects.

Insect life, no matter how small, can be photographed successfully. Even the very minute forms, that are invisible to the naked eye, can, by the aid of the micro-photographic camera, be enlarged to any desired size on the plate. I do not consider it necessary, however, to describe this camera or enter into the details of the manner in which it is worked, as this does not properly come under the head of nature photog- 
raphy, and those photographs are of interest only to the scientist who is studying the lower forms of animal and insect life. I shall confine myself, therefore, solely to the methods used in photographing those insects which we commonly know and see.

One need not suppose that this is a limited field of action. There is a plentiful amount of work for the most ambitious photographer, and he will never be at a loss to know what to do next, even though he should confine himself entirely to the moths and butterflies.

Hunting butterflies is by no means a novel sport, and the gunner who has followed larger game with shot-gun or rifle need not imagine that there is no excitement in the chase. To be sure, the quarry sought is small and can offer no resistance to its capture but flight; but to follow a coveted specimen through brambles and thickets, across fields and meadows, until it descends to earth and alights upon some flower or leaf; to creep stealthily forward until within striking distance, perhaps only to see it, by a quick dart, escape the sweep of the net, and sail away again over the trees; to follow once more, heeding not where it leads, until it is safely bagged, requires quickness of eye and hand and a considerable amount of ingenuity, nor is it without its full quota of excitement. 


\section{Photograpby for the Sportsman Naturalist}

The desire to collect something seems to be a natural desire with every healthy American boy. Butterflies are among the collectable objects that are most frequently sought, and there is scarcely a town in the length and breadth of the United States that does not contain one of these embryo

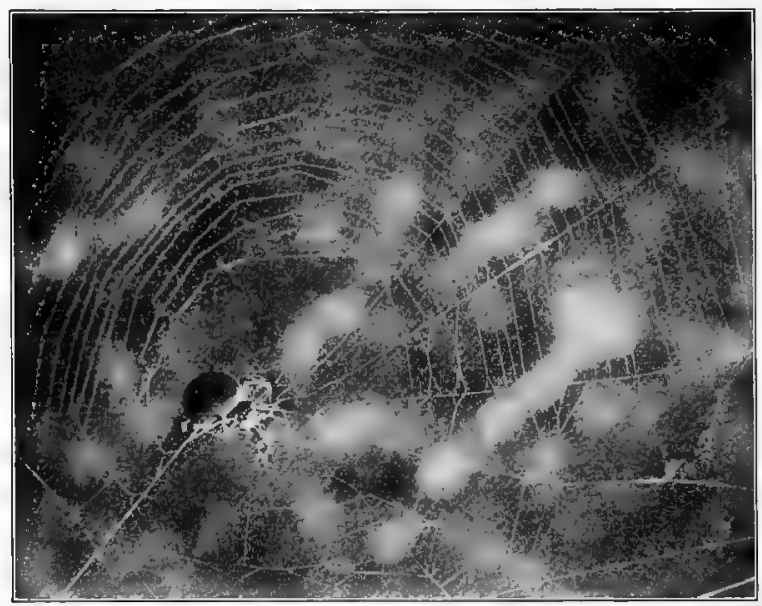

Spider repairing Web.

entomologists who is the proud possessor of a cabinet of illy mounted butterflies which he is wont to display on every possible occasion.

Instead of chasing these dainty denizens of the air, that aid so materially in completing the beauty of a midsummer day, with the sole intention of cutting shorter their already too short lives and pinning their dried bodies in a musty 


\section{Pbotograpbing Insects}

cabinet along with those of others of their fellows who have met a similar fate, how much better would it be were each one of these budding naturalists (who, by the way, seldom blossom) supplied with a camera with which to chase his "game," less dangerous to the insect and more instructive to the boy!

But it is not only the boys whom I should advise to follow the insects with a camera; for it is a chase prolific with possibilities, and many of its problems and obstacles can be successfully coped with only by a man. It is a most fascinating field for camera work and one in which there is much to be done, for there are, as yet, but

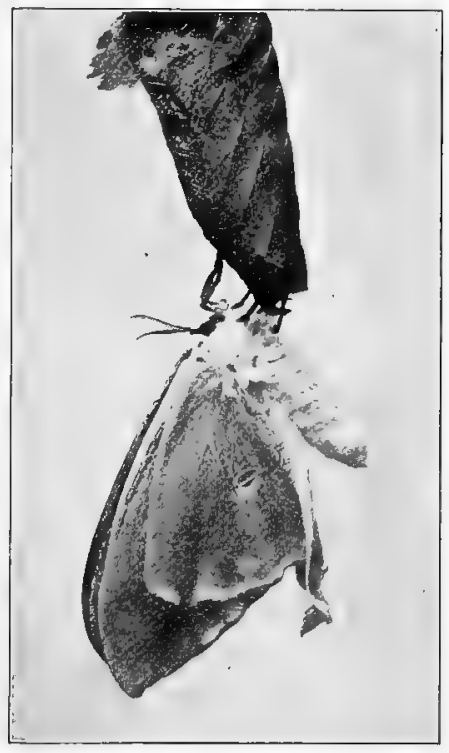

Lana Moth hanging from Cocoon. few serious workers in it and there is ample room for all those who wish to enter.

There are a diversity of difficulties to be overcome, but to the active man these difficulties are, or should be, nothing; and it is strange to me that, in a field which is so full of chances to obtain such 


\section{Photograpby for the Sportsman Naturalist}

intensely interesting and valuable material, there should be so few workers. While our books on animal and bird life are now profusely illustrated with excellent photographs of that life, those on insects still continue to use the old-style drawings, or, at the best, photographs from dead specimens. We seldom see anything but an occasional pho-

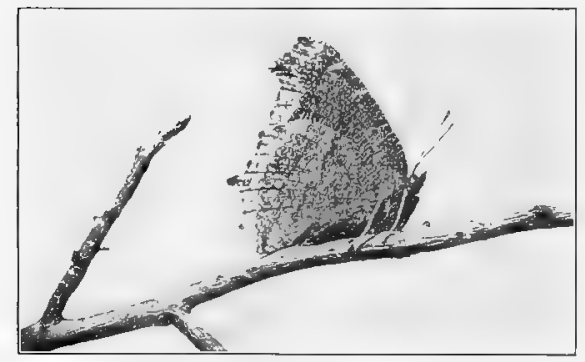

Mourning-cloak Butterfly. tograph of a moth or butterfly, and yet there is no reason why the photographs of insect life should not be just as plentiful and as good as are those in any other branch of natural history.

Of course, to do the best work possible in this branch, one should be something of an entomologist; but this knowledge will come, without any tedious studying, after one has taken up the pursuit of the insects with a camera. It is well to know, however, something of the habits of your subjects before you begin, else you will be at a loss where and when to look for them. This knowing where to look is rather necessary if one would be entirely successful in his quest of them, 


\section{Pbotograpbing Insects}

for all the insects have their chosen haunts, and, more or less consistently, remain in them. One cannot expect, for instance, to find a mourningcloak butterfly in low, swampy places, or one of the Fritillaries in the high, dry woods.

Insects can be found any and every where, however, and may be photographed the year round. From early April until late October, and even into November, they are abroad in greater or less numbers, and during the winter months there is always the pupal stage of which to make photographs.

It is seldom if ever necessary to use a camera larger than a four by five, for with this size it is possible to obtain life-size pictures of nearly all our native insects, provided we have a long-focus lens and a sufficient length of bellows extension. The focal length of the lens should not be less than nine or ten inches, and the bellows of the camera should be capable of an extension of at least twenty inches.

A great deal of the photography of insects can be done indoors, and, when possible, this is the best place in which to do it.

If one is taking up this pursuit seriously, he should have a place where he can rear insects, especially the Lepidoptera, from the larvæ, so that he may be enabled to photograph them in all their stages of growth and metamorphosis. 


\section{I96 Photograpby for the Sportsman Naturalist}

This is not a difficult thing to do, but it requires almost constant care and one must give up practically his entire time to it if he would carry it through successfully. The resulting pictures are well worth the trouble and are of the utmost interest from a naturalist's point of view.

The larvæ, or caterpillars, should be captured,

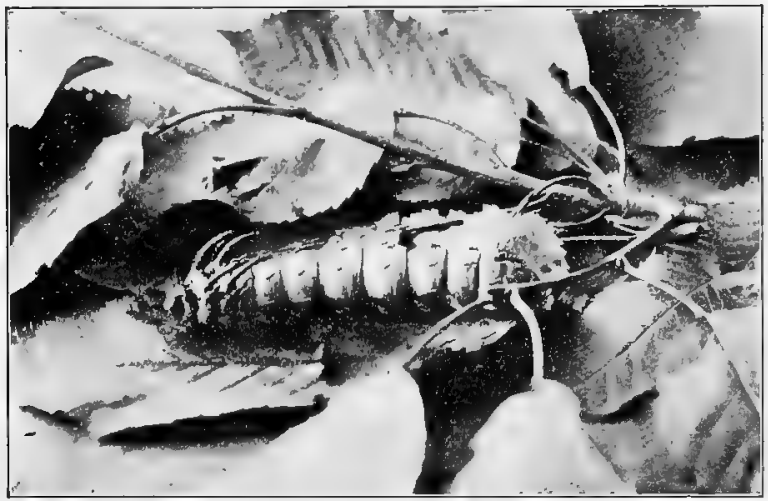

Larva of Walnut Moth.

of course, as young as possible, or, where practicable, hatched from the egg. They should be photographed several times during this stage, showing their various conditions of growth, and always on their food plant. The cocoons and pupa can be studied and photographed at one's leisure during the winter months, but from the first of May these must be watched constantly for the first sign of the coming forth of their inmates, 
or otherwise they may escape us entirely. Many of the Lepidoptera, especially the moths, give no intimation of their intended advent, but when we are lucky enough to obtain a series of photographs of one emerging from his cocoon it is intensely interesting.

The common milkweed butterfly makes an excellent subject for this work, for, by watching the chrysalid, we can tell almost to the minute when the butterfly will emerge. Also, in this connection, it is well to make pictures showing the various changes in the evolution from the larval to the pupal stage.

The butterfly or moth newly emerged from his pupal case is in a much crumpled and dampened condition, but its wings gradually grow and unfold, and photographs should be made during this process. After the wings are entirely spread there is a period, generally extending over about two or three hours, during which the insect is absolutely quiescent waiting for its wings to dry and harden sufficiently to bear its weight. It can, during this period, if handled carefully, be placed on any flower-head or other resting-place, and in any position desired, and the most satisfactory results in work on butterflies are thus obtained.

The photographing should be done close to a window. One facing the north is preferable, as the light is much more steady from that direction 
198 Pbotography for the Sportsman Naturalist

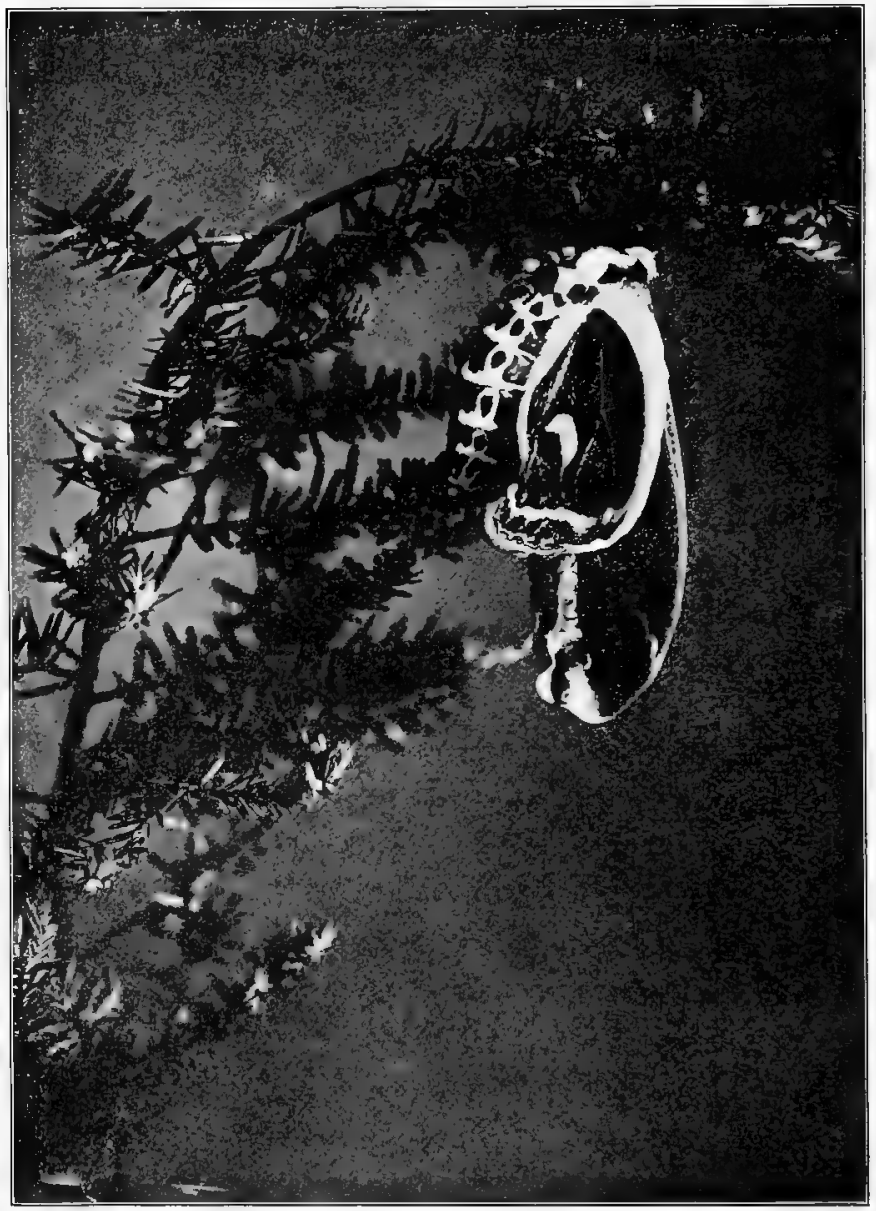

Newly Emerged Cecropia Moth. 


\section{Pbotographing Insects}

than from any other. The subject should be placed well to one side of the window, so that the light may fall upon it as full as possible. The light can also be equalized by the use of white paper or cardboard reflectors and by the white screen which should be used as a background and placed about a foot back of the subject.

The camera should be placed close enough to the subject to give at least a three-quarter-size picture and, where possible, a life-size one is preferable. In focussing, that portion of the subject nearest the lens should be made sharp on the ground glass and then the rest brought into clear detail by stopping down the lens. This will necessarily lengthen the time of exposure, but the subject, at this time of its life, is perfectly willing to remain absolutely still and allow plenty of time for focussing and exposing. By this method one can obtain better and clearer pictures than by any other, for there is no confusion of surroundings to detract from the main object and the resulting picture is clear and sharp cut in its details.

Much can and, necessarily, must be done out of doors, however, and it is impossible to obtain pictures of the quick changes of a butterfly, moth, or other insect from its pupal stage in anything but the bright sunlight, as instantaneous exposures are then necessary. 
200 Pbotograpby for the Sportsman Naturalist

I have obtained many satisfactory photographs, also, of butterflies as they alight naturally on flower-heads, in the following manner: Find, in some butterfly-frequented spot, a conspicuous flower-head, one that

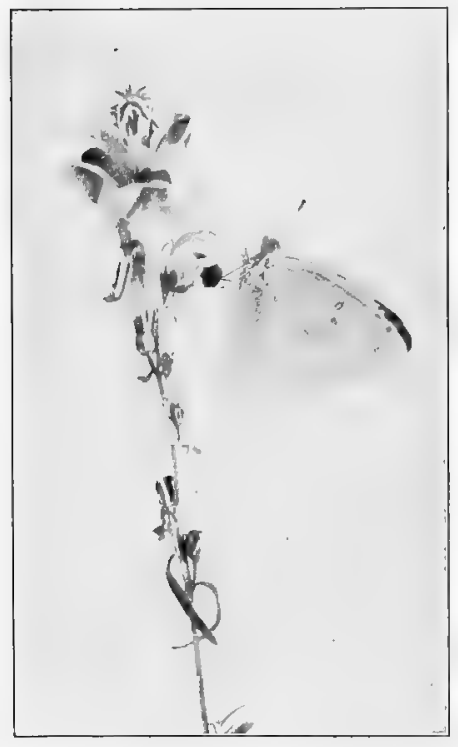

Cabbage Butterfly. stands well above its fellows and is, in consequence, more likely to be visited by the butterflies than are the others. Now set up the camera and focus upon the flower at a distance of about one and a half to two feet from it. If the flower should be in very bright sunlight, and it is best that it should be, and the lens is a rapid one, then it can be stopped down slightly to increase sharpness of detail and depth of field. The shutter should then be set to work at about $\frac{1}{100}$ of a second; the plate-holder inserted; the slide drawn; and the camera well covered by the focussing cloth to prevent any possible fogging of the plate. The rest is now simply a matter of waiting, with what patience we may have 
at our command, until some butterfly, bee, or other insect that we may wish to photograph condescends to choose that particular flower-head upon which to alight, when the exposure can be made and we have our picture, provided nothing has gone wrong. If the long rubber tubing is used, we may retire to the shade of some nearby tree and wait in greater comfort. This will sometimes insure quicker results, too, for a butterfly will often pass by a flower it might otherwise have visited, if it sees a human being standing near it. It is sometimes well to have a piece of white cloth or paper back of the flower to shut out what would otherwise be a disagreeably

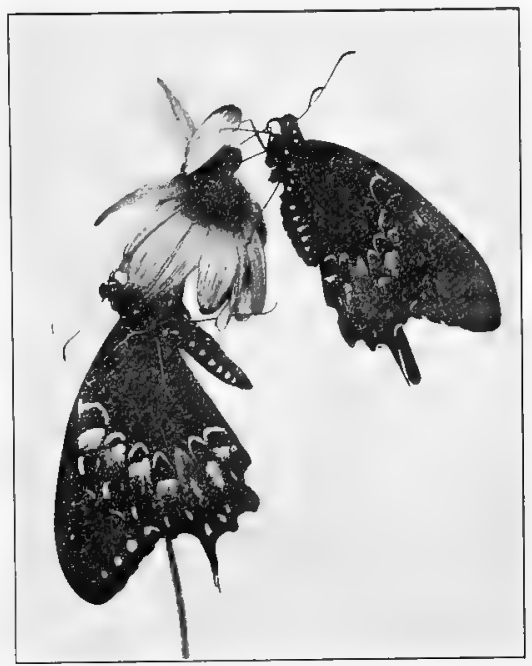

Black Swallow-tails. Male and female.

out-of-focus background; but this should be at least two feet back of the flower so as not to show in the picture as being what it is, and we should choose when possible a flower that will not make 


\section{Pbotography for the Sportsman Naturalist}

this necessary, for it, too, tends to scare away the butterfly.

Of course, the use of the reflex camera makes all this preliminary arrangement unnecessary, and we can by its aid obtain many pictures that would be impossible with the ordinary outfit. Moreover it allows us to work quicker and thus make more exposures in a certain length of time, thereby giving another example of the advantage of using this type of camera.

I would not advocate the use of the telephoto lens in this work, although it may be used to advantage occasionally; but an insect is so much more easily approached than are any other of the wild things that I consider the use of this lens in this connection unnecessary.

Always wait, before releasing the shutter, until the wings of the butterfly, if it is a butterfly that you are photographing, are at rest, for there is no shutter made, with the possible exception of the focal plane, that will work fast enough to entirely stop action in the fluttering of a butterfly's wings. The fast orthochromatic plates should always be used, as they reproduce the color values of the insect and flower almost to perfection.

All the appliances of the entomologist will come in handy for the insect photographer. It will frequently be found necessary to use the net, and many interesting subjects can be captured by 
beating the long grass and low herbage that would otherwise be passed by unnoticed. Occasionally it may be found advantageous to photograph dead specimens, and under such conditions the vertical stand, spoken of in Chapter $\mathrm{V}$, will be most convenient. I am never an advocate of the use of dead specimens, however, except in such few, exceptional cases when it is absolutely necessary to do so in order to illustrate more

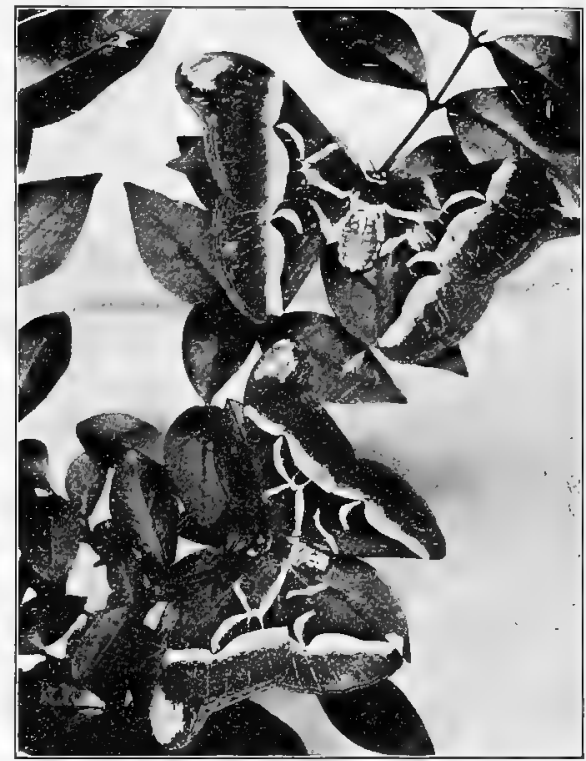

Moths Asleep in Daytime. clearly some particular point. The real value in all nature work lies in the fact that the products represent the subject exactly as it was in life, and this can never be so if it is photographed dead.

Of course the Lepidoptera (the butterflies and moths), among which are some of our largest insects, prove the most interesting subjects, and 


\section{Photography for the Sportsman Naturalist}

midsummer and early autumn are the gala seasons for these beautiful and dainty creatures. The moths, being principally night flyers, are best photographed from reared specimens, although one may often find them resting, during the day, among the thicker foliage. The butterflies may be photographed any and every where, how-

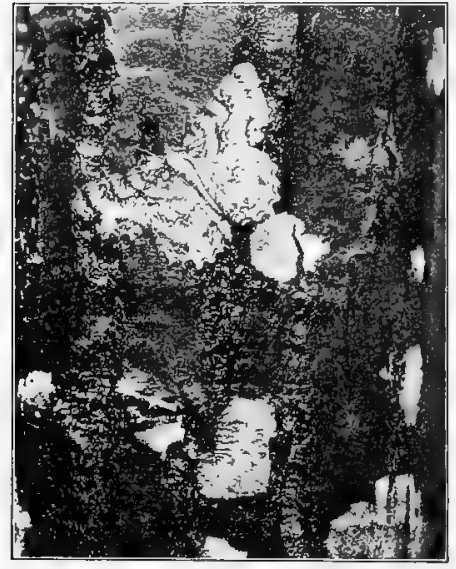

Moth on Tree Trunk.

Showing protective coloring. ever. One need not take long, wearisome tramps in the hot sun to find subjects. Any flower-covered field or piece of marshland will supply him with all the material he can conveniently use, and he will find that, in such a place, two dozen plates will be all too few for the demands made upon them.

The marshes, where grow the thoroughworts, milkweeds, sunflowers, and thistles, I have found to be the places most prolific with butterfly life, and have spent many a pleasant and instructive morning or afternoon in such a place.

The orchards are also good places to work, for they are the chosen haunts of the anglewings. 
These delightful little fellows are among the best examples of protective coloring in the insect world. Their flight is very rapid and jerky, and it needs a quick eye to follow them. When at rest on the trunk or limb of some apple or other tree their wings are folded tightly together, showing only the under sides, the indefinite coloring and marking of which so nearly matches that of the bark upon which they are resting that, at the distance of a few feet, it is almost impossible to distinguish them from it. In the autumn they feed upon the decayed fruit, and I have often seen as many as half a dozen on one half-rotten apple. This is the best time for the photographer to hunt them.

Many butterflies are lovers of the woods and seldom leave the deeper shaded places. Others can only be found at the seashores and still others in the higher mountains. In fact subjects can be found in any locality.

During June the butterflies increase in numbers very rapidly, and he who follows them with the camera will soon discover that he can occupy his time in this chase to the exclusion of all else. July and August are, however, the months in which they are abroad in the utmost profusion. Then they are everywhere, and one cannot go amiss in looking for them. They float over the meadows, swamps, and gardens, along the dusty roadsides and cool, green woodland paths in an 
206 Pbotograpby for the Sportsman Naturalist

ever changing, iridescent swarm. All the sunny places are alive with them. Gorgeous big fellows in deep velvety blacks, yellows, and reds, and smaller ones in more delicate blues and white. Their wings are of all shapes and outlines and covered with an infinite variety of designs and markings. They are all constantly on the move,

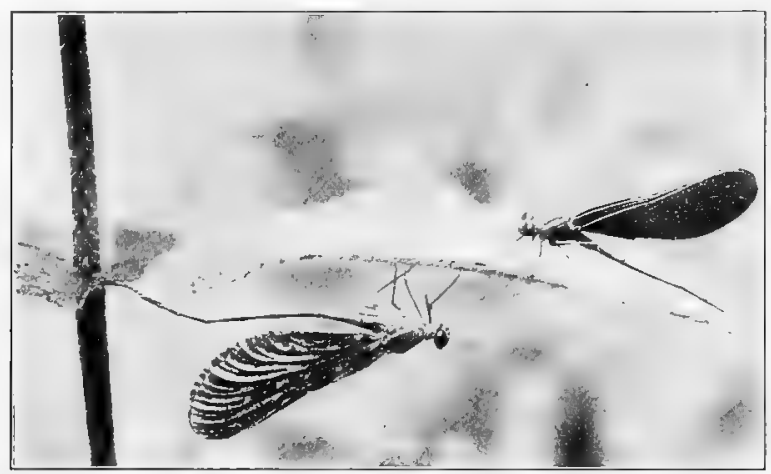

Dragon Flies.

seemingly tireless and seldom still, but they offer many opportunities to the picture hunter who is quick enough to take advantage of them, and the resulting pictures are ofttimes exceedingly beautiful as well as interesting.

To me it is enough simply to be abroad and a part of such a carnival of light and color, and I have no doubt that many will echo that sentiment. To those who must needs have an object in view, to take them to these beauty spots of the world 


\section{Photographing Insects}

when the day is breathless and the sun more than warm, the camera offers an incentive.

And how much better it is to carry a camera rather than a collecting net and killing jar; how much better to have the indestructible image of the butterfly on our sensitive plate than his all too destructible body in our cabinet! But if we must have the latter, why not take the former first? For, if we are a student of entomology, we will find that it will be of material aid to us in our studies.

That entomology cannot be placed in the category of useless pursuits has been sufficiently proved by the invaluable assistance, in the way of advice, which those who follow the study in a scientific manner have been enabled to give to the agriculturist. Advice which, when taken, has enabled him to successfully cope with the enormous army of vegetable-destroying insects.

That the photographic branch of entomology, although comparatively a new one, is also of immense importance is evidenced by the fact that the scientists have taken it up. Each one who enters this field has it in his power to be of some aid to the rest of mankind. So let us work with some serious end in view, not merely with the intention of passing away the time; and, moreover, let us do the best work that lies in our power, and, in order to do this, we should never be entirely satisfied with our results. 


\section{CHAPTER XII}

PHOTOGRAPHING FISH AND OTHER FORMS OF AQUATIC LIFE

THIs is the youngest of all the various branches of nature photography, and the one in which there are the fewest workers. Like many of the other branches it has been but a very few years since the only photographs of fish that we had were those made from mounted specimens, and to say merely that these were unsatisfactory would be to accord them undue praise. They were worse than worthless.

No one thought at that time that it could be possible to photograph the living fish, but some one, I have forgotten who, tried to improve on the old method by using freshly caught fish impaled on a nail. The results were no better, however, and it was left for Dr. Shufeldt of Washington (who, I believe, was the pioneer in this line of work) to show the world at large what beautiful results could be obtained from the living specimens in their natural element.

Fishes, like everything else, must be known to be photographed successfully, and so it is well, if 


\section{Pbotographing Fish}

we would do good work along this line, to first learn the principal habits of those fish that we intend to work with. We shall find that it will not only simplify matters, but tend toward better results.

From a scientific standpoint, and here is where fish photographs are most useful, it is necessary that the subject should show a correct delineation with absolutely no distortion and a sharp outline. One writer, who has done much good work in this line of photography, puts it thus: The following four characteristics should be observed as being of the most importance: the length of head, tail, and fins in proportion to the total length of the body; the general contour of the living specimen; the number of rays in his fins; the lateral line and the number of scales along it. It can be seen readily that the only correct view that can be taken of a fish in a photograph is a direct side view.

From the nature of this work it requires some special apparatus, and foremost among this is an aquarium. This will have to be made to order, for none of the aquariums that are sold by dealers in such things will answer the purpose. Any carpenter can make one from our own specifications; or, if we are at all handy with tools, we can do so for ourselves and, probably, with greater satisfaction. It should be made of white pine, 


\section{10 Photography for the Sportsman Naturalist}

clear of knot holes, for the bottom, sides, and back, and with a piece of absolutely the best quality of white plate-glass in the front. That this latter should be perfectly clear and free from bubbles is essential, for upon the fact of its absolute transparency depends much of the success of the pictures. The size of the tank depends entirely upon the size of the fish we intend to photograph; and it is a good idea, although not necessary, to have two made, one for small and one for large fishes. If only one is used, then it must be large enough to receive the largest fishes; and, naturally, when we put those of a small size into it, it will be difficult to prevent them from constantly swimming out of the field of focus.

The wood should be thoroughly shellacked and painted white on the inside (with enamel paint) before being put together.

If long brass screws are used in the construction of the tank, it will admit of its being taken apart and packed in a small space for transportation; but if this is done, the parts that come into contact should be made water-tight by strips of rubber inserted between them. When a fish is first placed in a tank, almost his first act is to retire to the very back of his prison; and as we need him as near the front with as little water intervening between him and the lens as is possible, it is obvious that we must have some means of forcing him to 


\section{Photograpbing Fish}

go and stay where we wish him. This can be accomplished by means of a glass partition which can be slipped into grooves on the side boards. There should be several pairs of these grooves at different distances from the front glass, so that we can make the compartment in which we wish to confine our subject of any size that we please.

The plate-glass in the front should be fastened by means of hardwood battens at the sides and bottom, between which and the glass there should also be inserted the strips of rubber so that, when they are screwed down tight, there will be no leakage.

This tank can be placed on any support and the ordinary tripod used with the camera, but it is convenient to have a support that will hold both tank and camera, which has the advantage of keeping them both upon the same plane. This may be simply a pair of wooden horses with a wide board laid across. This, of course, must be long enough to allow a sufficient distance between the lens and the tank, and will admit of varying the distance between the two easily and at will. If it is found necessary to raise the camera any, this can be done by means of an extra piece of board or two placed underneath it; and any simple device for clamping the camera to the board will answer to hold it steady, though, if care is used, this is not necessary. 


\section{I 2 Pbotography for the Sportsman Naturalist}

A lens of great focal length has no particular value in this work, as very little depth of field is necessary. I should advise the use of one of about nine or ten inches for a six and a half by eight and a half plate. Of course the faster

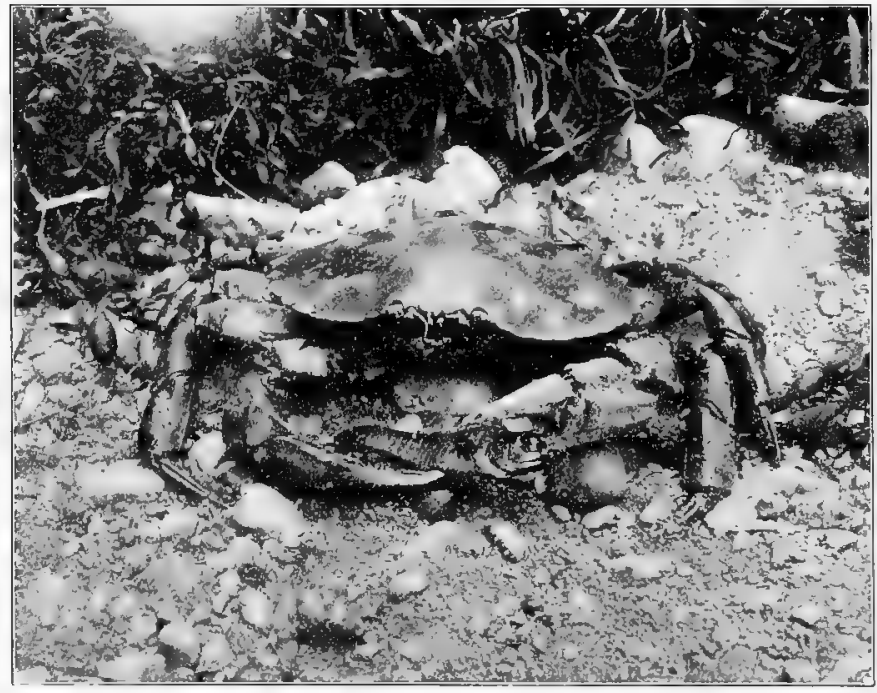

Common Crab.

it is the better, for fish will seldom stay absolutely quiet for a sufficient length of time to allow of anything but an instantaneous exposure.

Always use the orthochromatic plates, for many of the fish are brightly colored; and these plates, as has been before stated, are the only ones that reproduce anywhere near the true 
color values. They are somewhat slower than the ordinary fast plate, and this must be taken into consideration, but it is entirely compensated by the superior quality of the negative which we are enabled to obtain with them.

When the fish to be photographed will remain quietly in one position for a long enough time to allow us to do so, the very best results can be obtained by the use of the slow isochromatic plate in conjunction with the ray filter; but such fishes are few and far between, and we must not expect to find them often.

One of the greatest obstacles with which one has to contend in this work is the difficulty of getting perfectly clean, clear water and keeping it in this condition. Of this Mr. Dugmore, who has done probably the best work on fishes of anybody in this country, or elsewhere for that matter, has considerable to say, and, as he is undoubtedly an authority, I will quote him:"Absolute clearness of water is highly desirable but almost impossible to obtain. After straining the water so that it is clear enough for ordinary work in a good light take an apparently clean stone, not a smooth marble of course, but an ordinary moderately rough stone, drop it in the aquarium, and watch the result. The water will be seen to be filled with a muddy substance, and, instead of crystal-like clearness, we have a 


\section{I4 Pbotograpby for the Sportsman Naturalist}

murky-looking water that is most undesirable. But your troubles have just commenced. Add some fresh, green aquatic plants, and you will notice that they too give off scum and muddy material, even though they may be placed in the water with the greatest care. Now when the fish runs amuck through these beautiful plants and really disturbs the mud and scum, the water has lost all its clearness, so that it is impossible to photograph a fish through it. With tropical aquatic vegetation the difficulty is even greater than with our more simple northern plants.

"The beautiful 'sea-feathers' that one sees waving about with every movement of the water in the tropical seas appear to be a clear, clean purple or yellow; but on putting them into an aquarium they will be found to discolor the water immediately. 'Sea-caps' are even worse, and sponges cause so much trouble that after a few discouraging attempts we give up the idea of using them. What, you may ask, is the remedy for these difficulties? The only thing I have found to answer at all is to thoroughly clean each leaf by washing it with a soft cloth. It is a task requiring great patience; but once the plant is really clean it will remain so for several days, requiring only to be well rinsed in clear water each time it is used. Between whiles it is; of course, kept in clear water, which should 
be as near as possible the temperature to which the plant is accustomed. Over-warm water will cause the plant to lose its color and become covered with scum. Never put any plant, stone, or in fact any accessory into the aquarium until you have ascertained that it is free from scum and other foreign matter.

"Stones, especially those that are rough and honeycombed, require to be scrubbed with a hard brush and sand until they are perfectly clean. Sand, if it is necessary to use it, may be cleaned by throwing a little at a time into a bucketful of water. The part that does not immediately sink should be emptied out. This must be repeated until only the clean, heavy sand remains. But even this should not be used until you have a quiet fish to photograph. A restless fish will disturb the sand, which in sinking will fall on the fish; so that if he remains still enough to be photographed, he will be covered with a fine deposit of sand, and, needless to say, this will entirely spoil the picture. Occasionally one finds a fish so well behaved that he will allow this deposit to be swept off, staying quiet the meanwhile. Such fish are very rare. A piece of white coral looks so clean that one is tempted to place it in the water without previous washing, and too late we discover our mistake."

It has been my experience that a good plan 


\section{Pbotograpby for the Sportsman Naturalist}

for preventing the fish from disturbing the plants is to put but a few in the compartment in which he is confined and the majority immediately back of the glass partition. This shows no difference, for if the confining apartment is made sufficiently narrow, the fish will be practically against the plants, and of course the glass partition will not show. This arrangement also has the advantage of adding perspective and distance to the picture, thus giving it a much more natural aspect. In selecting the accessories to be used with each fish, always choose those that are native to the habitat of the fish and, if possible, use the plants among which he is most often found. To do this knowingly one must be somewhat conversant with the habits of his subject, as I have already said.

The front glass of the aquarium must always be kept absolutely clear and clean, free from marks of any kind and from the accumulation of moisture on the outside, for it is astonishing with what distinctness such marks will show in the picture and how easily that same picture can be spoiled by them.

The temperature of the water used is something that must not be overlooked, or about which we cannot afford to be careless, for a fish will often die in a very short time if a sudden change of ten or fifteen degrees is made in the 
water. Therefore, we must have the water in which we place him as near the temperature of the water from which he was taken as possible; also this must be constantly changed in order that it may be always fresh. Above all, never try to place salt-water fish in fresh water, or freshwater fish in salt water.

It may easily be seen from the amount of preparation necessary that the photography of fish is not accomplished without much tedious work and trouble. This is more or less true of all the branches of nature work, but perhaps more so in this than in any other. It is work that requires the utmost patience and care, for it must not be done hurriedly, and we cannot afford to overlook any of the smaller details.

I wish to warn the beginner before he starts that the preparation of the aquarium and the accessories to be placed in it is by far the easiest part. When he has finished all this, his troubles are but beginning, for in the catching and handling of his subjects and the final photographing lie the principal difficulties.

In catching the fish, first of all, a hook and line should never be used when it is possible to take them in any other way, for, especially with the smaller fish, the hook is not only apt to tear the gills, but will often injure the fish to such an extent as to cause it to quickly die. As soon 
218 Pbotograpby for the Sportsman Naturalist

as caught they should be placed in a live car and kept in the water, in the shade, until wanted, when they can be removed with a landing-net.

In handling the fish always use the greatest care not to hold them too tightly or rub off any of their scales, which, in many species, is a very easy thing to do. Also, for your own comfort, take care that the sharp spines of the dorsal fin do not stick into you, for, with some species, these are somewhat poisonous, and the wound made by them is always more or less painful. Many of the forms of jellyfish are poisonous to the touch, causing a sensation to the skin as though the hand had been brushed heavily with nettles.

Having caught the fish you want to photograph, set up your aquarium and camera in some place where the sunlight will fall directly through the front glass of the aquarium. Put in your water and accessories, and in arranging the latter, too much care cannot be used, as the setting must be as natural as possible, and upon it depends much of the success of the picture. As I have already said, most of these accessories should be placed back of and close to the partition glass, with only a very few in the compartment in which you are going to place the fish. Now select the specimen upon which you are going to make your first exposure, and lift him 


\section{Photograpbing Fish}

carefully from the car with the landing net. Take him quickly in your hand, holding him firmly but with not too strong a clasp, and place him gently in the compartment arranged to reccive him. At first he will undoubtedly be extremely restless and will swim rapidly from one end of the compartment to the other looking for some means of escape, and you must wait until he quiets down before anything can be done. When he has finally satisfied himself that he cannot get away, he will probably sink to the bottom and sulk. Now you can focus upon him, and, in doing so, be sure that there are no reflections from the sun's rays upon the glass, for this would entirely ruin the picture. Also be careful to note just what portion of the aquarium you can see upon the ground glass, so that you may be sure to have the fish in that portion when the exposure is made. It is rather discouraging, after having spent much time in photographing a subject, to find, upon development, that only one-half of his image is upon the plate, and maybe not that much, and it does not make the discouragement any the less to realize that it was our own stupidity that caused it.

After having focussed to your satisfaction, insert the plate-holder, draw the slide, set the shutter, and then cover the camera well with a dark cloth 
to prevent the possible fogging of the plate, for you may have to wait for some little time before you can get your fish into the exact position in which you wish him. Only those species that live on the bottom should be photographed in that position, for with the others it carries the idea of a dead specimen laid there, besides showing the fish under false conditions.

Some fish will quickly become accustomed to their artificial surroundings and will assume the desired position, if left entirely alone, in a very short time. Others will have to be coaxed to do so, either by gently pushing them with a stick or by lifting them repeatedly from the bottom until they remain suspended in the water long enough for you to make the exposure. With the best-behaved fish it will usually mean a considerable wait, and you must keep your patience. Above all, never make the exposure until the fish is in exactly the position that you desire. You will be fully repaid for the waiting by the much better results which you will thus obtain.

There are three things necessary to be careful about before releasing the shutter: that the fish is entirely in the field chosen; that he is no farther from or nearer to the front glass than he was when you focussed; and that his fins, especially the dorsal one, are well spread, for the latter precaution not only adds to the beauty of the 
picture, but is also an aid from a scientific standpoint in determining the species.

The exposure necessary is entirely according to whether your specimen is of a quiet turn of mind or not. Usually from $\frac{1}{5}$ to $\frac{1}{25}$ of a second will be found fast enough, but occasionally greater speed is necessary, and sometimes a specimen will remain still enough for a sufficient length of time to allow of a time exposure, but it is best never to depend upon this.

It is always a good plan to make several exposures on the same specimen. This decreases the chances of failure, and should each negative prove good the change of the position of your subject will make each one of them valuable; while if but one exposure is made, and that should turn out poorly, you will have had all your trouble and used your time and patience for nothing. Moreover, many fish change their coloring and markings very materially, at times often suddenly, and apparently without cause or reason. It is sometimes done, however, as a means of protection by conforming more nearly to the colors of their surroundings, and, when possible, pictures showing the various phases should be made. The fish of the tropical waters are the ones that show the most pronounced changes, and with some these changes are so decided as to completely alter the appearance of the specimen. 


\section{Photography for the Sportsman Naturalist}

I have spoken thus far in this chapter entirely of the photographing of fishes, but there are many other forms of aquatic life that can be successfully photographed, and which make most instructive as well as interesting pictures. Any of the jellyfish family may be photographed in the aquarium,

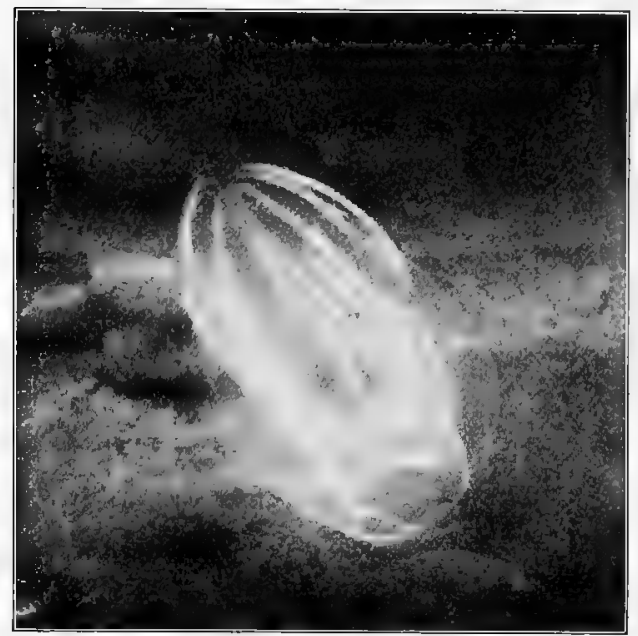

Jellyfish. but they make rather difficult subjects. In the first place they are extremely delicate, many of them so much so that when lifted in the hand they willslip away between the fingers, not as a whole, but tearing away in pieces until there is nothing left. Consequently, in taking them from their native element, they must be dipped up with a quantity of the water and thus transferred to the aquarium. Moreover, it is best never to let any of them come into contact with the skin of the hand or arm, for, as I have already said, many of 


\section{Pbotograpbing Fish}

them are poisonous; and while this poison is not particularly virulent, its effects are often extremely disagreeable.

These forms of aquatic life are, mostly, nearly transparent or with delicate tones of pink, blue, violet, and yellow. This, naturally, adds to the difficulty of successfully photographing them; but when one does succeed in obtaining a good picture of one, it is remarkably beautiful and should fully repay him for the trouble. They must always be photographed against a black background, for otherwise they would not show at all. A piece of board or zinc, coated upon one side with asphalt or any other waterproof paint that will give an absolutely dead black, can be used for this background and slipped in at the back of the tank. The sides should be left white in order to reflect as much light as possible. When using this black background, it will be found almost impossible to entirely eliminate all reflection from the picture, for the glass front of the aquarium against the black background forms an almost perfect mirror that will reflect the camera and any other object that is in front of it. These reflections are lessened by the use of a perfectly deadblack background, and by careful manipulation and the placing of your camera you can get rid of them entirely, or at least cause them to appear in such positions as will not interfere with the picture. 


\section{Pbotography for the Sportsman Naturalist}

The Portuguese man-of-war is an interesting little fellow to photograph and should be pictured with his sail set to the fullest extent. The sea anemones form another most interesting group and should always be photographed attached to the original support upon which they were found. These latter do not need the black background, and it is best never to use it except in such cases as are found to be absolutely necessary in order to show your subject to the best advantage.

The sea-urchins, corals, sponges, and the thousand and one other things that are to be found in the ocean can be photographed if one wishes to do so. In fact, there is an immense field here that has hardly been touched and that offers unlimited possibilities to any one who wishes to enter it.

It must be borne in mind, however, that all forms of aquatic life are more or less delicate and will not stand rough handling. Many of them, as the jellyfishes, cannot be taken from the water with safety, and any of them, even the most hardy of the fishes, are easily injured, so that as little handling of them as possible is always advisable. Above all, never allow them to remain out of water for any length of time, for a few minutes out of its native element often means death to one of these creatures. 


\section{Pbotograpbing Fish}

If a negative shows motion of the subject, or is blurred from being out of focus, throw it away and make another one. Clearness of outline and sharpness of detail are more necessary to the value of the picture in this than in any other branch of nature photography; and although you may be tempted to keep a negative that is not

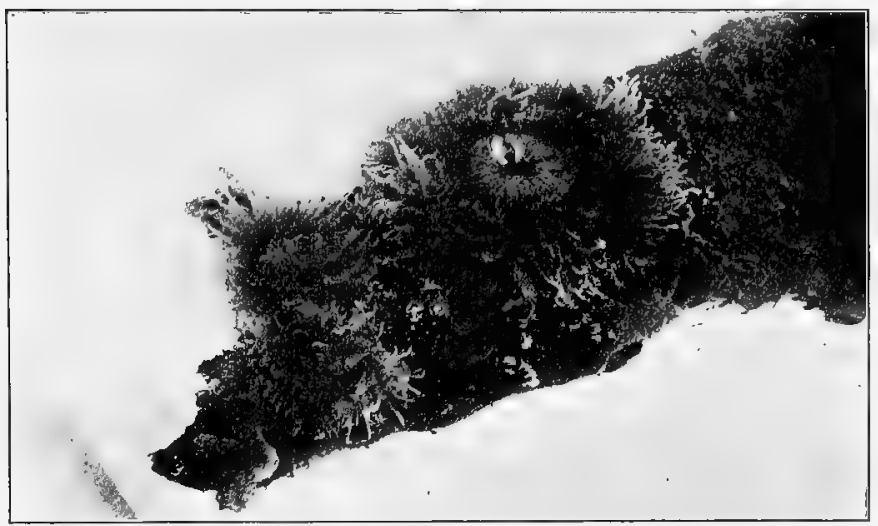

Sea Anemones.

perfect in these respects, you will find yourself better satisfied, in the end, and will consider the time well spent if you will discard it and keep on doing this until you have reached perfection. Poor work is undesirable and is of less value than the usual poor drawing. So, if you are too impatient never to be satisfied with any results other than the very best, you had better lay your camera aside and try some less difficult line of work, for 
226 Pbotography for the Sportsman Naturalist

there are already altogether too many poor workers in the field.

If you are serious, however, and wish to do some work that will last and be of value, then there is nothing that offers better opportunities than this same field of aquatic photography. 


\section{CHAPTER XIII}

PHOTOGRAPHING REPTILES, E'TC.

IF one can but overcome the instinctive abhorrence and fear which most people have of snakes, and learn to know them as the beautiful and harmless creatures which most of them are, he will find that they make the most interesting subjects possible for nature photography. They are, in every respect, preëminently graceful, and every position which they assume is a naturally artistic pose, for a snake is never awkward in any of his movements.

Of course, I realize that with many people the horror of a snake is too deep-seated to be easily eradicated, and I have known some otherwise courageous people whom the mere sight of a snake would affect most powerfully. To expect these people to handle one would be entirely out of the question. In fact, I know one man, who has lived very close to nature all of his life, who would rather walk a mile out of his way than encounter one of these creatures.

Since time immemorial the snake has been the symbol of all that is most vile and obnoxious, 
228 Pbotography for the Sportsman Naturalist

and since the days of the Garden of Eden fable to the present time he has been persecuted without just cause wherever found. It is remarkable that he is not already extinct, for with most people the first thought, upon seeing one, is to kill him as quickly and thoroughly as possible. His habits and characteristics are less known to most

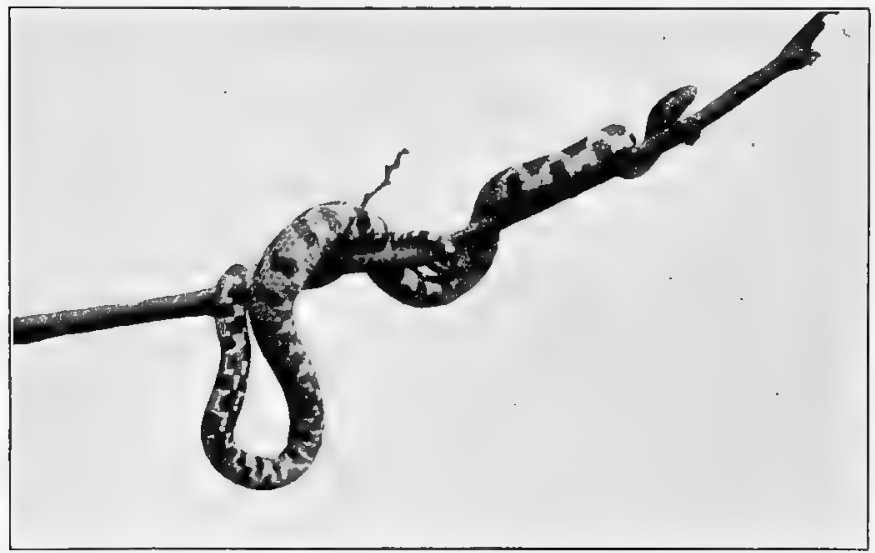

Milk Snake.

people than are those of many of our wild things, and it is a common belief that every snake is poisonous. I well remember the utter horror with which several country dwellers once watched me pick up a three-foot garter snake which I had found them stoning to death. When they saw what I intended to do, they kindly warned me that it was sure death, and I verily believe that 
they fully expected to see me bitten and drop dead before their very eyes. I tried to explain to them that the creature was harmless, but they would not be convinced and followed me with their eyes, their mouths wide open, as long as I was in sight.

The fact of the matter is that most snakes are not only harmless, but perform their part in helping along the day's work by killing off innumerable rodents that are injurious to the crops; and, did the farmer but know it, he could have no better allies than the snakes. Instead of allowing them the run of the farm, as he should do, he loses no opportunity to kill one, to his own loss.

One of the first requisites in snake photography is to lose this instinctive dread of your subjects and learn to handle them fearlessly. Of course, one must know the snakes thoroughly before he attempts to do this, else the results might be disagreeable should he pick up a copperhead or other poisonous species under the impression that it was not a dangerous one.

In the Eastern United States we have but four snakes, however, that are dangerous: the rattlesnake, the copperhead, the moccasin, and a little snake that inhabits the far South only and is known as the coral snake. Of these the rattlesnake is the most deadly, but none of them can be handled with impunity. All the rest of the snakes are harmless, and although, when cornered, they 
230 Pbotograpby for the Sportsman Naturalist

will strike with all the animosity of a poisonous species, even going so far as to take hold with their teeth, they have no fangs, secrete no poison, and therefore their bite is to be no more feared than that of a mosquito. To illustrate the necessity of knowing which snakes can be handled without danger, I will relate a little story which

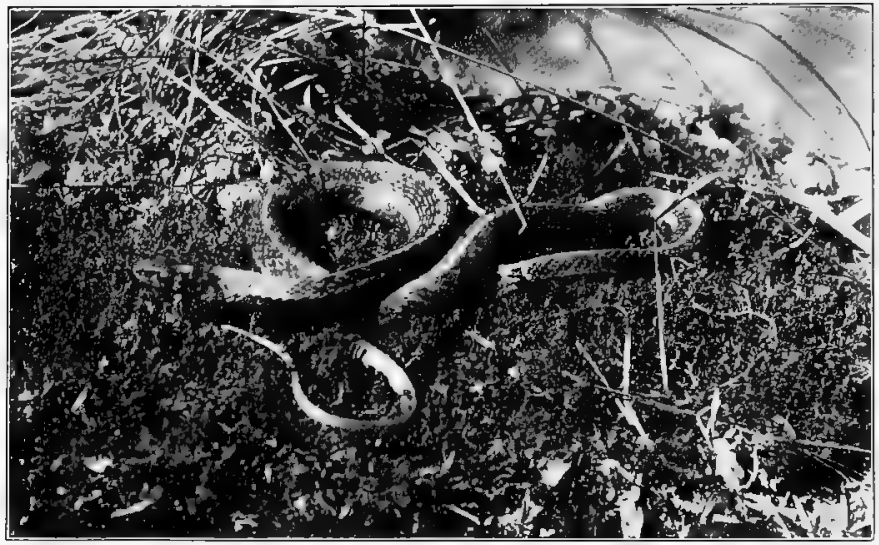

Garter Snake.

reflects somewhat upon my own good judgment and common sense. Some years ago, when I was younger and knew more, or thought I did, than I do now, I happened, in Florida, upon one of the coral snakes mentioned above. It is a beautiful little creature and one that would attract anybody's attention as the one I found did mine. I picked it up, for I had never had much fear of 
snakes, and carried it home with me, where I allowed it the free run of my room for several weeks. It would not eat, however, and finally died, much to my sorrow; and it was not until some months afterward that I discovered this species to be extremely venomous. It is true that the little knowledge which I had of the snakes was a dangerous thing and not sufficient to warn me against this one. Had it not been that this particular species is hard to anger and will not bite except under great provocation, I might not now be here to tell the tale.

Of the rattlesnakes, of course, there are many different varieties. They are all easily told by. their unvarying habit of signalling the fact of their presence to any one whom they may consider a trespasser upon their domain. I am free to confess that I have never had any great desire to hunt these creatures with a camera, although, should the opportunity offer, I should unhesitatingly do so. Many excellent photographs have been made, however, by those who have no particular fear of them.

Mr. Sumner W. Matteson, in the Cosmopolitan for April, I898, describes a visit which he made to a rattler's den, for the purpose of securing specimens and pictures, that for cool daring I think deserves a reward. He says that "Having had some experience with rattlers in Montana, Iowa, 
232 Pbotograpby for the Sportsman Naturalist

and Minnesota, I was anxious to know more of them, and accepted an invitation to a famous den at Fortification Rock, in Routt County, Colorado.... Here a trachyte dike several miles in length extends westward from Fortification Creek, standing fifty feet above the ridge on the north side and fully one hundred and fifty on the south. Much of the wall has fallen over to the lower side, making great piles of débris and loose rocks, at the foot of which thousands of rattlesnakes make their winter home. The land is still 'public land' and offered to any citizen of the United States complying with the laws relating thereto, but as yet the nearest ranch is two miles below and that deserted because the snakes would insist upon coming in at the open door or through knot holes in the floor and were always to be found in the boot box." In this den $\mathrm{Mr}$. Matteson with some companions, one of whom was a little girl, spent the greater part of a day, securing not only some excellent photographs, but some valuable specimens.

Mr. W. H. Backus, in "Country Life in America," gives some exciting accounts of rattlesnake hunting with a camera. It seems that once, while on a grizzly hunt in California, he came literally face to face with a big rattler, for it was coiled on a rock at a level with his head and but about a foot away. He says: "One of the 


\section{Pbotograpbing Reptiles, etc.}

things that came flashing through my brain as we glared into each other's eyes during that extremely long instant of time was 'What a picture the fellow would make!' What an eye!

Never before had I been so close to a free and angry rattler. I saw no blazing eye darting fire, that I had read about, nor was there any of the terrible fury in it with which the timid deer turns on his pursuer when brought to bay. It was clear and brilliant, but it seemed to me cold and calculating and, oh! so fiercely intent. Before I left that cañon I made up my mind I would have a camera.

"Next summer found me on the road to the San Bernardino Mountains, armed with a four by five camera of the "press-the-button 'type."

He had some little trouble in finding the rattlers now that he wanted them, but finally his quest was rewarded.

"He was already coiled, and as I dismounted he began to sound his rattle. He stood his ground fearlessly, as is generally the case, knowing his deadly power and probably knowing the fear in which he is held. The increasing darkness prevented any photographing on the spot, and the only thing to be done was to take him alive. After an exciting struggle among the rocks I succeeded in pinning him down with a forked stick. ... I seized him by the neck and 


\section{Photograpby for the Sportsman Naturalist}

dropped him into an open bag, and my first 'model' was captured.

"Selecting an open spot the next day, I spread out a large piece of canvas in order to get a clear, smooth background. I set the shutter of the camera and turned the focussing scale down to two feet, as I had to work at that distance to get a picture large enough to be of any value. I then opened the bag and dumped Mr. Rattler out upon the canvas. At this unceremonious treatment he coiled up for a fight and began rattling. Hastily grabbing up my camera I tried to take a photograph of him, when he struck the camera front, breaking one fang, as I afterward discovered. This negative was a blur, for I pressed the button with a convulsive grip. The next was the same; in fact, the entire set was a failure, partly from lack of knowlege of how to handle a rattlesnake and partly from inexperience with a camera. The many reasons of failure are well known to those who have photographed animals of any kind.

" After repeated trials with different specimens, I found it not only took infinite time and patience to get a characteristic pose that showed the best form of coil for striking, but that I had to approach with a steady, easy motion till I got up to the right distance. ... I have now been studying rattlesnakes for several years, and in the sum- 


\section{Pbotographing Reptiles, etc.}

mer of I 90 I I went out better prepared than before to watch them and get photographs; but before I had fairly started I had the misfortune to be bitten by one. This cut short my studies and nearly ended them altogether, as I was far from help except a boy who was with me. But it has added to my interest, and I expect to go again next summer with a camera better suited to that class of work."

Had Mr. Backus on his first trip been supplied with the proper outfit for doing this work, he would have found less trouble and obtained better results. It is this kind of experience that proves to be the best teacher.

Snakes, especially the harmless ones, are easily tamed, and I have often in an hour or two gotten one of them so well acquainted with me that he would stay quietly in almost any position in which I placed him.

Quick motion always scares a snake much more than any amount of handling or loud noise. A rattlesnake is a gentleman and will allow of a close approach if one but shows entire fearlessness and moves slowly and gently, but a quick jump or any sudden movement will cause him to strike instantly. In this fact lies most of the secret of success in working with snakes, and would we but bear it in mind we would find them far from the deep-dyed villains they are painted. 


\section{Photography for the Sportsman Naturalist}

In work afield in this branch the reflex camera is often necessary, but much can be done with the ordinary tripod box. I have often taken photographs of snakes by confining them in my carrying case or holding them in my hand while setting up and focussing my camera upon some suitable spot, then after having quieted my subject somewhat, I have placed him on the spot chosen and have found that often he would remain there long enough for me to even stop down my lens and make a time exposure; for when a snake is still he is absolutely motionless.

The best method, however, is to photograph them in an indoor studio, for then they can be brought home, studied and photographed at one's leisure; and any one who will try this will find that they make not only good subjects, but interesting pets as well. The studio should be arranged in some place with a good, strong diffused light, as the direct sunlight is apt to give bad reflections on the scales of your subject.

It is well to have a posing stand on which to photograph your "sitter," as it is more convenient than to do so on the ground or floor and the results are likely to be much better. This should be about two feet high, so as to allow the camera to point downward toward it, at an angle, from a slight elevation. It should be at least two feet square, so that the edges may not show on the 
plate, and with large snakes even this will be found too small. On this stand, with a few simple accessories, such as some pieces of sod, stones, leaves, and small plants, any kind of an artificial setting may be made. This should be arranged to look as natural as possible, but any one can do it by the exercise of a little care. A snake that has been kept in the studio for two or three days, until he has become accustomed to your presence and his surroundings and to being handled, will nearly always allow himself to be placed in the desired position on the stand and will stay there motionless for a sufficient length of time to allow you not only to focus properly upon him, but you can stop down the lens so as to get clear definition of the entire field and give as long an exposure as is then necessary.

Of course, there is always the chance of the snake deciding it is about time for him to make a move when the exposure is about half over and then you must try again, but these are the trials that you must expect.

Naturally, this kind of a studio is impracticable when photographs of the snake striking or ready for a strike are wanted. Then, of course, it is necessary to have the strongest light possible, for a snake's movements in coiling, striking, etc., are very quick. One can easily move his posing stand out into the direct sunlight, however, when 
${ }_{23} 8$ Photograpby for the Sportsman Naturalist

such pictures are needed or when the subject proves too refractory to allow of photographing him indoors.

While I do not believe in photographing birds or animals in a studio, I do think that snakes can be best photographed in this manner, for they do

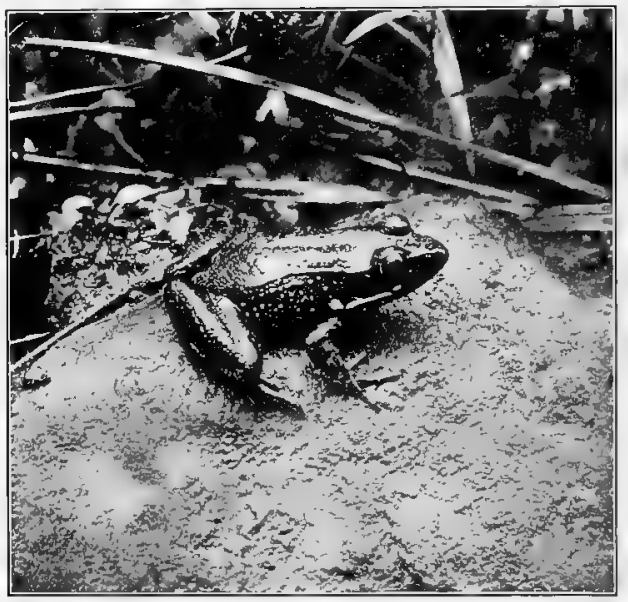

Common Frog.

not show their fear so readily as do the warmblooded animals and they always immediately assume natural poses when released from the hand.

For the smaller snakes, the lizards, frogs, toads, etc., a very convenient arrangement is a small glass cage, at one end of which the lens may be inserted. One that is suitable, easy to make, and costs but little consists of a rectangular case, 


\section{Pbotograpbing Reptiles, etc.}

preferably with glass sides and wooden ends and bottom. In one of the ends an opening is cut and covered with strong rubber cloth with a slit through which the lens of the camera may be thrust. The bottom of the box should be covered with earth or neutral-tinted plaster of Paris, which should be so rounded at the back and corners as to show no sign of the junction of the back and

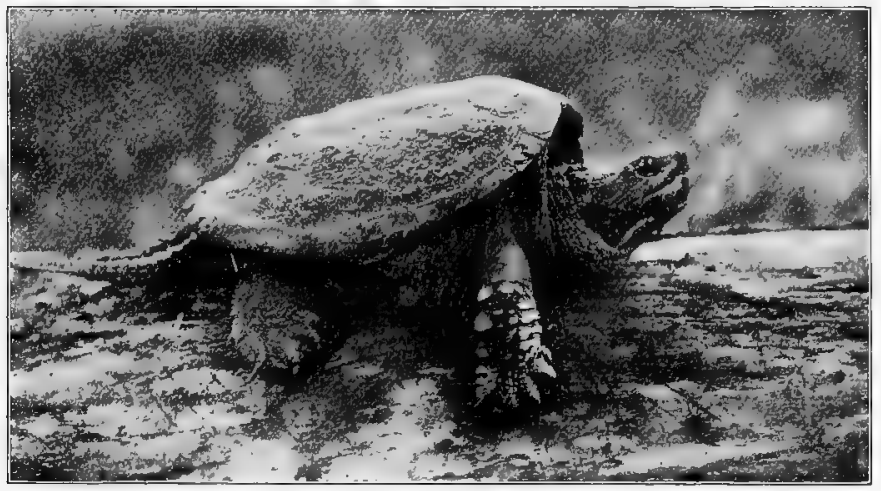

Snapping Turtle.

bottom. The back should be painted a neutral tint also. The box should be about two to two and a half feet long. This will allow a sufficient distance between the lens and the subject. A central partition of glass can be provided, to be slipped into position when it is necessary to confine the subject to the back of the box, and this will not interfere with the photograph provided the glass is perfectly clear and clean. The top 


\section{Photograpby for the Sportsman Naturalist}

should be a piece of glass simply laid on so that the subjects can be easily admitted and there will be no obstruction to the passage of light.

This cage should be supported at a sufficient height on any small stand or table, and by the introduction of twigs, stones, grass, pieces of wood, leaves, etc., natural conditions may be simulated and most excellent results obtained.

It is most discouraging to try to photograph frogs, toads, or lizards out of doors, for, although they may sit quietly and allow us to focus upon them, they are most liable to jump or move away just as we are ready to make the exposure. In order to obtain a sufficiently large image of them it is often necessary to work at such close range that the lens must be stopped down to get both them and the background in sharp focus. This makes it impossible to use the reflex camera. In fact I never use this camera with any of these subjects, as I find I can obtain so much better results by carrying them home and photographing them in the manner I have described.

The aquarium, which I have described in Chapter XII, is a useful adjunct in this connection, for many of the newts, salamanders, and lizards are water creatures and as such should be photographed in their native element. Frogs, too, may be photographed in the water as well as on land, and, should one desire a series of pictures 
(which, by the way, is most interesting) showing the different stages of the frog from the egg up, it can be successfully accomplished only in such an aquarium. During the tadpole stage they can be kept from the bottom and near the front by a piece of glass inserted at an angle and with its lower edge resting against the glass front of the aquarium three or four inches below the surface of the water. Care must be taken, however, when working in the direct sunlight, not to get disagreeable reflections from this glass which might spoil the picture. Otherwise it cannot be seen, and these reflections are not apt to show except when a dark background is used, which is never advisable.

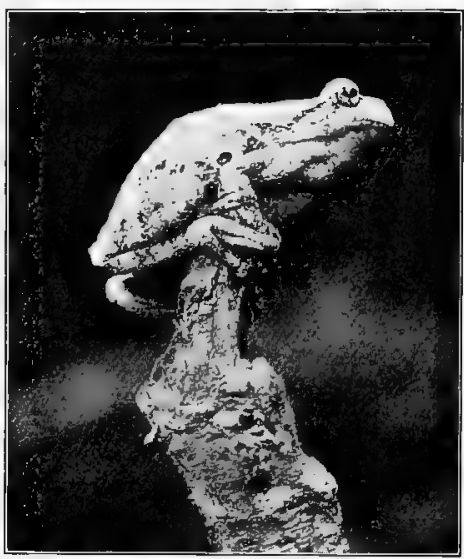

Tree Toad "singing."

Of all the exasperating subjects in the whole range of nature work, I think the box tortoise is probably without exception the worst. His fault lies in remaining too still. He will withdraw himself into his case, and no amount of coaxing will induce him to emerge until he is ready. I have often waited for, what seemed to me, an inter- 


\section{Pbotograpby for the Sportsman Naturalist}

minable length of time for one to show his head, only to have him in the end stick out the tip of his beak and one claw sufficiently to shove himself away from the camera and entirely out of range.

The snapping and water turtles are much better subjects, as they seem to be far less exclu-

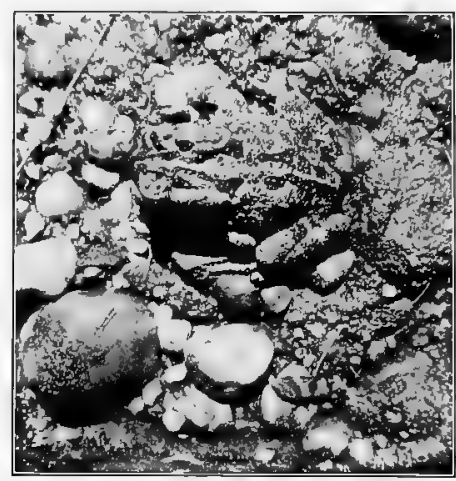

Common Toad.

Showing protective coloration. sive than are their land relatives.

In this particular branch are many excellent instances of protective coloring which make most interesting photographs.

Of such are the chameleons, the hylas or tree-toads, and the wood-frogs, all of which resemble their natural surroundings, often so closely as to make it difficult to distinguish them.

There are many instances of this protective coloring among the smaller wild things. It is one of nature's many schemes for giving to her offspring a means of defence against their numerous enemies, and truthful pictures, which are not always obtained by means of a pencil and brush, of those creatures that affect the color, shape, or markings of their surroundings are not only interesting but valuable. 


\section{Pbotographing Reptiles, etc.}

If we would do good work along all lines of nature photography, we must bear in mind that there is no creature, no matter how mean or lowly he may be, but has interest for somebody; and although we may not care for the snakes, lizards, and such creatures, and think them repulsive, there are many who do not have the same idea of them as do we, and therefore good photographs of them or of any of nature's children, even the smallest and meanest, are always in demand and have their value. 


\section{CHAPTER XIV}

PHOTOGRAPHING WILD FLOWERS, CUT AND GROWING

ConsIDERED as a means of artistic expression, flowers offer a greater opportunity to the photographer than does any other subject in the whole range of photography. They are more adaptable to arrangement, and, to any one of any pretence to artistic ability, they offer unlimited possibilities for beautiful photographs. It is not always the rarer or more gorgeous blooms that make the finest subjects either, for it is often the case that the commonest roadside "weed" affords material from which the best picture can be made if we but know how to handle it.

There is the advantage in this work of a great diversity of form and coloring, and the foliage also presents much that is interesting in its almost infinite variety of shape, and tones of greens, browns, and bronzes.

But, outside of the artistic possibilities of this branch of photography, it is of considerable value from a scientific standpoint.

It has been a source of wonder to me that botanists do not make a greater use of the camera 
to aid them in their studies, for it is certain that by no other means can such perfect illustrations be obtained; and, for an herbarium, such pictures are, it would seem to me, invaluable. Not only is it possible to obtain pictures of the plant in its entirety, but each small part of the flower itself is capable of being photographed and afterward enlarged to any size desired, giving the student a chance to study carefully and at his leisure the minute construction of the plants upon which he is at work ; while for comparison and identification no drawing or description can equal a first-class photograph.

Not only to botanists, however, would I recommend the photography of wild flowers, but to any one who has a desire for instructive amusement. Not one person in a hundred has the least idea of the number of really beautiful wild flowers that each year adorn the fields and woods immediately surrounding our homes.

They, of course, know the daisy, dandelion, thistle, and those more common plants that bloom by thousands through our fields and along our roadsides; but let them create some reason for becoming interested in the flora and they will be surprised to find how many blooms they will discover which they have never before seen or, at least, noticed.

But, in order to have any success in flower 
246 Photograpby for the Sportsman Naturalist

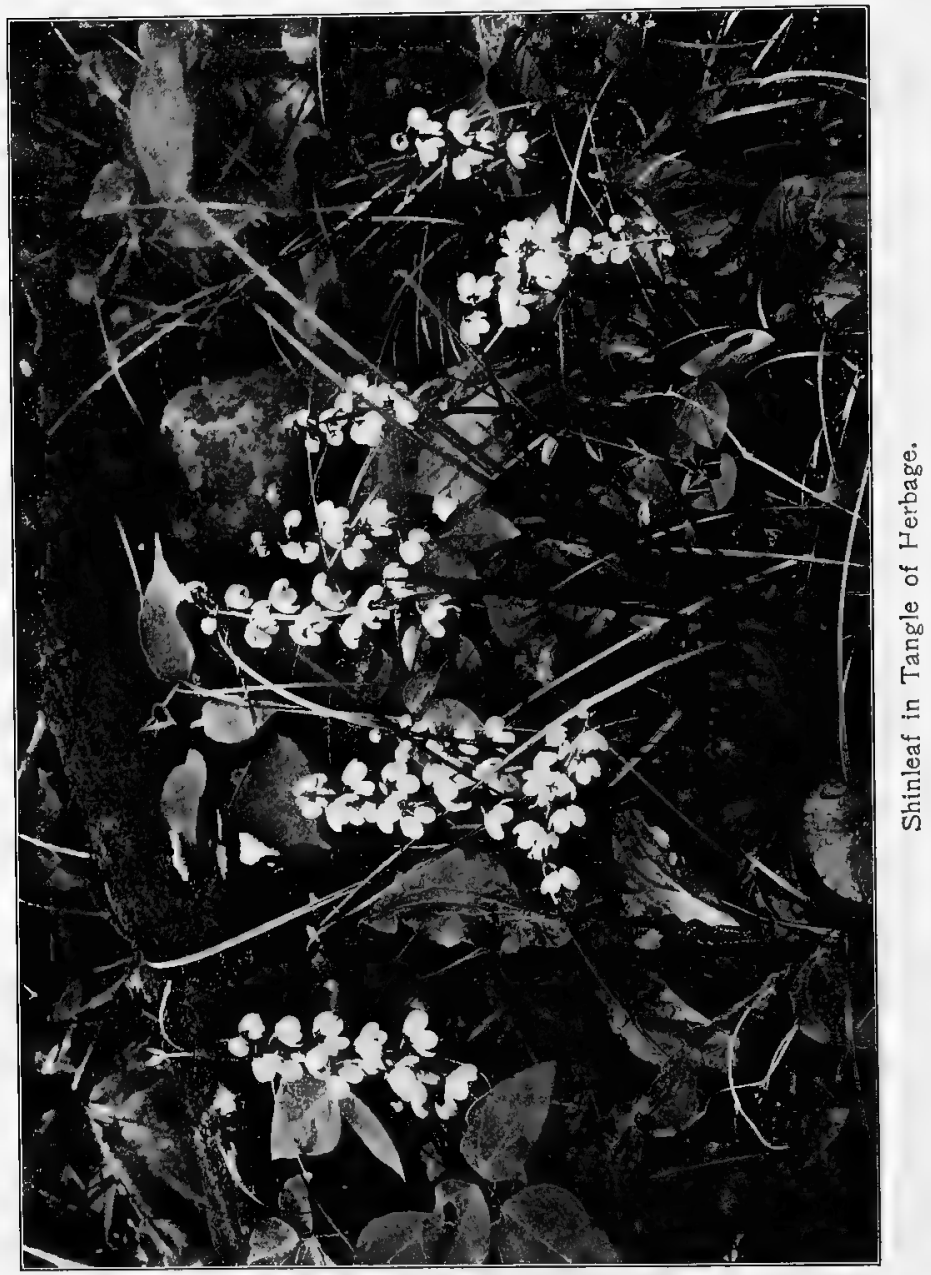


photography, one must be possessed of a little sense of the artistic, for the flowers should be grouped in such a manner as to show to the best advantage and not thrown together without thought as to their arrangement.

There are two ways in which flowers can be photographed: cut and growing. The latter is useful in showing their manner of growth, and the former in presenting the blossom on a larger scale and more in detail.

In photographing cut flowers the greatest difficulty with which we have to contend lies in the fact that they so easily wilt. Especially is this true of those plants that grow in water or in very damp soil.

I once spent nearly an entire week and dozens of plates in the attempt to get a good picture of one of our common flowering water plants. Specimen after specimen I carried home to no avail. It seemed to be impossible to do anything with it, for the flowers invariably wilted and dropped off, and the leaves curled up within ten minutes after it was removed from the soil. Placing it in water or in dampened sand, or, in fact, the use of any of the methods by which flowers are revived, appeared to have not the least beneficial. effect.

I was almost in despair of accomplishing anything with this species until one day I chanced 
248 Pbotograpby for the Sportsman Naturalist

upon a plant that was growing in a somewhat drier place than usual, and which, seemingly, was more hardy than any I had yet tried. By wrap-

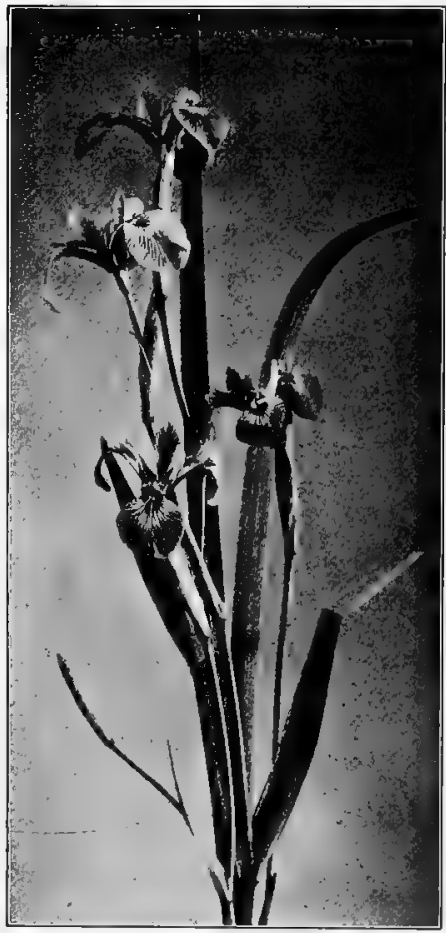

Blue Flag.

ping it in wet cloths and carrying it in a case entirely protected from the sun's rays, I managed to get it home in good condition. Once there I immediately made an exposure and, upon development of the plate, I found that my efforts were at last crowned with the success for which I had been striving.

This but serves to illustrate the point that I wish to impress upon all nature workers, in this as well as any of the other branches, that persistency generally wins in the end. One must never acknowledge himself defeated until he has tried every possible means of gaining the result which he wishes, and even then he should go back and try them all over again. 


\section{Pbotograpbing Wild Flowers}

The water plants are the most difficult to work with, for even if placed in water immediately after being picked, the leaves will generally dry and curl up and the flowers die and drop off in a very short time. It is necessary, in order to get a photograph of them at all, to make the exposure as soon after picking them as possible.

With those flowers growing in drier soil this difficulty is not nearly so great, for, no matter if they have become badly wilted while being carried home, they will, in most cases, revive in a few hours after being placed in water. With these flowers it has been my practice, generally, to pick them and arrange them in the groups in which I wish to photograph them in the late afternoon and allow them to stand over night, doing the photographing the next morning. By doing so they are usually in as fresh condition when I come to work with them as when they were first picked.

In gathering plants for subjects, always choose the best flowered specimens that you can find and pick them with as long stems as possible. It is best to carry them home in a botany box or some other kind of closed case, for they will wilt less than if carried in the hand; and if, before putting them in water, about an inch of the end of each stem is cut off they will revive much more quickly. 
250 Pbotograpby for the. Sportsman Naturalist

Cut flowers must always be photographed indoors. It is necessary to get as clear a photograph with as sharp an outline and as much detail as is possible, in order that it shall have any value; and as the least movement on the

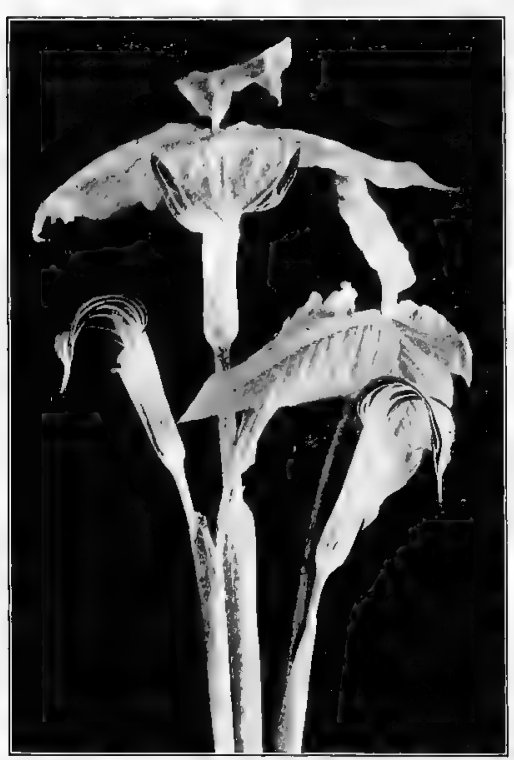

Jack-in-pulpit. part of the plant during exposure will completely ruin this, it is obvious that the work must be done where there is absolutely no air stirring. Therefore work in the open is here out of the question.

As the exposure is, necessarily, long, movement on the part of the plant is, under any circumstances, one of the chief difficulties, but by working indoors the chances for movement are naturally lessened materially. It is often the case, however, that a plant will voluntarily change its position during the exposure, perhaps imperceptibly to the eye, but sufficiently to utterly destroy all sharpness of detail and make the negative 


\section{Pbotographing Wild Flowers}

worthless. The least jar, such as made by a person walking across the floor, will also cause them to move, and I have even found that, with some of the more delicate flowers, the vibration of my body, if I stood too close to them, would cause them to tremble. The flowers must be absolutely still before they can be successfully photographed.

I always do this work in the room of an unoccupied building where there will be no unexpectedly slammed doors or heavy footfalls to jar my subjects. During the exposure I always remain as far from the flower stand as possible, and I sit down. One can more easily keep absolutely still seated than standing, for there is always a tension to the body when standing, especially if the attitude is at all constrained, that causes it to vibrate. Some may think that all such precaution is nonsense, but I can assure them that it is not. I learned the necessity of it through the bitter experience of many wasted plates, and I am now giving the results of that experience to those who are about to enter the same paths.

One might think that, in comparison to photographing animal life, the work upon floral life should be easy. It is much easier, as-would naturally be the case in the difference between animate and inanimate objects, but should any 
252 Pbotograpby for the Sportsman Naturalist

one attempt it with the impression that it is all plain sailing he will be speedily undeceived, and maybe he will not entirely enjoy the undeceiving process. In order to give my readers some idea of what they will have to contend with, I wish to say that I have often worked from four to six hours over a single flower without obtaining a satisfactory negative and have finally been forced to desist on account of waning light, and many times have I been compelled to hunt up a new specimen of some flower, the ones I had having become wilted beyond all resuscitation while I was trying to obtain with them the results which I wished.

One man, who has made some of the finest flower studies which I have ever seen, once told me that before he obtained a result that pleased him, when he first started at this work, he made and discarded over a thousand negatives. $\mathrm{He}$ was probably almost hypercritical, but it is much better to be too particular than not particular enough.

I hope all this will not discourage any one, however, or deter them from trying the work. I simply tell it that those who are entering the field of flower photography may not expect too much at the beginning. After having once acquired the knack of knowing just when and how to make an exposure and what length of exposure 


\section{Pbotograpbing Wild Flowers}

is best suited to the different combinations of color in order to reproduce them in as nearly the correct values as possible, one steadily improves and the number of failures that he makes as steadily diminishes.

The work should be done within two feet of a window (one facing north is the best, as the light from that quarter is apt to be much more steady than from any other), and it is a good idea to cover the window with a tightly stretched piece of thin cheesecloth in order to soften the light. The flowers should be placed on a stand well at one side of the window, so that the light will fall upon

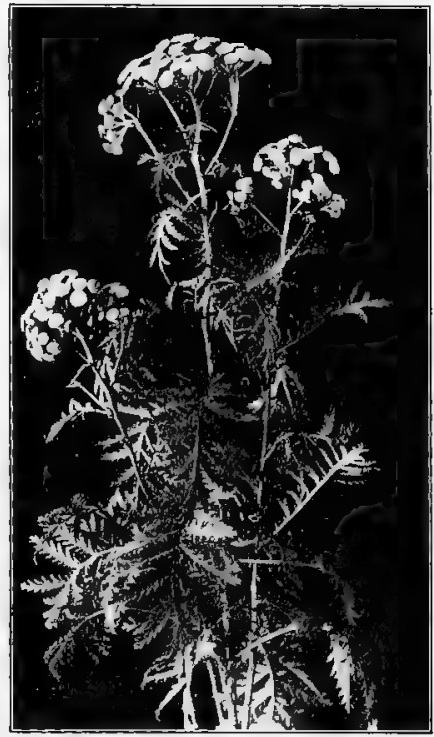

Tansy. them as full as possible, but not so far at the side as to cause any of them to be in the shadow. The background should be put at least a foot back of the flowers, so that their shadow will not fall upon it. There should be at least three backgrounds, one white, one black, and one of a neutral tint, and the operator must learn which 


\section{Pbotograpby for the Sportsman Naturalist}

background is best suited to the different colors of the flowers.

The light should be equalized on the side farthest from the window by the use of white cardboard reflecting screens placed as close to the flowers as possible without showing in the picture.

The camera used should never be smaller than the six and a half by eight and a half size, and an eight by ten is even better, for the image should be reproduced as nearly life size as is compatible with good work. A flower negative should never be enlarged, as a great deal of the delicate detail is bound to be lost in the operation.

The make of lens used is more or less immaterial, the one with which the operator is best acquainted being the one best suited to him. It should never be of less focal length than nine or ten inches, however, and the longer than this it is the better. It should also be one of the faster makes, as the more speedily an exposure can be made the less danger of the flowers moving during the process.

In this work orthochromatic plates used in conjunction with the ray filter are an absolute necessity, and the slow ones are the best as giving the truer color values. In the use of the ray filter, or color screen, one must carefully consider the color of his flowers in order to get the best results. A very deep-colored screen is rarely 
necessary, and I have found that for all-round work one of a light lemon tone is the best. With blue or violet flowers it should always be used, with the yellows and oranges it gives better results, but with the reds it is not necessary and only tends to lengthen the time of exposure. With pink or white flowers, however, it should be used, especially where the color of the foliage is dark, in order to preserve the proper relation of tones between the white or pink of the flower and the green of the leaves.

Now, after having arranged your flowers to your satisfaction, set up the camera close enough to give at least a two-thirds size image, - life size if possible. Focus upon that flower of the group that is nearest to the camera and then stop down the lens until all are in sharp focus. I have found it best to always work my lens at the smallest aperture, for, while this necessitates a longer exposure, it invariably gives the best results in delicacy and sharpness of detail. In focussing, always do so with the color screen in place.

The time of exposure can only be learned by experience, for it is governed entirely by circumstances and there is but little advice of value that can be given upon the subject. I have found, however, that under ordinary circumstances, when the light is strong, an exposure of about six or seven minutes is necessary when using the 


\section{Pbotograpby for the Sportsman Naturalist}

slow plate with the color screen. This with a nine and a half inch Goerz lens stopped down to F. 64. It all depends upon the speed of the lens, the condition of the light, the density of the color screen, the distance the lens is from the flowers, and the color of the flowers. Darkcolored flowers need a much longer exposure than do those which are light in tone, and this must always be taken into consideration.

The light of early morning or late afternoon is often deceptive, seeming to be much stronger than it really is, and therefore the best time for work is from about the middle of the forenoon to the middle of the afternoon, or, say, about four hours of the middle of the day. The light at these hours, when the day is clear, is almost absolutely steady. Never attempt to do any work upon a cloudy day or one upon which the light is at all variable, for you will find that you will lose many plates through not being able to judge accurately the length of time for a correct exposure.

Always remember that it is better to slightly overexpose than to err in the opposite direction, for an underexposed plate is almost useless, much of the fine detail being entirely lost, while with an overexposed plate one can so develop it as to make an excellent negative; that is, if the over exposure is not too great. Of course a plate that 
is correctly exposed is always the best, for that needs no special manipulation in the development.

Many people use a vertical stand, such as was spoken of in Chapter $\mathrm{V}$, for this work, and arrange their flowers by laying them on a piece of clear glass with the background a foot or so below. The flowers are less apt to move by this arrangement, but they cannot be made to look so natural as when they are photographed erect.

The arrangement of the flowers is beyond doubt one of the most difficult parts of the whole operation, and it is here that one

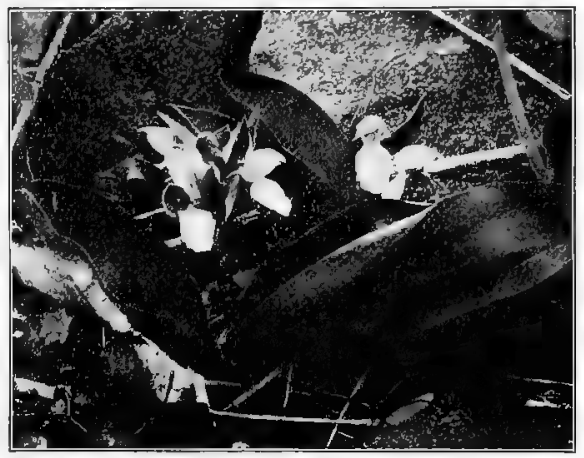

Spring Orchis.

can give full scope to whatever of the artistic sensibilities he may possess. In this arrangement one can follow no given instructions, but must rely entirely upon his own ideas, and depending upon whether these ideas be good or bad lies much of the success of the picture from an artistic standpoint. Some flowers are so stiff that it is impossible to impart to them one iota of grace, but in this very stiffness there often lies 


\section{Pbotography for the Sportsman Naturalist}

great beauty if one can but see it and understand how to group them so as to bring it out.

One little suggestion may be of service: never crowd the flowers; much better to have too few than too many. A single spray is often sufficient and, almost invariably, two, or at the most three or four, give better results than do a dozen or fifteen. Occasionally it is necessary to use more than this, but very rarely, and one's judgment should tell him when to do so.

I use bottles to hold the flowers, as I find that, their necks being small, the flowers can more easily be made to stand erect than in an ordinary vase. It is well to use two or three of these bottles for a group, for if only one bottle is used it shows the stems of the flowers all rising from the same point.

With vines and flowers that are pendent, such as the locust blooms, I use a square frame with notches cut in the top, which I can stand up on the table, and from which I can hang the flowers; for they should always be shown in the natural position in which they grow.

Photographing wild flowers, growing out of doors in their native haunts, is a somewhat different matter from photographing them indoors completely protected from the wind. If it were not for the fact that the slightest breath of air, almost imperceptible to us, will cause a growing 
flower to move, especially those that have long, slender stems, and that it is seldom possible to find a day when there is not some breeze stirring, then the photographing of the wild flowers in

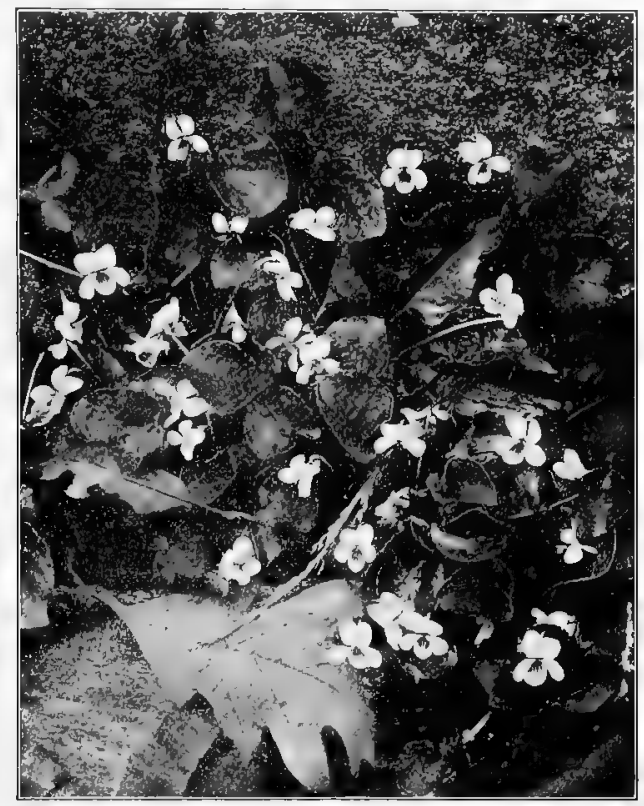

White Violets.

their haunts would be comparatively easy, for they naturally compose themselves into artistic groupings. But, if one wishes to discover for himself what difficulties confront him, let him watch a bunch of anemones on what seems to him to be an absolutely still day. Although he 


\section{Photography for the Sportsman Naturalist}

can feel no breath of air, still he will see that the flower-heads on their slender stems keep up a constant motion, and are seldom still for a second at a time. I once was forced to wait for over an hour, when trying to get the photograph of a group of seeded dandelion heads, before they all remained quiet enough for the three seconds' exposure that was necessary, and there was not enough air stirring to evaporate the perspiration that continually gathered on my forehead, or to give me one instant of relief from the intense heat.

This difficulty, happily, does not extend to all plants, as there are some, such as the skunk cabbage, that can be photographed even when there is considerable breeze blowing.

If the breeze is slight, the more delicate flowers may be protected from it, during the exposure, by means of a cloth screen stretched about them, but it must be so placed as not to show in the picture for what it is.

The value of pictures of growing flowers lies principally in showing their manner of growth and environments. In every case the whole plant should be shown, and we should select typical specimens, and ones that are growing under normal conditions. A skunk cabbage, for instance, is a plant of the low, swampy woods, but I have found it growing, occasionally, in dry, 
open places. It should be photographed, however, in the former situation, for that is its natural habitat. Nearly all plants frequently stray from their natural locations, but these wanderers are not the ones that should be chosen as subjects.

The isochromatic plate is here again a necessity, of course, but in this work the fast one will be found to be the best one to use, as it gives us more speed, and speed is a great object in out-door flower photography. When possible, the use of the color screen is advantageous, but this increases the length of exposure to such an extent that I would not advise any one to attempt it except upon

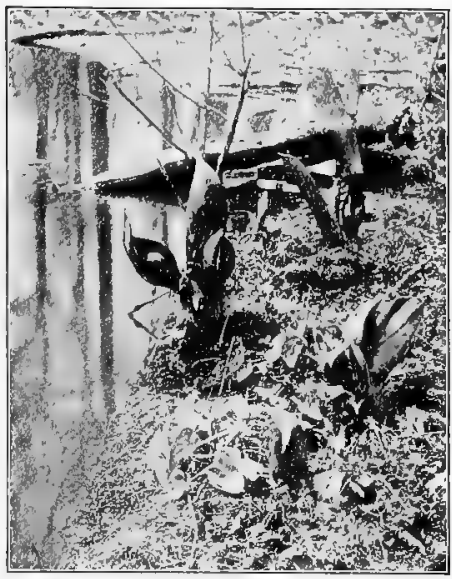

Young Skunk Cabbage. a very still day; for nothing is more exasperating than to feel a breath of air steal up and watch it sway your subjects about just in the midst of an exposure, and realize that the plate is irretrievably ruined and that you might as well take it out and try another one. When the day is still enough to allow the use of the slow plates, so much the better, for they will give the best results. 


\section{Photography for the Sportsman Naturalist}

The long-focus camera with a lens of a good focal length must be used, and the short tripod, spoken of in the chapter on photographing nests, is a very convenient accessory for photographing the flowers that grow close to the ground, for it is not well to look directly downward upon them.

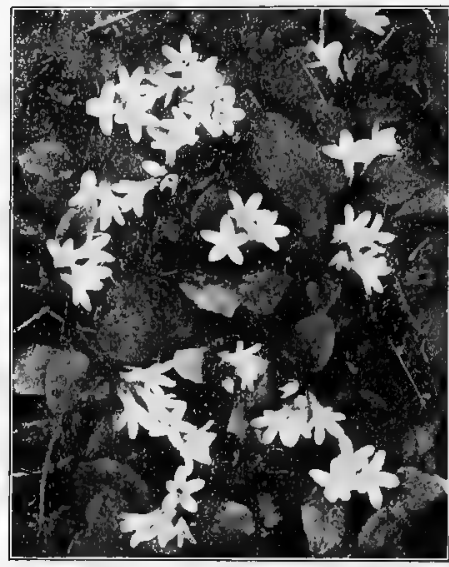

Trailing Arbutus.

In this work the swingback is a very necessary adjunct to the camera, for by its use much of the foreground and background can be brought into clearer focus, especially when the camera is tilted downward, which will be necessary in most cases. Any grasses or leaves that obtrude between the flowers and the camera should be removed, but the plant that is to be photographed should never be touched; for the value of the picture lies in the fact that it is an exact representation of the plant as it grows, and to change its position in any way would be liable to spoil this truthfulness.

The focussing should be done on the flower or flowers of the group that are nearest to the camera, and the rest brought into sharp focus, 


\section{Photographing Wild Flowers}

after doing this as much as possible by the use of the swing-back, by stopping down the lens. It will sometimes be found necessary to stop it down, nearly if not quite to its smallest opening. This, of course, will necessitate a long exposure,

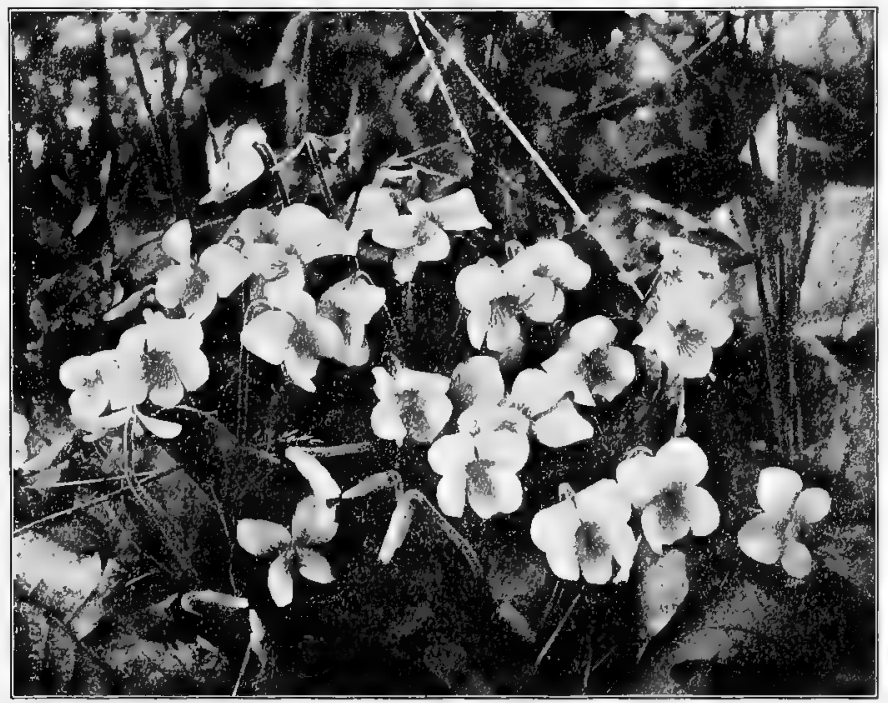

Common Furple Violets.

and we must take our chances that the wind will not move the flowers during it, for every flower of the group should always be in perfectly sharp focus, and also as much of the surroundings as it is possible to have. It can readily be seen that a day upon which there is any wind is a poor one for this work, and those flowers whose 


\section{Pbotograpby for the Sportsman Naturalist}

growth is not particularly sturdy, had best not be attempted except on an absolutely calm day.

Flowers should never be photographed in the bright sunlight, for the glaring light of the sun causes too contrasty a picture with a consequent loss of much of the delicate detail that helps to make it beautiful. If they are not already growing in the shade, then they must be shaded during the exposure, and care must be taken that this shade extends over the entire field covered by the lens; otherwise, with a normal exposure for the shaded parts, that part not shaded will be overexposed.

Never attempt to make the image so big that it will occupy too much of the plate. It must be large enough to show distinctly in detail, but small enough to allow its surroundings to show plainly and sufficiently for one to tell at a glance in just what kind of a situation it was growing. If you attempt to photograph it life size, unless the flower is a very small one, you will find that the image will not only be considerably distorted, owing to the foreshortened view which you must take of the plant, but that it will be almost impossible to get any of the background or surroundings in focus, and, consequently, much of the value and beauty of your picture will be lost.

In this line of work there are many chances for 


\section{Photograpbing Wild Flowers $\quad 265$}

beautiful effects. A field of blue flag makes a picture that may always be admired, as does also a field or group of wild carrots or daisies. Ferns are most excellent subjects, and, from the softness and grace of their outline and the masses in which

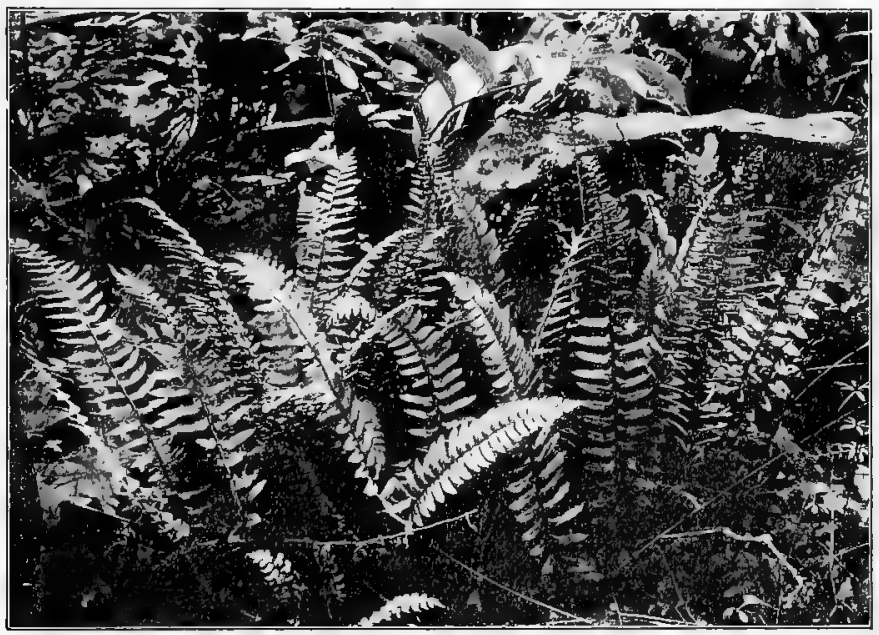

Bank of Christmas Ferns.

they grow, they lend themselves most admirably to the making of artistic pictures.

The flower photographer who would make a really beautiful and valuable collection of negatives cannot afford to pass by anything, not even the meanest and lowliest of the "weeds." I have photographed flowers on the edges of roadways, where I had first to shake the dust from them, 


\section{Pbotograpby for the Sportsman Naturalist}

because it happened to be the best group of that flower which I had seen. I have photographed them in swamps, standing to my knees in water. I have photographed them in ponds and creeks, where I had to do my focussing from a boat and stand my tripod in the water, lengthening the legs so that they could reach bottom. I have photographed them in the deepest, darkest woods,

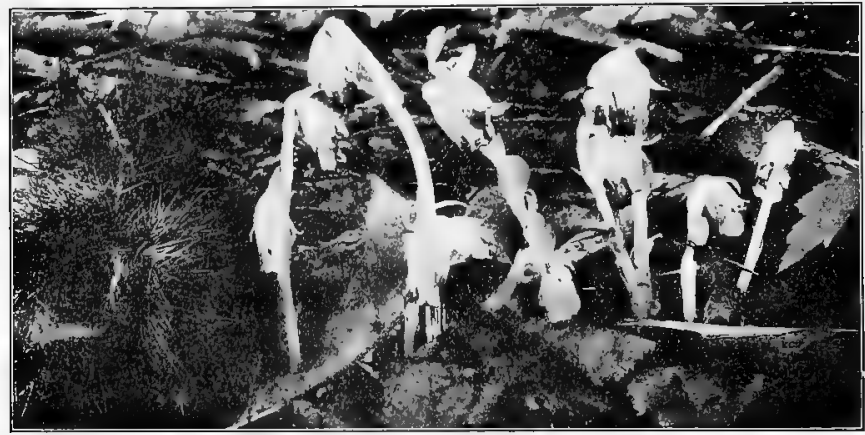

Indian Pipes.

in fields, salt marshes, dry woodlands, in fact everywhere; but I have never yet passed by a flower because of its insignificance, and I have found that some of those that appeared, at first sight, to have very few artistic possibilities, made some of the best pictures.

If we are working to get together a collection of flower negatives that will have value, we should photograph everything in plant life, and not only 


\section{Photograpbing Wild Flowers $\quad 267$}

singly, but in groups. We should photograph the flowers that grow in colonies, showing them thus; and we should photograph individual specimens at different times, showing the manner of their growth and condition at the various stages.

All of these things are of interest and scientific value, and we should never consider time wasted that is spent in obtaining the best possible results along these lines. 


\section{CHAPTER XV}

PHOTOGRAPHING TREES, FUNGI, ETC.

THE photography of trees is a delightful pastime and can be accomplished along much the same lines as flower photography; in fact, the two pursuits are almost inseparable, and may be worked together with ease and to our advantage, for they intermingle. Some of the most beautiful flowers grow upon trees, and, in order to show them in their natural position, obviously the tree must be taken into consideration; and so the photographing of trees must be closely connected with outdoor flower work.

There is much to be gained by a study of tree forms, and more especially twig and branch forms, in connection with their decorative value. There is more that can be done in the way of decorative photography with a blossom-covered branch, if we know how to use it, than with any other one thing, and even the bare branches themselves must not be despised, for they have much of beauty in them.

Many photographers complain that in the winter there is nothing that can be done along their lines, but it need not be so with the photographer who 


\section{Pbotograpbing Trees, Fungi, etc. $\quad 269$}

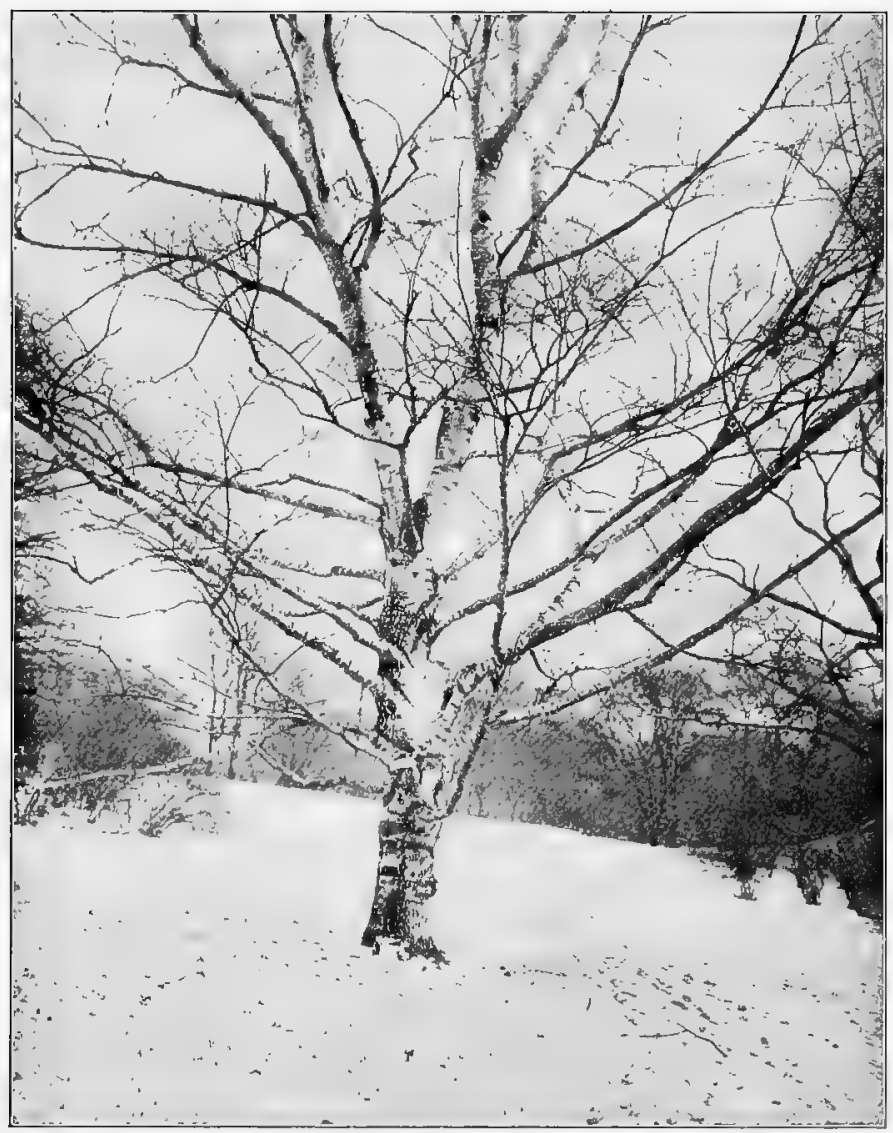

White Birch in Winter.

realizes the beauty and individuality of the trees and shrubs in their leafless condition, and I am not alone in the opinion that the winter garb of the trees is by far the most interesting. 


\section{Pbotograpby for the Sportsman Naturalist}

A most instructive series of photographs can be made by photographing the tree, not only in its summer and winter garb, and this proves more interesting when done with the same tree, but

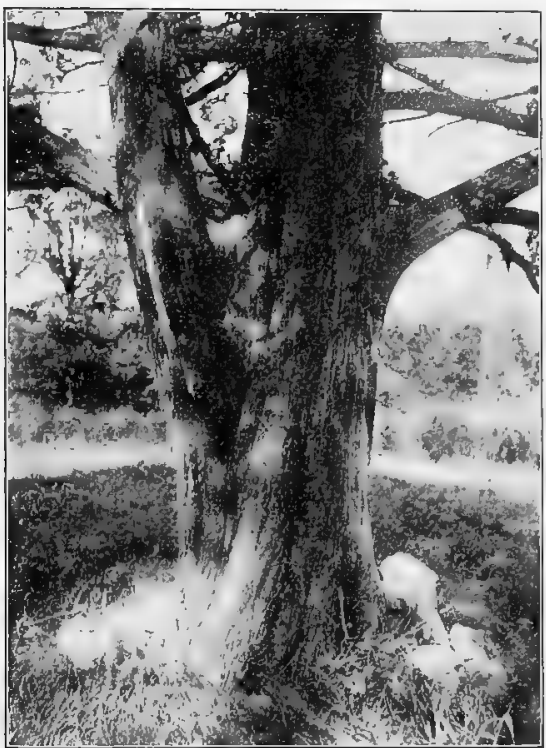

Trunk of Red Cedar.

also its trunk at close range, showing detail of the bark, and the leaf-buds, flowers, fruit, and leaves, as nearly life size as possible. These latter should be done indoors and more properly come under the head of the preceding chapter than this. In photographing the entire tree, either in summer or winter, we should always select one that is entirely typical and well branched, not one that is in any way misshapen, unless this is done for some particular purpose. Also, it should be a tree that stands well out from its fellows, so that it may show in the photograph without any detracting features. 


\section{Photographing Trees, Fungi, etc.}

In summer-tree photography, the main trouble is again, as with the flowers, the wind; for when one can feel not the slightest zephyr from his station on the ground there seems to be always enough air stirring in the upper currents to cause the topmost twigs and branches to sway. It is worth while noting that after a sharp blow of two or three minutes' duration there is almost always a lull, and, if we are on the constant lookout, we may catch the tree, during this small period, when the leaves are sufficiently still for the short time necessary for the exposure.

This question of exposure is again entirely dependent upon many things, principally the light; but usually, with a near-by tree, a quarter of a second is amply sufficient unless we are using the ray filter, which is never necessary in this work. Of course, we will be forced on occasions to stop down our lens somewhat, in order to get the whole tree in sharp focus, and we naturally must take this into consideration when judging the length of exposure to be given. Certainly it is always best to have an accurately timed exposure; but here, as with the flowers, it is better to err on the side of over than under exposure.

The work should be done either in the early morning or late afternoon, never in the middle of the day, for the sun directly overhead gives a very poor light for this work. We must remember 
272 Pbotograpby for the Sportsman Naturalist

that, in order to get all the detail in the foliage that is possible, the light must be falling divectly into it, not striking it from the side; and, also, that a photograph taken directly against the source

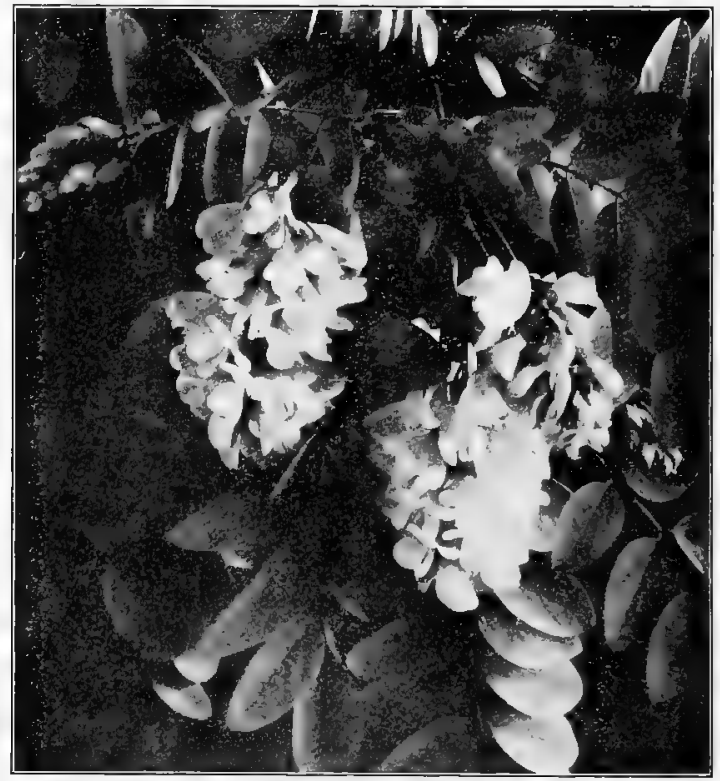

Locust Blossoms.

of light shows nothing of the foliage but a mass of black, no matter what length of exposure may be given in the attempt to overcome this. So we must always have the sun at our back in order to obtain good results, and the nearer it is to the horizon the better, for then there is little chance 
of any deep masses of shadow in the foliage. The very best pictures of trees can be obtained on days when the sun is slightly obscured, and should there be light clouds in the sky it is always best to wait until one crosses the sun before making the exposure. The light then is sufficiently intense for all purposes and it will give no hard contrasts.

We must use the non-halation plate, for that is the only one that will reproduce perfectly the delicate outline of the upper branches and prevent the blurring of halation, caused by the bright background of sky, which is always a disagreeable feature of this kind of a negative made on the ordinary plate. If we had rather do it, we can "back" an ordinary plate which gives it the nonhalation properties. This consists in painting the back of the plate with a preparation that is sold by all photographic dealers. This "backing" must, of course, be done in the dark room and washed off again, before development, in clean water. Care must be exercised, when putting it on, not to allow it to run over the edges of the plate on to the film side. Many people prefer these backed plates to the regular non-halation, but they are considerable trouble, and I cannot see that they give any better results.

It is important, however, that we use one of these two plates, as one can soon discover for 
274 Pbotography for the Sportsman Naturalist

himself if he will make two negatives of the same tree, one on the ordinary plate without the "backing" and the other on the non-halation

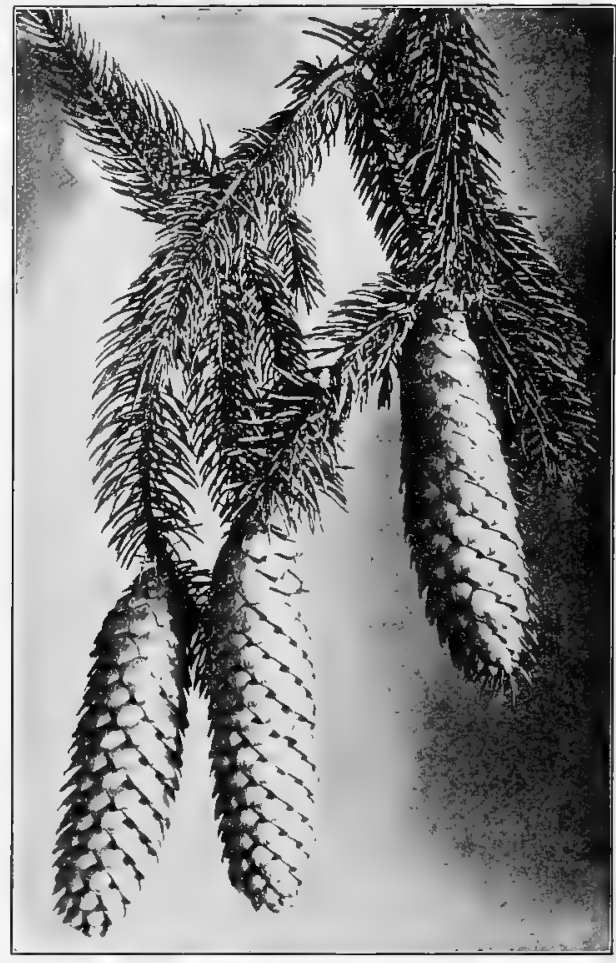

Spruce Cones.

or the backed plate. If we use the plate combining the qualities of non-halation with those of orthochromatism, we will obtain the best possible results. 
The camera should be the long-focus type with both the rising and falling front and the swingback. We will find both of these adjuncts necessary, in order to get the full image of the tree on the plate and to keep that image from having the appearance of falling over, which will happen when the camera is tilted upward without the compensating aid of the swing-back.

As for the lens, the one we use for flower work will answer every purpose, although the best results can probably be obtained by the use of a wide angle, as this lens will give more prominence to the main object, and allow the rest of the background to diminish in size and importance without being too much out of focus.

Naturally, a large camera is best for this work, and I should advise nothing smaller than a six and a half by eight and a half, and an eight by ten is even better. The smaller sizes show the detail so very minute, that the pictures made by them are of very little value either pictorially or scientifically.

In photographing the flowers, fruit, leaves, etc., the work is, of course, similar to that with the cut flowers, and so the directions given in the last chapter can be followed here. In photographing the trunk we should get near enough to it to show clearly the detail of the bark, but not so near as to entirely exclude the first branches of the tree. 
276 Pbotograpby for the Sportsman Naturalist

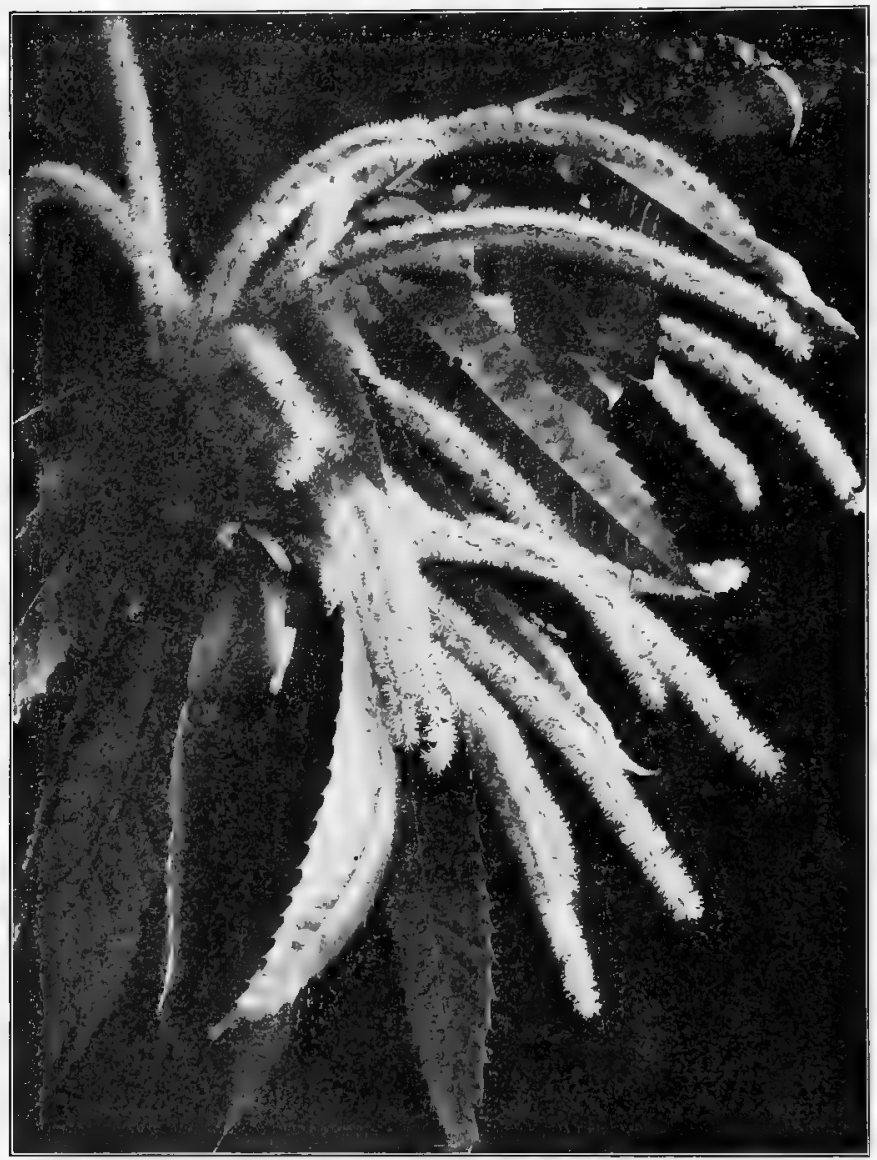

Blossoms of American Chestnut.

No patches of sunshine should fall through the foliage upon the trunk, for this gives a very disagreeable spotty appearance to the picture. 
In photographing the fungi we come to the easiest branch of all nature work, and, for that very reason, the most satisfactory so far as results are concerned; for, if we do not get a good negative with every exposure, then it is our own fault.

There is a great diversity of form in the Fungi family, from the mould on our bread and cheese to the large "toadstools," some of them over a foot in breadth. In this family, however, are many members whose forms, markings, and coloring are exceedingly striking and beautiful, and exquisite photographs can be made of them with a little care.

The Clavarias, or coral fungi, make most excellent subjects from a point of beauty, as do also many of the genus Pleurotus, and there are great numbers of others, notably the Amanitas, whose beauty must not, nor can it be, overlooked. The hunt for the different species is most enjoyable, taking one, as it does, to those parts of the woods that would never be visited by him otherwise, for many of them grow in grewsome places. From this fact the "toadstools," as the larger growths are commonly called, have long been considered as a kind of uncanny growth, all of them poisonous except the species ordinarily used as an article of food and which, by most people, is the only one given the name of "mushroom." In point of fact this distinction between the "mushrooms" and "toadstools" has no scientific basis. They are all one 
278 Photograpby for the Sportsman Naturalist

or the other as you like, and many of the so-called "toadstools" are not only edible, but much more delicious in taste than the ones ordinarily eaten. It is better, however, that any one not well acquainted with them should stick to the well-known species

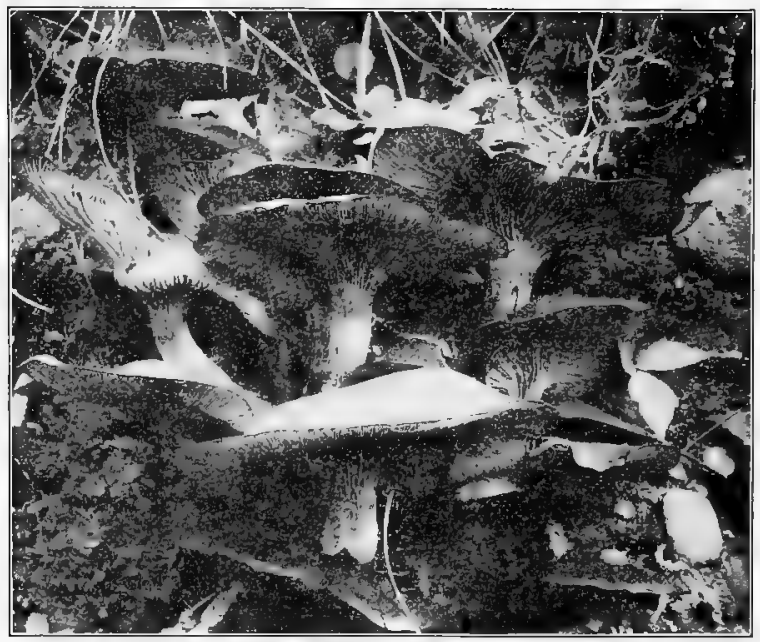

Mushrooms.

Photographed as growing.

when gathering them for the table, for many of them do secrete a virulent poison, and it is dangerous to experiment with them.

Fungi grow not only in the grewsome, dank woods, however, but are to be found everywhere; and the mushroom hunter must look for them in every imaginable locality. Moreover, if we would 


\section{Pbotograpbing Trees, Fungi, etc.}

make a good series of their photographs, we must be constantly on the outlook for them, for they are extremely short-lived, some even springing up, attaining their full growth, and sinking down into a mass of decay, all in the course of a few hours.

The early morning is the best time to look for them, for then they are in the most perfect condition and, if picked, will remain fresh for some time. If we wish to carry them home with us in order to photograph them indoors, this may be done; but they must be removed with a goodly quantity of the earth which surrounds them, or the bark of the tree, or whatever other substance they may be attached to, so that the true nature of their growth and surroundings may be accurately shown. It is not at all necessary or advisable, however, to remove them from their natural situation, for they are not easily affected by the wind, and exposures of any length of time may be made upon them, as they stand, without any danger of their moving.

The orthochromatic plate should be used, and, with the more highly colored ones, it is well also to use the color screen. The short tripod is necessary, or we can sometimes get even better results by placing the camera flat on the ground; but, in doing this, care must naturally be used not to move it after the focus has been made.

It is sometimes a good idea to lay one of the 


\section{So Photography for the Sportsman Naturalist}

mushrooms of the group we are photographing flat on the ground, as if it had fallen over, so that its under side may be shown, for it is the gills of a mushroom that often aid materially in its identification, and so it is better, when possible, to have them show distinctly.

Some object, such as an acorn, a leaf, or anything of the sort that would naturally be found on the ground, should be placed by the side of them, so as to give some accurate idea of their size.

If we are going into the purely scientific side of this branch of photography, then we should also make sectional views of them, in order to show the inner construction and the manner in which the gills are attached to the cap; but I do not think that many of my readers will care to do this.

As in the outdoor photography of flowers, the image of the mushroom, or whatever variety of fungi you are photographing, should not be made so large that its surroundings will not show clearly, for it is important that the picture should show the nature of the situation in which the specimen was found.

Above all, learn your fungi before you photograph them; for a picture of a mushroom will not alone determine its species and it is important that you should know each species that you photograph and label the picture correctly, otherwise it will have no scientific value. 


\section{CHAPTER XVI}

\section{PHOTOGRAPHING IN THE ZOOS}

While the photographing of wild animals in captivity cannot be compared to photographing the same animals in their native haunts so far as pleasure and excitement are concerned, still there is no better place to work for obtaining really excellent pictures of the animals or birds themselves than in a modern, up-to-date zoölogical garden. It is a good place to learn how to photograph the wild things, and I should advise a beginner to first try his hand on the inmates of some Zoo before starting out to do work in the field. By so doing he will learn many things that will be of immense service to him, and even the small Zoo in Central Park is a good place to commence to learn these things. It must not be imagined, however, that all is plain sailing even in the Zoos, for if you set out with the idea that you can snap right and left and get a picture at every snap, you will be most wofully disappointed.

The Bronx Zoölogical Park in New York and the Washington National Zoo are two ideal 


\section{Pbotograpby for the Sportsman Naturalist}

places for obtaining most excellent pictures, and yet even in these places the difficulties are many.

If one does not object to having the bars of the cage or fence showing between his subject and himself, then things are comparatively plain sailing; but to obtain really first-class pictures that will show the animal in characteristic attitudes without the introduction of any disturbing features that prove it to be in captivity, is not so easy, as any one will soon learn when he tries it.

One of the great difficulties is that the animals are usually too tame and, either from curiosity or a wish to make friends with you, will come close to the bars the instant you approach and will stay there no matter how much you attempt to drive them away. I remember once trying to obtain the photograph of the head only of a full-grown lion cub in the Bronx Zoo, which I wished for a particular purpose. There were four of them in the cage, and as I approached they were all lying down, two at just the right distance from the bars to enable me to get the picture the exact size I wanted. As I came up to the cage, however, and prepared to make an exposure, they all jumped to their feet and crowded close to the bars of the cage where I stood. I think this was actuated both by curiosity and friendship, for they tried to make me 


\section{Pbotograpbing in the Zoos 283}

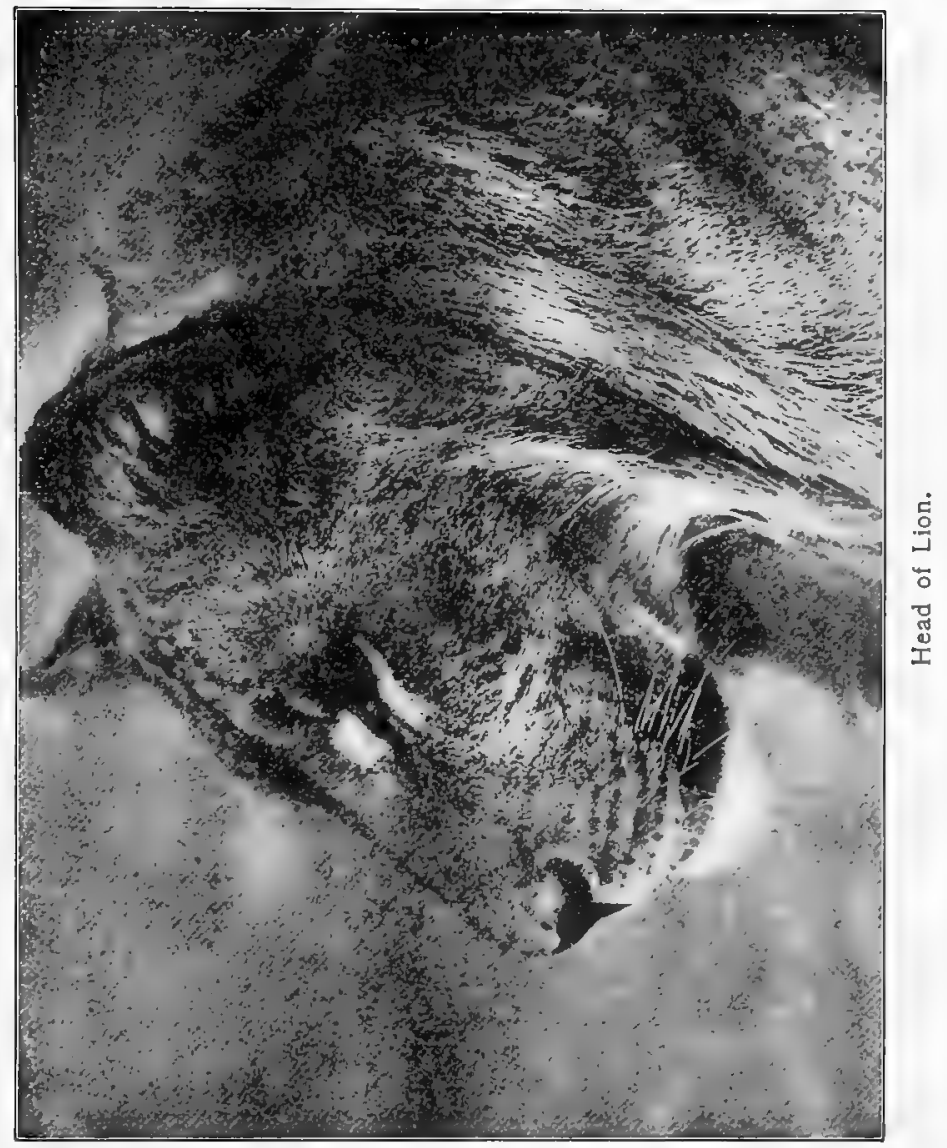




\section{Photography for the Sportsman Naturalist}

play with them and at the same time they seemed to be somewhat in doubt about the camera. It took me over an hour to get any one of them to move far enough away from the bars to enable me to make the shot that I wanted, and that was the only one that I obtained. Luckily it turned out fairly well, so I was not disappointed.

The wolves, too, acted in much the same manner, insisting on having their heads scratched or sticking their noses through the bars to lick my hand. Going inside the cage does not mend matters much, as they crowd around so closely as to make it impossible to do anything.

The animals that are more wild are easier subjects, for, even though they may refuse to come near enough for you to use an ordinary lens, still fine pictures may be obtained with the telephoto, and even if the ordinary lens is used and the resulting image very small it can always be enlarged, provided it is sharp enough in detail. But the animals that insist on coming close to the bars to be petted, and especially those that try to examine the camera by sticking their paws through the bars and making dabs at it, are the ones that try your patience.

The use of a tripod camera in the Zoos is seldom necessary, except when using a telephoto lens, and is most disheartening; and I should never advise its use. With the reflex or the twin lens 


\section{Photograpbing in the Zoos}

very excellent results can be obtained, and even with a kodak, provided the lens is a fast one, some good work may be done.

Most of my work in the Zoos has been done with a five by seven reflex camera, fitted with a very fast lens made to cover an eight by ten plate. By the use of so large a lens I obtain greater illumination and greater length of focus, allowing me to obtain larger images of my subjects than I could with a shorter focus lens. With this outfit I have taken pictures practically indoors with the tenth of a second exposure, that, while being somewhat underexposed, were, by careful development, made into good printing negatives. Of course when working in the bright sunlight such a rapid lens is unnecessary, but it can always be stopped down and will then give greater definition and depth of field. Moreover, in work in the Zoos one can never tell under what conditions of lighting he will be forced to take his pictures, and it is always well to be supplied with a lens that will allow you the maximum speed of exposure.

The three most essential points to be considered are: first, the pose of the animal, one characteristic of the species being of the most importance; second, the surroundings, which should always be natural and with no disturbing element, such as a fence or other sign of civilization, in the picture, if this can be avoided; and third, the 


\section{Photography for the Sportsman Naturalist}

light. This is of considerable importance, for the careful distribution of light and shade means much to the success of the picture. Very strong sunlight should usually be avoided, especially with very light-colored subjects. White birds or animals are best photographed against the light, or at least in a

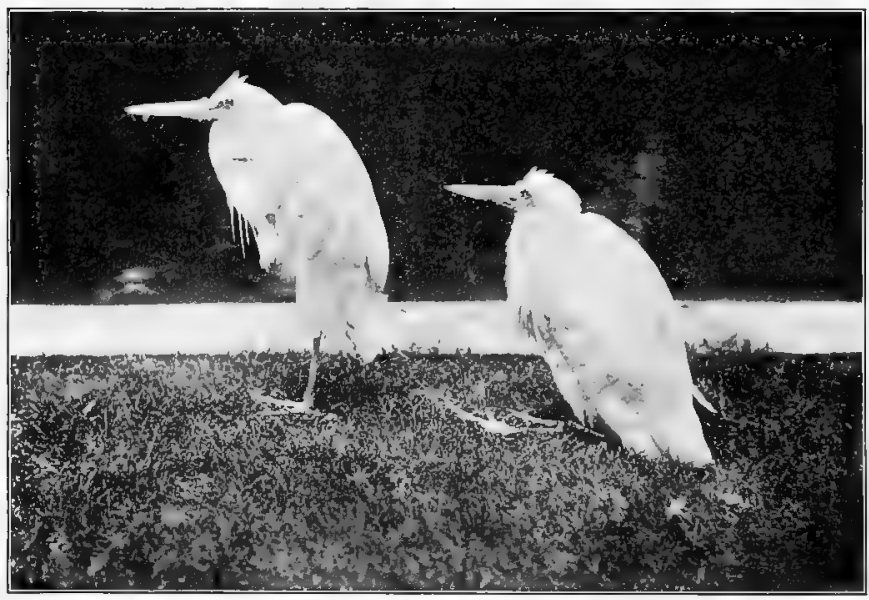

Snowy Herons.

very much diffused light, for in the direct rays of the sun much of the delicate details of their plumage is lost, and often they will even reflect the light to such an extent as to cause halation on the plate and a consequent poor negative. Dark birds or animals naturally require all the light directly upon them that is possible. So it is always well, if we would obtain really excellent results, to care- 


\section{Pbotographing in the Zoos}

fully study all the details. One can usually take his time when photographing the wild things in captivity, and so we can afford to be much more careful in our selection of pose, surroundings, and lighting than when working in the open. So it is that for really good pictures of the animals themselves there is no place where better work can be done than in the Zoos.

Should we find it impossible to eliminate all the disturbing elements from the picture, we can often get rid of them by careful manipulation of the negatives after development. The knowledge of how to do this most effectively will come as we become better acquainted with the different processes of photography. If no other method will serve to do this properly, we can always gain our end by double printing, which consists of blocking out the main object on the original plate and printing it with the background from another negative. This often gives very pleasing results, but is rather a delicate process and must be done carefully in order to keep the correct proportion of things and to avoid having the animal overlap the background or vice versa.

The bars of the fence or cage which are between you and your subject need never be a serious menace, as you can always hold your camera close enough to them with the lens pointing between them to keep them from showing in the picture. 


\section{Photograpby for the Sportsman Naturalist}

Work on domestic animals, too, is not without its full quota of pleasure and interest as well as benefit. It is remarkable how few really good

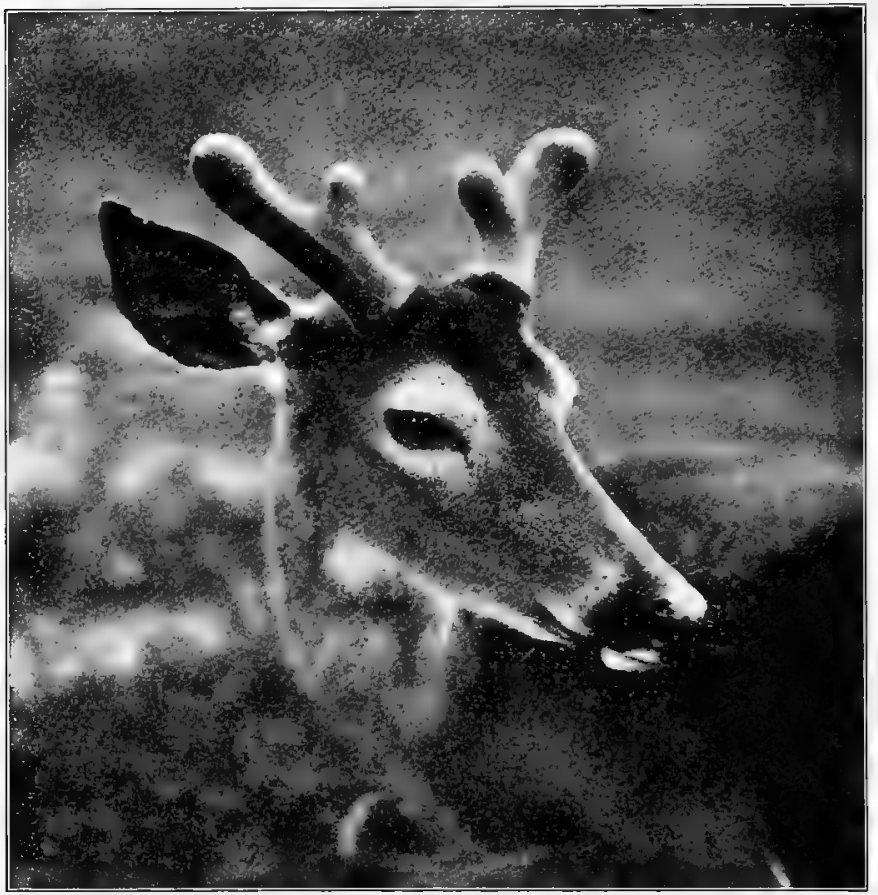

Head of White-tailed Deer.

pictures of our domestic animals there are obtainable, as I have had occasion to find out. One is apt to think this work too easy, but let me assure you that it is not quite so easy as it would seem, and a good series of pictures of our cattle, horses, 
sheep, dogs, cats, chickens, etc., would be a valuable addition to any one's collection of pictures of animal life.

One cannot always afford the time to take long trips afield after the wild animals, but there is always time for one to spend a day now and then among the dumb inhabitants of a farm or in a zoölogical park, and should he work carefully, with patience and some forethought, he can obtain long series of not only entertaining and beautiful but really valuable pictures.

Cats and kittens make most delightful subjects, for their attitudes are innumerable and in every one they are interesting. Dogs also make interesting subjects, and are not always easy to photograph, for they are so constantly on the move that it is often difficult to snap them. Here again the reflex camera is invaluable, for it is almost impossible to do any good work on these animals with a tripod outfit.

One never realizes what remarkable and astonishing positions the feet of a horse, in full trotting or running action, assume, until he has seen a picture of one taken under such conditions. To take such a photograph, naturally, necessitates the use of the strongest light, the fastest plate, and the quickest shutter, for, with a horse at full speed, an exposure of $\frac{1}{1000}$ part of a second is necessary in order to entirely stop motion, or, in 
290 Photograpby for the Sportsman Naturalist

other words, that the image may not be blurred. So here the reflex is an absolute necessity. These negatives must be treated for under exposure, as such they will undoubtedly be, and may even require intensification afterward; but if carefully

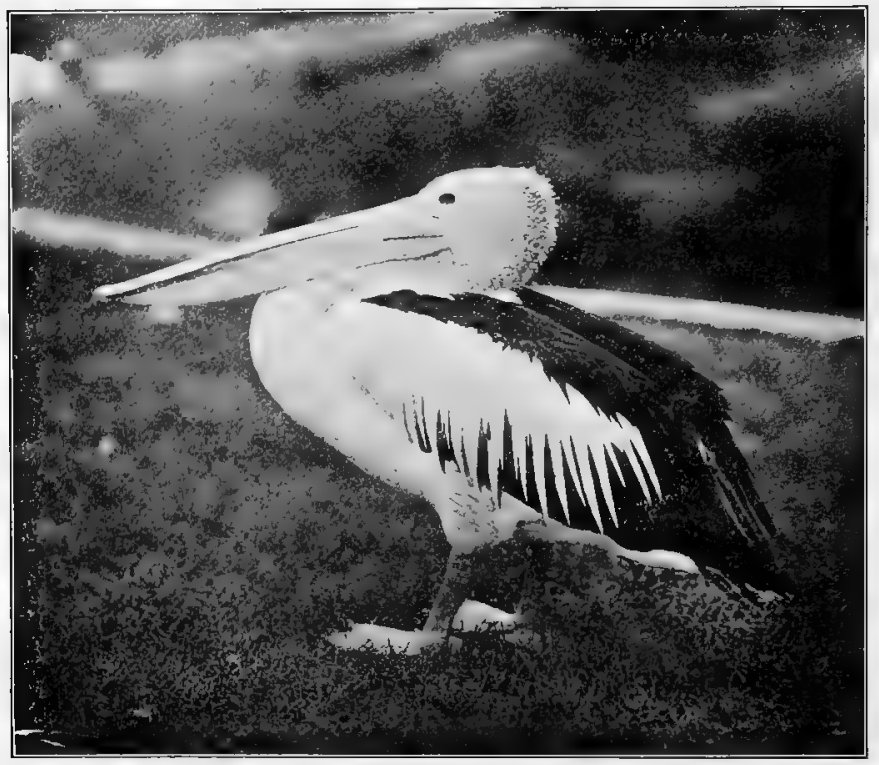

White Pelican.

developed, in a stand bath, they can be made of excellent printing quality and make exceedingly interesting studies.

Cows, swine, the domestic fowl, donkeys and mules, and the gentle sheep, all make excellent subjects for the naturalist photographer, although 
I regret to say that the last have already been somewhat overdone in the so-called "pictorial" efforts which are foisted upon an unsuspecting and overgenerous public by some of our "artist photographers." Good photographs of them are, however, not so common.

I have made this chapter a comparatively short one, for many of my readers may think that it does not rightly belong in a book which treats of the photography of nature. Their idea is an entirely erroneous one, however, for a photograph of any animal, whether it be wild or tame, showing it in any natural and characteristic attitude, is of value, and our familiarity with the subjects should not lead us into contempt for them from a photographic standpoint. I am, if anything, a nature photographer, doing that to the almost exclusion of other work, and yet I do not consider it beneath my dignity to photograph the domestic animals, and I can find great pleasure and profit from a day spent with my camera in the Zoo. If many of the men who would enter nature work would first try themselves out, so to speak, on the animals that are comparatively easy to photograph, they would find themselves better fitted for the work which they have before them. 


\section{CHAPTER XVII}

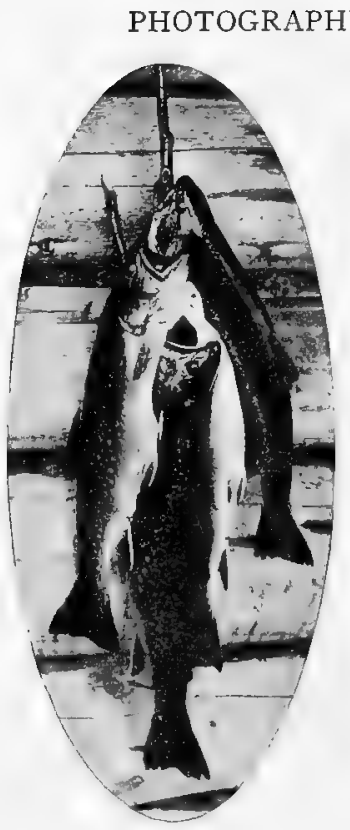

Trophies.

For the sportsman who wishes to take a camera into the woods with him for the purpose of obtaining simply pleasing records, in the way of photographs, of the camp life and incidents of the chase, I will say a few words.

There is much that can be done in the woods with a camera, many pictures of both beauty and interest that can be taken, by any one who does not care to spend the time, patience, and energy necessary to the photographing of the wild life. A series Photograph by F. M. Hale. of pictures of the life in the camp and on the trail, of the quarry taken and the manner of taking it, are easy to obtain and prove most interesting trophies, and which can be looked at again and again with much pleasure 


\section{Pbotograpby in Camp and Woods 293}

both to yourself and your friends during the long days between times when you must live over in retrospection the pleasures of the days and nights spent in the woods.

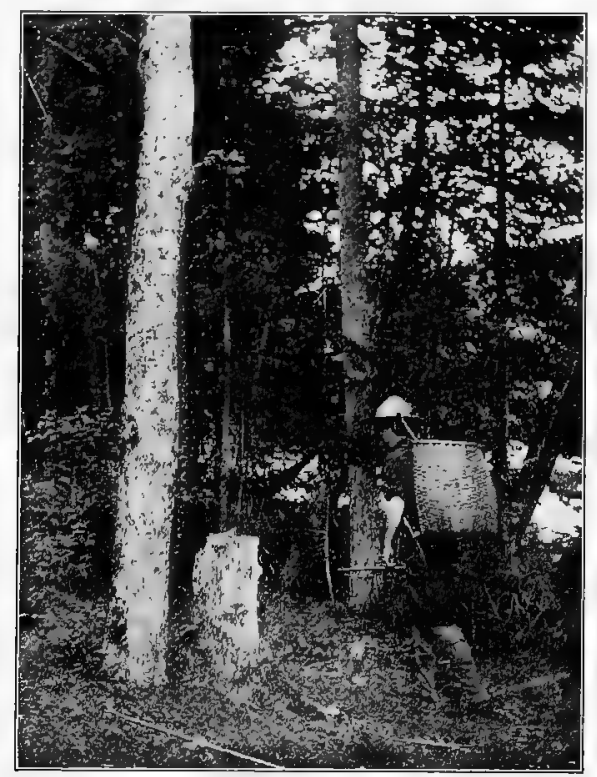

Hitting the Trail.

Photograph by S. D. Dixon.

Moreover, the apparatus necessary to obtain these pictures need not be either extensive or expensive, and the knowledge required is merely that of knowing how to use your camera.

The style and size of the camera to be used must depend entirely upon the desires of the 
294 Photograpby for the Sportsman Naturalist

sportsman. I should advise the use of one not larger than four by five, as this size is more easily handled, is much lighter, and takes up less room in the pack than any larger size and, what is often well to take into consideration, is much less costly, both in the original expense and in the making of the pictures. A four by five makes a most convenient size of picture for keeping in an album, and should you wish to have any particular picture somewhat larger for framing or other purpose, it can very easily be enlarged to any desired size with no loss of detail or beauty, provided the original is properly taken. On the other hand, I should not advise the use of anything smaller than this, for the resulting pictures are so very small if, for instance, one of the smaller pocket kodaks is used, that, while it is all sharp and clear, the detail is so minute as to require a magnifying glass to properly see the picture, and when it is enlarged to a respectable size it is apt to be more or less fuzzy and indistinct.

While for work on animals or birds, flowers, etc., I always, invariably, advocate the use of plates, in this kind of photography I think that films are just as good, - if not, indeed, preferable. They have the advantages over plates of being less bulky, much lighter, not breakable, and much more easily handled, and, when the roll films or the film pack are used, they require no dark room for 


\section{Pbotography in Camp and Woods}

their insertion in the camera or removal therefrom. Moreover, since the advent of the noncurling, orthochromatic films, about the only thing that can be said against them is that they have not quite the fineness of grain of a plate; but for ordinary work they are, in every respect, the equal of a plate except that they are somewhat more expensive.

Of course, if one wishes to spend the amount necessary, I should advise the use of a tripod camera with a high-grade lens. The lens need not be one of the very fastest; indeed, this is not advisable, for here depth of field is preferable to great speed and therefore a lens working at about F.6.5 is plenty fast enough. If you do not care to make much of an outlay on your outfit, then there is no better camera made for this purpose than one of the four by five folding kodaks made by the Eastman Company. It can be used either on a tripod, or other stationary stand, for time exposures or in the hand for snap shots, and while it cannot be used to photograph objects nearer than about six feet, still this is no serious drawback, as it is seldom that one will care to make so large an image of anything. The lens that is sold with the camera is a good one for ordinary work, though, if we should wish for one with greater speed, any make can be fitted to it. 


\section{Photograpby for the Sportsman Naturalist}

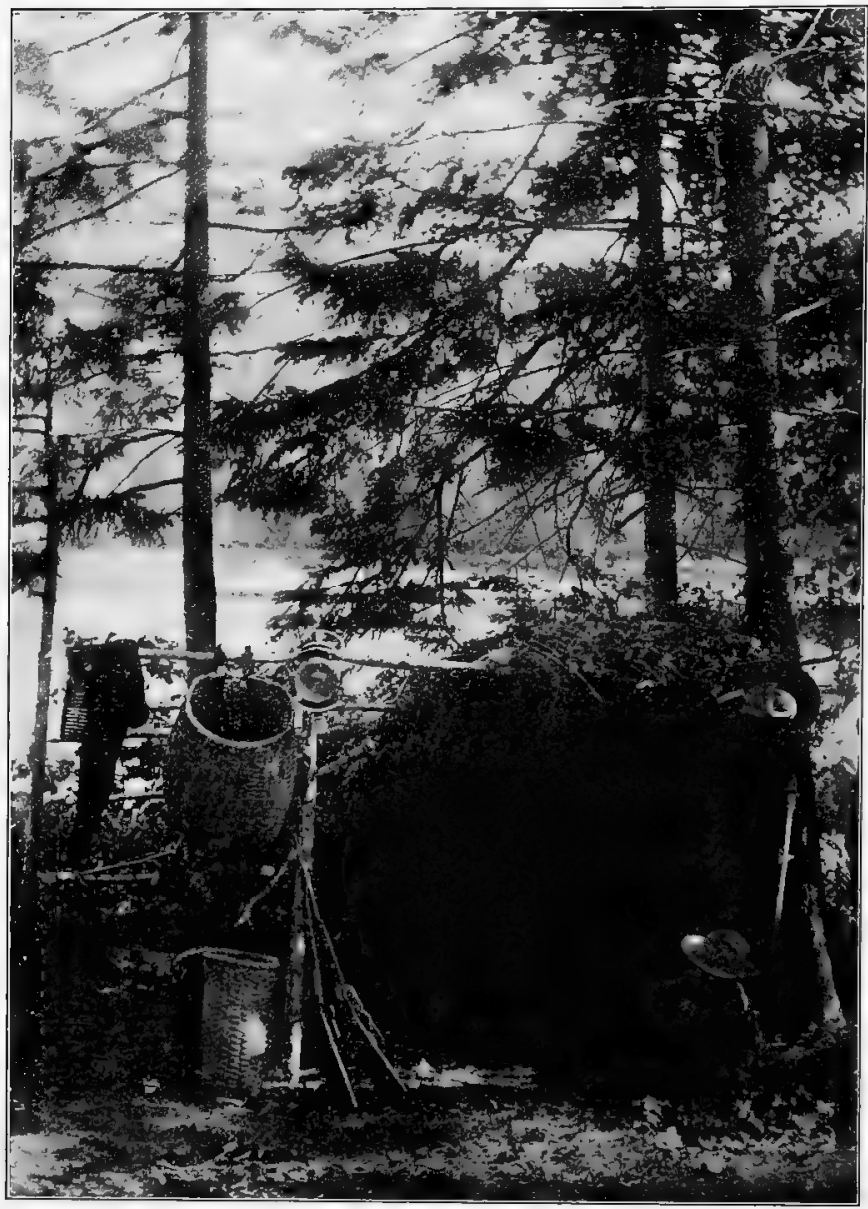

A Temporary Shack.

Photograph by S, D. Dixon. 


\section{Pbotograpby in Camp and Woods 297}

It is well, if we are to depend upon the focussing scale on these cameras, to test that scale when we first buy one in order to be sure that it registers correctly, else we may find all our results out of focus and fuzzy. This can be readily ascertained by focussing upon a piece of white paper, with heavy black letters printed upon it at the different distances, as marked upon the scale, and noting if the distance at which a sharp

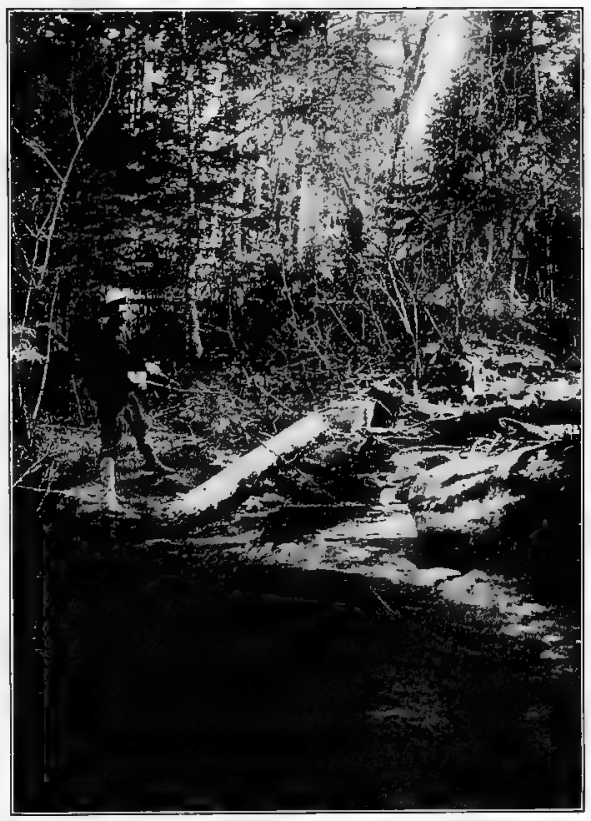

Whipping a Mountain Stream. Photograph by S. D. Dixon. image is obtained corresponds to the figures upon the scale. These scales are usually carefully tested before leaving the factory, but occasionally one is found that has been put on carelessly and is, in consequence, out of register. Also, if we are intending to rely to any extent upon the view 


\section{Photograpby for the Sportsman Naturalist}

finder, we must be sure that it shows the view exactly as it will appear in the negative. This can be determined by making an exposure and, after development, comparing it with the view as it appears in the finder from exactly the same point from which the negative was taken. By these simple preliminary precautions much future annoyance may be avoided.

If only one camera is to be used, the reflex of course is out of the question; for much of the work will necessarily be done in the shade of the deeper woods, where an instantaneous exposure is impracticable and, therefore, the reflex would be useless.

Successful photography in the woods is not entirely an easy matter, as the play of light and shadow makes exposures uncertain. This matter of exposure is one that it is extremely difficult to give any definite advice about, as it so entirely depends upon the varying conditions of light. There are many exposure metres upon the market designed to aid the photographer in this respect, but none of them that I know of are infallible. In a little book, published by the Eastman Company, Mr. Frank M. Steadman describes a system by which exposures may be simply approximated with considerable exactness under almost any ordinary circumstances. While this system has been received with some ridicule, it is still most excellent for any ordinary landscape, view, or 


\section{Photograpby in Camp and Woods 299}

interior work, and if the beginner would learn and follow it, he would avoid many failures that are bound to occur when he depends entirely upon his own judgment in the matter of exposures.

One thing we must remember in wood photography: always expose for the deeper shadows and let the high lights take care of themselves. By this I mean give enough exposure to bring out the detail in the places that are the most deeply shaded, and if those parts that are in the strongest light prove to be overexposed, the negative must be doctored either during or after development.

Light in the woods

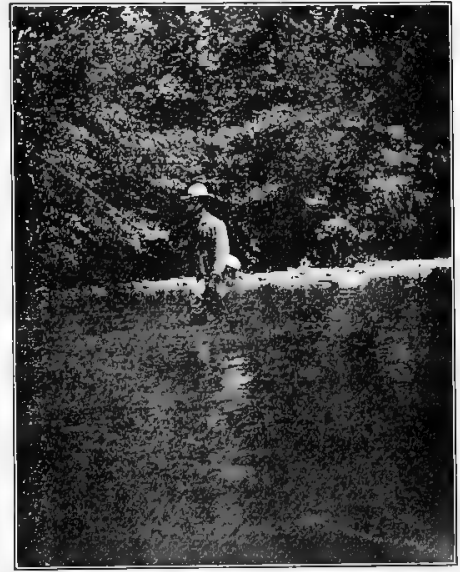

In Quiet Waters.

Photograph by F. M. Hale.

is often deceptive, appearing to be much stronger than it really is, so if you are not certain of the length of exposure that should be given, it is a good rule to always give a little more than you think to be right, for an overexposed plate, if properly treated in development, gives a much better negative than one that is underexposed.

But, after all is said and done, the best advice 
300 Pbotograpby for the Sportsman Naturalist

that can be given is: learn to know your lens under all conditions and then you will make but few errors, and this can only be accomplished by repeatedly experimenting with it.

Of course it must always be remembered that the length of exposure increases in accordance

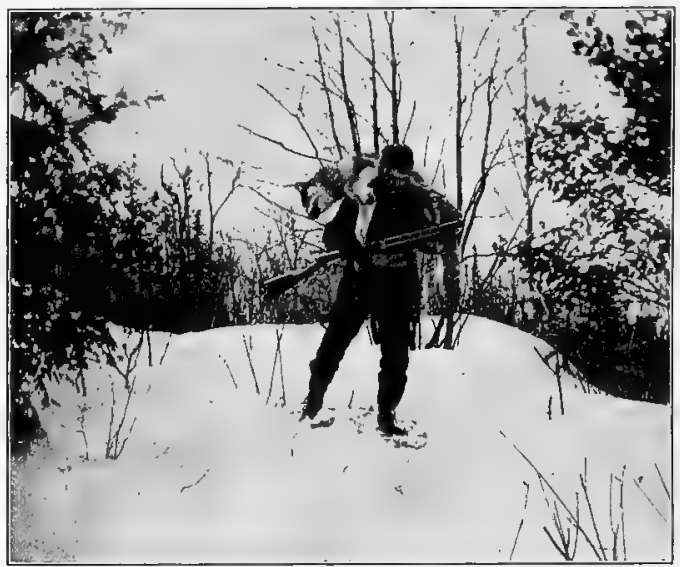

Bringing in the Quarry.

Photograph by F. M. Hale.

with the diminishing in the size of the stop used in the lens, and there are few lenses that can be used at anything but the largest aperture for an instantaneous exposure. And, by the way, never try to take a snap shot in the shadow of the woods, for the result will be worthless from under exposure unless you are using one of the very fastest lenses. 


\section{Pbotograpby in Camp and Woods $30 \mathrm{I}$}

Gray-day pictures often give pleasing results, and sometimes the light, in the open, on a cloudy day, is sufficiently strong for rapid work. In the shadow of the woods, however, on such a day the

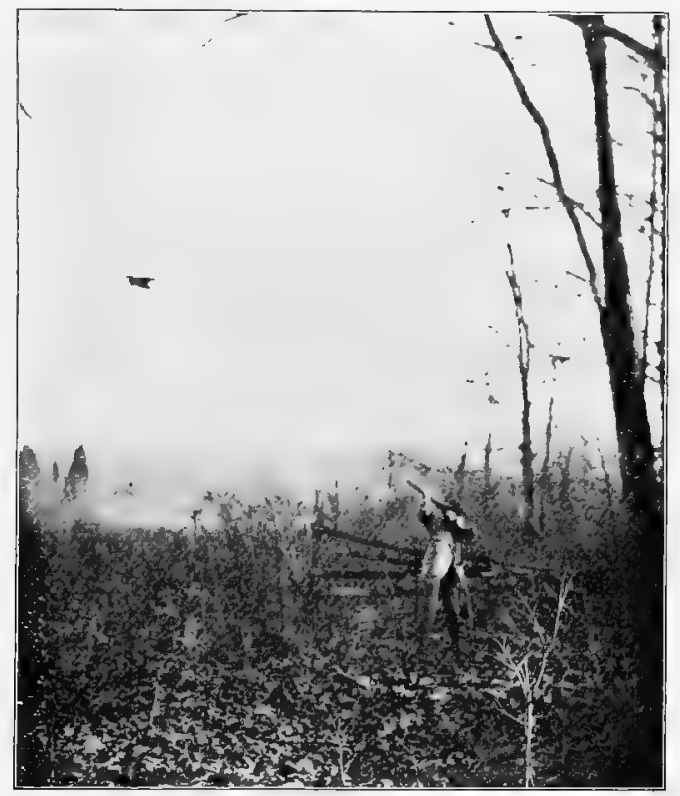

A Fair Shot.

Photograph by F. M. Hale.

light is apt to be very dull, and if we attempt to do any work under such conditions, exposures of at least two or three seconds must be given. It is best, however, to do such work on a bright day, as the play of light and shadow often proves to be one of the chief beauties in a woodland scene. 


\section{Photograpby for the Sportsman Naturalist}

If a portion of sky is included in a picture, always remember that the beauty of that picture will be greatly enhanced if we wait for an opportunity to get some clouds in the sky, for a glaring white sky invariably spoils what might otherwise be a very pleasing effect.

Many otherwise good woodland views are often marred, if not entirely ruined, by improper lighting. It is the generally preconceived iclea of most beginners that the sun should be shining directly in the direction that the picture is taken and that the angle of the sun's rays and the point of sight through the lens should be, at the most, but a few degrees apart. As a matter of fact this is all entirely wrong, and the pictures thus obtained are never so satisfactory as they might be.

Depth of prospective is best shown through the medium of shading, and this is best obtained by so placing the camera as to bring the sun from forty-five to sixty degrees from the point of sight. This causes the shadows of the trees to fall at right angles to or slightly pointing toward the camera and gives a realistic charm to the picture that can be obtained in no other way. Of course, the middle of the day is a bad time for forest photography, for, the sun being directly overhead, the lighting is exceedingly flat. Early morning or late afternoon, when the shadows are long, is the best time. 


\section{Pbotograpby in Camp and Woods 303}

Most pleasing pictures can frequently be made directly against the sun, but in doing this one must be careful that the sun's direct rays do not enter the lens.

One cannot be too careful in selecting the point of view for a scene of any kind, and it is here that one's artistic ability shows itself. There is a picture in every scene if we but know how to find it, and whether we make good or bad pictures depends entirely upon our artistic judgment.

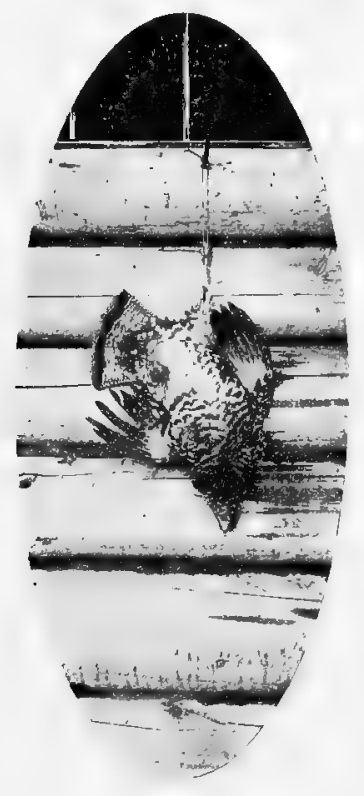

FINIS 



\section{N DEX}

Acetone sulphite, 53 .

Agfa intensifier, 6 I.

Amanitas, genus of fungi, 277 .

Angle of view of lens, see Lens.

Anglewings, 204, 205.

Apparatus for field work -

Ball and socket clamp, 9r.

Camera, 85-86.

Camera stand, 91 .

Changing bag, 89 .

Color screen, Ioo.

Cut film, Ioo, Ior.

Developing tent, 96, 97.

Focussing work, 94, 95 .

General suggestions, 8I-85.

Lens, 91-93.

Minor accessories, 94-96.

Plates, 98-100, I0I.

Quantity and weight, 85 .

Ray filter, 100.

Shutters, 93-94.

Sundries, 97-98.

Tripod, 90.

Aquatic life, photographing of, see Fish and other forms of aquatic life.

Artificial tree trunks, I7I, I73.

Background of picture, 64,65 .

Backus, W. H., quoted as to rattlesnake hunting with camera, 232-235.

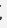

Bath, acid, 53 .

Нуро, 52, 53 .

Beaver, I37.

Birds and young, photographing -

As a pursuit, 160-162.

Best time for, 162-164.

By means of decoys, 182-184.

By means of flash-light, 187 .

By use of artificial tree trunk, I 71,173 .

By use of bait, I84-I 86 .

Effect of fear of man, 164-167.

Nesting site, change of, I75-177.

Obstacles to success, I66-169.

Old birds, I8I, I82, I86, I87, I88.

Quickness always essential, 188.

Scientific value of, I6z.

When young are ready to leave nest, $177^{-1} 80$.

With young birds in nest, 170 , I 7I, I 73-I75.

Birds' nests, photographing -

Arrangement of surroundings, I 40-14 I.

Artistic possibilities, 138-139.

"Cave-dwellers" nests, I 57, 58.

Cliff breeders' nests, 158 .

Exposure, suggestions concerning, I44.

Ground-builders' nests, I42-I46.

Ideal day for, 145 .

In situ, 139 . 
Birds' nests, photographing [continued] -

Mirror, use of, I45, 146.

Near the ground -

Focussing, 148.

Lighting and arrangement, I 47, $148-15 \mathrm{I}$.

Outfit for, I 4I-I 42 .

Placing of camera, I46, I47.

Position of nest, I39-140.

Preservation of nests, 159.

Sandpiper's nest, I42.

Size of image, I 5 I.

Tree-builders' nests -

Opening of, $\mathrm{I}_{5} 6$.

Preliminary arrangements, I 5 I-I 54 .

Removal from site, I 54-156.

Telephoto lens, use of, I 54 .

Blistering, see Bath.

Box tortoise, 241, 242.

Bromide of potassium, 58.

Bronx Zoölogical Park, 28 I.

Buffalo, disæppearance of, 8.

Butterflies, 191, I92-193, 196-202, 204-207.

\section{Camera -}

Basic principles, 29.

Enlarging, 64.

For photographing cut flowers, 254.

For use with telephotographic lens, 7 I.

Hand, in the woods, 293-295, $297,298$.

Long focus, 275 .

"Lying" of, 4 .

Micro-photographic, I90, I9I.

Modern, briefly described, $3 \mathbf{I}$.

"Press the button" type, 32 .
Camera [continued]-

Protection of, I22.

Reflex, 32, 34, I I3, 127, 289, 298.

In insect photography, 202.

In photographing small mammals, I35.

In reptile photography, 236 , 240.

In photographing flying birds, 187.

Selection of, 35 .

Thorough acquaintance with, necessary, 35 .

Tripod, 32, 35, 120, 127 .

Twin lens, description of, 32-34.

See Nature Photography and

Photography.

Camera obscura, invention and development of, $30,3 \mathrm{I}$.

Camps and woods, photography in Advantages, 293, 294.

Apparatus, 293-295, 297.

Light and shadow, 298-303.

Caribou, I I9.

Carlin, W. E., achievements with a camera, 106-107, I 28-I 30.

Chapman, F. M., quoted as to bird photography, 182-184.

Clavarias, 277.

Cleanliness as a factor in photograpby, $5 \mathbf{I}$.

Color photography, 4.

Color screen, 254, 255.

Convertible lens, see Lens, modern double.

Cupperheads, the, 229.

Coral fungi, see Clavarias.

Coral snake, the, 229, 230, 23 I.

Corals, see Fish and other forms of aquatic life.

Cuthbert rookery, the, 189 . 
Dark room, the, 49-5 I.

Decoys, I82-I84.

Deer, "flash-light" pictures of, I I6118.

Securing photographs of, II II3.

Suggestions as to photographing, 119-120.

Developers -

Formulas for, 55 .

Metol as a, 55,56 .

Metol and hydrokinone, 57 .

Pyro, 54, 55.

Developing -

Air bubbles on plate, 52 .

Extent of, 56, 57 .

Handling of plates, 62.

Intensification, 6 I.

Orthochromalic plates, 6I, 62 .

Over exposure, 58,59 .

Reduction of negatives, 59, 60 .

Retardation of, 58 .

Tank method, 59 .

Under exposure, 58, 59 .

Diaphragm, see Lens.

Domestic animals, photographing of,

$$
\text { 288-29I. }
$$

Double exposures, I09, IIO.

Double printing, 65 .

Dugmore, $\mathrm{Mr}$., quoted as to -

A hunting experience, 108-I09.

Bird-nest photography, I47, I 48.

Changing bag, 89 .

Fish photography, 213-215.

Enlargements direct from negatives, see Negatives.

Entomology, economic importance of, 207.

Exposure in photographing birds' nests, I44, 145 .
Fear of man on part of birds, I64167.

Films, 294, 295.

Fish and other forms of aquatic life, photographing -

Aquarium, 209-211, 213-217.

Camera for, 21 1-213, 218-221.

Catching and handling fish for, $217,218,224$.

Early attempts, 208.

Good work, essentials of, 208, 209.

Jellylish, 222-223, 224.

Recent progress in, 208-209.

Thoroughness, 225, 226.

Flash-light, the, in phutographing aduit birds, 187 .

In photographing deer, I I 6-II9. Focal length of a lens, see Lens.

Focus, universal, see Lens.

Focussing on near-by objects, 37 .

Formaline, as a plate hardener, 53.

Frilling, see Bath.

Front, rising and falling, 37,275 .

Fungi, 277-280.

Gibson, W. Hamilton, 7 .

Gopher, 130.

Great auk, 8.

Hand camera, see Camera.

Hare, the little chief, see Rocky

Mountain pika.

Herons, 7 .

Hydrokinone, 57 .

Hypo, 6o.

Bath, 59.

Insects, photographing -

Camera suitable for, 195 .

From deạd specimens, 203. 
Insects, photographing [ cont $\left.^{\prime} d\right]-$ Importance of, 207.

Indoor work necessary, I95.

Knowledge of entomology desirable, 194, 195.

Need of photographs, 194.

Rearing of insects, 195, I96.

Size of insects a hindrance, $\mathbf{I} 90$.

See Butterfy.

Isochromatic plates, see Plates.

Kearton brothers, the, $158,17 \mathrm{I}$.

Kodaks, 294, 295.

Larger animals, photographing -

Apparatus for, II4.

See Apparatus for field work.

Bears, I2r.

Camera best adapted for, I 13 .

Care required, I09, IIO.

Caribou, IIg.

Compared with shooting, Io7Iog.

Deer, I I 4, I I 5, I I 6, I I 7, I I9-I 20.

With flash-light, I I6-II 9.

Lenses for, I I3, II 4 .

I.ynx, II 5 .

Methods discussed, I IO-I I 3 .

Natural attitude, importance of securing, 122.

Notable achievements, I03-107.

Obstacles to success, $102-103$.

Orthochromatic plates, I2I, I22.

Outfit, protection of, 122.

Rocky Mountain sheep, I2I.

Watchfulness necessary, I 14-1 I 6 .

Lens -

Age, effect of, 45 .

Anastigmatic and rectilinear compared, 43,44 .

Angle of view, 42 .
Lens [continued] -

Care of, 44-46.

Diaphragms (stops), 40-4I.

Field, depth of, 40.

Focal length, 38, 39 .

Focus, depth of, 40.

Universal, 39.

Focussing of, 44 .

For nature work, 42-43.

Functions of, 38 .

Marking systems, 41, 42.

Modern double, 38 .

More than one desirable, 43.

Pieces of, 43 .

Principles of, 38 .

Selection of, $42-43,44$.

Speed of, 4r, 42 .

"Stops" (diaphragms), 40-4I.

Testing of, 46 .

When necessary, 37 .

Marking lenses, see Lens.

Matteson, Sumner W., 23r, 232.

Metol, as a developer, 55,56 .

Mice, I 36, I 37 .

Mirror, use of, in photographing birds' nests, I $45,146,157$.

Moccasin, the, 229.

Moles, 136.

Moths, see Butterflies.

Mushrooms, see Fungi.

Nature photography -

Amateurish methods, 9-II.

As a means of studying nature: 4-6.

Compared with drawing, 12.

Deceptions attempted, I2.

Details, accuracy in, I3.

Difficulties in, 16,17 .

Effect of, on iliustrating, 3, 4 . 
\begin{tabular}{l|l} 
Nature photography [cont'd] - & Papers for printing, 62.
\end{tabular}

Field for, in other countries, 28. Passenger pigeon, 8.

In America, 28.

Focus, sharpness of, 44.

History of, briefly discussed, $1-3$.

Negatives, chances of success with, 17,18 .

Qualities making for the best work, 15,16 .

Requirements and results, 18.

Scientific value of, 6-8.

Scope, 4.

Serious work necessary, 9 .

Negatives -

Density of, reduced, 59-6I.

Development, 56, 57 .

Elimination of hypo, 54 .

Enlargement, 64.

I Handling in slevelopment, 62 .

Intensifying of, $6 \mathrm{r}$.

Keeping of large collection, 67 , 68.

Local manipulation, 6I.

Metol-developed, characteristics of, 56 .

Metol - hydrolinone - developed, $57,5^{8}$.

Practical results in use of, 18 .

Retouching of, 66.

Washing of, 54 .

See Developing.

Niepce, quoted as to his first picture with a camera, 29.

Non-halation plate, see Plate.

Opaque, 64 .

Opossum, I 30-13r.

Photography, cleanliness in, 5I, 52.

Compared with shooling, 2 r-24, 26-28.

In color, 4 .

"Photo-Miniature," 64.

Pied duck, 8.

Pinholes in negatives, 51,52 .

Plate hardeners, see laths.

Plate-holders, 86-89.

l'ates, isochromatic, 213, 26 I.

Non-halation, 273,274 .

Orthochromatic, I21, I22, 202, $212,213,254,279$.

Pleuraotus, genus of fungi, 277 .

Porcupine, 13 I-I 34 .

Porta, Bajtista, inventor of the camera obscura, $30,3 \mathrm{I}$.

Portuguese man-of-war, 224.

Printing -

Background, treatment of, 6465.

Local, 67 .

Negatives, enlarged, 64 .

Papers used, 62, 63 .

Retouching, 66, 67.

Skill in, importance of, 62 .

Spotting out, 67 .

Toning, 63.

Printing-out papers, silver, 62.

Protective coloring of smaller ani. mals, 242.

Pyro developer, the, 54, 55, 56 .

Raccoon, I34.

Orthochromatic plates, see Plates.

Outfit, protection of, 122 .

See Apparatus for field work.

Over exposure, see Developing.

Raptores, food of, 5,6 .

Rattlesnakes, 229, 231-235.

Ray filter, 254, 255.

Reflex camera, see Camera. 
Reptiles, photugraphing -

Antipathy to snakes an obstacle, $227-229$.

Arrangements for, 235-238.

Rattlesnakes, 232, 233-235.

Smaller snakes, lizards, frogs, etc., $238-241$.

Snapping and water turtles, 242.

Value of, 243 .

Retouching, 66, 67 .

Fluid, 66.

Rucky Mountain pika, I28-129.

Rookeries, water-bird, of Florida, I 88-I 89 .

- Roosevelt, Theodore, on hunting with camera compared with shooting, 24 .

Sea-urchins, see Fish and other forms of aquatic life.

Shrew, the, 136.

Shufeldt, Dr., a pioneer in photographing living fish, 208.

Shutter -

Care of, 48 .

Diaphragm, 46, 47.

Focal plane, 47 .

Knowledge of, essential, 48.

Silver papers, 62,63 .

Skunk cabbage, 260, 261.

Smaller mammals, photographing -

Beaver, 137.

Cage, use of, 136 .

Chipmunk, I24.

Gopher, I 30.

In captivity, 126 .

In native haunts, I 26.

Knowledge necessary, I 23, I37.

Mice, I23, I24-126, I 36, 137 .

Moles, 136 .

Opossum, I 30-I3I.
Smaller mammals, photographing [continued] -

Outfit, 135 .

Perseverance essential, 135 .

Porcupine, I3I-134.

Raccoon, I34.

Rocky Mountain pika, 128-129.

Shrew, 136.

Squirrels, 123, 124, 134 .

Weasel, r zo.

Woodchuck, 130 .

Snakes, dangerous and harmless, discussed, 227-23I.

Sportsman, term explained, $19,20$.

"Spotting out," 66, 67.

Squirrels, 134 .

Steadman, Frank M., 298.

"Stopping uut," 64, 65.

Stops, see Lens.

Swing-back, 35-37, 262, 275 .

Telephotographic lens -

Advantages of, $73-75,78$.

Capalilities of, 72 .

Described, 70.

Enlargement over ordinary lens, $7 \mathrm{I}$.

Exposures with, 77, 78 .

Focussing of, $7 \mathrm{I}$.

Indispensable in nature photography, 80 .

In photographing birds, 186.

Small mammals, 135 .

Tree builders' nests, 154 .

Lenses of, 70, 7r.

Precautions in use of, 72,73 .

Reflex, use in the, 78,80 .

Results obtained with, 77 .

Sluutter for, 73 .

Stops on, 73 .

See Lens. 
Toadstools, see Fungi.

Toning bath, 63 .

Trees, fungi, etc., photographing Apparatus, 275.

Artistic value of, 268-270.

Light suitable for, $27 \mathrm{I}-273,276$. Non-halation plate, 273,274 .

Wind an obstacle, 27I.

Under exposure of plates, see Developing.

Velox paper, 62.

Wallihan, A. G., 24, I 20, 125.

Washington National Zoo, 28 r.

Weasel, 130.

Wild animals, effect of noise on, I7.

Wild flowers, photographing -

Artistic and scientific value of, 244-247.

Compared with photographing animal life, $25 \mathrm{I}-253$.

Cut flowers - absolute stillness essential, 250, 25 I.

Apparatus used, 254, 255.
Wild flowers, photographing [continued] -

Arrangement of, 257, 258.

Focussing and exposure, 255257.

Indoor work necessary, 250.

Method of work, 253, 254 .

Wilting, 247-249.

Flowers growing out of doors -

All flowers available, $265-267$.

Image, size of, 264.

I.ight, regulation of, 264 .

Movement an obstacle, $25^{8-}$ 260.

Specimen and environment important, 260, $26 \mathrm{I}$.

Woodchuck, I 30.

Woods, photographing in, see Camps and woods.

Yellowstone Park, I2I.

Zoos, photography in the Apparatus for, 284, 285 . Difficulties met with, $28 \mathrm{I}$.

Essential points discussed, 285.

Negatives, manipulation of, 287 . 



\section{THE AMERICAN SPORTSMAN'S LIBRARY}

\section{Edited by CASPAR WHITNEY}

Crown 8vo

Cloth

$\$ 2.00$ net

SECOND SERIES

\section{THE SPORTING DOG}

By JOSEPH A. GRAHAM. With many illustrations from photographs.

\section{AMERICAN YACHTING}

By W. P. STEPHeNs. With many illustrations by E. A. Schell and Carlton T. Chapman.

\section{THE TROTTING AND THE PACING HORSE}

By HAMILTON BUSBEY. With many illustrations from photographs.

\section{LAWN TENNIS AND LACROSSE}

By J. PARMLY PARET and WILLIAM HARVEY MADDREN. With many illus= trations from photographs.

\section{PHOTOGRAPHY FOR THE SPORTSMAN NATURALIST}

By L. W. BROWNELL. With numerous illustrations from photographs.

$$
\text { IN PREPARATION }
$$

The American Race Horse, the Running Horse Rowing and Track Athletics

Skating, Hockey, and Kite Sailing Baseball and Football Riding and Driving

\section{THE MACMILLAN COMPANY}

66 FIFTH AVENUE, NEW YORK 


\section{THE AMERICAN SPORTSMAN'S LIBRARY}

\section{Edited by CASPAR WHITNEY}
Crown 8 vo
Cloth
Each $\$ 2.00$ net

THE DEER FAMILY

By THEODORE ROOSEVELT, T. S. VAN DYKE, D. G. ELLIOTT, and A. J. STONE. With many illustrations by CARL RUnglus, and map by DR. C. HART Merriam.

UPLAND GAME BIRDS

By EDWYN SANDYS and T. S. VAN DYKE. With many illustrations by L. A. Fuertes, A. B. Frost, J. O. Nugent, and C. L. Bull.

SALMON AND TROUT

BY DEAN SAGE, W. C. HARRIS, and C. H. TOWNSEND. With many illustrations by A. B. Frost and others.

THE WATER=FOWL FAMILY

By LEONARD C. SANFORD, L. B. BISHOP, and T. S. VAN DYKE. With many illustrations by L. A. Fuertes, A. B. Frost, and C. L. Bull.

BASS, PIKE, PERCH, AND PICKEREL

By JAMES A. HENSHALL, M.D. With many illustrations by Martin Justice and others.

THE BIG GAME FISHES OF THE UNITED STATES

By CHARLES F. HOLDER, With many illustrations in color by CHARLES F. W. MIELATZ and others.

MUSK=0X, BISON, SHEEP, AND GOAT

BY CASPAR WHITNEY, GEORGE BIRD GRINNELL, and OWEN WISTER. With many illustrations by CARL Rungius and others.

GUNS, AMMUNITION, AND TACKLE

By A. W. MONEY, HORACE KEPHART, W. E. CARLIN, A. L. A. HIMIMELWRIGHT, and J. BARRINGTON KEENE

$$
\text { In preparation for early issue }
$$

THE BEAR FAMILY

By DR. C. HART MERRIAM. With illustrations by CARL RunGiUs and others. COUGAR, WILD CAT, WOLF, AND FOX

\section{THE MACMILLAN COMPANY}




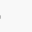


, 
. 
